
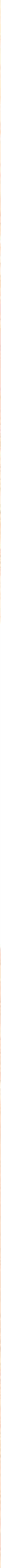



\section{THE STORIES WE LIVE BY The adaptive role of reminiscence in later life}




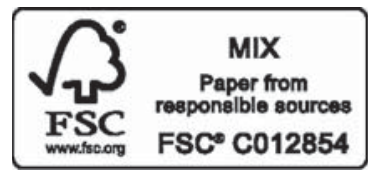

Korte, J. (2012). The stories we live by: The adaptive role of reminiscence in later life.

Enschede, the Netherlands: University of Twente.

\section{(C) Jojanneke Korte}

Design by Anne Floor Korte

Printed by Gildeprint Drukkerijen, the Netherlands

Thesis, University of Twente, 2012

ISBN: 978-90-365-3457-4

DOI: 10.3990/1.9789036534574 


\title{
THE STORIES WE LIVE BY
}

The adaptive role of reminiscence in later life

\section{PROEFSCHRIFT}

ter verkrijging van

de graad van doctor aan de Universiteit Twente, op gezag van de rector magnificus, prof. dr. H. Brinksma, volgens besluit van het College van Promoties in het openbaar te verdedigen op donderdag 29 november 2012 om 16:45 uur

\author{
door \\ Jojanneke Korte \\ geboren op 24 oktober 1983 \\ te Enschede
}


THE STORIES WE LIVE BY - The adaptive role of reminiscence in later life

Dit proefschrift is goedgekeurd door de promotor prof. dr. E. T. Bohlmeijer, de co-promotor prof. dr. F. Smit en de assistent-promotor dr. G. J. Westerhof. 


\section{SAMENSTELLING PROMOTIECOMMISSIE}

Promotor:

Co-promotor:

Assistent-promotor:

Leden:
Prof. dr. E. T. Bohlmeijer

(Universiteit Twente)

Prof. dr. H. F. E. Smit

(Trimbos-instituut; Vrije Universiteit Amsterdam)

Dr. G. J. Westerhof

(Universiteit Twente)

Prof. dr. K. M. G. Schreurs

(Universiteit Twente; Roessingh Research \& Development)

Dr. P. M. Ten Klooster

(Universiteit Twente)

Prof. dr. A. M. Pot

(Trimbos-instituut; Vrije Universiteit Amsterdam)

Prof. dr. N. L. Stevens

(Radboud Universiteit Nijmegen)

Prof. dr. C. W. A. M. Aarts

(Universiteit Twente) 
THE STORIES WE LIVE BY - The adaptive role of reminiscence in later life 


\section{CONTENTS}

Chapter 1

Chapter 2

Chapter 3

Chapter 4

Chapter 4

Chapter 6

Chapter 7

Chapter 8

Chapter 9
General introduction

8

Reminiscence and adaptation to critical life-

28

events in older adults with mild to moderate

depressive symptoms

Meaning in life and mastery mediate the

46

relationship of negative reminiscence with

distress among older adults with mild to

moderate depressive symptoms

Prevention of depression and anxiety in later life:

62

Design of a randomized controlled trial for the clinical and economic evaluation of a life-review intervention

Life-review therapy for older adults with

moderate depressive symptomatology: $A$

pragmatic randomized controlled trial

Cost-effectiveness of life-review for older adults with moderate depressive symptomatology: A pragmatic randomized controlled trial

Mediating processes in an effective life-review intervention

Life-review in groups? An explorative analysis of 142 social processes that facilitate or hinder the effectiveness of life-review

General discussion

Summary in Dutch

Acknowledgments 


\section{GENERAL INTRODUCTION}




\section{CHAPTER}

When older adults are confronted with difficult life experiences, they tend to look back upon their lives. The way in which they do so can be either adaptive or maladaptive for their mental health. Therefore, it is important to know how making use of the past can be adaptive and how this information can be used successfully in interventions that have been developed explicitly to improve mental health. This thesis investigates the adaptive role of reminiscence in a sample of older adults with mild to moderate depressive symptoms. A structured way of reminiscence, known as life-review, can be regarded as an evidencebased method for both preventing and treating major depression in later life. A substantial proportion of the older population experiences mild to moderate depressive symptoms or suffers from mild to moderate major depression at some point and is therefore at risk of developing a severe major depression. Hence, effective preventive interventions that reduce depressive symptoms, and thereby reduce the onset of a major depression, are crucial. In this thesis, the effects of a life-review group intervention for older adults with mild to moderate depressive symptoms are evaluated in a large, pragmatic randomized controlled trial. Until now, hardly any empirical evidence has been available about the factors that might explain the effectiveness of life-review. This thesis addresses this gap by studying possible moderating and mediating factors of life-review, and by investigating the added value of offering life-review in groups.

The aim of this thesis is three-fold. First, the adaptive role of reminiscence in later life will be further studied in older adults with mild to moderate depressive symptoms. Second, the effectiveness of a life-review intervention ("The stories we live by") for older adults with mild to moderate symptomatology will be evaluated in a large, randomized controlled trial. Third, possible mechanisms of life-review will be studied. This introductory chapter begins by presenting an overview of the research on reminiscence and mental health. Subsequently, the epidemiology of depression in later life is described, followed by a needs assessment for preventive and early interventions aimed at older adults with mild to moderate depressive symptoms. The introduction concludes with an overview of the studies conducted within the context of this thesis.

\section{Reminiscence and its adaptive functions}

The need to adjust to change and the experience of loss is one of the most important and difficult developmental tasks that older adults face (Erikson, 1964). Change is an inescapable part of life. Although some changes may be positive, many changes are regarded as negative by older adults. The change process and subsequent feelings of loss occur in a variety of situations. Examples of these include critical life events, such as the death of a spouse, retirement, caring for sick relatives, and coping with the onset of a chronic illness (Davidhizar \& Shearer, 1999). Such changes are associated with higher levels of distress (e.g., Anderson, Freedland, Clouse \& Lustman, 2001; Cassileth, 1985; Ho \& Jones, 1999; Holahan, Moos, Holahan \& Brennan, 1995; Kraaij, Arensman \& 
Spinhoven, 2002; Stolz, Baime \& Yaffe, 1999), which is a risk factor for developing clinical mental disorders (Cuijpers, de Graaf \& van Dorsselaer, 2004; Smit, Ederveen, Cuijpers, Deeg \& Beekman, 2006). Hence, it is important to know which mechanisms are linked to coping successfully with distress in later life.

In the last fifty years, several authors have acknowledged the adaptive value of reminiscence for the mental health of older adults (e.g., Butler, 1963; Cappeliez \& O'Rourke, 2006; O'Rourke, Cappeliez \& Claxton, 2011; Webster, Bohlmeijer \& Westerhof, 2010; Westerhof, Bohlmeijer \& Webster, 2010; Wink \& Schiff, 2002; Wong, 1995; Wong \& Watt, 1991). As a response to change and loss, it is a natural reaction for many older people to start thinking about the meaning of life and reviewing their lives (Butler, 1963; Parker, 1995; 1999; Wong, 1995) noticed that when the power to recall is properly channelled, reminiscence helps older people to maintain a sense of integrity and mastery. Reminiscence gained a lot of attention in gerontological research after Butler's (1963) seminal article on life-review. Whereas classical scholars have viewed reminiscence as a naturally occurring process in later life, current evidence suggests that it is an important process in regulating individual development throughout the lifespan (Westerhof, Bohlmeijer \& Webster, 2010). Scholars like Pasupathi, Weeks and Rice (2006), Thorne (2000), Webster (1995; 1999), and Whitbourne (1985) described the act of remembering as a key process in development from early to late adulthood. Although everybody intuitively knows that reminiscence is about personal memories, it has been rather difficult to provide a good scientific definition of the phenomenon (Fitzgerald, 1996). Bluck and Levine (1998, p. 188) provided a comprehensive definition; complete enough to encompass all aspects of the phenomenon of remembering our lives: "Reminiscence is the volitional or non-volitional act or process of recollecting memories of one's self in the past. It may involve the recall of particular or generic episodes that may or may not have been previously forgotten, and that are accompanied by the sense that the remembered episodes are veridical accounts of the original experiences. This recollection from autobiographical memory may be private or shared with others."

This definition elucidates how reminiscence can take on different forms. On the basis of a taxonomy of reminiscence functions developed by Webster (1993; 1997), Cappeliez and O'Rourke (2006) developed a model that distinguishes between three different types of reminiscence functions (see Table 1). First, they describe the positive functions: Identity, problem-solving and death preparation. In identity, memories are actively used to develop our identity by discovering, clarifying and crystallizing important dimensions of the sense of who we are. Problem-solving refers to how memories of past coping strategies can be reused in the present. Death preparation is the way we use our past to arrive at a calm and accepting attitude towards our own mortality. Second, they also identify three negative functions: Bitterness revival, boredom reduction and intimacy maintenance. Bitterness revival is also about our identity, but in a negative, complaining way. Instead of being integrated in the sense of who we are, negative experiences are constantly brought up. In boredom reduction, the main goal is to escape from the present by romanticizing the past. Intimacy maintenance is a process whereby cognitive and emotional representations of important persons in our lives are resurrected, mostly deceased persons. Finally, the various social functions are described: Teach/inform and 
conversation. In teach/inform, memories are used to relay personal experiences and life lessons to others. Conversation reminiscence is the informal use of memories in order to connect or reconnect to others.

\section{Table 1. Description of reminiscence functions}

\begin{tabular}{|c|c|}
\hline FUNCTION & DESCRIPTION \\
\hline \multicolumn{2}{|l|}{ Positive reminiscence } \\
\hline Identity & $\begin{array}{l}\text { Using the past to discover, clarify or crystallize our sense } \\
\text { of who we are. }\end{array}$ \\
\hline Problem-solving & $\begin{array}{l}\text { Remembering past problem-solving strategies to cope with } \\
\text { current problems. }\end{array}$ \\
\hline Death preparation & $\begin{array}{l}\text { Using the past in order to arrive at a calm and accepting } \\
\text { attitude towards our own mortality. }\end{array}$ \\
\hline \multicolumn{2}{|l|}{ Negative reminiscence } \\
\hline Bitterness revival & $\begin{array}{l}\text { Ruminating about difficult life experiences, lost opportunities } \\
\text { and misfortune. }\end{array}$ \\
\hline Boredom reduction & $\begin{array}{l}\text { Using the past to escape an under-stimulating environment } \\
\text { or a lack of engagement in goal-directed activities. }\end{array}$ \\
\hline Intimacy maintenance & $\begin{array}{l}\text { Keeping alive the memory of a significant other who is no } \\
\text { longer present, often because they are deceased }\end{array}$ \\
\hline \multicolumn{2}{|l|}{ Social reminiscence } \\
\hline Teach/inform & $\begin{array}{l}\text { Using the past to relay personal experiences and life lessons } \\
\text { to others. }\end{array}$ \\
\hline Conversation & $\begin{array}{l}\text { Using the past to communicate personal memories to } \\
\text { (re)connect to others. }\end{array}$ \\
\hline
\end{tabular}

There is an increased awareness and understanding about how reminiscence is related to mental health in the ageing population (see Westerhof, Bohlmeijer \& Webster, 2010 for a recent review). The types of reminiscence most consistently associated with mental health are identity, problem-solving, bitterness revival and boredom reduction. Reminiscence can have both positive and negative effects on mental health. Several studies have indicated that bitterness revival and boredom reduction are positively correlated with depression and anxiety, and negatively with well-being (Cappeliez, O'Rourke \& Chaudhury, 2005; Cully, LaVoie \& Gfeller, 2001). Conversely, identity and problem-solving 
were found to be positively associated with psychological well-being (Cappeliez et al., 2005) and successful ageing (Wong \& Watt, 1991). Cappeliez and O'Rourke (2006) found that the positive functions of reminiscence were positively related to well-being and physical health and that negative reminiscence functions were negatively related to well-being and physical health; whereas social functions of reminiscence were indirectly related to well-being and physical health. These relationships of reminiscence with mental health were mostly found in cross-sectional studies. A recent study found corroborating evidence in a longitudinal study (O'Rourke et al., 2011). The extent to which, and why, people reminisce is also influenced by personality. Cully et al. (2004) showed that neurotic behaviour is correlated positively with bitterness revival and boredom reduction. This was borne out by Cappeliez and O'Rourke (2002), who found that a higher score on neuroticism predicted higher scores on identity and bitterness revival. More openness also predicted a higher total level of identity and death preparation.

The next step towards understanding the adaptive value of reminiscence is to explore in more detail how reminiscence is related to mental health. In a longitudinal study, Cappeliez and Robitaille (2010) obtained evidence that assimilative and accommodative coping mediate the effects of positive and negative reminiscence and mental health. Assimilative coping helps to deal with potential or actual problems or losses by promoting compensatory coping efforts, while accommodative coping refers to flexibly adjusting goals to constraints and impairments (Rothermund \& Brandtstädter, 2003). It was demonstrated that positive reminiscences are related to improved psychological well-being via assimilative and accommodative coping, while, in contrast, negative reminiscences are associated with reduced psychological well-being through their negative relationships with both coping modes. Furthermore, it has been suggested that reminiscence may foster mental health by the accumulation of feelings of mastery and meaning in life (Wong, 1995). The concept of mastery refers to the extent to which individuals believe they are in control of their important life experiences (Pearlin \& Schooler, 1978). Meaning in life can be defined as having a sense of direction and order, a reason for existence, a clear sense of personal identity, and a high degree of social consciousness (Reker, 1997). Several studies with older adults demonstrate strong relationships of mastery and meaning in life with mental health. In a large, recent study with older adults, Forbes (2010) demonstrated that mastery was a strong predictor, stronger than sociodemographic factors, of both health status and perceived health. In the same vein, Steunenberg, Beekman, Deeg, Bremmer and Kerkhof (2007) showed that higher levels of mastery predicted recovery from depression in later life. Similar results were found by Gadella (2010), who demonstrated that higher levels of mastery were associated with lower levels of distress in older adults. Other studies have also shown that high levels of mastery facilitate adaptation to distress in the face of stressful events (Jang, Haley, Small \& Mortimer, 2002; Kempen, van Heuvelen, van Sonderen, van den Brink, Kooijman \& Ormel, 1999; Kempen, Jelicic \& Ormel, 1997; Roberts, Dunkle \& Haug, 1994; Schieman \& Turner, 1998). Another line of research suggests that older adults with a strong sense of meaning in life report better mental health than those with less meaning in their lives (Nygren, Alex, Jonsen, Gustafson, Norberg \& Lundman, 2005; Reker, 1997). 
In a large meta-analysis, Pinquart (2002) showed that purpose in life (meaning) has a strong negative correlation with depression. Like mastery, meaning in life appears to fulfil a stress-buffering and counter-depressive role in older adults (Krause, 2004; 2007). Reminiscence may either impede or strengthen the mental resources of mastery and meaning. When reminiscing for negative purposes, people ruminate on unpleasant events, reflecting a failure to integrate problematic past experiences with the more positive aspects of life and thereby obstructing the feeling that life is manageable and meaningful (Wong, 1989; 1995). On the other hand, reminiscence for positive purposes makes use of past experiences that might play a role in enhancing a sense of mastery and meaning, for example by recalling events of previous accomplishments or by remembering events that provide a sense of meaning and direction (Wong, 1995). To summarize, there is a growing body of knowledge about using the various functions of reminiscence throughout the lifespan of an individual and their impacts on mental health.

However, there are three important limitations, which are addressed in this thesis. First, the functions of reminiscence and how they relate to mental health have scarcely been studied within specific contexts, while our memories are triggered, negotiated, and situated within particular contexts (Webster, Bohlmeijer \& Westerhof, 2010). It is often assumed that people start to reminisce more in times of transition, but there are few studies that support this notion (e.g., Haight, Michel \& Hendrix, 1998; 2000; Parker, 1999). Second, almost all of the studies about reminiscence functions and how they relate to mental health have been conducted among the general population with people who do not display any symptoms of distress. However - in the field of mental healthcare - it is relevant to study reminiscence functions in older adults presenting with mild to moderate levels of distress. Most reminiscence interventions are primarily aimed at reducing symptoms of depression or clinical depression, while empirical studies on reminiscence functions are mostly carried out among the general population. Hence, it is important to know whether the relationship between reminiscence functions and mental health are similar among people with distress and people from the general population as a whole. Third, it is still not clear how reminiscence is related to distress. It has been suggested that, theoretically, reminiscence may foster mental health by stimulating the accumulation of feelings of mastery and meaning in life (Wong, 1995). These resources may even mediate the effects of reminiscence interventions on depressive symptoms (Watt, 1996; Westerhof, Bohlmeijer, van Beljouw \& Pot, 2010). To address the above gaps, we will study the contextual factors of reminiscence, as well as the mental resources that mediate the relationship between reminiscence and mental health, in a sample of older adults with mild to moderate symptoms of depression. We hypothesize that contextual factors, i.e., the presence of chronic diseases and experiencing critical life events, influence how older adults look back upon their lives. Additionally, we hypothesize that, just as in the general older population, in a sample of older adults with mild to moderate depressive symptoms positive reminiscence functions will be negatively related to distress, while negative reminiscence functions would be positively related to distress. Finally, we hypothesize that reminiscence may reinforce positive mental health by stimulating the accumulation of feelings of mastery and meaning in life (see Figure 1). 
Figure 1. Reminiscence and distress in the general older population

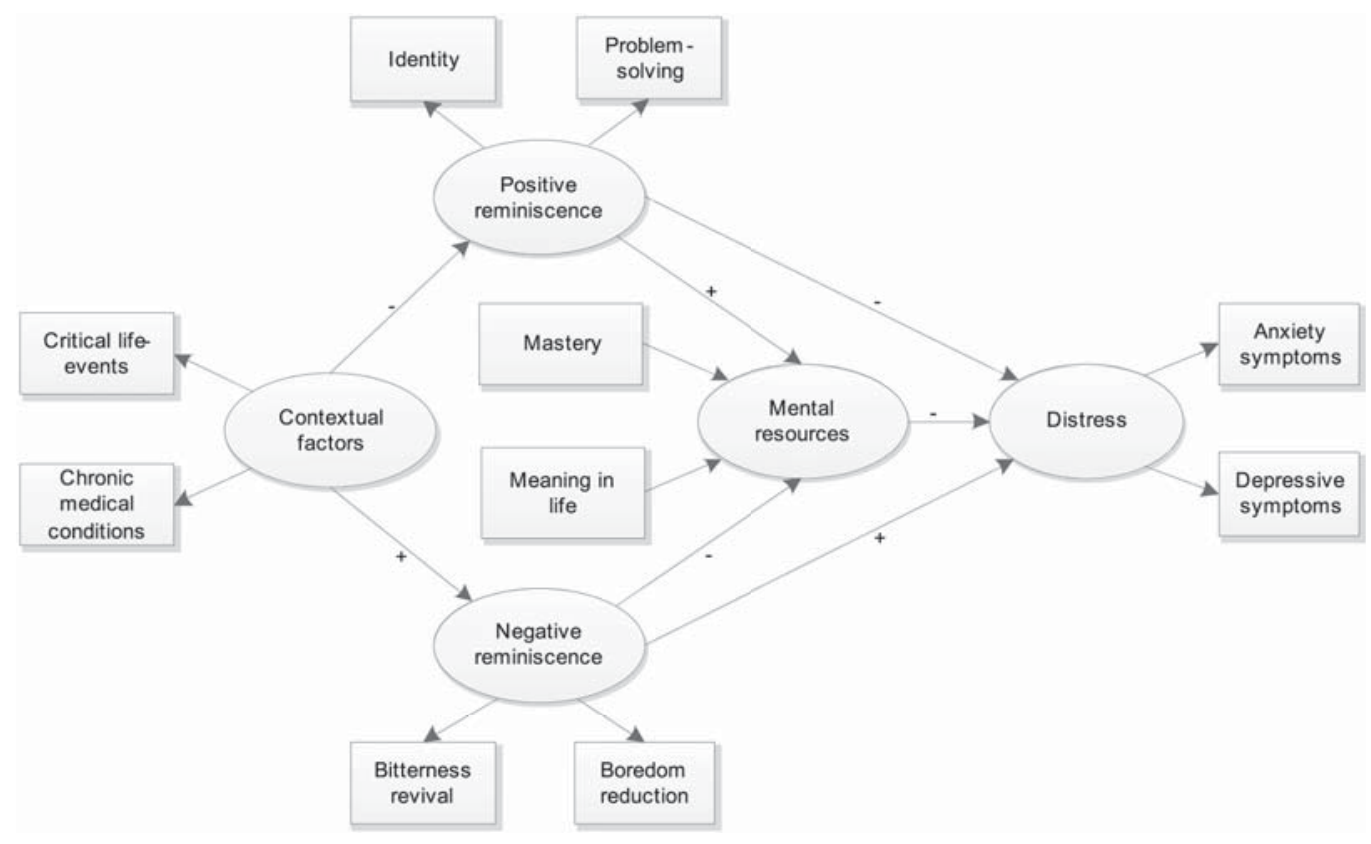

\section{The need to prevent depression in later life}

Clinical depression in later life is highly prevalent (Copeland, Beekman, Dewey, Hooijer, Jordan, Lawlor, et al., 1999; Djernes, 2006; McDougall, Kvaal, Matthews, Paykel, Jones, Dewey, et al., 2007), characterized by poor prognosis (Beekman, Penninx, Deeg, de Beurs, Geerings \& van Tilburg, 2002; Cole, Bellavance \& Masour, 1999; Licht-Strunk, van der Windt, van Marwijk, de Haan \& Beekman, 2007), and is associated with substantial societal costs (Smit et al., 2006). Clinical depression is characterized by a depressed mood or loss of interest in almost every activity and occurs most of the day, almost daily and lasts for at least a fortnight. Symptoms associated with depression are loss of concentration and/or appetite, disturbed sleep, fatigue and loss of energy, feelings of worthlessness, and recurrent thoughts of death (American Psychiatric Association, 2000). Regarding the prevalence of depression in later life, rates of between $8.8 \%$ and 23.6\% have been reported (Copeland et al., 1999; McDougall et al., 2007).

The most important risk factor for developing late-life, clinical depression is the presence of sub-threshold depression; depressive symptoms not (as yet) meeting diagnostic criteria (Cuijpers et al., 2004; Smit et al., 2006). The economic costs associated with sub-threshold depression are slightly less than those associated with 
major depression (Cuijpers, Smit, Oostenbrink, de Graaf, ten Have \& Beekman, 2007). Consequently, effective preventive interventions directed at older adults with subthreshold depression are of utmost importance. There are three different categories of prevention: universal, selective and indicated prevention (Mzarek \& Haggerty, 1994). Universal prevention is the application of an intervention across a whole population, regardless of an individual's risk of developing a depression. Selective prevention is the application of an intervention to subgroups of the population with a known risk of developing depression. Indicated prevention targets people with a high risk and who show clinically relevant depressive symptoms, but who do not meet the diagnostic criteria for depression. Whereas preventive interventions are aimed at people without a disorder, early interventions are aimed at people who meet the criteria for a disorder but are in the less severe range (Meulenbeek, 2010)

Meta-analytic evidence indicates that preventive and early interventions for older adults with depressive symptoms are indeed promising in preventing depressions (Cuijpers, van Straten, Smit, Mihalopoulos \& Beekman, 2008). Several psychological interventions are currently available for reducing depressive symptoms in older people, including psycho-educational approaches, cognitive behaviour therapy, psychodynamic therapy, and interpersonal therapy (Cuijpers, 1998; Miller, 2008; van 't Veer-Tazelaar, van Marwijk, van Oppen, van Hout, van der Horst, Cuijpers, et al., 2009; Wilson, Mottra \& Vassilas, 2008). However, previous interventions are associated with low uptake rates. Hence, there is a need for interventions that are more acceptable. Life-review is currently gaining popularity because many -though not all- older adults tend to look back on and evaluate their lives (Westerhof, Bohlmeijer \& Webster, 2010), which seems to suggest that it will be acceptable for older people and might even be regarded as attractive.

\section{Life-review interventions}

There is substantial meta-analytic evidence that life-review interventions are an effective treatment for depression in later life (Bohlmeijer, Smit \& Cuijpers, 2003; Hsieha \& Wang, 2003; Payne \& Marcus, 2008; Peng, Huang, Chen \& Lu, 2009; Pinquart, Duberstein \& Lyness, 2007; Pinquart \& Forstmeier, 2012). The most important aim of this thesis is to further corroborate the effectiveness of life-review as an early intervention for depression, in ecologically valid contexts (Pot, Bohlmeijer, Onrust, Melenhorst, Veerbeek \& de Vries, 2010; Westerhof, Bohlmeijer \& Webster, 2010). Some studies showed that life-review is also effective in reducing symptoms of anxiety (Bohlmeijer, Roemer, Cuijpers \& Smit, 2007; Pot et al., 2010).

Life-review seems especially suitable for older adults who experience loss of meaning in life and who hold a negative view of themselves. Critical life events may increase the use of specific negative functions of reminiscence such as reviving bitter experiences or escaping from present problems (Cappeliez, 2002; Wink \& Schiff, 2002; Wong, 1995). Life-review refers to a structured evaluation of one's life in a manner that involves two distinct, but related, adaptive processes; integrative reminiscence and instrumental reminiscence (Butler, 1963; Haight, 1992; Westerhof, Bohlmeijer \& Webster, 2010; Wong, 1995). 
Integrative reminiscence is the integration of both positive and negative memories within the life-story, whereas instrumental reminiscence concerns the use of past memories to cope with current problems and challenges (Cappeliez, 2002; Watt \& Cappeliez, 2000; Westerhof, Bohlmeijer \& Webster, 2010; Wong, 1995). The numerous studies on reminiscence and mental health (see the section entitled "reminiscence and its adaptive functions" within this introduction), made it clear that both integrative and instrumental reminiscence can play an important role in an individual's ability to adapt to distress. This generates useful information regarding effective therapeutic processes in life-review interventions (Westerhof, Bohlmeijer \& Webster, 2010) (see Table 2).

Table 2. Description of the therapeutic processes of life-review

\begin{tabular}{|c|c|}
\hline TYPE OF REMINISCENCE & THERAPEUTIC PROCESS \\
\hline \multicolumn{2}{|l|}{ Integrative reminiscence } \\
\hline Strengthens positive identity & Focuses on successes and strengths \\
\hline Reduces bitter experiences & Systematically evaluates the course of life \\
\hline \multicolumn{2}{|l|}{ Instrumental reminiscence } \\
\hline $\begin{array}{l}\text { Remembers past problem-solving stra- } \\
\text { tegies }\end{array}$ & $\begin{array}{l}\text { Recalls memories involving a successful } \\
\text { adaptation }\end{array}$ \\
\hline $\begin{array}{l}\text { Reduces the tendency to use the past to } \\
\text { escape from present-day problems }\end{array}$ & $\begin{array}{l}\text { Formulates new goals that are related to } \\
\text { important life values and objectives }\end{array}$ \\
\hline \multicolumn{2}{|l|}{ Integrative and instrumental reminiscence } \\
\hline $\begin{array}{l}\text { Develops positive thoughts about the self } \\
\text { and the future }\end{array}$ & Retrieves positive memories \\
\hline
\end{tabular}

Accordingly, integrative reminiscence can be divided into two therapeutic processes. The first therapeutic process is to use the past in order to strengthen one's positive identity (i.e., identity reminiscence). This is accomplished by focusing on the client's successes and strengths during various stages of his or her life and on different ways of functioning. The second therapeutic process is to reduce the revival of bitter experiences (i.e., bitterness revival reminiscence). Reduction of bitterness revival involves providing new meaning and value to negative memories. One way to achieve this is for an individual to systematically evaluate the course of his or her life. In this way, important themes may come forward, leading to new insights and fewer bitter memories. These two processes, strengthening identity reminiscence and reducing bitterness revival reminiscence, may lead to an increase in meaning in life (Wong, 1995). 
Instrumental reminiscence can also be divided into two therapeutic processes. The first therapeutic process is to remember past problem-solving strategies (i.e., problemsolving reminiscence). This is achieved by recalling memories involving a successful adaptation on the part of the client; for example, an adaptation to critical life events or chronic medical conditions. Such memories may be helpful in applying successful coping strategies to present problems. The second therapeutic process involves reducing memories that are conjured up in order to escape from current problems (i.e., boredom reduction reminiscence). One way to discourage boredom reduction is to formulate new goals that are related to important life values and objectives. As depressed individuals have the tendency to pursue goals that are hard to fulfil (Pekrun, Elliot \& Maehr, 2006; Sideridis, 2005; 2007), it is important to formulate realistic goals. These two processes, strengthening problem-solving reminiscence and discouraging boredom reduction reminiscence, may lead to improved feelings of mastery. Wong (1995) and Parker (1995; 1999) discussed that a proper recall of problem-solving strategies can help an individual to experience and maintain a sense of mastery.

A more generic therapeutic process, which involves both integrative and instrumental reminiscence, is the development of more positive thoughts about the self and the future (Cappeliez, 2002). Individuals may maintain negative thoughts about themselves and may have negative thoughts regarding the causes and consequences of negative personal events in the past. As a result, they may therefore also have negative thoughts about their ability to cope successfully with future events. Using both integrative and instrumental reminiscence, these negative thoughts about the self and the future are uncovered and restructured. Developing more positive thoughts is accomplished through the retrieval of specific positive memories. As people with depression tend to have a stronger association with negative and more general memories (Brewin, 2006; Williams, Barnhofer, Crane, Herman, Raes, Watkins, et al., 2007), paying more attention to specific positive memories in depressive older adults will help to activate memories that were almost forgotten (Serrano, Latorre, Gatz \& Montanes, 2004). By recalling specific positive memories, the tendency of depressed individuals to focus only on the negative and the more general is discouraged.

Until now, hardly any empirical evidence has been available concerning the factors that moderate or mediate the effects of life-review on depression. Conceptually, the analysis of moderators would help to identify subgroups where the intervention could be particularly effective, whereas the analysis of mediators may shed light on how treatment effects are relayed over various clinical pathways and have a final impact on clinical endpoints (Kraemer, Wilson, Fairburn \& Agras, 2002). Successful integrative and instrumental reminiscence may contribute to the accumulation of mental resources that are related to depression and anxiety. Three such resources that are known to be related to mental health are meaning in life (Pinquart, 2002), mastery (Steunenberg et al., 2007), and positive thoughts (Ingram, Kendall, Siegle, Guarino \& McLaughlin, 1995).

Integrative reminiscence may contribute to a sense of meaning in life as it contributes to finding coherence and purpose in one's own life experiences. Indeed, some studies found a cross-sectional or longitudinal relationship between identity reminiscence and meaning in life (Cappeliez \& O'Rourke, 2006; Krause, 2004). 
Instrumental reminiscence may contribute to an enhanced sense of mastery, as it makes productive use of successful coping strategies from the past. Again, cross-sectional and longitudinal studies have found a relationship between successful reminiscence and aspects of mastery, such as coping (Cappeliez \& Robitaille, 2010) or goal seeking (Cappeliez \& O'Rourke, 2006). Finally, when reminiscing about positive past experiences, both integrative and instrumental reminiscence may contribute to the development of positive thoughts. Cross-sectional relationships were found between reminiscence and life satisfaction, happiness, and self-esteem (Cappeliez \& O’Rourke, 2006; Cappeliez et al., 2005; Webster, 1998; Webster \& McCall, 1999).

As far as we know, no studies were conducted on the changes in integrative and instrumental reminiscence that may explain the alleviation of depressive symptoms through life-review interventions. Westerhof, Bohlmeijer, Van Beljouw et al. (2010) demonstrated that improvement in meaning in life mediates the effects of a life-review intervention on depressive symptoms. An early empirical study on the effectiveness of life-review for older adults' depression suggested that improvement in mastery is a key process driving the effect of decreasing depressive symptoms (Watt, 1996). A mediation study by Serrano et al. (2004) has shown that training the autobiographical memory for specific positive memories explains the effectiveness of life-review on depression. Figure 2 shows our hypotheses regarding the mechanisms of life-review. The moderating factors of life-review will be studied in a rather explorative way. We investigate a large number of prognostic factors that might be associated with the effectiveness of life-review, i.e., sociodemographic variables, personality, reminiscence functions, past major depressive episodes, chronic medical conditions and critical life events. Regarding the mediating factors of life-review, we hypothesize that the effects of life-review on distress are mediated by positive and negative reminiscence and by the mental resources of mastery, meaning in life and positive thoughts. Building on the adaptive processes of life-review, integrative and instrumental reminiscence, "The stories we live by" life-review intervention was developed (Westerhof, Bohlmeijer \& Webster, 2010).

\section{The stories we live by}

Recently, attempts have been made to combine life-review with other interventions aimed at people with mild to moderate distress (Cappeliez, 2002; Watt \& Cappeliez, 2000; Westerhof, Bohlmeijer \& Webster, 2010), for example narrative therapy (Bohlmeijer, Kramer, Smit, Onrust \& van Marwijk, 2009; Bohlmeijer, Westerhof \& Emmerik-de Jong, 2008). In narrative therapy, life-stories are considered as a reconstruction of autobiographical memories (Atwood \& Ruiz, 1993; Bluck \& Levine, 1998). The most crucial element in life-review combined with narrative therapy is to develop alternative, more agentic life-stories, in which clients take responsibility for their own preferred ways of living (Bohlmeijer et al., 2008; 2009). In this thesis, an intervention was evaluated that integrates life-review and narrative therapy; "The stories we live by" intervention (Bohlmeijer \& Westerhof, 2010).

"The stories we live by" was conducted in groups of four to six participants and consisted of eight two-hour sessions. The intervention is based on the two adaptive 
Figure 2. Possible mechanisms of life-review

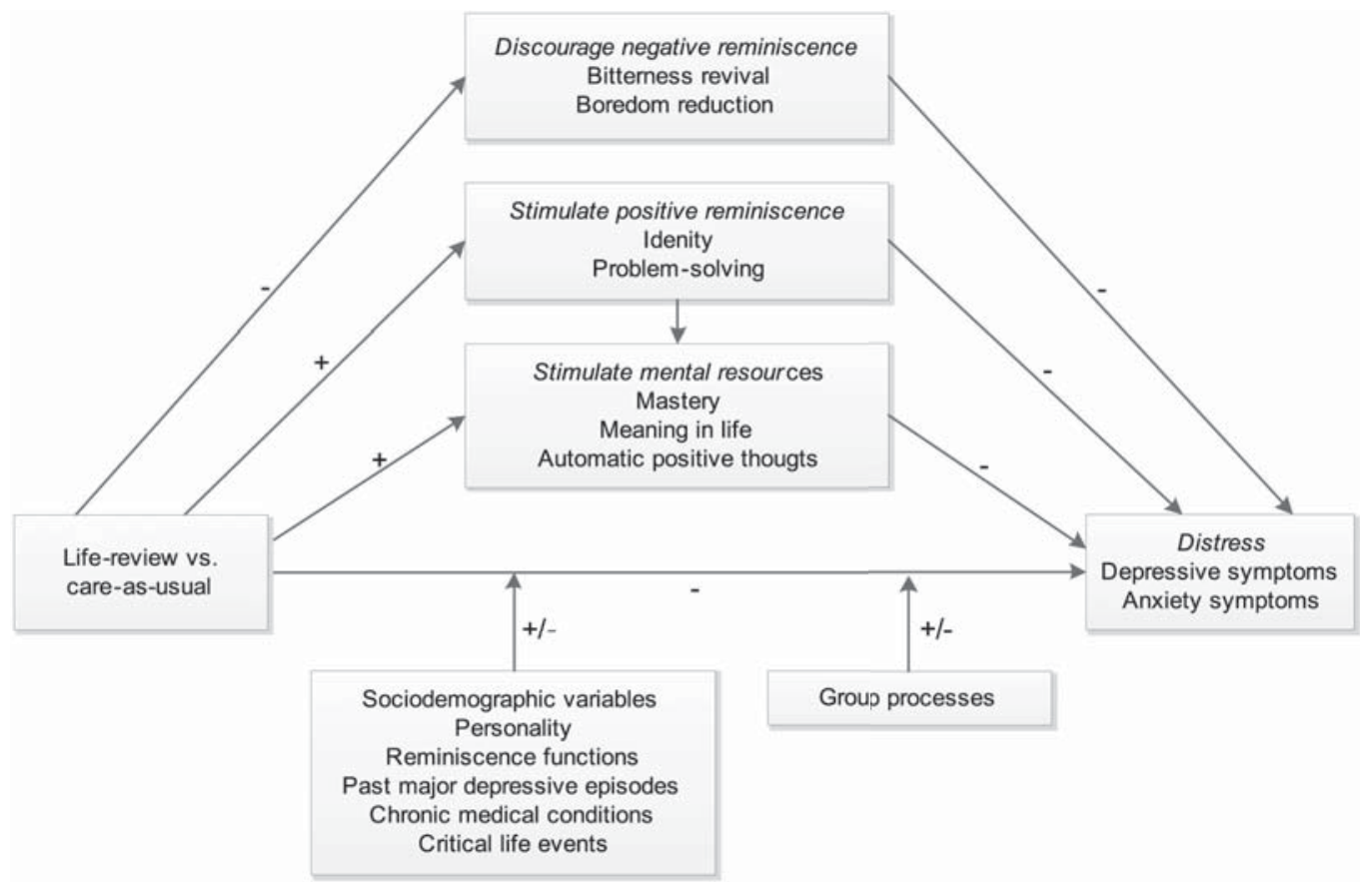

processes of life-review: integrative and instrumental reminiscence (Westerhof, Bohlmeijer \& Webster, 2010). The intervention has three core elements. First, the integration of difficult life-events from the past; second, the development of agentic life-stories which helps the participants to cope with present life events and to formulate new goals; third, the retrieval of specific positive memories which can serve as the building blocks of the new life-stories.

The first two elements were developed by integrating life-review into a narrative therapeutic framework that connects to theories about the role of life-stories in the formation of identity and meaning (e.g., Freedman \& Combs, 1996; Gergen, 1985). A narrative therapeutic framework enhances the integration of negative events and the restoration of meaning in life in several ways. It stimulates clients to adopt an attitude of curiosity and not-knowing. In this way, ample space is created for clients to explore alternative stories and preferences (White \& Epston, 1990). Furthermore, therapists have an arsenal of questions that may be helpful in constructing alternative and more empowering stories about negative life-events and difficult periods (e.g., How were you able to cope with this situation? Where there any pleasant moments in this difficult time? 
Now, at a much later date, can you say that you have also learned from that period?). In addition, by always focusing on the preferences of clients and relating them to other memories, clients are continually invited to express their values and past experiences (White, 2007). Lastly, alternative stories are further elaborated, by relating them to identity (e.g., What does this say about the person you are?) and by relating them to future goals and action (What can you do in the near future to live by this value or meaning?). The third core element was the attention to specific positive memories, special and unique for a certain period in the participants' lives, which are expected to activate nearly forgotten memories, especially in people with depressive symptoms (Brewin, 2006; Serrano et al., 2004; Williams et al., 2007).

The first five intervention sessions were focused on different life themes: origin, youth, work and care, love and conflicts, and loss and difficult times. Before each session, participants had to answer questions about those life themes. For each theme the participants had to describe one difficult life-event they are still struggling with. Then they had to answer questions that guided them to develop alternative stories that help to integrate this life-event. For each session they had to describe a specific positive memory as well. During the sessions, participants had the opportunity to exchange and discuss the experiences with each other. In session 6, participants had to recall an image that symbolizes their lives and explain why this was so (metaphor). In session 7, participants had to make an overview of the ups and downs in their lives. In the last session, participants had to think about how they wanted to restructure their lives with the knowledge they gained during the intervention.

"The stories we live by" was evaluated in a pilot study (Bohlmeijer et al., 2008). The results were promising. A randomized controlled trial $(R C T)$ is now required in order to make this life-review intervention available as an evidence-based intervention for older people with mild to moderate depressive symptoms.

\section{Outline of the thesis}

Chapters 2 and 3 study reminiscence functions in relation to mental health in a sample of older adults with mild to moderate depressive symptoms. An investigation was carried out into how contextual factors (i.e., critical life events and chronic medical conditions) are related to reminiscence functions and how these functions are related to mental health (i.e., depressive symptoms, anxiety symptoms and satisfaction with life). To assess whether reminiscence indeed plays a role in a person's ability to adapt to contextual factors, an analysis was carried out to determine which reminiscence functions mediate the relation between contextual factors and mental health. Furthermore, a mediational model was used to investigate how reminiscence can contribute to mental resources, and thus also to distress, in older adults with mild to moderate depressive symptomatology. It was predicted that mastery and meaning in life are relevant mental resources that play a mediating role in the relationship between reminiscence functions and the reduction of distress. Using structural equations, we tested a model that involved both direct links between positive (identity, problem-solving) and negative (bitterness revival and boredom reduction) reminiscing on the one hand, and distress (depression and anxiety) on 
the other, together with indirect links mediated by mental resources (mastery and meaning in life).

Chapters 4 to 6 describe a large, pragmatic, multi-site randomized controlled trial that evaluated "The stories we live by"; an early life-review group intervention for adults of 55 years of age and over with mild to moderate depressive symptoms. Both the clinical and economic effectiveness of the intervention were evaluated. The effects of life-review on depressive symptoms, anxiety symptoms, positive mental health, quality of life and major depressive episodes were investigated. The cost-effectiveness of life-review was compared to care-as-usual. The decision about whether or not the intervention offers good value for money may depend on the willingness to pay (WTP) for a favourable treatment response. Therefore we evaluated how sensitive the costeffectiveness aspect was for a range of WTP-levels. In addition, an investigation was also carried out to establish whether the intervention would be more cost-effective when delivered by a single therapist instead of two therapists and if it were carried out with groups of 8 people (instead of 4-6 people).

Chapters 5, 7 and 8 address the important gap in the existing evidence-base of the mechanisms of life-review. To determine the suitability of the intervention for different target groups, moderator analyses were conducted. The mediating effects of theoretically and empirically proposed life-review processes (integrative and instrumental reminiscence, meaning in life, mastery and positive thoughts) were studied in the context of a large randomized controlled trial on the effectiveness of life-review. Life-review can be implemented within a group as well as on an individual level. There has been some discussion about which format is most effective. The social aspects of a life-review group intervention were investigated from the perspective of the client.

In the general discussion in the final chapter, the major findings of this thesis are summarized and discussed. Limitations and suggestions for future research are also shared, followed by implications for clinical practice. 


\section{REFERENCES}

American Psychiatric Association. (2000). Diagnostic and statistical manual of mental disorders (4th ed., text revision). Washington, DC: Author.

Anderson, R. J., Freedland, K. E., Clouse, R. E., \& Lustman, P. J. (2001). The prevalence of comorbid depression in adults with diabetes. Diabetes Care, 24, 1069-1078.

Atwood, J. D., \& Ruiz, J. (1993). Social constructionist therapy with the elderly. Journal of Family Psychotherapy, 4, 1-32.

Beekman, A. T. F., Penninx, B. W. J. H., Deeg, D. J. H., de Beurs, E., Geerings, S. W., \& van Tilburg, W. (2002). The impact of depression on the well-being, disability and use of services in older adults: A longitudinal perspective. Acta Psychiatrica Scandinavica, 105, 20-27.

Bohlmeijer, E., Kramer, J., Smit, F., Onrust, S., \& van Marwijk, H. (2009). The effects of integrative reminiscence on depressive symptomatology and mastery of older adults. Community Mental Health Journal, 45, 476-484.

Bohlmeijer, E., Roemer, M., Cuijpers, P., \& Smit, F. (2007). The effects of life-review on psychological well-being in older adults: A meta-analysis. Aging \& Mental Health, 11, 291-300.

Bohlmeijer, E., Smit, F., \& Cuijpers, P. (2003). Effects of reminiscence and life-review on late-life depression: A meta-analysis. International Journal of Geriatric Psychiatry, 18, 1088-1094.

Bohlmeijer, E. T., \& Westerhof, G. J. (2010). The stories we live by [in Dutch]. Amsterdam: Boom Uitgeverij.

Bohlmeijer, E. T., Westerhof, G. J., \& Emmerik-de Jong, M. (2008). The effects of integrative reminiscence on meaning in life: Results of a quasi-experimental study. Aging \& Mental Health, 12, 639-646.

Brewin, C. R. (2006). Understanding cognitive behaviour therapy: A retrieval competition account. Behaviour Research and Therapy, 44, 765-784.

Bluck, S., \& Levine, L. J. (1998). Reminiscence as autobiographical memory: A catalyst for reminiscence theory development. Ageing and Society, 18, 185-208.

Butler, R. N. (1963). The life-review: An interpretation of reminiscence in the aged. Psychiatry, 26, 65-76.

Cappeliez, P. (2002). Cognitive-reminiscence therapy for depressed older adults in day hospital and long-term care. In J. D. Webster and B. K. Haight (Eds.), Critical Advances in Reminiscence Work: From Theory to Application (pp. 300-313). New York, NY: Springer.

Cappeliez, P., \& O'Rourke, N. (2002). Personality traits and existential concerns as predictors of the functions of reminiscence in older adults. Journal of Gerontology: Psychological Sciences, 57B, P116-P123.

Cappeliez, P., \& O'Rourke, N. (2006). Empirical validation of a model of reminiscence and health in later life. Journal of Gerontology: Series B: Psychological Sciences and Social Sciences, 61, 237-244.

Cappeliez, P., O'Rourke, N., \& Chaudhury, H. (2005). Functions of reminiscence and mental health in later life. Aging \& Mental Health, 9, 295-301. 
Cappeliez, P., \& Robitaille, A. (2010). Coping mediates the relationships between reminiscence and psychological well-being among older adults. Aging \& Mental Health, 14, 807-818.

Cassileth, B. R. (1985). Psychosocial problems and support of the advanced cancer patient. Rays, 30, 131-134.

Cole, M. G., Bellavance, F., Masour, A. (1999). Prognosis of depression in elderly community and primary care populations: A systematic review and meta-analysis. American Journal of Psychiatry, 156, 1182-1189.

Copeland, J. R., Beekman, A. T., Dewey, M. E., Hooijer, C., Jordan, A., Lawlor, B.A., et al. (1999). Depression in Europe. Geographical distribution among older people. British Journal of Psychiatry, 174, 312-321.

Cuijpers, P. (1998). A psycho-educational approach to the treatment of depression: A meta analysis of Lewinsohn's 'Coping with Depression' course. Behavior Therapy, 29, 521-533.

Cuijpers, P., de Graaf, R., \& van Dorsselaer, S. (2004). Minor depression: Risk profiles, functional disability, health care use and risk of developing major depression. Journal of Affective Disorders, 79, 71-79.

Cuijpers, P., Smit, F., Oostenbrink, J., de Graaf, R., ten Have, M., \& Beekman, A. (2007). Economic costs of minor depression: A population-based study. Acta Psychiatrica Scandinavica, 115, 229-236.

Cuijpers, P., van Straten, A., Smit, F., Mihalopoulos, C., \& Beekman, A. (2008). Preventing the onset of depressive disorders: A meta analytic review of psychological interventions. American Journal of Psychiatry, 165, 1272-1280.

Cully, J. A., LaVoie, D., \& Gfeller, J. D. (2001). Reminiscence, personality, and psychological functioning in older adults. Gerontologist, 41, 89-95.

Davidhizar, R., \& Shearer, R. A. (1999). Helping elderly clients adjust to change and loss. Home Care Provider, 4, 147-149.

Djernes, J. K. (2006). Prevalence and predictors of depression in populations of elderly: A review. Acta Psychiatrica Scandinavica, 113, 312-321.

Erikson, E. (1964). Childhood and society. New York: Norton.

Fitzgerald, J. M. (1996). Intersecting meanings of reminiscence in adult development and aging. In D.C. Rubin (Ed.), Remembering our past: Studies in autobiographical memory (pp. 360-383). New York: Cambridge University Press.

Forbes, D. A. (2010). Enhancing mastery and sense of coherence: important determinants of health in older adults. Geriatric Nursing, 22, 29-32.

Freedman, J., \& Combs, G. (1996). Narrative therapy: The social construction of preferred realities. New York, NY: W. W. Norton.

Gadella, T. M. (2010). The role of mastery and social support in the association between life stressors and psychological distress in older Canadians. Journal of Gerontological Social Work, 53, 512-530.

Gergen, K. J. (1985). The social constructionist movement in modern psychology. American Psychologist 40, 266-275.

Haight, B. K. (1992). Long-term effects of a structured life-review process. Journal of Gerontology, 47, 312-315. 
Haight, B. K., Michel, Y., \& Hendrix, S. (1998). Life review: Preventing despair in newly relocated nursing home residents short and long term effects. International Journal of Aging and Human Development, 47, 119-142.

Haight, B. K., Michel, Y., \& Hendrix, S. (2000). The extended effects of the life review in nursing home residents. International Journal of Aging and Human Development, 50, 151-168.

Ho, S. F., \& Jones, D. (1999). Morbidity in older people with self-reported asthma. Age and Ageing, 28, 475-480.

Holahan, C. J., Moos, R . H., Holahan, C. K., \& Brennan, P.L. (1995). Social support, coping and depressive symptoms in a late-middle-aged sample of patients reporting cardiac illness. Health Psychology, 14, 152-163.

Hsieh, H. F., \& Wang, J. J. (2003). Effect of reminiscence therapy on depression in older adults: A systematic review. International Journal of Nursing Studies, 40, 335-345.

Ingram, R. E., Kendall, P. C., Siegle, G., Guarino, J., \& McLaughlin, S. C. (1995). Psychometric properties of the Positive Automatic Thoughts Questionnaire. Psychological Assessment, 7, 495-507.

Jang, Y., Haley, W. E., Small, B. J., \& Mortimer, J.A. (2002). The role of mastery and socia resources in the associations between disability and depression in later life. Gerontologist, 6, 807-813.

Kempen, G. I. J. M., Jelicic, M., \& Ormel, J. (1997). Personality, chronic medical morbidity, and health-related quality of life among older persons. Health Psychology, 16, 539-549.

Kempen, G. I. J. M., van Heuvelen, M. J., van Sonderen, E., van den Brink, R. H., Kooijman, A.C., \& Ormel, J. (1999). The relationship of functional limitations to disability and the moderating effects of psychological attributes in community-dwelling older adults. Social Science \& Medicine, 48, 1161-1172.

Kraaij, V., Arensman, E., \& Spinhoven, P. (2002). Negative life-events and depression in elderly persons: A meta-analysis. Journal of Gerontology: Psychological Sciences, 57B, P87-P94.

Kraemer, H. C., Wilson, T., Fairburn, C. G., \& Agras, W.S. (2002). Mediators and moderators of treatment effects in randomized clinical trials. Archives of General Psychiatry, 59, 877-883.

Krause, N. (2004). Stressors arising in highly valued roles and the physical health status of older adults. The Journals of Gerontology, 59B, S287-S291.

Krause, N. (2007). Evaluating the stress-buffering function of meaning in life among older people. Journal of Aging and Health, 19, 792-812.

Licht-Strunk, E., van der Windt, D. A, van Marwijk, H. W., de Haan, M., \& Beekman, A. T. (2007). The prognosis of depression in older patients in general practice and the community. A systematic review. Family Practice, 24, 168-180.

McDougall, F. A., Kvaal, K., Matthews, F. E., Paykel, E., Jones, P. B., Dewey, et al. (2007). Prevalence of depression in older people in England and Wales: The MRC CFA Study, Psychological Medicine, 37, 1787-1795.

Meulenbeek, P. A. M. (2010). Prevention and early intervention of panic disorder. The 
effectiveness of the 'Don't Panic' course (Doctoral Dissertation). Amsterdam: Faculty of Psychology and Eductation, Vrije Universiteit.

Miller, M. D. (2008). Using interpersonal therapy (IPT) with older adults today and tomorrow: A review of the literature and new developments. Current Psychiatry Reports, 10, 16-22.

Mrazek, P. J., \& Haggerty, R. J. (1994). Reducing the risk for mental disorders. Washington, DC: National Academy Press.

Nygren, B., Alex, L., Jonsen, E., Gustafson, Y., Norberg, A., \& Lundman, B. (2005) Resilience, sense of coherence, purpose in life and selftranscendence in relation to perceived physical and mental health among the oldest old. Aging \& Mental Health, 9, 354-362.

O'Rourke, N., Cappeliez, P., \& Claxton, A. (2011). Functions of reminiscence and the psychological well-being of young-old and older adults over time. Aging \& Mental Health, 15, 272-281.

Parker, R. G. (1995). Reminiscence: A community theory framework. Gerontologist, 35, 515-525.

Parker, R. G. (1999). Reminiscence as continuity: Comparison of young and older adults. Journal of Clinical Geropsychology, 5, 147-157.

Pasupathi, M., Weeks, T., \& Rice, C. (2006). Reflecting on life: Remembering as a major process in adult development. Journal of Language and Social Psychology, 25, 244-263.

Payne, K. T., \& Marcus, D. K. (2008). The efficacy of group psychotherapy for older adult clients: A meta-analysis. Group Dynamics: Theory, Research, and Practice, 12, 268-278.

Pearlin, L. I., \& Schooler, C. (1978). The structure of coping. Journal of Health and Social Behaviour, 19, 2-21.

Pekrun, R., Elliot, A. J., \& Maier, M. A. (2006). Achievement goals and discrete achievement emotions. Journal of Educational Psychology, 98, 583-597.

Peng, X. D., Huang, C. Q., Chen, L. J., \& Lu, Z. C. (2009). Cognitive behavioural therapy and reminiscence techniques for the treatment of depression in the elderly: A systematic review. The Journal of International Medical Research, 37, 975-982.

Pinquart, M. (2002). Creating and maintaining purpose in life in old age: a meta-analysis. Ageing International, 27, 90-114.

Pinquart, M., Duberstein, P. R., \& Lyness, J. M. (2007). Effects of psychotherapy and other behavioral interventions on clinically depressed older adults: A metaanalysis. Aging \& Mental Health, 11, 645-657.

Pinquart, M., \& Forstmeier, S. (2012). Effects of reminiscence interventions on psychosocial outcomes: A meta-analysis. Aging \& Mental Health, 16, 541-558.

Pot, A. M., Bohlmeijer, E. T., Onrust, S., Melenhorst, A. S., Veerbeek, M., \& De Vries, W. (2010). The impact of life-review on depression in older adults: A randomized controlled trial. International Psychogeriatrics, 22, 572-581.

Reker, G. T. (1997). Personal meaning, optimism, and choice: Existential predictors of depression in community and institutional elderly. Gerontologist, 37, 709-716.

Roberts, B. L., Dunkle, R., \& Haug, M. (1994). Physical, psychological, and social 
resources as moderators of the relationship of stress to mental health in the very old. Journal of Gerontological Social Work, 49, 535-543.

Rothermund, K., \& Brandtstädter, J. (2003). Coping with deficits and losses in later life: From compensatory action to accommodation. Psychology and Aging, 18, 896-905.

Schieman, S., \& Turner, H. A. (1998). Age, disability and the sense of mastery. Journal of Health and Social Behavior, 39, 169-187.

Serrano, J. P., Latorre, J. M., Gatz, M., \& Montanes, J. (2004). Life-review therapy using autobiographical retrieval practice for older adults with depressive symptomatology. Psychology and Aging, 19, 270-277.

Sideridis, G. D. (2005). Goal orientation, academic achievement, and depression: Evidence in favour of a revised goal theory framework. Journal of Educational Psychology, 97, 366-375.

Sideridis, G. D. (2007). Why are students with LD depressed? A goal orientation model of depression vulnerability. Journal of Learning Disabilities, 40, 526-539.

Smit, F., Ederveen, A., Cuijpers, P., Deeg, D., \& Beekman, A. (2006). Opportunities for cost-effective prevention of late-life depression. An epidemiological approach. Archives of General Psychiatry, 63, 290-296.

Steunenberg, B., Beekman, A. T., Deeg D. J., Bremmer, M. A., \& Kerkhof, A. J. (2007). Mastery and neuroticism predict recovery of depression in later life. American Journal of Geriatric Psychiatry, 15, 234-242.

Stolz, C. M., Baime, M. J., \& Yaffe, K. (1999). Depression in the patient with rheumatologic disease. Rheumatic Diseases Clinic of North America, 25, 687-702.

Thorne, A. (2000). Personal memory telling and personality development. Personality and Social Psychology Review, 4, 46-56.

van 't Veer-Tazelaar, P. J., van Marwijk, H. W. J., van Oppen, P., van Hout, H. P. J., van der Horst, H. E., Cuijpers, P., et al. (2009). Stepped-Care Prevention of Anxiety and Depression in Late Life: A Randomized Controlled Trial. Archives of General Psychiatry, 66, 297-304.

Watt, L. M. (1996). Integrative and instrumental reminiscence therapies for the treatment of depression in older adults. (Doctoral Dissertation). Ottawa: School of Psychology, University of Ottawa.

Watt, L. M., \& Cappeliez, P. (2000). Integrative and instrumental reminiscence therapies for depression in older adults: Intervention strategies and treatment effectiveness. Aging \& Mental Health, 4, 166-177.

Webster, J. D., Bohlmeijer, E. T., \& Westerhof, G. J. (2010). Mapping the future of reminiscence: A conceptual guide for research and practice. Research on Aging, 32, 527-564.

Webster, J. D. (1993). Construction and validation of the Reminiscence Functions Scale. Journal of Gerontology: Psychological Sciences, 48, 256-262.

Webster, J. D. (1995). Adult age differences in reminiscence functions. In B.K. Haight \& J.D. Webster (Eds.), The art and science of reminiscing: Theory, research, methods, and applications (pp. 89-102). Philadelphia, PA: Taylor \& Francis.

Webster, J. D. (1997). The Reminiscence Functions Scale: A replication. International Journal of Aging and Human Development, 44, 137-148. 
Webster, J. D. (1998). Attachment styles, reminiscence function, and happiness in young and elderly adults. Journal of Aging Studies, 12, 315-330.

Webster, J. D., \& McCall, M. E. (1999). Reminiscence functions across adulthood: A replication and extension. Journal of Adult Development, 6, 73-85.

Westerhof, G. J., Bohlmeijer, E. T., van Beljouw, I. M. J., \& Pot, A. M. (2010). Improvement in personal meaning mediates the effects of a life review intervention on depressive symptoms in a randomized controlled trial. Gerontologist, 50, 541-549.

Westerhof, G. J., Bohlmeijer, E. T., \& Webster, J. D. (2010). Reminiscence and mental health: A review of recent progress in theory, research, and intervention. Ageing and Society, 30, 697-721.

Whitbourne, S. K. (1985). The psychological construction of the life-span. In J.E. Birren \& K.W. Schaie (Eds.), Handbook of the psychology of aging (pp. 594-618). New York: Van Nostrand Reinhold.

White, M., \& Epston, D. (1990). Narrative means to therapeutic ends. New York, NY: W. W. Norton.

White, M. (2007). Maps of narrative therapy. New York: W. W. Norton.

Williams, J. M., Barnhofer, T., Crane, C., Herman, D., Raes, F., Watkins, E., et al. (2007). Autobiographical memory specificity and emotional disorder. Psychological Bulletin, 133, 122-148.

Wilson, K. C., Mottram, P. G., \& Vassilas, C. A. (2008). Psychotherapeutic treatments for older depressed people. Cochrane Database of Systematic Reviews, 1, CD004853.

Wink, P., \& Schiff, B. (2002). To review or not to review? The role of personality and lifeevents in life review and adaptation to older age. In J. D. Webster \& B. K. Haight (Eds.), Critical advances in reminiscence work: From theory to application (pp. 44-60). New York: Springer.

Wong, P. T. (1989). Personal meaning and successful aging. Canadian Journal of Psychology, 30, 516-525.

Wong, P. T. (1995). The processes of adaptive reminiscence. In B. K. Haight \& J. D. Webster (Eds.), The art and science of reminiscing: Theory, research, methods, and applications (pp. 23-35). Washington, DC: Taylor \& Francis.

Wong, P. T., \& Watt, L. M. (1991). What types of reminiscence are associated with successful aging? Psychology and Aging, 6, 272-279. 


\section{REMINISCENGE AND ADAPTATION TO CRITICAL LIFE-EVENTS IN OLDER ADULTS WITH MILD TO MODERATE DEPRESSIVE SYMPTOMS}

Korte, J., Bohlmeijer, E. T., Westerhof, G. J., \& Pot, A. M. (2011). Reminiscence and adaptation to critical life-events in older adults with mild to moderate depressive symptoms. Aging \& Mental Health, 15, 638-646. 


\section{CHAPTER}

\section{ABSTRACT}

The role of reminiscence as a way of adapting to critical life-events and chronic medical conditions was investigated in older adults with mild to moderate depressive symptoms. Reminiscence is the (non)volitional act or process of recollecting memories of one's self in the past. 171 Dutch older adults with a mean age of 64 years $(S D=7.4)$ participated in this study. All of them had mild to moderate depressive symptoms. Participants completed measures on critical life-events, chronic medical conditions, depressive symptoms, symptoms of anxiety and satisfaction with life. The reminiscence functions included were: identity, problem-solving, bitterness revival and boredom reduction. Critical lifeevents were positively correlated with identity and problem-solving. Bitterness revival and boredom reduction were both positively correlated with depressive and anxiety symptoms, and negatively to satisfaction with life. Problem-solving had a negative relation with anxiety symptoms. When all the reminiscence functions were included, problemsolving was uniquely associated with symptoms of anxiety, and bitterness revival was uniquely associated with depressive symptoms and satisfaction with life. Interestingly, problem-solving mediated the relation of critical life-events with anxiety. This study corroborates the theory that reminiscence plays a role in coping with critical life-events, and thereby maintaining mental health. Furthermore, it is recommended that therapists focus on techniques which reduce bitterness revival in people with depressive symptoms, and focus on problem-solving reminiscences among people with anxiety symptoms. 


\section{INTRODUCTION}

The need to adjust to change and loss is one of the most important and difficult developmental tasks that older adults face (Erikson, 1964). Change is an inescapable part of life. Although some changes may be positive, many changes are regarded as negative by older adults. The change process and subsequent feelings of loss occur in a variety of situations. Examples are critical life-events, such as the death of a spouse, friends or relatives, retirement, role changes, and caring for ill relatives or others, or the development of a chronic medical condition (Davidhizar \& Shearer, 1999).

The impact of critical life-events on an individual's well-being in later life has been studied extensively (Ganguli, Gilby, Seaberg \& Belle, 1995; Glass, Kasl \& Berkman, 1997; Murrell, Norris \& Grote, 1988; Orrell \& Davies, 1994). From a meta-analysis of 25 studies, Kraaij, Arensman, and Spinhoven (2002) concluded that critical life-events appear to have a modest but significant effect on depression among people aged 65 or over. Several studies among patients with common chronic medical conditions, such as diabetes, cardiovascular disease, arthritis or cancer, have demonstrated an increased level of depressive symptomatology (e.g., Anderson, Freedland, Clouse \& Lustman, 2001; Cassileth, 1985; Ho \& Jones, 1999; C.J. Holahan, Moos, C.K. Holahan \& Brennan, 1995; Shimoda \& Robinson, 1999; Stolz, Baime \& Yaffe, 1999).

The way in which older people cope with these critical life-events and chronic medical conditions is of great importance. Reminiscence may play a part in this process. As a response to change and loss, it is a natural reaction for many older people to start thinking about the meaning of life and reviewing their lives (Butler, 1963; Parker, 1995, 1999; Wong, 1995). Wong (1995) and Parker (1995, 1999) noticed that when the power to recall is properly channelled, reminiscence can help to maintain a sense of integrity and mastery. Reminiscence has gained much attention in gerontological research after Butler's (1963) seminal article on life-review. Whereas classical scholars have viewed reminiscence as a naturally occurring process in later life, current evidence suggests that it is an important process in regulating individual development throughout the whole lifespan (Westerhof, Bohlmeijer \& Webster, 2010). Scholars like Pasupathi, Weeks, and Rice (2006), Thorne (2000), Webster (1995, 1999), and Whitbourne (1985) described the act of remembering as a key process in development from early to late adulthood. Although everybody intuitively knows that reminiscence is about personal memories, it has been rather difficult to provide a good scientific definition of the phenomenon (Fitzgerald, 1996). Bluck and Levine (1998, p. 188) provided a comprehensive definition which is complete enough to grasp all aspects of the phenomenon of remembering our lives: Reminiscence is the volitional or non-volitional act or process of recollecting memories of one's self in the past. It may involve the recall of particular or generic episodes that may or may not have been previously forgotten, and that are accompanied by the sense that the remembered episodes are veridical accounts of the original experiences. This recollection from autobiographical memory may be private or shared with others.

This definition elucidates how reminiscence can take on different forms. On the basis of a taxonomy of reminiscence functions developed by Webster (1994, 1997), Cappeliez and O'Rourke (2006) developed a model that distinguishes between 
three different types of reminiscence functions. First, they distinguish positive functions: identity, problem-solving and death preparation. In identity, memories are actively used to develop our identity by discovering, clarifying and crystallizing important dimensions of the sense of who we are. Problem-solving refers to how memories of past coping strategies can be reused in the present. Death preparation is the way we use our past to arrive at a calm and accepting attitude towards our own mortality. Second, they also distinguish three negative functions: bitterness revival, boredom reduction and intimacy maintenance. Bitterness revival is also about our identity, but in a negative, complaining way. Instead of being integrated in the sense of who we are, negative experiences are constantly brought up. In boredom reduction, the main goal is to escape from the present by romanticizing the past. Intimacy maintenance is a process whereby cognitive and emotional representations of important persons in our lives are resurrected, mostly deceased persons. Finally, pro-social functions are also distinguished: teach/inform and conversation. In teach/inform, memories are used to relay personal experiences and life lessons to others. Conversation reminiscence is the informal use of memories in order to connect or reconnect to others.

Researchers have gained increasing knowledge on how reminiscence is related to mental health (Westerhof et al., 2010). Reminiscence can have both positive and negative effects on mental health. Several studies have indicated that bitterness revival and boredom reduction are positively correlated with depression and anxiety, and negatively with wellbeing (Cappeliez, O'Rourke \& Chaudhury, 2005; Cully, LaVoie \& Gfeller, 2001). In contrast, identity and problem-solving were found to be positively associated with psychological well-being (Cappeliez et al., 2005) and successful ageing (Wong \& Watt, 1991). Cappeliez and O'Rourke (2006) found that the positive functions of reminiscence were positively related to well-being and health and that negative reminiscence functions were negatively related to wellbeing and health; whereas prosocial functions of reminiscence (conversation and teach/inform) were indirectly related to well-being and health.

To summarize, there is a growing body of knowledge about the use of functions of reminiscence throughout the life-span of an individual and their relationship to mental health. However, there are two important limitations. First, the functions of reminiscence and their relation to mental health have scarcely been studied within specific contexts, while our memories are triggered, negotiated and situated within particular contexts (Webster, Bohlmeijer \& Westerhof, 2010). It is often assumed that people start to reminisce more in times of transition, but there are few studies that confirm this (e.g., Haight, Michel \& Hendrix, 1998, 2000; Parker, 1999). Second, almost all the studies about reminiscence functions in relation to mental health have been conducted among the general population with people who do not display any clinical symptoms. However - in the field of mental healthcare - it is relevant to study reminiscence functions in a group of older adults with mild to moderate distress for several reasons. The presence of depressive symptoms, which do not meet the diagnostic criteria, are by far the most important risk factors of late-life clinical disorder (Cuijpers, De Graaf \& van Dorsselaer, 2004; Smit et al., 2007; Smit, Ederveen, Cuijpers, Deeg \& Beekman, 2006). Additionally, most reminiscence interventions are aimed at reducing the symptoms of depression and 
anxiety, while empirical studies on reminiscence functions are mostly carried out among the general population. Hence, it is important to know whether the relationship between reminiscence functions and mental health are similar among people with distress and people from the general population, and more specifically, among people who are willing to participate in reminiscence interventions.

Therefore, this cross-sectional study addresses reminiscence functions a specific sample of older adults with mild to moderate depressive symptoms. We wanted to study how critical life-events and chronic medical conditions are related to reminiscence functions and how these functions are related to depressive symptoms, anxiety symptoms and satisfaction with life. Moreover, to assess whether reminiscence indeed plays a role in a person's ability to adapt to critical life-events and chronic medical conditions, we analyzed which reminiscence functions mediate the relation between critical life-events or chronic medical conditions, and depression, anxiety or satisfaction with life.

\section{METHODS}

\section{Participants}

A total of 171 Dutch older adults living in the community participated in this study $(73 \%$ female), with a mean age of 64 years ( $S D=7.4$, range $51-90)$. Of these participants, $83 \%$ was not employed, $6 \%$ had a low level of education, $19 \%$ had no children and $62 \%$ had no partner. All these people participated in a randomized controlled trial on the effectiveness of a reminiscence intervention on depression (Pot Pot, Bohlmeijer, Onrust, Melenhorst, Veerbeek \& de Vries, 2010). This study consists of baseline measurements of the participants in the study. All measurements were taken before the randomization process. The study was approved by the METiGG, a medical-ethics committee for research in mental healthcare settings in the Netherlands.

In cooperation with 12 Dutch mental healthcare institutions, an open recruitment strategy was used via advertisements in regional and national newspapers, posters and information booklets available at healthcare institutions and general practitioners' surgeries. The intervention was implemented by psychologists at these mental healthcare institutions. In order to participate, people had to experience mild to moderate depressive symptoms and had to be aged 50 or over. To ensure that only older adults with mild to moderate symptoms of depression were included, people with a low score (0-4) on the Center for Epidemiological Studies Depression Scale (CES-D; Radloff, 1977) were excluded. All older adults who scored 24 or higher on the CES-D were further examined with the Mini International Neuropsychiatric Interview (MINI; Sheehan et al., 1998). Diagnosis of a major depressive disorder through the MINI resulted in exclusion from the study. People were also excluded when they were currently receiving any treatment in a mental health institution, or had recently started with pharmacological treatment (within the previous two months). Applicants who were eligible to participate were asked to sign an informed consent form. For an elaborate description of the design of the study, see Pot, Melenhorst, Onrust, and Bohlmeijer (2008). 


\section{Measurements}

Participants had to report if any, out of 19, critical life-events had occurred in the previous three years; an instrument partly based on the Social Readjustment Rating Scale with good psychometric properties in different US samples (Hobson \& Delunas, 2001; Holmes \& Rahe, 1967). Only more frequent critical life-events or critical life-events that are relevant for older adults were included. Examples of these critical life-events were the loss of a spouse or child, divorce, retirement, sexual problems, family problems, having grandchildren or having moved house. Participants could also indicate whether they had experienced any critical life-events that were not mentioned on the list. Participants were assigned one point for every event they experienced during the previous three years and a total score was computed, indicating the number of critical life-events.

Furthermore, participants were asked if they had had any, out of 8, chronic medical conditions for six months or longer; a measure based on a checklist of chronic medical conditions published by Statistics Netherlands (1989). These conditions consisted of lung disease, heart disease, coronary disease, CVA/stroke, diabetes, cancer, incontinence or rheumatism. Participants could also indicate if they had any chronic medical conditions that were not mentioned on the list. The total score of chronic medical conditions was calculated as the number of conditions, adding one point for every condition experienced for six months or longer.

Reminiscence functions were measured using the Dutch version of the Reminiscence Functions Scale (RFS); a questionnaire that assesses reminiscence functions over the course of a person's life (Webster, 1993, 1997). The scale comprises eight subscales (factors) reflecting possible functions of reminiscence for the individual. For the purpose of this study, we used four subscales (23 items): identity (six items), problem-solving (six items), bitterness revival (five items) and boredom reduction (six items). Because the older adults in this study participated in a large randomized controlled trial, we did not want to put too much strain on them. Therefore, we only included four of the RFS subscales that were more consistently related to mental health than the other subscales (Cappeliez et al., 2005; Cappeliez \& O’Rourke, 2006; Cully et al., 2001; Westerhof et al., 2010; Wong \& Watt, 1991). Questions typically started with "When I reminisce, it is..." and are completed using reasons or motivations to reminisce. Respondents were asked to indicate the extent to which each of the reasons applied to them. Possible answers ranged from 1 to 6 (never, rarely, seldom, occasionally, often or very often). Examples were: "When I reminisce, it is... to see how my past fits in with my journey through life" (identity), "to help me plan for the future" (problem-solving), "to keep painful memories alive" (bitterness revival) or "to pass the time during idle or restless hours" (boredom reduction). Scores were each averaged per subscale, representing a reminiscence function. The higher the score, the more the indicated function prevails. The RFS has shown satisfactory psychometric properties in different samples of (older) adults (Webster, 1993, 1997). The four subscales showed good internal consistency in the present sample (identity: $\alpha=.85$, problemsolving: $\alpha=.80$, bitterness revival: $\alpha=.80$, boredom reduction: $\alpha=.80$ ).

Participants' depressive symptoms were measured using the Dutch version of the CES-D. The CES-D is a 20-item, self-report scale developed to measure depressive symptoms in the community. Participants had to indicate how often they had experienced 
each symptom during the previous week. Response categories, ranging from 0 to 3 , are "rarely or never", "some of the time", "occasionally" or "mostly or always". Summation results in a CES-D score, ranging from 0 to 60 (Radloff, 1977). Only the total scores of the CES-D were available in this study, because they were calculated by the psychologists as a part of the inclusion procedure. This means that we cannot report the internal consistency of the scale in our sample. However, the psychometric properties of the scale were found to be good in older populations (Radloff \& Teri, 1986), and more particularly in a similar sample of older Dutch people with depressive symptoms (Haringsma, Engels, Beekman \& Spinhoven, 2004).

Participants' anxiety symptoms were assessed using the HADS-A. The HADS$A$ is a seven-item, self-report screening scale against which respondents are asked to indicate whether they had experienced feelings of restlessness, tenseness or panic during the past four weeks (Zigmond \& Snaith, 1983). Items range from 0 "rarely or never" to 3 "always or most of the time". The Dutch translation has shown good psychometric properties in six different groups of Dutch subjects (Spinhoven et al., 1997). In this study, the HADS-A shows a good internal consistency $(\alpha=.80)$.

Satisfaction with life was measured using the Manchester Short Assessment of Quality of Life (MANSA). The MANSA comprises 16 items: four objective questions and 12 subjective questions (Priebe, Huxley, Knight \& Evans, 1999). For the purpose of this study, we only used the 12 subjective items, assessing satisfaction with life as a whole, employment or retirement, financial situation, friendships, leisure, accommodation, personal safety, people the individual lived with (or whether he/she lived alone), sex life, relationship with family, physical health and mental health. Each item is rated on a seven-point scale ranging from 1 (could not be worse) to 7 (could not be better). Summary scores range from 12 to 84 ; the higher the score, the better the life satisfaction. The MANSA has good psychometric properties in different study samples (Björkman \& Svensson, 2005; Priebe et al., 1999). In our study, the MANSA shows a good internal consistency ( $\alpha=.83$ ).

\section{Analyses}

First, Pearson correlations were calculated to assess the bivariate associations between critical life-events, chronic medical conditions, reminiscence functions and mental health (depression, anxiety and satisfaction with life). Then, regression analyses were carried out to investigate if reminiscence functions are related to mental health. Finally, to examine if reminiscence functions mediate the relation between critical life-events or chronic medical conditions and mental health, mediation analyses were performed. We use multiple regression techniques in accordance with the four steps outlined by Baron and Kenny (1986). The first step is to show that the initial variable (critical life-events or chronic medical conditions) is correlated with the outcome (mental health). This step establishes that there is an effect that may be mediated. The second step is to show that the initial variable (critical life-events or chronic medical conditions) is correlated with the mediator (reminiscence functions). This step essentially involves treating the mediator as an outcome variable. The third step is to show that the mediator (reminiscence functions) affects the outcome variable (mental health), even when controlling for the initial variable (critical life-events or chronic conditions). The fourth step is to establish that the effect of the initial 
variable (critical life-events or chronic conditions) declines after introducing the mediator (reminiscence functions). The Sobel-test was used to check whether the indirect effect is significant.

\section{$\overline{\text { RESULTS }}$}

\section{Baseline characteristics}

Table 1 shows that participants experienced, on average, two to three critical life-events in the last three years, and that they had one to two medical conditions. The five most frequently reported life-events were death of a close family member (29\%), a change in the person's financial situation (24\%), death of a good friend (23\%), health change in a family member (19\%) and retirement (18\%). Furthermore, Table 1 shows the reasons why the older adults in this study reminisced. On a six-point scale they did this most often for the purposes of identity and problem-solving, followed by bitterness revival and boredom reduction. Finally, Table 1 also shows that the older adults score an average of 21 on the CES-D (scale from 0 to 60 for depressive symptoms), 9 on the HADS-A (scale from 0 to 21 for anxiety symptoms) and 54 on the MANSA (scale from 12 to 84 for satisfaction with life).

\section{Bivariate correlations and regression analyses}

First, we discuss how the number of critical life-events and chronic medical conditions are related to reminiscence. Table 1 indicates that critical life-events were positively correlated with identity and problem-solving, but were unrelated to bitterness revival and boredom reduction. To investigate the relation of the individual critical life-events with these positive reminiscence functions, we performed exploratory analyses which showed that identity and problem-solving had mostly significant - however small - correlations with work-related events (e.g., change of job and being turned down for a job). Furthermore, we did not find any relationship between chronic medical conditions and the reminiscence functions. Second, we discuss how the reminiscence functions are related to depression, anxiety and satisfaction with life. Table 1 shows that bitterness revival and boredom reduction were positively correlated with depressive symptoms. We did not find a relationship between identity and problem-solving with depressive symptoms. Regression analysis showed that - after controlling for the other reminiscence functions - only bitterness revival remained significantly associated with symptoms of depression (Table 2). As can be seen in Table 1, problem-solving had a negative relation with anxiety symptoms, and bitterness revival and boredom reduction had a positive relation with anxiety symptoms. No relation was found between identity and anxiety symptoms. When we controlled for all the reminiscence functions; it was found that only problem-solving had a unique association with symptoms of anxiety (Table 2). Table 1 shows that identity and problem-solving were unrelated to satisfaction with life, whereas bitterness revival and boredom reduction were negatively related to satisfaction with life. Only bitterness revival had a unique association with satisfaction with life (Table 2). 
THE STORIES WE LIVE BY - The adaptive role of reminiscence in later life

Table 1. Overview of measures and bivariate correlations.

\begin{tabular}{|c|c|c|c|c|c|c|c|c|c|c|}
\hline$N=171$ & $M(S D)$ & 1 & 2 & 3 & 4 & 5 & 6 & 7 & 8 & 9 \\
\hline $\begin{array}{l}\text { 1. Chronic } \\
\text { medical } \\
\text { conditions }\end{array}$ & $1.50(1.22)$ & - & & & & & & & & \\
\hline $\begin{array}{l}\text { 2. Critical } \\
\text { life-events }\end{array}$ & 2.35 (1.61) & $.24^{\star *}$ & - & & & & & & & \\
\hline $\begin{array}{l}\text { 3. Identity } \\
(1-6)\end{array}$ & $3.81(.973)$ & .05 & $.19^{*}$ & - & & & & & & \\
\hline $\begin{array}{l}\text { 4. Problem- } \\
\text { solving }(1-6)\end{array}$ & $3.70(.866)$ & .03 & $.29^{\star \star}$ & $.83^{\star *}$ & - & & & & & \\
\hline $\begin{array}{l}\text { 5. Bitter- } \\
\text { ness revival } \\
(1-5)\end{array}$ & $2.69(1.02)$ & .01 & .08 & $.32^{\star \star}$ & $.32^{\star *}$ & - & & & & \\
\hline $\begin{array}{l}\text { 6. Boredom } \\
\text { reduction } \\
(1-6)\end{array}$ & $2.23(.885)$ & .06 & -.00 & $.35^{\star \star}$ & $.34^{\star \star}$ & $.49^{\star \star}$ & - & & & \\
\hline $\begin{array}{l}\text { 7. Anxiety } \\
\text { (HADS-A } \\
\text { score 0-21) }\end{array}$ & $9.28(3.37)$ & .01 & $.16^{\star}$ & -.14 & $-.23^{\star \star}$ & $.25^{\star \star}$ & $.24^{\star \star}$ & - & & \\
\hline $\begin{array}{l}\text { 8. Depres- } \\
\text { sion (CES-D } \\
\text { score 0-60) }\end{array}$ & $20.7(7.63)$ & .02 & .07 & -.04 & -.04 & $.24^{\star \star}$ & $.22^{\star \star}$ & $.27^{\star *}$ & - & \\
\hline $\begin{array}{l}\text { 9. Satisfac- } \\
\text { tion with } \\
\text { life (MANSA } \\
\text { score 12- } \\
84 \text { ) }\end{array}$ & $54.8(8.54)$ & -.11 & -.12 & .07 & .08 & $-.26^{\star *}$ & $-.21^{\star *}$ & $-.27^{\star \star}$ & $-.58^{\star \star}$ & - \\
\hline
\end{tabular}

Note. ${ }^{\star} p<.05,{ }^{\star *} p<.01$

Table 2. Regression analysis of reminiscence functions on mental health

\begin{tabular}{|c|c|c|c|c|}
\hline TYPE OF REMINISCENCE & $N=171$ & $\begin{array}{l}\text { DEPRESSION } \\
\beta\end{array}$ & $\begin{array}{l}\text { ANXIETY } \\
\beta\end{array}$ & $\begin{array}{l}\text { SATISFACTION } \\
\text { WITH LIFE } \beta_{\beta}\end{array}$ \\
\hline \multirow[t]{4}{*}{ Reminiscence functions } & Identity & -.06 & -.21 & .05 \\
\hline & Problem-solving & -.02 & $-.30^{*}$ & .01 \\
\hline & Bitterness revival & $.19^{*}$ & .16 & $-.21^{*}$ \\
\hline & Boredom reduction & .15 & .14 & -.12 \\
\hline Adjusted $R^{2}$ & & .05 & .09 & .06 \\
\hline
\end{tabular}




\section{Mediation analyses}

A mediation analysis was carried out to examine whether reminiscence functions mediated the effect of critical life-events and chronic medical conditions on mental health. Only critical life-events, problem-solving reminiscence and anxiety were mutually related to each other, so we only assessed the mediating effect of problem-solving on the relation between critical life-events and anxiety. The first regression analysis, with anxiety symptoms as the dependent variable and critical life-events as the predictor, yielded a significant relation ( $\beta=.16, p=.039$ ). The second regression analysis, with problem-solving as the dependent variable and critical life-events as the predictor, showed a significant relation ( $\beta=.29, p=.000$ ). The third regression analysis was performed with the dependent variable anxiety symptoms and with the predictors problem-solving and critical life-events. This analysis showed that the previous relation between critical life-events and anxiety became insignificant $(\beta=.10, p=.196)$, whereas the mediator problem-solving retained its significance ( $\beta=-.20, p=.013$ ), confirmed by a significant Sobel-test. This indicated that problem-solving mediates the relation of critical life-events with anxiety (Figure 1).

Figure 1. Mediation model with problem-solving reminiscence as a mediator.
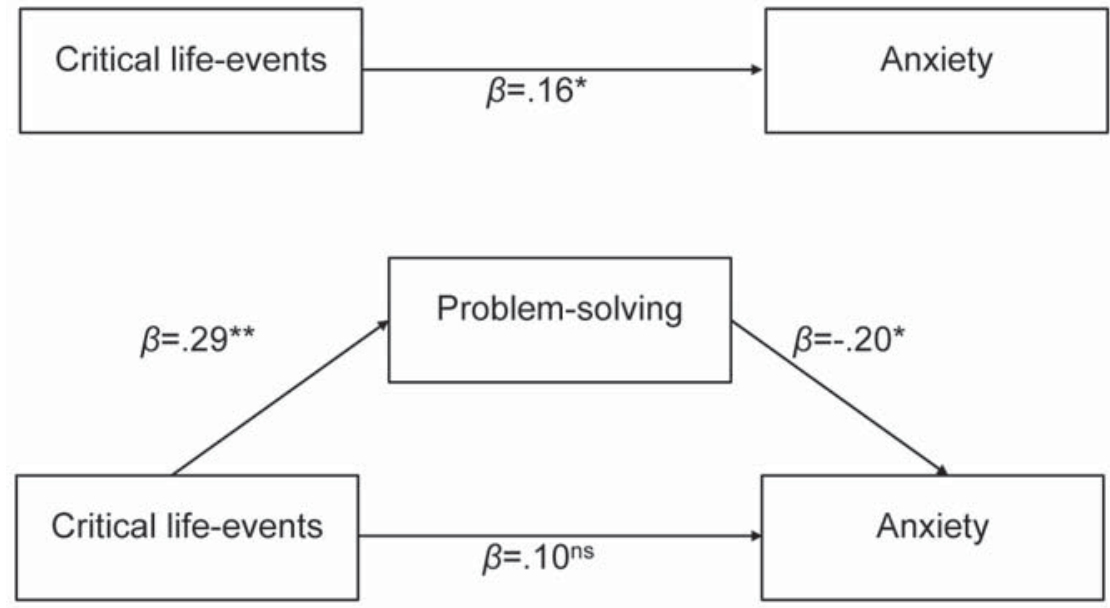

Note. ${ }^{*} p<.05,{ }^{* *} p<.01,{ }^{\text {ns }}$ non-significant. 


\section{$\overline{\text { DISCUSSION }}$}

It has often been claimed that reminiscence may facilitate or hinder adaptation or healthy ageing in later life. However, to the best of our knowledge this claim has never been studied in direct relationship to critical life-events and chronic medical conditions. Additionally, the relation between reminiscence and mental health has been extensively studied, but not in clinically relevant samples. In our study, we were able to study the mediating effects of reminiscence in a sample of 171 older adults with mild to moderate symptoms of depression.

First, we discuss how critical life-events and chronic medical conditions are related to reminiscence. Our results show that older adults, who experienced more critical life-events, reminisce more often for identity and problem-solving. The experience of critical life-events is related to positive reminiscence functions, but not to negative functions of reminiscence. This might be explained by the nature of the life-events. The life-events that were found to be related to the positive functions were most often work-related, e.g., change of job and turned down from a job. So, these are life-events that lead to the recruitment of personal resources rather than the activation of regrets and boredom. Remarkably, we did not find any relation between chronic medical conditions and reminiscence functions. This may possibly be explained by the way in which the presence of chronic medical conditions was measured. Participants' medical conditions were considered chronic when they had been present for at least six months (or longer) at baseline. It might be that, in fact, the chronic medical conditions had been present for much longer. In such a case, the older adults might have already accepted their disease.

Second, we discuss how reminisce is related to mental health, in a sample of older adults with mild to moderate depressive symptoms. Our results show a positive correlation of bitterness revival and boredom reduction with mental health (absence of depression and anxiety and presence of life satisfaction), which is in line with the findings for the general older population (Cappeliez et al., 2005; Cappeliez \& O'Rourke, 2006; Cully et al., 2001). This implies that the research on reminiscence functions in the general population may be generalized to older adults with symptoms of depression and anxiety. More specifically, in this study bitterness revival is uniquely associated with depression, after controlling for identity, problem-solving and boredom reduction. An explanation for this might be that bitterness revival is the result of unresolved conflicts, related for instance to interpersonal issues, past deceptions, failures or losses. Therefore, it may be a manifestation of the self-focused ruminative response style that has been found to maintain depression (Cappeliez, Rivard \& Guindon, 2007). When we control for identity, bitterness revival and boredom reduction, our results show that problem-solving had a unique association with anxiety. A possible explanation for this is that anxiety is more often associated with worrying about the present and future, whereas depression is associated with worrying about the past (Borkovec, Ray \& Stöber, 1998). Problem-solving reminiscence is directly related to coping with present difficulties (Wong, 1995). It possibly enhances a feeling of mastery, thereby reducing anxiety. 
Contrary to what one might expect, there were only limited associations of critical life-events and chronic diseases with mental health (depression, anxiety and satisfaction with life) in our study. We only found a relatively weak significant relation between critical life-events and anxiety $(r=.16)$. Because the nature of the individual life-events and the diseases differed, we did a post hoc analysis on the relation between the individual critical life-events and the individual diseases with mental health. This analysis showed that individual life-events and diseases were weakly related to depression, anxiety and life satisfaction. Apparently, it might be more likely that it is the accumulation of critical life-events which is related to symptoms of anxiety. Another explanation for the lack of associations might be that our study sample is rather homogeneous. Given that these older adults already have mild to moderate depressive symptoms - and therefore little symptom variation - it might be difficult to find a relation between life-events combined with diseases and mental health.

Finally, we discuss whether reminiscence mediates the relationship between both critical life-events and chronic medical conditions and mental health. Interestingly, our findings show that problem-solving mediates precisely the significant relation between critical life-events and anxiety. Problem-solving reminiscence involves reflecting on past strategies, coping techniques and skill sets which enabled persons to cope successfully in the past. If people become aware, and believe in the efficacy of such strengths, then current problems should not generate so much anxiety. Moreover, if the older adults access memories of former successful coping strategies, they feel reassured and this results in a reduction in anxiety. This finding relates to work carried out recently by Cappeliez and Robitaille (2010), in which they found that coping mediates the relation between reminiscence and psychological well-being among older adults.

\section{Limitations}

Some limitations of our study should be noted. First, this is a cross-sectional study. Longitudinal studies are needed in order to be conclusive about causality. For example, an increase in symptoms of depression and anxiety might result in particular uses of reminiscence rather than the other way around. Second, for practical reasons we only included four reminiscence functions (identity, problem-solving, bitterness revival and boredom reduction). In future research, it might be interesting to investigate how the functions of intimacy maintenance, death preparation, conversation and teach/inform are related to critical life-events and chronic medical conditions. Third, the participants in our study are relatively young, higher educated older adults and most of them are female. Therefore, generalizations with regard to age, education and sex must be made with some caution. Fourth, participants were only mildly distressed and were in relatively good health (i.e., one to two chronic conditions per person). So, there was only limited variability within these variables. Fifth, this study comprises only limited contexts of reminiscence (critical lifeevents and chronic medical conditions) and mental health outcomes (depression, anxiety and satisfaction with life) of reminiscence. Future research should also take into account other factors, such as personality, functional dependence, loss of social contacts, and 
isolation as contexts of reminiscence and quality of life, positive mental health or meaning in life as possible mental health outcomes. Furthermore, it is debatable whether the assessed critical life-events and chronic medical conditions really measure change. Therefore, in future research it might be interesting to include indicators of change that are clearer, e.g., by asking participants more explicitly what changes they have experienced.

\section{Implications}

Our data yields implications for both future research and clinical practice. Our results support the premise that it is useful to focus not only on how reminiscence is related to mental health, but also on the contextual factors of reminiscence. Therefore, we advise including both types of factors to examine the role of reminiscence in adaptation or evaluating life-review based interventions. Webster et al. (2010) developed a sophisticated model of reminiscence that identifies and discusses the antecedents, modes, contexts, mediators, moderators, functions and consequences of reminiscence. We believe that such models can guide future research and practice. We would therefore encourage researchers to examine these models for specific hypotheses and concepts.

Since the older adults in our study experience subclinical distress, our results are relevant for clinical practice. In order to reduce clinically relevant symptoms - and prevent mental disorders - we advise therapists to focus on techniques that reduce bitterness revival reminiscence in people with depressive symptoms. This ties in with the finding that reminiscence-based interventions lead to a reduction in the symptoms of depression, comparable to the effects of cognitive behavioural therapy (Bohlmeijer, Smit \& Cuipers, 2003; Pinquart, Duberstein \& Lyness, 2007). The integration of life-review and cognitive therapy (Shellman, Mokel \& Hewitt, 2009; Watt \& Cappeliez, 2000) is very promising. Our study also suggests that it is useful to focus on problem-solving reminiscence in people with anxiety symptoms. Pot et al. (2010) indeed found significant effects on anxiety using a protocol that integrated life-review with problem-solving therapy. However, more studies are needed to confirm these preliminary findings.

To conclude, our findings underscore the importance of differentiating reminiscence interventions by their intended purpose and target group. In doing so, therapists must be aware that reminiscence interventions could have negative effects. Therefore, careful planning and testing of reminiscence protocols, by making use of research findings and scientific theories that link psychological processes in reminiscence and its outcomes, is now crucial (Bluck \& Levine, 1998; Goldfried \& Wolfe, 1996; Westerhof et al., 2010). Reminiscence interventions have to value factors, such as context, goals of the intervention, psychological and developmental theory, characteristics of the target-group (e.g., level of distress) and the skills and education of counsellors (Lin, Dai \& Hwang, 2005). 


\section{REFERENCES}

Anderson, R. J., Freedland, K. E., Clouse, R. E., \& Lustman, P. J. (2001). The prevalence of comorbid depression in adults with diabetes. Diabetes Care, 24, 1069-1078.

Baron, R. M., \& Kenny, D. A. (1986). The moderatormediator variable distinction in social psychological research: Conceptual, strategic, and statistical considerations. Journal of Personality and Social Psychology, 51, 1173-1182.

Björkman, T., \& Svensson, B. (2005). Quality of life in people with severe mental illness. Reliability and validity of the Manchester Short Assessment of Quality of Life (MANSA). Nordic Journal of Psychiatry, 59, 302-306.

Bluck, S., \& Levine, L. J. (1998). Reminiscence as autobiographical memory: A catalyst for reminiscence theory development. Ageing and Society, 18, 185-208.

Bohlmeijer, E., Smit, F., \& Cuipers, P. (2003). Effects of reminiscence and life review on late-life depression: A meta-analysis. International Journal of Geriatric Psychiatry, 18, 1088-1094.

Borkovec, T. D., Ray, W. J., \& Stöber, J. (1998). Worry: A cognitive phenomenon intimately linked to affective, physiological, and interpersonal behavioral processes. Cognitive Therapy and Research, 22, 561-576.

Butler, R. N. (1963). The life-review: An interpretation of reminiscence in the aged. Psychiatry, 26, 65-76.

Cappeliez, P., \& O'Rourke, N. (2006). Empirical validation of a model of reminiscence and health in later life. Journals of Gerontology: Psychological Sciences, 61, 237-244.

Cappeliez, P., \& Robitaille, A. (2010). Coping mediates the relationships between reminiscence and psychological wellbeing among older adults. Aging \& Mental Health, 14, 807-818. 644

Cappeliez, P., O'Rourke, N., \& Chaudhury, H. (2005). Functions of reminiscence and mental health in later life. Aging \& Mental Health, 9, 295-301.

Cappeliez, P., Rivard, V., \& Guindon, S. (2007). Fonctions des réminiscences à l'âge adulte avancé: Proposition d'un modèle théorique avec ses applications cliniques. [Functions of reminiscence in later life: Proposition of a model and applications]. Revue Européenne de Psychologie Appliquée, 57, 151-156.

Cassileth, B. R. (1985). Psychosocial problems and support of the advanced cancer patient. Rays, 30, 131-134.

Cuijpers, P., De Graaf, R., \& van Dorsselaer, S. (2004). Minor depression: Risk profiles, functional disability, health care use and risk of developing major depression. Journal of Affective Disorders, 79, 71-79.

Cully, J. A., LaVoie, D., \& Gfeller, J. D. (2001). Reminiscence, personality, and psychological functioning in older adults. Gerontologist, 41, 89-95.

Davidhizar, R., \& Shearer, R. A. (1999). Helping elderly clients adjust to change and loss. Home Care Provider, 4, 147-149.

Erikson, E. (1964). Childhood and society. New York: Norton.

Fitzgerald, J. M. (1996). Intersecting meanings of reminiscence in adult development and aging. In D. C. Rubin (Ed.), Remembering our past: Studies in autobiographical memory (pp. 360-383). New York: Cambridge University Press. 
Ganguli, M., Gillby, J., Seaberg, E., \& Belle, S. (1995). Depressive symptoms and associated factors in a rural elderly population: The MoVIES Project. American Journal of Geriatric Psychiatry, 3, 144-160.

Glass, T. A., Kasl, S. V., \& Berkman, L. F. (1997). Stressful life-events and depressive symptoms among the elderly: Evidence from a prospective community study. Journal of Aging and Health, 9, 70-89.

Goldfried, M. R., \& Wolfe, B. E. (1996). Psychotherapy practice and research: Repairing a strained relationship. American Psychologist, 51, 1007-1016.

Haight, B. K., Michel, Y., \& Hendrix, S. (1998). Life review: Preventing despair in newly relocated nursing home residents short and long term effects. International Journal of Aging and Human Development, 47, 119-142.

Haight, B.K., Michel, Y., \& Hendrix, S. (2000). The extended effects of the life review in nursing home residents. International Journal of Aging and Human Development, $50,151-168$.

Haringsma, R., Engels, G. I., Beekman, A. T. F., \& Spinhoven, P. (2004). The criterion validity of the Center for Epidemiological Studies Depression Scale (CES-D) in a sample of self-referred elders with depressive symptomatology. International Journal of Geriatric Psychiatry, 19, 558-563.

Ho, S. F., \& Jones, D. (1999). Morbidity in older people with self-reported asthma. Age and Ageing, 28, 475-480.

Hobson, C. J., \& Delunas, L. (2001). National norms and life-event frequencies for the revised social readjustment rating scale. International Journal of Stress Management, 8, 299-314.

Holahan, C. J., Moos, R. H., Holahan, C. K., \& Brennan, P. L. (1995). Social support, coping and depressive symptoms in a late-middle-aged sample of patients reporting cardiac illness. Health Psychology, 14, 152-163.

Holmes, T. H., \& Rahe, R. H. (1967). The social readjustment rating scale. Journal of Psychosomatic Research, 11, 213-218.

Kraaij, V., Arensman, E., \& Spinhoven, P. (2002). Negative life-events and depression in elderly persons: A metaanalysis. Journal of Gerontology: Psychological Sciences, 57B, P87-P94.

Lin, Y. C., Dai, Y. T., \& Hwang, S. L. (2005). The effect of reminiscence on the elderly population: A systematic review. Public health nursing, 20, 297-306.

Murrell, S. A., Norris, F. H., \& Grote, C. (1988). Life-events in older adults. In I. H. Cohen (Ed.), Life-events and psychological functioning: Theoretical and methodological issues (pp. 96-122). Newbury Park, CA: Sage.

Orrell, M. W., \& Davies, A. D. M. (1994). Life-events in the elderly. International Review of Psychiatry, 6, 59-71.

Parker, R. G. (1995). Reminiscence: A community theory framework. Gerontologist, 35, 515-525.

Parker, R. G. (1999). Reminiscence as continuity: Comparison of young and older adults. Journal of Clinical Geropsychology, 5, 147-157.

Pasupathi, M., Weeks, T., \& Rice, C. (2006). Reflecting on life: Remembering as a major process in adult development. Journal of Language and Social Psychology, 25, 244-263. 
Pinquart, M., Duberstein, P. R., \& Lyness, J. M. (2007). Effects of psychotherapy and other behavioral interventions on clinically depressed older adults: A metaanalysis. Aging \& Mental Health, 11, 645-657.

Pot, A. M., Bohlmeijer, E. T., Onrust, S., Melenhorst, A. S., Veerbeek, M., \& de Vries, W. (2010). The impact of life review on depression of older adults: A randomized controlled trial. International Psychogeriatrics, 22, 572-581.

Pot, A.M., Melenhorst, A., Onrust, S., \& Bohlmeijer, E. T. (2008). (Cost)effectiveness of life review for older adults: Design of a randomized controlled trial. BMC Public Health, 8, 211.

Priebe, S., Huxley, P., Knight, S., \& Evans, S. (1999). Application and results of the Manchester Short Assessment of quality of life (MANSA). International Journal of Social Psychiatry, 45, 7-12.

Radloff, L. S. (1977). The CES-D scale: A self-report depression scale for research in the general population. Journal of Applied Psychological Measurement, 1, 385-401.

Radloff, L. S., \& Teri, L. (1986). Use of the CES-D with older adults. Clinical Gerontology, 5, 119-136.

Sheehan, D. V., Lecrubier, Y., Sheehan, K. H., Amorim, P., Janavs, J., \& Weiller, E. (1998). The Mini-International Neuropsychiatric Interview (MINI): The development and validation of a structured diagnostic psychiatric interview for DSM-IV and ICD10. Journal of Clinical Psychiatry, 59, 22-33.

Shellman, J. M., Mokel, M., \& Hewitt, N. (2009). The effects of integrative reminiscence on depressive symptoms in older African Americans. Western Journal of Nursing Research, 31, 772-786.

Shimoda, K., \& Robinson, R. G. (1999). The relationship between poststroke depression and lesion location in longterm follow-up. Biological Psychiatry, 45, 187-192.

Smit, F., Comijs, H. C., Schoevers, R., Cuijpers, P., Deeg, D., \& Beekman, A. (2007). Target groups for the prevention of late-life anxiety. The British Journal of Psychiatry, 190, 428-434.

Smit, F., Ederveen, A., Cuijpers, P., Deeg, D., \& Beekman, A. (2006). Opportunities for cost-effective prevention of late-life depression. An epidemiological approach. Archives of General Psychiatry, 63, 290-296.

Spinhoven, P. H., Ormel, J., Sloekers, P. P. A., Kempen, G. I. J. M., Speckens, A. E. M., \& van Hemert, A. M. (1997). A validation study of the Hospital Anxiety and Depression Scale (HADS) in different groups of Dutch subjects. Psychological Medicine, 27, 363-370.

Statistics Netherlands (1989). Health Interview Questionnaire. Heerlen, The Netherlands: Central Bureau of Statistics.

Stolz, C. M., Baime, M. J., \& Yaffe, K. (1999). Depression in the patient with rheumatologic disease. Rheumatic Diseases Clinic of North America, 25, 687-702.

Thorne, A. (2000). Personal memory telling and personality development. Personality and Social Psychology Review, 4, 46-56.

Watt, L. M., \& Cappeliez, P. (2000). Integrative and instrumental reminiscence therapies for depression in older adults: Intervention strategies and treatment effectiveness. Aging and Mental Health, 4, 166-177. 
Webster, J. D. (1993). Construction and validation of the Reminiscence Functions Scale. Journal of Gerontology: Psychological Sciences, 48, 256-262.

Webster, J. D. (1994). Predictors of reminiscence. A lifespan perspective. Canadian Journal on Aging, 13, 66-78.

Webster, J. D. (1995). Adult age differences in reminiscence functions. In B. K. Haight \& J. D. Webster (Eds.), The art and science of reminiscing: Theory, research, methods, and applications (pp. 89-102). Philadelphia, PA: Taylor \& Francis.

Webster, J. D. (1997). The Reminiscence Functions Scale: A replication. International Journal of Aging and Human Development, 44, 137-148.

Webster, J. D. (1999). World views and narrative gerontology: Situating reminiscence behavior within a lifespan perspective. Journal of Aging Studies, 13, $29-42$.

Webster, J. D., Bohlmeijer, E. T., \& Westerhof, G. J. (2010). Mapping the future of reminiscence: A conceptual guide for research and practice. Research on Aging, 32, 527-564.

Westerhof, G. J., Bohlmeijer, E. T., \& Webster, J. D. (2010). Reminiscence and mental health: A review of recent progress in theory, research, and intervention. Ageing and Society, 30, 697-721.

Whitbourne, S.K. (1985). The psychological construction of the life-span. In J. E. Birren \& K. W. Schaie (Eds.), Handbook of the psychology of aging (pp. 594-618). New York: Van Nostrand Reinhold.

Wong, P. T. (1995). The processes of adaptive reminiscence. In B. K. Haight \& J. D. Webster (Eds.), The art and science of reminiscing: Theory, research, methods, and applications (pp. 23-35). Washington, DC: Taylor \& Francis.

Wong, P. T., \& Watt, L. M. (1991). What types of reminiscence are associated with successful aging? Psychology and Aging, 6, 272-279.

Zigmond, A. S., \& Snaith, R. P. (1983). The hospital anxiety and depression scale. Acta Psychiatrica Scandinavica, 67, 361-370. 


\section{MEANING IN LIFE AND MASTERY MEDIATE THE RELATIONSHIP OF NEGATIVE REMINISCENGE WITH DISTRESS AMONG OLDER ADULTS WITH MILD TO MODERATE DEPRESSIVE SYMPTOMS}

Korte, J., Cappeliez, P., Bohlmeijer, E. T., Westerhof, G. J. (2012, online first). Meaning in life and mastery mediate the relationship of negative reminiscence with distress among older adults with mild to moderate depressive symptoms. European Journal of Ageing, doi: 10.1007/s10433-012-0239-3. 


\section{CHAPTER}

\section{ABSTRACT}

To understand the adaptive value of reminiscence, a mediational model of reminiscence was tested in a sample of older adults with mild to moderate depressive symptoms. Using structural equation modeling, we investigated if mental resources (mastery and meaning in life) mediate the relation between reminiscence (positive: identity construction and problem-solving; and negative: bitterness revival and boredom reduction) and distress (depressive symptoms and anxiety symptoms). A total of 202 older Dutch adults living in the community participated in this study. The present study consisted of baseline measurements of a randomized controlled trial that evaluated the effectiveness of a lifereview therapy intervention on depression. Results showed that mental resources fully mediated the relation between negative reminiscence and distress. Specifically, negative reminiscing is related to decreased distress through meaning in life and sense of mastery. The study contributes to current knowledge on the relation between reminiscence and mental health, both empirically and clinically. It helps to increase understanding of how reminiscence is related to distress, especially in depressed older adults, and the relative importance of mental resources, i.e., mastery and meaning in life. From a clinical perspective, these findings suggest the usefulness of focusing on strengthening mental resources in therapeutic reminiscence-based strategies for older adults with depressive symptoms. 


\section{$\overline{\text { INTRODUCTION }}$}

In general, older adults face several challenges associated with aging, like cognitive decline, a deteriorated physical health, and loss of mental resources; processes which can lead to distress. Hence, it is important to know which mechanisms are related to a successful coping with distress in later life. In the last fifty years, several authors have acknowledged the adaptive value of reminiscence for the mental health of older adults (e.g., Butler, 1963; Cappeliez \& O'Rourke 2006; Korte, Bohlmeijer, Westerhof \& Pot, 2011; O’Rourke, Cappeliez \& Claxton, 2011; Webster, Bohlmeijer \& Westerhof, 2010; Westerhof, Bohlmeijer \& Webster, 2010; Wink \& Schiff 2002; Wong, 1995; Wong \& Watt, 1991). Reminiscence can be briefly defined as a volitional or non-volitional process that involves recalling one's private or shared memories (Bluck \& Levine 1998). The present study investigates how reminiscence can contribute to mental resources and thus also to distress in older adults with mild to moderate depressive symptomatology.

Research shows that particular ways of reminiscing are correlated with distress. The types of reminiscence most consistently associated with mental health are identity construction, problem-solving, bitterness revival, and boredom reduction (Westerhof, Bohlmeijer \& Webster, 2010). Identity construction consists of using memories to identify who we are, whereas problem-solving is about reflecting on past coping strategies to cope with present difficulties (Webster, 1993). Bitterness revival can be defined as rehashing and ruminating about memories of difficult life circumstances, lost opportunities, and misfortunes, whereas boredom reduction involves using memories to fill a void of stimulation or interest (Webster, 1993). Using structural equation modeling (SEM), it was shown that identity construction and problem-solving comprise one factor, called positive reminiscence, whereas bitterness revival and boredom reduction comprise a second factor called negative reminiscence. Positive reminiscence is negatively related to distress and negative reminiscence is positively related to distress (Cappeliez \& O'Rourke 2006; Cappeliez, O'Rourke \& Chaudhury, 2005; O'Rourke et al., 2011). These findings are supported by meta-analytic studies showing that interventions, focusing on reducing negative reminiscing and promoting positive reminiscing, lead to a decrease in distress (Bohlmeijer, Roemer, Cuijpers \& Smit; Bohlmeijer, Smit \& Cuijpers, 2003; Cuijpers, van Straten \& Smit, 2006; Pinquart, Duberstein \& Lyness, 2007).

A next step in our effort to understand the adaptive value of reminiscence for distress is to explore in greater detail how these different types of reminiscence are related to distress. Recently, Cappeliez and Robitaille (2010) investigated the role played by assimilative and accommodative coping in mediating the relations of positive and negative functions of reminiscence with mental health. Using SEM, they showed that coping resources fully mediated these relations. We expanded their model in two ways. First, as these authors also suggested, our focus was to test a mediational model of reminiscence and mental health in a sample of older adults already presenting moderate distress. This is especially important from a clinical perspective, because it can generate useful information on tailoring reminiscence-based interventions to characteristics of participants. Korte et al. (2011) indeed underscored the importance of differentiating 
reminiscence interventions by means of their intended purpose and target group. They found that reminiscence mediated the relationship between critical life-events and distress in a sample of older adults with subclinical distress.

Second, and from a clinical perspective, we were interested in examining mental resources which were previously used in studies on the effects of reminiscence-based interventions. It has been suggested that reminiscence may foster mental health by the accumulation of feelings of mastery and meaning in life (Wong, 1995). The concept of mastery refers to the extent to which individuals believe they are in control of their important life experiences (Pearlin \& Schooler 1978). Meaning in life can be defined as having a sense of direction and order, a reason for existence, a clear sense of personal identity, and a high degree of social consciousness (Reker, 1997). Mastery and meaning are theoretically related resources; for example, manageability (mastery) and meaningfulness (meaning) comprise components of Antonovsky's model of sense of coherence (Antonovsky, 1993), whereas environmental mastery (mastery) and purpose in life (meaning) are two of the six components of Ryff's model of psychological well-being (Ryff, 1989). Several authors have found that mastery and meaning in life work together as protective mental resources of mental health (e.g., Seligman, 1998; Taylor, 1989; Taylor, Kemeny, Reed, Bower \& Gruenewald, 2000).

Several studies with older adults demonstrate strong relationships of mastery and meaning in life with mental health. In a large, recent study with older adults, Forbes (2010) demonstrated that mastery was a strong predictor, stronger than sociodemographic factors, of both health status and perceived health. In the same vein, Steunenberg, Beekman, Deeg, Bremmer and Kerkhof (2007) showed that higher levels of mastery predicted recovery of depression in later life. Similar results were found by Gadella (2010), who demonstrated that higher levels of mastery were associated with lower levels of distress in older adults. Other studies have also shown that high levels of mastery facilitate adaptation to distress in the face of stressful events (Jang, Haley, Small \& Mortimer, 2002; Kempen, van Heuvelen, van Sonderen, van den Brink, Kooijman \& Ormel, 1999; Kempen Jelicic \& Ormel, 1997; Roberts, Dunkle \& Haug, 1994; Schieman \& Turner 1998). Another line of research suggests that older adults with a strong sense of meaning in life report better mental health than those with less meaning in their lives (Nygren, Alex, Jonsen, Gustafson, Norberg \& Lundman, 2005; Reker, 1997). In a large meta-analysis, Pinquart (2002) showed that purpose in life (meaning) has a strong negative correlation with depression. Like mastery, meaning in life appears to fulfil a stress-buffering and counterdepressive role in older adults (Krause 2004; 2007).

Reminiscence may either impede or strengthen the mental resources of mastery and meaning. When reminiscing for negative purposes, people ruminate on unpleasant events, reflecting a failure to integrate problematic past experiences with the more positive aspects of life and thereby obstructing the feeling that life is manageable and meaningful (Wong, 1989; 1995). On the other hand, reminiscence for positive purposes makes use of past experiences that might serve a role in enhancing a sense of mastery and meaning, for example by recalling events of previous accomplishments or by remembering events that provide a sense of meaning and direction (Wong, 1995). Empirical studies have shown that reminiscence interventions may indeed enhance mastery and meaning 
in life (Bohlmeijer, Kramer, Smit, Onrust \& van Marwijk, 2009; Bohlmeijer, Valenkamp, Westerhof, Smit \& Cuijpers, 2005; Pot, Bohlmeijer, Onrust, Melenhorst, Veerbeek \& de Vries, 2010; Westerhof \& Bohlmeijer, 2004). These resources may even mediate the effects of reminiscence interventions on depressive symptoms (Watt, 1996; Westerhof Bohlmeijer, van Beljouw \& Pot, 2010). We will therefore concentrate on these resources in our mediating model.

In line with the above studies, the present study tested a mediational model of reminiscence and mental health in a sample of older adults with mild to moderate depressive symptoms. We predicted that mastery and meaning in life are relevant mental resources in the relation between reminiscence functions and distress. A recent study shows that findings on the relation between reminiscence and distress in the general older population may be generalized to older adults with depressive symptomatology (Korte et al., 2011). Therefore, using SEM, we tested a model that involved both direct links between positive (identity and problem-solving) and negative (bitterness revival and boredom reduction) reminiscing, on the one hand, and distress (depression and anxiety), on the other, together with indirect links mediated by mental resources (mastery and meaning in life). More specifically, it was hypothesized that positive reminiscing would be positively linked to the personal resources of mastery and meaning leading to reduced distress. Furthermore, it was hypothesized that negative reminiscing would be negatively related to these two resources, resulting in increased distress.

\section{DESIGN AND METHODS}

\section{Participants}

A total of 202 older Dutch adults living in the community participated in this study $(77 \%$ female), with a mean age of 63 years ( $S D=6.48$, range 55-83). Participants' level of formal education was equally represented among three categories $(33.6 \%<11$ years, $33.7 \%$ 11-14 years, and $32.7 \%>14$ years of schooling). A high number of participants were retired (30.7\%). Participants' daily activities could best be described as doing volunteer work (18.3\%), having a paid job, doing the housekeeping, receiving a disability pension (each $15.8 \%$ ), or unemployed (3.5\%). On average, participants reported one to two chronic medical conditions $(M=1.5, S D=1.4$, range $0-6)$ and they experienced two to three critical life-events in the last three years $(M=2.3, S D=1.5$, range $0-7)$. All of these older adults participated in a randomized controlled trial that evaluated the effectiveness of a life-review therapy intervention on depression (Korte, Bohlmeijer, Cappeliez, Smit \& Westerhof, 2012; Korte, Bohlmeijer \& Smit, 2009). The present study consisted of baseline measurements of the participants in that study. All measurements were taken before the randomization process.

\section{Recruitment}

In cooperation with 14 Dutch mental healthcare institutions, an open recruitment strategy was used via advertisements in regional and national newspapers, posters, and information booklets available at healthcare institutions and surgeries of general 
practitioners, plus a radio interview and a commercial. The intervention was implemented by psychologists and other therapists in the participating mental healthcare institutions. In order to take part, people had to experience mild to moderate depressive symptoms and be aged 55 or over. To ensure that only older adults with mild to moderate symptoms of depression were included, people with a low score (0-4) on the Center for Epidemiologic Studies Depression Scale (CES-D; Radloff, 1977) were excluded. Furthermore, all older adults were examined with the Mini International Neuropsychiatric Interview (MINI; Sheehan, Lecrubier, Sheehan, Amorim, Janavs \& Weiller, 1998). Diagnosis of a severe major depressive disorder through the MINI resulted in exclusion from the study. People were also excluded if they were currently receiving any form of treatment in a mental healthcare institution, or had recently started taking antidepressant medication (within the previous 2 months). Eligible applicants were asked to sign an informed consent form. This study was approved by the METiGG, a medical-ethics committee for research in mental health care settings in the Netherlands. Furthermore, this study has been registered in the Netherlands Trial Register, the primary Dutch register for clinical trials (TC=1860). For a more elaborate description of the design of the study, we refer to Korte et al. (2009).

\section{Measurements}

Reminiscence functions

Reminiscence functions were measured with the Dutch version of the reminiscence functions scale (RFS), a questionnaire that assesses reminiscence functions over the course of a person's life (Webster, 1993). The scale comprises eight subscales reflecting possible functions of reminiscence. We only included four of the RFS subscales that have been most consistently related to mental health in previous research (Cappeliez et al., 2005; Cappeliez \& O'Rourke, 2006; Cully et al., 2001; Westerhof, Bohlmeijer \& Webster, 2010), namely identity (6 items), problem-solving (6 items), bitterness revival (5 items), and boredom reduction (6 items). Prompted by "When I reminisce, it is..." various reasons or motivations to reminisce were proposed to the participants. Possible answers ranged from 1 to 6 (never, rarely, seldom, occasionally, often, or very often). Examples were: "When I reminisce, it is ...to see how my past fits in with my journey through life" (identity), "...to help me plan for the future" (problem-solving), "...to keep painful memories alive" (bitterness revival), or "...to pass the time during idle or restless hours" (boredom reduction). Scores were each averaged per subscale representing a particular reminiscence function, a higher score signifying a more frequent reliance on that reminiscence function. The RFS has shown satisfactory psychometric properties in different samples of adults of various ages, including older adults (Webster 1993; Robitaille, Cappeliez, Coulombe \& Webster, 2010). The four subscales showed good internal consistency in the present sample (identity: $\alpha=.85$, problem-solving: $\alpha=.79$, bitterness revival: $\alpha=.83$, boredom reduction: $\alpha=.86$ ).

\section{Mastery}

To assess the degree of mastery over one's life, the Dutch version of the Mastery Scale was used (Pearlin \& Schooler, 1978). This scale consists of seven items intended to assess beliefs in perceived control over one's life in general or beliefs regarding one's 
ability to control an event. We used the abbreviated version of five items which are each phrased in a negative way. Possible responses were given on a 5-point scale ranging from 1 "strongly disagree" to 5 "strongly agree". Summary scores ranged from 5 to 25. Higher scores on the scale thus indicate higher levels of mastery. The Mastery Scale has good psychometric properties (Pearlin \& Schooler, 1978). In the present study, the scale showed a good internal consistency $(\alpha=.79)$.

\section{Meaning in life}

Meaning in life was measured using the Dutch version of the meaning in life questionnaire (MLQ), a 10-item measure (Steger, Frazier, Oishi \& Kaler, 2006). The scale comprises two subscales: the presence of meaning and the search for meaning in life. The presence of meaning refers to comprehension of life experiences and a sense of overarching purpose, whereas search for meaning refers to the intensity and activity with seeking to establish and/or increase thereof. For the purpose of this study, we only included the 5-item presence of meaning scale, as this yielded more consistent relations with mental health than the search for meaning scale (Steger, Frazier, Oishi \& Kaler, 2006). Participants answered on a 5-point scale from 1 "absolutely untrue" to 5 "absolutely true" to what they thought made their life feel important to them. Examples were: "I understand my life's meaning" and "I have discovered a satisfying life purpose". The MLQ has good psychometric properties (Steger, Frazier, Oishi \& Kaler, 2006). The subscale presence of meaning showed a good internal consistency in the present study $(\alpha=.80)$.

\section{Depressive symptoms}

Participants' depressive symptoms were measured using the Dutch version of the Center for Epidemiologic Studies Depression Scale (CES-D), a 20-item, self-report scale developed to measure depressive symptoms in the community. Participants indicated how often they had experienced each symptom during the previous week. Response categories, ranging from 0 to 3, are "rarely or never", "some of the time", "occasionally", or "mostly or always". Summation results in a CES-D score range from 0 to 60 . A score of 16 or higher is considered indicative of clinically relevant depressive disorders. (Radloff, 1977). The psychometric properties of the scale were found to be good (Radloff, 1977), and particularly in a similar sample of older Dutch people with depressive symptoms (Haringsma, Engels, Beekman \& Spinhoven, 2004). In this study, the scale showed good internal consistency $(\alpha=.84)$.

\section{Anxiety symptoms}

Participants' anxiety symptoms were assessed using the anxiety scale of the Hospital Anxiety and Depression Scale (HADS-A), a 7-item, self-report screening scale on which respondents are asked to indicate whether they had experienced feelings of restlessness, tenseness, or panic during the past four weeks (Zigmond \& Snaith, 1983). Items range from 0 "rarely or never" to 3 "always or most of the time". The Dutch translation has shown good psychometric properties in six different groups of Dutch subjects (Spinhoven, Ormel, Sloekers, Kempen, Speckens \& van Hemert, 1997). The scale showed satisfactory internal consistency in this study $(\alpha=.78)$. 


\section{Data analysis}

Analyses were performed with Missing Value Analysis in PASW 18 to impute all missing data on the continuous measures with the expectation-maximization (EM) method. Missing values based on maximum likelihood estimates were imputed using observed data in an iterative process (Dempster, Laird \& Rubin, 1977). The total percentage of missing data was $2.48 \%$. All variables were inspected for skewness and kurtosis. Next, descriptive analyses were carried out to analyze the means, standard deviations, and bivariate correlations of all study variables. An exploratory factor analysis was carried out to provide the first evidence for the measurement model.

Using SEM with AMOS 16.0, a mediational model of reminiscence and distress was tested. Positive reminiscence functions (identity and problem-solving), negative reminiscence functions (bitterness revival and boredom reduction), mental resources (mastery and meaning in life), and distress (depression and anxiety) were modeled as latent variables composed of measured variables. To test the significance of the mediated effect, we compared the fit of two predictor- mediator-outcome models: one with a direct and an indirect path from the predictor to the outcome and one with only the indirect path (Frazier, Tix \& Barron, 2004). A mediational model is supported if the first model does not provide a better fit to the data than the second model. We calculated the difference between the $x^{2}$ values and the degrees of freedom of both models to assess whether they differ significantly. If there is no significant difference, this implies that the model without the direct path explains the data equally well and is preferred to the fuller model that includes the direct path.

The fit of the model was judged by the $x^{2}$ test, the comparative fit index (CFI), the root mean square error of approximation (RMSEA), and the goodness-of-fit index $(G F)$. The CFl evaluates the fit of the estimated model relative to the fit of the independent model (where no relationships are estimated between variables), whereas the RMSEA is a popular measure that also considers the complexity of the model (i.e., the degrees of freedom). Finally, the GFI is a measure of the proportion of variance and covariance that the proposed model is able to explain (similar to $R^{2}$ in regression; Byrne, 2001). CFI and GFI values $>.95$ are indicative of an acceptable fit. RMSEA values $<.05$ represent a good fit, while values $<.08$ represent a reasonable fit (Hu \& Bentler, 1999).

\section{RESULTS}

The skewness and kurtosis of all study variables varied between -1.09 and .614, and -.603 and 1.68 respectively, values which are well within the acceptable range to proceed with SEM (West, Finch \& Curran, 1995). Descriptive results and bivariate correlations between all observed study variables are presented in Table 1. On average, participants scored $20.5(S D=8.57)$ on the CES-D, indicating that the older adults in this study reported mild to moderate depressive symptoms. In total, $68.8 \%$ of the participants met the cut-off for clinically relevant depressive symptoms. It can be seen that not all variables were significantly related. First, bitterness revival and boredom reduction reminiscence 
were both positively related to depression, but unrelated to anxiety, whereas identity and problem-solving reminiscence were both unrelated to depression and anxiety. Second, bitterness revival and boredom reduction reminiscence were negatively related to mastery, but unrelated to meaning in life, whereas identity and problem-solving reminiscence were unrelated to both mastery and meaning in life. Third, mastery and meaning in life were negatively related to depression and anxiety. The exploratory factor analysis revealed four factors: positive reminiscence (identity construction and problem-solving), negative reminiscence (bitterness revival and boredom reduction), mental resources (mastery and meaning in life), and distress (depression and anxiety).

Table 1. Descriptive statistics and bivariate correlation of all observed variables $(\mathrm{N}=202)$

\begin{tabular}{|c|c|c|c|c|c|c|c|c|c|}
\hline VARIABLES & MEAN (SD) & 1 & 2 & 3 & 4 & 5 & 6 & 7 & 8 \\
\hline 1. Identity & $23.6(5.44)$ & - & & & & & & & \\
\hline 2. Problem-solving & $23.0(5.07)$ & $.78^{\star \star}$ & - & & & & & & \\
\hline 3. Bitterness revival & $14.4(5.39)$ & $.31^{\star \star}$ & $.33^{\star *}$ & - & & & & & \\
\hline $\begin{array}{l}\text { 4. Boredom reduc- } \\
\text { tion }\end{array}$ & $13.4(5.99)$ & $.36^{* *}$ & $.29^{\star *}$ & $.58^{\star \star}$ & - & & & & \\
\hline 5. Mastery & $14.8(3.38)$ & -.10 & -.05 & $-.30^{\star *}$ & $-.21^{* *}$ & - & & & \\
\hline 6. Meaning in life & $15.1(3.44)$ & .02 & -.10 & $.36^{\star \star}$ & -.03 & $.34^{\star \star}$ & - & & \\
\hline $\begin{array}{l}\text { 7. Depressive } \\
\text { symptoms }\end{array}$ & $20.5(8.57)$ & .05 & .02 & $.14^{\star}$ & $.16^{\star}$ & $-.37^{\star \star}$ & $-.36^{\star *}$ & - & \\
\hline $\begin{array}{l}\text { 8. Anxiety } \\
\text { symptoms }\end{array}$ & $8.35(3.51)$ & -.00 & .01 & .05 & .01 & $-.25^{\star *}$ & $-.19^{\star *}$ & $.52^{\star \star}$ & - \\
\hline
\end{tabular}

Note. ${ }^{\star} p<.05$

Correlations between all latent variables are shown in Table 2. At the latent level, corrected for measurement error, negative reminiscence was positively related to distress and negatively to mental resources. Furthermore, the variable mental resources was negatively related to distress. There are no significant relations of positive reminiscence with mental resources and distress. Mediation was supported, as the model including a direct path between reminiscence and distress did not provide a better fit to the data than the model with only the indirect path $\left(\Delta x^{2}=.893, d f=2 ; p>\right.$.05). Besides, the previous low, but significant latent correlation $(r=.20)$ between negative reminiscence and distress becomes insignificant. Therefore, we report fit indices for the preferred second model. A non-significant $x^{2}$ was obtained $\left(x^{2}=22.7, d f=16, p=.121\right)$, indicating a good overall model fit. Furthermore, the goodness-of-fit of the model was confirmed using the values of the CFI (0.99), RMSEA (.05), and GFI (.97).

Figure 1 shows the standardized regression weights for each path tested in the model. Identity and problem-solving, and bitterness revival and boredom reduction 
Table 2. Correlations between latent variables

\begin{tabular}{|l|l|l|}
\hline & CORRELATIONS & P-VALUE \\
\hline Positive and negative reminiscence & .474 & .000 \\
\hline Positive reminiscence and mental resources & -.036 & .729 \\
\hline Negative reminiscence and mental resources & -.411 & .003 \\
\hline Distress and mental resources & -.654 & .050 \\
\hline Positive reminiscence and distress & .042 & .610 \\
\hline Negative reminiscence and distress & .197 & .029 \\
\hline
\end{tabular}

contribute equally to the measurement of the positive and negative latent constructs, respectively. As for the latent construct mental resources, mastery contributes somewhat more than meaning in life. Depression contributed most to the measurement of the latent construct distress. There is no direct relation between positive reminiscence and mental resources. However, there is a significant relation between negative reminiscence and mental resources. Moreover, mental resources fully mediate the relation between negative reminiscence and distress. The indirect effect of negative reminiscence on distress is .36 (standardized estimate).

Figure 1. SEM model of reminiscence and distress and mental resources as a mediator

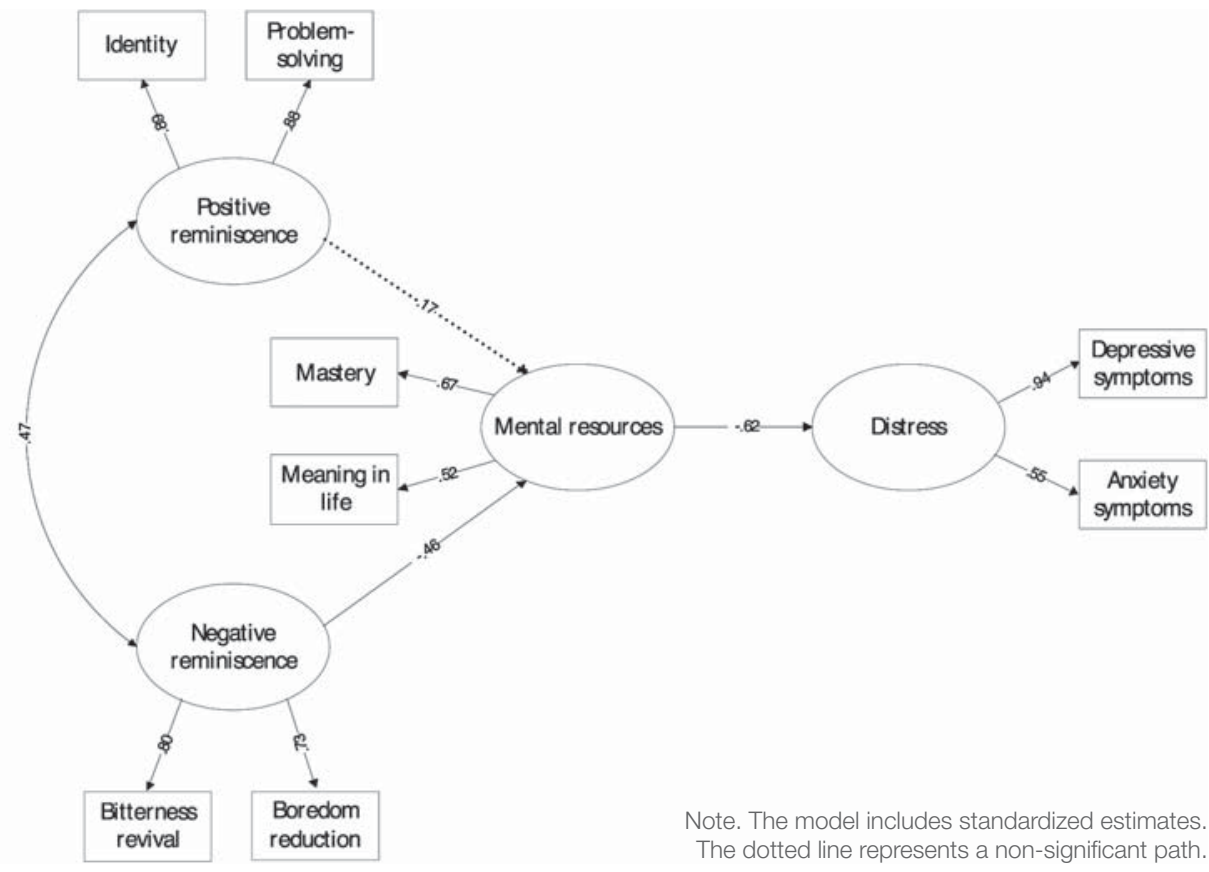




\section{$\overline{\text { DISCUSSION }}$}

The purpose of this study was to test the mediating effects of mental resources (mastery and meaning in life) in the relation of positive reminiscence (identity and problem-solving) and negative reminiscence (bitterness revival and boredom reduction) with distress (depression and anxiety) among older adults reporting mild to moderate distress. Our hypothesis of an indirect effect of both negative and positive reminiscence functions on distress, through mental resources, is partly supported by the results. To be precise, negative functions of reminiscence are related to lower distress through mental resources. However, this hypothesized mediating link of mental resources was not found in the case of the positive functions of reminiscence. These results mean that more frequent reminiscences for bitterness revival and boredom reduction are accompanied by lower levels of the mental resources: meaning in life and sense of mastery. In turn, the negative relation between these mental resources and distress indicate that lower levels of mental resources are associated with increased distress.

Our results are largely in line with a recent study carried out by Cappeliez and Robitaille (2010). As in our study, they also found a negative relation between negative reminiscence and coping (i.e., assimilative coping and accommodative coping). However, in contrast to our findings, they also identified a significant mediation of the link between positive reminiscence and well-being by coping. The model can only be partially expanded to people with mild to moderate distress and to the mental resources investigated in our study. The sample of Cappeliez and Robitaille's (2010) study was composed of a general sample of older adults, whereas our study targeted specifically older adults with mild to moderate depressive symptomatology. One might wonder why engaging in positive reminiscence functions does not lead to decreased distress in older adults who are depressed. Studies on autobiographical memory have shown that depressed individuals have difficulties in recalling specific positive memories (Williams, Barnhofer, Crane, Herman, Raes, Watkins et al., 2007). When engaging in positive reminiscence, they might in fact stick to over-general memories. This might not be helpful for the purposes of consolidating identity or finding a solution to a current problem. The self-reported use of positive reminiscence on the RFS might therefore not be related to depression. Serrano, Latorre, Gatz and Montanes (2004) showed that providing practice in producing specific positive memories is indeed effective in reducing distress among depressed older adults. The present study underlines that mental resources, more specifically mastery and meaning in life, are important in explaining the link between negative reminiscence and distress. Other studies indeed acknowledged the adaptive function of meaning in life (Krause, 2004; 2007) and mastery (Zarit, Femia, Gatz \& Johansson, 1999) in depressive symptoms among older adults. Using one general construct for mastery and meaning in life, as we did in our study, might suggest that these are overlapping resources which can be influenced by one type of reminiscence intervention. Although the literature describes these resources separately, reminiscence-based interventions often try to influence these processes at once. For example, formulating new, realistic goals may improve meaning in life when these goals are related to the personal past and to important life values, but they may also influence mastery when people experience that they are able to actually reach those goals. 
These findings have direct clinical implications. To decrease distress in later life, it might be useful, perhaps even necessary, to focus on strategies that strengthen mastery and meaning in life. This is supported by the finding that reminiscence functions aimed at reducing negative functions are effectively enhancing mastery and meaning in life in older adults (Bohlmeijer et al., 2005; Bohlmeijer, Westerhof \& Emmerik-de Jong; 2008; Bohlmeijer et al., 2009; Pot et al., 2010; Westerhof, Bohlmeijer \& Webster, 2010). This point is further supported by the demonstration by Westerhof, Bohlmeijer, van Beljouw et al. (2010) that improved meaning in life mediates the effects of a reminiscence-based intervention on depressive symptoms.

Some limitations of this study should be acknowledged. First, this study used cross-sectional data to test a mediational model. Although testing mediation with SEM, a single-step approach, has advantages over more traditional mediation models, it is still not a method that can truly establish the existence of causal relations between variables. Rather they provide an evaluation of the fit between a hypothesized causal model and data as collected. A reverse causality might still be possible, for example an increase in distress might cause fewer mental resources, which would lead to negative forms of reminiscence. In order to be conclusive about causality, experimental studies or controlled intervention studies are needed. Second, for practical reasons, we have included only four reminiscence functions. It may be worthwhile to investigate how other, more social reminiscence functions are related to distress. A related limitation is that we have included only two mental resources as potential mediators in the relation between reminiscence and distress. In future studies, it might be interesting to investigate other potentially mediating mental resources, for example self-efficacy or self-esteem, which might also be related to positive reminiscing. Third, the majority of the older adults in our study were female and relatively "young", which implies a limitation for the generalization of the findings. Therefore, in future studies it would be interesting to broaden the study sample by including adults from more senior segments of the population and also men. This would allow for testing possible differences between men and women and youngold and old-old adults. Finally, the sample comprised participants who had volunteered to participate in a clinical trial on the effectiveness of a reminiscence-based intervention. It may be that they have higher expectations about the effectiveness of reminiscing and even more experience with reminiscence as a helpful coping strategy compared to people who did not choose to participate. So they might have interpreted the RFS differently, which might have affected the findings. Possibly, this has led to a reduction in the variance, which makes it more difficult to find significant associations between reminiscence and mental health.

Despite these limitations, the present study contributes to the present knowledge of the relation between reminiscence and mental health, both empirically and clinically. Our study affords a better understanding of how reminiscence is related to distress, especially in depressed older adults. In this respect, we have shown how important mental resources, i.e., mastery and meaning, are. From a clinical perspective, our findings suggest that it might be useful in therapeutic reminiscence-based strategies for older adults with depressive symptoms and to focus on strengthening these mental resources. 


\section{REFERENCES}

Antonovsky, A. (1993), The structure and properties of the sense of coherence scale. Social Science \& Medicine, 36, 725-733.

Bluck, S., \& Levine, L. J. (1998). Reminiscence as autobiographical memory: A catalyst for reminiscence theory development. Ageing and Society, 18, 185-208.

Bohlmeijer, E. T., Valenkamp, M., Westerhof, G., Smit, F., \& Cuijpers, P. (2005). Creative reminiscence as an early intervention for depression: Results of a pilot project. Aging \& Mental Health, 9, 302-304.

Bohlmeijer, E. T., Westerhof, G. J., \& Emmerik-de Jong, M. (2008). The effects of integrative reminiscence on meaning in life: Results of a quasi-experimental study. Aging \& Mental Health, 12, 639-646.

Bohlmeijer, E., Kramer, J., Smit, F., Onrust, S., \& van Marwijk, H. (2009). The effects of integrative reminiscence on depressive symptomatology and mastery of older adults. Community Mental Health Journal, 45, 476-484.

Bohlmeijer, E., Roemer, M., Cuijpers, P., \& Smit, F. (2007). The effects of life-review on psychological well-being in older adults: A meta-analysis. Aging \& Mental Health, 11, 291-300.

Bohlmeijer, E., Smit, F., \& Cuijpers, P. (2003). Effects of reminiscence and life-review on late-life depression: A meta-analysis. International Journal of Geriatric Psychiatry, 18, 1088-1094.

Butler, R. N. (1963). The life-review: An interpretation of reminiscence in the aged. Psychiatry, 26, 65-76.

Byrne, B. M. (2001). Structural equation modeling with AMOS. Mahwah: Erlbaum.

Cappeliez, P., \& O'Rourke, N. (2006). Empirical validation of a model of reminiscence and health in later life. Journal of Gerontology: Series B: Psychological Sciences and Social Sciences, 61, 237-244.

Cappeliez, P., \& Robitaille, A. (2010). Coping mediates the relationships between reminiscence and psychological well-being among older adults. Aging \& Mental Health, 14, 807-818.

Cappeliez, P., O'Rourke, N., \& Chaudhury, H. (2005). Functions of reminiscence and mental health in later life. Aging \& Mental Health, 9, 295-301.

Cuijpers, P., van Straten, A., \& Smit, F. (2006). Psychological treatment of late-life depression: a meta-analysis of randomized controlled trials. International Journal of Geriatric Psychiatry, 21, 1139-1149.

Cully, J. A., LaVoie, D., \& Gfeller, J. D. (2001). Reminiscence, personality, and psychological functioning in older adults. Gerontologist, 41, 89-95.

Dempster, A. P., Laird, N. M., \& Rubin, D. B. (1977). Maximum Likelihood from incomplete data via the EM algorithm. Journal of the Royal Statistical Society, 39, 1-38.

Forbes, D. A. (2010). Enhancing mastery and sense of coherence: important determinants of health in older adults. Geriatric Nursing, 22, 29-32.

Frazier, P., Tix, A., \& Barron, K. (2004). Testing moderator and mediator effects in counseling psychology research. Journal of Counseling Psychology, 51, 115-134. 
Gadella, T. M. (2010). The role of mastery and social support in the association between life stressors and psychological distress in older Canadians. Journal of Gerontological Social Work, 53, 512-530.

Haringsma, R., Engels, G. I., Beekman, A. T. F., \& Spinhoven, P. (2004). The criterion validity of the Center for Epidemiological Studies Depression Scale (CES-D) in a sample of self-referred elders with depressive symptomatology. International Journal of Geriatric Psychiatry, 19, 558-563.

Hu, L. T., \& Bentler, P. M. (1999). Cut-off criteria for fit indices in covariance structure analysis: conventional criteria versus new alternatives. Structual Equation Modeling, 6, 1-55.

Jang, Y,, Haley, W. E., Small, B. J., \& Mortimer, J. A. (2002). The role of mastery and social resources in the associations between disability and depression in later life. Gerontologist, 6, 807-813.

Kempen, G. I. J. M., Jelicic, M., \& Ormel, J. (1997). Personality, chronic medical morbidity, and health-related quality of life among older persons. Health Psychology, 16, 539-549.

Kempen, G. I. J. M., van Heuvelen, M. J., van Sonderen, E., van den Brink, R. H., Kooijman, A.C., \& Ormel, J. (1999). The relationship of functional limitations to disability and the moderating effects of psychological attributes in communitydwelling older adults. Social Science \& Medicine, 48, 1161-1172.

Korte, J., Bohlmeijer, E. T., \& Smit, F. (2009). Prevention of depression and anxiety in later life: design of a randomized controlled trial for the clinical and economic evaluation of a life-review intervention. BMC Public Health, 9, 250.

Korte, J., Bohlmeijer, E. T., Westerhof, G. J., \& Pot, A. M. (2011). Reminiscence and adaptation to critical life-events in older adults with mild to moderate depressive symptoms. Aging and Mental Health, 15, 638-646.

Korte, J., Bohlmeijer, E.T., Cappeliez, P., Smit, F., \& Westerhof, G.J. (2012). Life-review therapy for older adults with moderate depressive symptomatology: a pragmatic randomized controlled trial. Psychological Medicine, 42, 1163-1173.

Krause, N. (2004). Stressors arising in highly valued roles and the physical health status of older adults. The Journals of Gerontology, 59B, S287-S291.

Krause, N. (2007). Evaluating the stress-buffering function of meaning in life among older people. Journal of Aging and Health, 19, 792-812.

Nygren, B., Alex, L., Jonsen, E., Gustafson, Y., Norberg, A., \& Lundman, B. (2005) Resilience, sense of coherence, purpose in life and selftranscendence in relation to perceived physical and mental health among the oldest old. Aging \& Mental Health, 9, 354-362.

O'Rourke, N., Cappeliez, P., \& Claxton, A. (2011). Functions of reminiscence and the psychological well-being of young-old and older adults over time. Aging \& Mental Health, 15, 272-281.

Pearlin, L. I., \& Schooler, C. (1978). The structure of coping. Journal of Health and Social Behaviour, 19, 2-21.

Pinquart, M. (2002). Creating and maintaining purpose in life in old age: a meta-analysis. Ageing International, 27, 90-114. 
Pinquart, M., Duberstein, P. R., \& Lyness, J. M. (2007). Effects of psychotherapy and other behavioral interventions on clinically depressed older adults: A metaanalysis. Aging \& Mental Health, 11, 645-657.

Pot, A. M., Bohlmeijer, E. T., Onrust, S., Melenhorst, A. S., Veerbeek, M., \& de Vries, W. (2010). The impact of life-review on depression in older adults: A randomized controlled trial. International Psychogeriatrics, 22, 572-581.

Radloff, L.S. (1977). The CES-D scale: A self-report depression scale for research in the general population. Journal of Applied Psychological Measurement, 1, 385-401.

Reker, G. T. (1997). Personal meaning, optimism, and choice: Existential predictors of depression in community and institutional elderly. Gerontologist, 37, 709-716.

Roberts, B. L., Dunkle, R., \& Haug, M. (1994). Physical, psychological, and social resources as moderators of the relationship of stress to mental health in the very old. Journal of Gerontological Social Work, 49, 535-543.

Robitaille, A., Cappeliez, P., Coulombe, D., \& Webster, J. D. (2010). Factorial structure and psychometric properties of the reminiscence functions scale. Aging \& Mental Health, 14, 184-192.

Ryff, C. D. (1989). Happiness is everything, or is it? Explorations on the meaning of psychological well-being. Journal of Personality and Social Psychology, 57, 1069-1081.

Schieman, S., \& Turner, H. A. (1998). Age, disability and the sense of mastery. Journal of Health and Social Behavior, 39, 169-187.

Seligman, M. E. P. (1998). Learned optimism: How to change your mind and your life. New York: Pocket Books.

Serrano, J. P., Latorre, J. M., Gatz, M., \& Montanes, J. (2004). Life review therapy using autobiographical retrieval practice for older adults with depressive symptomatology. Psychology and Aging, 19, 272-277.

Sheehan, D. V., Lecrubier, Y., Sheehan, K.H., Amorim, P., Janavs, J., \& Weiller, E. (1998). The Mini-International Neuropsychiatric Interview (MINI): The development and validation of a structured diagnostic psychiatric interview for DSM-IV and ICD10. Journal of Clinical Psychiatry, 59, 22-33.

Spinhoven, P. H., Ormel, J., Sloekers, P. P. A., Kempen, G. I. J. M., Speckens, A. E. M., \& van Hemert, A.M. (1997). A validation study of the Hospital Anxiety and Depression Scale (HADS) in different groups of Dutch subjects. Psychological Medicine, 27, 363-370.

Steger, M., Frazier, P., Oishi, S., \& Kaler, M. (2006). The meaning in life questionnaire, assessing the presence of and search for meaning in life. Journal of Counselling Psychology, 53, 80-93.

Steunenberg, B., Beekman, A. T., Deeg D. J., Bremmer, M. A., \& Kerkhof, A. J. (2007). Mastery and neuroticism predict recovery of depression in later life. American Journal of Geriatric Psychiatry, 15, 234-242.

Taylor, S. E. (1989). Positive illusions: creative self-deception and the healthy mind. New York: Basic Books.

Taylor, S. E., Kemeny, M. E., Reed, G. M., Bower, J. E., \& Gruenewald, T. L. (2000). 
Psychological psychological resources, positive illusions, and health. American Psychologist, 55, 99-109.

Watt, L. M. (1996). Integrative and instrumental reminiscence therapies for the treatment of depression in older adults. (Doctoral Dissertation). Ottawa: School of Psychology, University of Ottawa.

Webster, J. D. (1993). Construction and validation of the Reminiscence Functions Scale. Journal of Gerontology: Psychological Sciences, 48, 256-262.

Webster, J. D., Bohlmeijer, E. T., \& Westerhof, G. J. (2010). Mapping the future of reminiscence: A conceptual guide for research and practice. Research on Aging, 32, 527-564.

West, S. G., Finch, J. F., \& Curran, P. J. (1995). Structural equation models with nonnormal variables. Thousand Oaks: SAGE.

Westerhof, G. J., Bohlmeijer, E. T., \& Valenkamp, M. W. (2004). In search of meaning: a reminiscence program for older adults. Educational Gerontology, 30, 751-766.

Westerhof, G. J., Bohlmeijer, E. T., \& Webster, J. D. (2010). Reminiscence and mental health: A review of recent progress in theory, research, and intervention. Ageing and Society, 30, 697-721.

Westerhof, G. J., Bohlmeijer, E. T., van Beljouw, I. M. J., \& Pot, A. M. (2010). Improvement in personal meaning mediates the effects of a life review intervention on depressive symptoms in a randomized controlled trial. Gerontologist, 50, 541-549.

Williams, J. M., Barnhofer, T., Crane, C., Herman, D., Raes, F., Watkins, E., et al. (2007). Autobiographical memory specificity and emotional disorder. Psychological Bulletin, 133, 122-148.

Wink, P., Schiff, B. (2002). To review or not to review? The role of personality and lifeevents in life review and adaptation to older age. In J. D. Webster \& B. K. Haight (Eds.), Critical advances in reminiscence work: From theory to application (pp. 44-60). New York: Springer.

Wong, P. T. (1989). Personal meaning and successful aging. Canadian Journal of Psychology, 30, 516-525.

Wong, P. T. (1995). The processes of adaptive reminiscence. In B. K. Haight \& J. D. Webster (Eds.), The art and science of reminiscing: Theory, research, methods, and applications (pp. 23-35). Washington, DC: Taylor \& Francis.

Wong, P. T., \& Watt, L. M. (1991). What types of reminiscence are associated with successful aging? Psychology and Aging, 6, 272-279.

Zarit, S. H., Femia, E. E., Gatz, M., \& Johansson, B. (1999). Prevalence, incidence and correlates of depression in the oldest old: the OCTO study. Aging \& Mental Health, 3, 119-128.

Zigmond, A. S., \& Snaith, R. P. (1983). The hospital anxiety and depression scale. Acta Psychiatrica Scandinavica, 67, 361-370. 


\section{PREVENTION OF DEPRESSION AND ANXIETY IN LATER LIFE DESIGN OF A RANDOMIZED CONTROLLED TRIAL FOR THE CLINICAL AND ECONOMIC EVALUATION OF A LIFE-REVIEW. INTERVENTION}

Korte, J., Bohlmeijer, E. T., \& Smit, F. (2009). Prevention of depression and anxiety in later life: Design of a randomized controlled trial for the clinical and economic evaluation of a life-review intervention. BMC Public Health, 9, 250. 


\section{CHAPTER}

\section{ABSTRACT}

Depressive and anxiety symptoms in older adults could develop into significant health problems with detrimental effects on quality of life and a possibly poor prognosis. Therefore, there is a need for preventive interventions which are at once effective, acceptable and economic affordable. This paper describes the design of a study evaluating "The stories we live by", a preventive life-review group intervention, which was recently developed for adults of 55 years and over with depressive and anxiety symptoms. Both clinical and economic effectiveness will be evaluated in a pragmatic randomized controlled trial. The participants in the intervention condition will receive the 8-session preventive intervention. The participants in the control condition will have access to usual care. Clinical end-terms are depressive and anxiety symptoms, current major depressive episode, quality of life and positive mental health post-treatment ( 3 months after baseline) and at follow-ups (6 and 12 months after baseline). Additional goals of this study are to identify groups for whom the intervention is particularly effective and to identify the therapeutic pathways that are vital in inducing clinical change. This will be done by analysing if treatment response is moderated by demographics, personality, past major depressive episodes, important life-events and chronically disease, and mediated by reminiscence functions, perceived control, automatic positive thoughts and meaning in life. Finally the cost-effectiveness of the intervention relative to care-as-usual will be assessed by computing incremental costs per case of depression and anxiety avoided (cost-effectiveness) and per quality adjusted life year (QALY) (cost utility). It is expected that both the life-review intervention and its evaluation will contribute to the existing body of knowledge in several ways. First, the intervention is unique in linking life-review with narrative therapy and in its focus on specific, positive memories. Second, the evaluation is likely to answer questions regarding the acceptability and cost-effectiveness of life-review that have not been addressed thoroughly until now. Positive results of this study will make available a new evidencebased intervention to improve public health among people of 55 years and over. 


\section{BACKGROUND}

Clinical depression and anxiety in older adults is a significant health problem carrying a poor prognosis (Beekman, Penninx, Deeg, de Beurs, Geerings \& van Tilburg, 2002; Cole, Bellavance \& Masour, 1999; Cuijpers \& Smit, 2002; Licht-Strunk, van der Windt, van Marwijk, de Haan \& Beekman, 2007; Schuurmans, Comijs, Beekman, de Beurs, Deeg, Emmelkamp et al., 2005), with prevalence rates reported as high as $8.8 \%$ to $23.6 \%$ (Copeland, Beekman, Dewey, Hooijer, Jordan, Lawlor et al., 1999; McDougall, Kvaal, Matthews, Paykel, Jones, Dewey et al., 2007) for depressive disorders and 1.2\% to 15\% for anxiety disorders (Bryant, Jackson \& Ames, 2008).

The presence of depressive and anxiety symptoms which do not meet the diagnostic criteria are by far the most important risk factors of late-life depression and anxiety (Cuijpers, de Graaf \& van Dorsselaer, 2004; Smit, Comijs, Schoevers, Cuijpers, Deeg \& Beekman, 2007; Smit, Ederveen, Cuijpers, Deeg \& Beekman, 2006). Therefore, there is a great need to develop effective, low-threshold preventive interventions for older people reducing the risk to develop clinical depression and anxiety. A recent meta-analysis shows that low-threshold, psychological interventions for older adults with depressive symptoms are indeed promising in preventing depressive disorders (Cuijpers, Smit \& van Straten, 2007).

Several psychological interventions are currently available for reducing depressive and anxiety symptoms in older people, including psycho-educational approaches, cognitive behaviour therapy, psychodynamic therapy, and interpersonal therapy (Ayers, Sorrell, Thorp \& Loebach Wetherell, 2007; Cuijpers, 1998; Miller, 2008; Wilson, Mottram \& Vassilas, 2008; van 't Veer-Tazelaar, van Marwijk, van Oppen, van Hout, van der Horst, Cuijpers et al., 2009). However, previous interventions are associated with low uptake rates. Hence, there is a need for interventions that are more acceptable. Life-review is currently gaining popularity, because this type of intervention can be specifically used in older adults. Life-review is characterized by a structured re-evaluation of one's own life, on the one hand aimed at coping with negative experiences and conflicts and on the other hand at giving a positive meaning to life (Haight, 1992; Westerhof, Bohlmeijer \& Webster, 2010; Wong, 1995). Life-review's popularity could reflect the research findings that many - though not all - older adults tend to look back on and evaluate their lives (Butler, 1963), which seems to suggest that it will be acceptable for older people and might even be regarded as attractive. Moreover, research indicated that life-review leads to a strong reduction of depressive symptoms, comparable to the effects of cognitive behaviour therapy (Bohlmeijer, Roemer, Cuijpers \& Smit, 2007; Bohlmeijer, Smit \& Cuijpers, 2003; Fry, 1983; Haight, Coleman \& Lord, 1995; Watt \& Cappeliez, 2000). This method is probably also effective in reducing anxiety symptoms (Bohlmeijer, 2007a; Schuurmans, 2006). Jointly, this evidence appears to indicate that life-review is a promising venue to offering a possibly effective preventive intervention for older people otherwise not easily engaged in treatment for the milder manifestations of anxiety and depression.

With regard to reminiscing styles, Webster (1994) differentiates among others between the functions of identity developing, problem-solving, bitterness revival, 
and boredom reduction. The function "identity developing" uses memories actively in developing one's identity by discovering, clarifying and crystallizing important dimensions of the sense of who one is. "Problem-solving", also known as instrumental reminiscence, refers to how memories of past coping strategies can be reused in the present. "Bitterness revival" is also about one's identity, but in a negative, complaining way. Instead of being integrated in the sense of who we are, negative experiences are constantly brought up. In "boredom reduction", the main goal is to escape from the present by romanticizing the past. Several studies indicate that reminiscence aimed at bitterness revival or boredom reduction is positively correlated with depression and anxiety, and negatively with wellbeing (Cappeliez, O’Rourke \& Chaudhury, 2005; Cully, LaVoie \& Gfeller, 2001). However, identity developing and problem-solving are positively associated with psychological well-being (Cappeliez et al., 2005) and successful aging (Wong \& Watt, 1991).

The extent to which and why people reminiscence is also influenced by personality. Cully et al. (2001) showed that neurotic behaviour is correlated positively with bitterness revival, boredom reduction and the overall level of reminiscence. This was borne out by Cappeliez and O'Rourke (2002), who found that a higher score on neuroticism predicted higher scores on total reminiscence, identity and bitterness revival. More openness also predicted a higher total level of reminiscence (identity). The intrapsychical functions of reminiscence (boredom reduction, identity, bitterness revival) appear to be well predicted by personality characteristics.

Recently, life-review has become increasingly linked to other therapeutic theories aiming at people with clinically relevant mental distress (Bohlmeijer, Westerhof \& Emmerik-de Jong, 2008). For example, Watt and Cappeliez (2000) developed a protocol in which life-review was linked to cognitive theories about depression. They proposed that life-review in depressive persons trigger recall of unrealistic, negative cognitions about themselves and life in general, and that these cognitions can be challenged and modified by both the therapist and clients. A promising combination of theories might be created by integrating life-review with narrative therapy. After all, a central assumption of narrative therapy is that life-stories are essentially a process of reconstruction of autobiographical memories (Atwood \& Ruiz, 1993; Bluck \& Levine, 1998). Furthermore, narrative theory suggests that reminiscence in depressed older adults is likely to generate "problem-saturated" stories (Payne, 2000). Characteristic of these stories is their (selective) focus on negative memories (Brewin, 2006) often structured as a victimic plot (Polkinghorne, 1996), in which something good turns bad (McAdams, Reynold, Lewis, Patten \& Bowman, 2001). In contrast to cognitive theory, narrative therapy does not look for changing underlying cognitions on the basis of reality testing, but invites people to explore alternative stories (reconstructions) that may express optimism, a greater sense of mastery, and a fresh focus on positive experience. Different stories may unveil new meanings, and there is no "final truth" in those stories. At all times the individual client is the expert who determines which constructions of reality are meaningful (Linssen \& Habekotté, 2006).

We propose to integrate narrative therapy and life-review into a new and unified approach to alleviate depressive and anxiety symptoms in older people; "The stories we 
live by" (Bohlmeijer, 2007b). The essence of the intervention is to discover stories about one's life that help the individual to lead a contented life. The memories people have are considered as both stories and social reconstructions of reality. It invites people to dwell on the meanings of their experiences and to evaluate those meanings. We expect that in this way, people can discover answers about what they regard as most important in their lives and which experiences were most valuable, in that they can give meaning to their lives (Haight, 1992). Moreover, by looking back the coherence of the own life-story increases. Bearger and McAdams (1999) discovered a positive connection between the coherence of life-stories and psychological well-being.

The literature offers different explanations for the efficacy of life-review in mental disorders, such as depression. However, until now there hardly has been any empirical evidence for the factors that moderate or mediate the effects of life-review on mental distress. A first explanation for the effectiveness of life-review is that depressive people have associations which have been reinforced by negative memories (Brewin, 2006; Serrano, Latorre, Gatz \& Montanes, 2004; Williams \& Scott, 1988). By consciously focusing on specific and positively charged memories, negative memories are likely to be pushed further to the background, while other positive memories will be retrieved more easily. Another explanation is that people experience a greater sense of control over their lives when looking back (Wong, 1995). People become aware that they are much stronger than expected.

"The stories we live by" intervention was evaluated in a pilot study (Bohlmeijer, Westerhof \& Emmerik-de Jong, 2008). The results were promising and to make this life-review intervention available as a possibly evidence- based intervention for older people, we think a logical next step is to carry out a randomized controlled trial (RCT). This paper describes the design of a RCT to assess clinical and economic effectiveness. The understanding of moderating and mediating effects is an important focus of this study. Conceptually, analysis of moderators would help to identify subgroups for whom the intervention is particularly (cost-)effective, whereas analysis of mediators may shed light on how treatment effects are relayed over various clinical pathways and have a final impact on clinical endpoints (Kraemer, Wilson, Fairburn \& Agras, 2002). Therefore, the specific hypotheses that the RCT addresses are described below.

Our main hypothesis is that the life-review intervention leads to a significant reduction of depressive and anxiety symptoms, and in current major depression, and a significant improvement in quality of life and positive mental health, compared to the no-treatment control condition. In addition, we explore if gender, age, education level, personality, past major depressive episodes, important life-events and chronic diseases, in combination with the intervention, predict higher or lower effects on depressive and anxiety symptoms, quality of life and positive mental health. Furthermore, we hypothesize that reminiscence functions, perceived control, automatic positive thoughts and meaning in life mediate the intervention's effects on clinical endpoints. Finally, we expect that the incremental costs per case of depression and anxiety avoided (cost-effectiveness) and 
per quality adjusted life year (QALY; cost-utility) are lower in the intervention condition, compared to the care-as-usual condition.

\section{METHODS AND DESIGN}

To evaluate the effectiveness of the life-review intervention, we will carry out a pragmatic RCT and a cost-effectiveness analysis (CEA). Participants will be randomly assigned to either the 8-session preventive intervention or the control condition; the care-as-usual condition. The research has been approved by the METiGG, a medical-ethics committee for research in mental health care settings in the Netherlands.

\section{Participants}

An open recruitment strategy will be used, in cooperation with Dutch regional mental health care institutions, via advertisements in regional and national newspapers, information booklets available at health care institutions and general practitioners, plus a radio interview and commercial. Health care professionals at these mental health care centres (therapists, psychologists, etc.) will support the participant recruitment and intake, and eventually take care of organizing and offering the course at their centre. When people wish to participate, they will be invited by the nearest mental health care centre for an interview. In this interview, information is given about the intervention and the accompanying study, and the in- and exclusion criteria are examined.

The inclusion criteria are an age of 55 years or over, and the presence of slight to moderate depressive and anxiety symptoms. The presence of these symptoms will be measured by a score of 10 and above on the Dutch version of the Center for Epidemiological Studies Depression Scale (CES-D; Radloff, 1977) and a score of 3 and above on the Dutch version of the anxiety scale of the Hospital and Anxiety Scale (HADS-A; Zigmond \& Snaith, 1983). The CES-D is a 20-item self-report scale developed to measure depressive symptoms in the community (Radloff, 1977). Participants will be asked to indicate how often they experienced each symptom during the previous week. Response categories, ranging from 0 to 3, are "rarely or never", "some of the time", "occasionally", or "mostly or always". Summation results in a CES-D score, ranging from 0 to 60 . A score of 16 or higher is considered indicative of clinically relevant depressive syndromes. The psychometric properties of the scale are found to be reliable in older populations (Radloff \& Teri, 1986), and more particularly in a sample of older Dutch people with depressive symptoms (Haringsma, Engels, Beekman \& Spinhoven, 2004). The HADS-A is a 7-item, self-report screening scale against which respondents are asked to indicate whether they had experienced feelings of restlessness, tenseness, or panic during the past four weeks (Zigmond \& Snaith, 1983). Items range from 0 "rarely or never" to 3 "always or most of the time". The Dutch translation has shown good psychometric properties in six different groups of Dutch subjects (Spinhoven, Ormel, Sloekers, Kempen, Speckens \& 
van Hemert, 1997). Bjelland et al. (2002) showed that among the general population and in somatic patients samples an optimal balance between sensitivity and specificity was achieved when caseness was defined by a score of 8 or above.

People will be excluded if diagnosed with full-blown depression or having a moderate to high suicide risk according the Dutch version of the Mini International Neuropsychiatric Interview (MINI; Sheehan, Lecrubier, Sheehan, Amorim, Janavs \& Weiller, 1998; van Vliet \& de Beurs, 2007), a short diagnostic psychiatric interview to assess DSM-IV and ICD-10 disorders. The MINI was validated in a cross-national study involving more than 600 subjects. The concordance and psychometric values of the MINI Core, as compared to the CIDI (Lecrubier, Sheehan, Weiller, Amorim, Bonora, Sheehan et al., 1997) and the SCID-P (Sheehan, Lecrubier, Sheehan, Janavs, Weiller, Keskiner et al., 1997), were found to be satisfactory. Furthermore, applicants scoring below the inclusion criteria of depressive and anxiety symptoms will be excluded, measured by a score of 9 and below on the Dutch version of the CES-D (Radloff, 1977) and a score of 2 and below on the Dutch version of the HADS-A (Zigmond \& Snaith, 1983). In addition, when applicants started taking anti-depressant medication or benzodiazepines recently (within the previous 2 months) or are currently receiving any psychological treatment they will be excluded. Finally, people will be excluded if the health care professionals assess that other serious psychopathology is present; then they are referred for psychological treatment. Applicants eligible to participate will be asked to sign an informed consent form.

\section{Randomization}

Participants will be randomly assigned to either the experimental or control condition by means of a centrally conducted randomization process, stratified for gender and symptom level (no major depressive episode (0-4 symptoms) or slight (5 symptoms) to moderate (6-7 symptoms) major depressive episode). The randomization will be conducted at the University of Twente, independent of the participating mental health care centres. The mental health care centres and participants receive the outcome of the randomization by mail.

\section{Experimental condition}

In total, 14 Dutch mental health care centres - in both rural and urban areas - have expressed their agreement to participate in this study. The therapists and prevention workers (from now on called therapists) at these centres - that will implement "The stories we live by" - all have therapeutic backgrounds or an education in behavioural sciences (e.g., psychology) or social work. For the purpose of offering the intervention they have received a two-day training program, which was supervised by a psychotherapist specialized in narrative therapy and a psychologist specialized in life-review. During the intervention, they will participate in two half-day follow-up meetings and a booster training. "The three main components in "The stories we live by" are described below. The first component is a focus on developing alternative, more positive, "thicker" life-stories. Since the intervention is aimed at older adults with depressive and anxiety symptoms, 
we expect their stories to contain themes such as incapacity, disappointment and "being a victim". The therapists ask questions via deconstruction and reconstruction, two processes that are central in narrative therapy (Kroph \& Tandy, 1998; Osis \& Stout, 2001; Payne, 2000). In the deconstruction phase, the therapists will explore values and norms that are inherent to the "problem-saturated stories" - and that may be inauthentic to the participant - unique memories that seem to contradict the dominating problemorientated story. An example of a deconstruction question that the therapist could ask is "Where there any exceptions (e.g., pleasant moments) in this difficult time of your life?". In the reconstruction phase, alternative, more authentic stories based on the participant's strength are constructed and "thickened". Examples of these questions are "How were you able to cope with this situation?", and "Now, at a much later date, can you say that you have also learned from that period in your life, could you explain?".

The second important component of the intervention is the systematic evaluation of one's life course, with a special focus on integrating negative life-events with positive life-events within participants' life-stories. The intervention places the problems and conflicts that participants experience in the context of their life course, which involves making explicit links between the past and the present. This makes the intervention different from narrative therapy, where there is often much more focus on the present or themes the client feels like introducing into a session. During the intervention meetings, participants have to review their lives. Each intervention meeting has a different life theme, namely "our origin", "youth", "work and care", "love and conflicts", "loss and difficult periods", "metaphor", "the course of life" and "the future". Before each meeting, participants have to answer questions about different life themes. At home, they have to reflect upon these questions and write the responses down briefly. During the meetings, they have the opportunity to exchange and discuss the answers and experiences with the other participants. At home, participants can do creative assignments, which stimulate the imagination and may open up new ways of expression besides the verbal mode. To minimize resistance, we consciously choose to offer these assignments in a facultative manner. In the final meetings, attention is focused on the near future, to invite participants to convert their "new identity" into concrete actions.

The third important component of the intervention is the attention for specific positive memories, which are special and unique for a certain period in the participant's life. Participants have to write down exactly what they remember of this situation and describe it by means of the following questions: "Where was it?", "What did the environment look like?", "Which people where there and what did everyone look like?", "What happened exactly?". We expect that especially in depressive and anxious people these questions will activate memories that were "forgotten". This probably leads to a better balance between positive and negative memories, in that positive details are coming to the forefront again.

The intervention is aimed at four to six people and consists of eight similarly structured two-hour sessions. At the start of the sessions people are asked to explain into two or three sentences what they have learnt from the previous session with regard to their lives. Then, participants have to review their lives and exchange and discuss their experiences with the other participants. Finally, in each session attention is given to specific positive memories that the participants come up with. 


\section{Control condition}

Participants in the control condition receive no intervention. However, they have unrestricted access to care-as-usual and may receive all health care they desire. Moreover, participants are not withheld from any treatment (e.g., they may receive psychological treatment). In the context of the economic evaluation, health care uptake will be closely monitored. After conclusion of the RCT, the participants in the control condition will be invited to take part in the intervention.

\section{Measurements}

\section{Overview}

Table 1 gives an overview of all measurements. Participants will be asked to complete questionnaires at baseline ( $t 0)$, directly after the end of the intervention ( $t 1), 3$ months after the end of the intervention ( $t 2)$, and - only in the intervention condition - 6 months after the end of the intervention (t3). The primary and secondary outcome measures will be recorded at all measurements (except for current major depressive episode), moderators only once at $\mathrm{t} 0$, the mediators at $t \mathrm{0}, \mathrm{t} 1$ and $t 2$ and the measures for economic evaluation only at $t 0$ and $t 2$.

\section{Primary outcome measure}

1. Depressive symptoms will be measured using the Dutch version of the CES-D (Radloff, 1977).

\section{Secondary outcome measures}

2. The presence of anxiety symptoms will be assessed using the Dutch version of the HADS-A (Zigmond \& Snaith, 1983).

3. The presence of a current major depressive episode will be measured using the Dutch version of the MINI (Sheehan et al., 1998; van Vliet \& de Beurs, 2007).

4. Quality of life will be determined using the Dutch version of the EuroQol (EQ-5D). The EQ-5D is a validated instrument for measuring health-related quality of life (Brooks, 1996). It covers five domains of health: mobility, self-care, usual activity, pain/discomfort and depression/ anxiety. Each of the five domains has three severity levels; 0 (none), 1 (some) and 2 (severe). Permutation of the EQ-5D scores generates a total of 243 distinct health states, each of which is associated with a utility score ranging from 0 (poor health, similar to death) to 1 (perfect health). These utilities (also known as "tariffs") have been obtained in the UK and in the Netherlands (Euroqol group, 1990; Lamers, Stalmeier, McDonnell, Krabbe \& van Busschbach, 2005). In our study, we will use the Dutch EQ-5D tariffs to compute quality adjusted life years (QALYs) gained, and these will be used as outcome for the cost-utility analysis.

5. Positive mental health will be assessed using the Dutch version of the Mental Health Continuum Short Form (MHC-SF; Keyes, 2005). The MHC-SF measures the mental health that according to Keyes is not simply the absence of mental illness, but the 
Table 1. Measurement overview (intake, to, t1, t2 and t3)

\begin{tabular}{|c|c|c|c|c|c|}
\hline OUTCOME MEASURE & INSTRUMENT & to & $t 1$ & t2 & $t 3^{*}$ \\
\hline \multicolumn{6}{|l|}{ Primary outcome measure } \\
\hline Depressive symptoms & CES-D & $x$ & $x$ & $x$ & $\mathbf{x}$ \\
\hline \multicolumn{6}{|l|}{ Secondary outcome measures } \\
\hline Current major depressive episode & MINI & $\mathrm{x}$ & & $\mathrm{x}$ & \\
\hline Anxiety symptoms & HADS-A & $\mathrm{x}$ & $\mathrm{x}$ & $x$ & $x$ \\
\hline Quality of life & EQ 5-D & $\mathrm{x}$ & $x$ & $x$ & $x$ \\
\hline Positive mental health & MHC-SF & $\mathbf{x}$ & $x$ & $x$ & $x$ \\
\hline \multicolumn{6}{|l|}{ Moderating measures } \\
\hline Demographics (age, gender and education level) & & $\mathrm{x}$ & & & \\
\hline Personality & NEO-FFI & $\mathrm{x}$ & & & \\
\hline Past major depressive episodes & MINI & $x$ & & & \\
\hline Important life-events & & $x$ & & & \\
\hline Chronic diseases & & $x$ & & & \\
\hline
\end{tabular}

Mediating measures

\begin{tabular}{|l|l|l|l|l|}
\hline Reminiscence functions & RFS & $\mathbf{x}$ & $\mathbf{x}$ & $\mathbf{x}$ \\
\hline Perceived control & Mastery scale & $\mathbf{x}$ & $\mathbf{x}$ & $\mathbf{x}$ \\
\hline Automatic positive thoughts & ATQ-P & $\mathbf{X}$ & $\mathbf{x}$ & $\mathbf{x}$ \\
\hline Meaning in life & MLQ-SF & $\mathbf{x}$ & $\mathbf{x}$ & $\mathbf{x}$ \\
\hline
\end{tabular}

Measures for the economic evaluation

\begin{tabular}{|l|l|l|l|l|}
\hline Resource use & TIC-P & $\mathbf{x}$ & $\mathbf{x}$ \\
\hline Production losses & PRODISQ & $\mathbf{x}$ & $\mathbf{x}$ \\
\hline
\end{tabular}

Note. *Only in intervention condition 
presence of positive feelings (emotional well-being) together with positive functioning in both individual life (psychological well-being) and community life (social wellbeing) (Keyes, 2006). The MHC-SF is a 14-item questionnaire and measures three dimensions: hedonic well-being ( 3 items), social well-being (5 items) and psychological well-being (6 items). Participants are asked how often they have experienced the feelings described in the items during the past month, using a 6-point answer format ranging from "never", "once or twice", "approximately once a week", "two or three times a day", "almost every day" to "every day". The MHC-SF has been shown to have good psychometric properties (Keyes, 2002), also for the Dutch population (Westerhof \& Keyes, 2008).

\section{Moderating measures}

1. The demographics that we will measure are age, gender and level of education.

2. Personality will be assessed using the Dutch version of the NEO-FFI (Costa \& McCrae, 1992; Hoekstra, Ormel \& de Fruyt, 1996). This self-report questionnaire consists of 60 statements covering 5 main dimensions of personality: neuroticism, extraversion, openness to new experiences, agreeableness, and conscientiousness. Each statement is rated on a 5-point scale ranging from "strongly disagree" to "strongly agree," resulting in total dimension score between 12 and 60. The NEO-FFI has good psychometric properties (Costa \& McCrae, 1992; Murray, Rawlings, Allen \& Trinder, 2003).

3. Past major depressive episodes will be measured using the Dutch version of the MINI (Sheehan et al., 1998; van Vliet \& de Beurs, 2007).

4. We will ask participants if they have any chronic disorders, such as coronary diseases, lung diseases, or rheumatism.

5. Participants have to report if any critical life-events had occurred within in the previous three years, such as the loss of a spouse or a divorce.

\section{Mediating measures}

1. Reminiscence functions will be measured using the Dutch version of the Reminiscence Functions Scale (RFS), a valid and reliable 43-item questionnaire that assesses reminiscence functions over one's life course (Webster, 1993; 1997). The scale comprises eight subscales (factors) reflecting possible functions of reminiscence for the individual. The subscales are labelled "boredom reduction", "death preparation", "identity", "problem- solving", "conversation", "intimacy maintenance", "bitterness revival", and "teach/inform". Questions typically start with "when I reminiscence, it is..." and are completed using 43 possible reasons or motivations to reminiscence. Respondents will be asked to indicate the extent to which each of the 43 reasons applies to them. Possible answers range from 1 to 6 (never, rarely, seldom, occasionally, often, or very often). For the purpose of this research, 23 questions covering four 
subscales have been selected: 6 about boredom reduction, 6 about identity, 6 about problem-solving, and 5 about bitterness revival. Examples are: "When I reminisce, it is... to pass the time during idle or restless hours" (boredom reduction), "to see how my past fits in with my journey through life" (identity), "to help me plan for the future" (problem-solving), or "to keep painful memories alive" (bitterness revival). Scores are averaged per subscale each, representing a reminiscence function. The higher the score, the more the indicated function prevails. In addition, the summary score of all items indicates the extent to which a person reminiscences, irrespective of the reason or function of reminiscence.

2. To assess the degree of perceived control over one's life, we will use the Dutch version of the Mastery Scale (Pearlin \& Schooler, 1978). This consists of seven items that are intended to assess beliefs about perceived control over one's life in general or beliefs regarding one's ability to control an event. We use the abbreviated version of five items which are each phrased in a negative way. Possible responses are given on a 5-point scale ranging from 1 "strongly disagree" to 5 "strongly agree". Summary scores range from 5 to 25 . Higher scores on the scale indicate lower levels of perceived control. The Mastery- Scale has good psychometric properties (Pearlin \& Schooler, 1978).

3. Automatic positive thoughts will be measured using the Dutch version of the Automatic Thoughts Questionnaire Positive (ATQ-P), which asks respondents to rate how frequently each of the 30 positive self-statements or a similar thought occurred during the preceding week on 5-point scales ranging from 1 (never) to 5 (all the time). The scale's total score represents the degree of overall positive thinking (Ingram \& Wisnicke, 1988). The ATQ-P has good psychometric properties in 257 Dutch bereaved adults (Boelen, 2007).

4. Meaning in life will be measured using the Meaning in Life Questionnaire (MLQ), a 10item measure of the presence of, and the search for, meaning in life. We will use a Dutch version in which participants have to answer on a 5-point scale from 1 "absolutely untrue" to 5 "absolutely true" what they think makes their life feel important to them. The MLQ has good psychometric properties (Steger, Frazier, Oishi \& Kaler, 2006).

\section{Measures for the economic evaluation}

The economic evaluation will be carried out using the Trimbos and Institute of Medical Technology Assessment Questionnaire on Costs Associated with Psychiatric Illness (TIC-P), the PROductivity and DISease Questionnaire (PRODISQ), and the EQ-5D. The costs of receiving formal or informal health care will be measured using the TIC-P (Hakkaart-van Rooijen, van Straten, Doner \& Tiemens, 2002). Costs will be assessed from a societal perspective and include both direct and indirect costs related to receiving formal and informal health care. Production losses due to illness in the four weeks preceding the research, in terms of both paid and unpaid work, are covered by the relevant parts of the PRODISQ (Koopmanschap, 2005). These costs arise when people are absent from work, or work less efficiently due to depression, for example. A lost working day will 
be monetarily valued using the gender and age specific value of productivity losses, as reported by Oostenbrink, Bouwmans, Koopmanschap and Rutten (2004) indexed for the reference year 2007. The EQ-5D health state valuations correspond with QALYs gained or lost when each person stays in a particular health state for precisely one year. For the health state valuations we will make use of the Dutch tariffs (Lamers et al., 2005).

\section{Effectiveness analysis of primary and secondary outcome measures}

To test the null-hypothesis of the intervention's non-inferiority relative to care-as-usual, analysis will be conducted on an intention-to-treat basis following the CONSORT guidelines (Altman, Schulz, Moher, Egger, Davidoff, Elbourne et al., 2001). To that end, missing observations at follow- up will be imputed. If there are missing values at different measurements due to drop-out, multiple imputation (MI) is used to replace the missing values with ten new estimates. Relative improvements in the clinical endpoints in the experimental condition as compared to the care-as-usual control condition will be evaluated with help of linear modelling (e.g., regression analysis for Gaussian distributed dependent variables). In linear modelling framework, adjustments for confounders can be carried out, when so required. In the likely absence of confounders, this approach is equivalent to conducting a $t$-test of the clinical endpoint on the conditions (coded 1 for the experimental and 0 the control condition). When the clinical endpoint of interest is not normally distributed, the test and the 95\% confidence intervals will be based on robust standard errors (i.e., while using the first-order Taylor-series linearization method) or on non-parametric bootstrap techniques (with 2,500 bootstrap replications). This would help to ascertain the effectiveness of the treatment relative to the comparator condition.

\section{Power calculation and sample size}

To demonstrate presence of an effect of at least .35 standard units, (considered to be the lower-bound of a medium-sized effect; Lipsey \& Wilson, 1993) as statistically significant in a one-tailed test at alpha $=.05$ and a power of (1-beta) $=.80$ a minimum of 80 participants in each condition will be required at follow-up (power calculation in Stata 7.0). Anticipating a drop-out rate of $20 \%$ between $t 0$ and $t 2,100$ participants per condition need to be included at $t 0$. We will use one-tailed tests in our study, because our hypotheses are directional. Moreover, a one-tailed test provides more power to detect an effect and requires a smaller sample size, which is preferred from a medical-ethics and financial point of view.

\section{Analysis of moderators}

Following Kraemer et al. (2002) moderating factors measured at baseline (t0) will be identified using multivariate regression analysis of the imputed clinical endpoints (at last follow- up) on the interaction terms of the putative moderators with the treatment dummy (alongside their constituent main-effects) (Kraemer et al., 2002). In this way, it can be tested if some baseline characteristics of the participants are prognostically favourable (or 
not) when this particular intervention is offered. This knowledge may alert us to possible improvements of the intervention, and should that prove difficult, then to at least be able to improve referral of patients to this intervention (i.e., indications and contra-indications for a more optimal patient - treatment match).

\section{Analysis of mediating measures}

Mediating analyses will be performed in accordance with the steps outlined by Kraemer et al. (2002). In step 1, the putative mediator (e.g., mastery) will be the dependent measure and the treatment the independent variable. This establishes that the intervention is correlated with the putative mediator. In step 2, the dependent measure will be the outcome measure (e.g., CES-D and HADS-A). The independent measures are: treatment (coded 1 for the experimental and -1 for the control condition, putative mediator (centred at the average of both conditions), and the "treatment $\times$ putative mediator" interaction. This will be done to assess whether there is either a main effect of the putative mediator or an interactive effect with treatment. In this model, the intercept is the mean response to both conditions. The main effect of treatment equals the treatment-control difference (i.e., the main effect of the mediator is the average slope of treatment and control). Finally, the interactive effect is the difference between the two slopes.

\section{Economic evaluation}

The aim of the economic evaluation is to estimate the incremental cost-utility in terms of quality-adjusted life years (QALYs) and the cost-effectiveness in terms of avoided cases of depression and anxiety in the treatment condition as compared to the comparator condition. In addition, costs of the intervention itself will be estimated. Cost calculations will be conducted following the Netherlands guidelines for economic evaluations (Oostenbrink et al., 2004), and will be carried out from the societal perspective and with the time-horizon set at one year. Due to this short time-horizon, costs will not be discounted.

Production losses will be valued monetarily with help of the so called "friction cost" method. Costs and QALYs will be assessed while employing the intention-totreatment method. If clinical and economic end-points are missing at follow-up, they will be replaced by expected values (based on MI). In addition, the incremental costeffectiveness ratio (ICER) will be calculated, the ratio of the difference in costs (cost of intervention condition minus cost of comparator condition) divided by the difference in effects (effect of intervention condition minus effect of comparator condition) (Barrett \& Byford, 2003). Its uncertainty will be graphically represented in the ICER plot with help of the bootstrap method (with 2,500 bootstrap replications), a statistical method based on repeatedly sampling from the observed data generated in an evaluation (Efron \& Tibshirani, 1993).

Finally, cost-effectiveness acceptability (CEAcc) curves will be plotted. CEAcc curves are a graphical representation of the probability that a particular intervention is cost-effective, over a range of possible values for the maximum willingness to pay for a 
unit improvement in health outcomes, $\lambda$ (Fenwick, Claxton \& Sculpher, 2001). However, given that the value of $\lambda$ is unknown, the probability that the new intervention is relatively more cost-effective than existing practice is presented for a range of levels of willingness to pay. Thus a CEAcc curve is created by varying the value of I from zero to infinity (Barrett \& Byford, 2003). In our study we ascertain how the likelihood of the intervention being more acceptable from a health economic point of view depends on the willingness to pay for a QALY. Sensitivity analyses will be carried out to ascertain the robustness of the findings under different scenarios, e.g., under varying values of the main cost drivers that represent the most significant expenses.

\section{$\overline{\text { DISCUSSION }}$}

The purpose of this study is to evaluate the effectiveness of "The stories we live by" intervention, a recently developed life-review intervention. We predict that the experimental condition will show superior effects in reducing depressive and anxiety symptoms and in improving quality of life and positive mental health, and will be cost effective. Both the intervention itself and its evaluation are likely to add to the existing body of knowledge in several ways, as described below.

\section{Strengths and limitations of the life-review intervention}

The life-review intervention is unique in linking life-review with narrative therapy and in its focus on specific positive memories. An advantage of life-review as an intervention method is that it connects with two activities often seen in older people: reminiscing and story-telling. Also, the method seems to suit people who struggle with identity and meaning-in-life questions, especially when people are confronted with traumatic or important life-events or with significant life transitions, which possibly could lead to confusion, and feelings of hopelessness. Life-review interventions may help people to come to stories of their lives and find starting points in their own experiences that may help to find their own identity.

However, the use of life-review as a method for therapeutic intervention may have limitations. A possible limitation is that participants' bitterness revival and feelings of victimization may be reinforced. This may happen when they over and over discuss their negatively coloured story. At the same time they are not able to distance themselves from it. When this is the case, the depressive symptoms exhibited by participants tend to increase, rather than decline. Life-review should not to be seen as a harmless method without the risk of inducing negative effects. Therefore, it is a priority that the life-review process is guided by experienced health care professionals. To ensure this, the therapists participating in our study our obliged to have a therapeutic background, or an education in behavioural sciences (e.g., psychology) or social work and have received a specific training program before working with participants. After this training, they are able to invite the participants - through directed questions - to come to new life-stories and to continuously link the present with the near future. 


\section{Strengths and limitations of the RCT}

Our study will answer questions regarding the acceptability and effectiveness of lifereview that have not been addressed until now. We will investigate who benefits most and will try to understand the clinical pathways that are responsible for inducing the treatment effect. For example, we have included the role of personality as a new potential moderator and we have included a measurement scale based on reminiscence styles the Reminiscence Function Scale - to investigate if it functions as a mediator. In addition, we have added an economic evaluation, and are one of the first to do this regarding life-review (also in the study protocol by Pot, Melenhorst, Onrust \& Bohlmeijer (2008)). However, it should be noted that these additional analyses cannot be conducted in absence of a treatment effect.

Furthermore, our RCT gives us the opportunity to make generalizations, as the intervention will be studied in its natural setting and the recruitment strategy of the study is very similar to the actual recruitment of the mental health care centres that will offer "The stories we live by". Another strength of this RCT is the use the MINI, a structured diagnostic interview for DSM-IV and ICD-10 psychiatric disorders. This allows us to stratify the randomization by symptom level (no major depressive episode or slight to moderate major depressive episode) and to detect any changes in the status of major depressive episode.

We recognize some limitations in this study. First, the time available to study a change in the outcome measures was only six months. For ethical reasons, the participants in the control condition received the intervention 3 months after t1. For future research an extended period is advised. Second, there is no control condition at six-month follow-up after the course. Therefore, definite conclusions that the possible effects at sixmonth follow-up may be related to the intervention cannot be made. Third, the extended follow-up period was only nine months following the conclusion of the course, but longer follow-up periods are needed to investigate for how long the possible effects will persist. Notwithstanding the limitations, the development and research of interventions that prevent depressive and anxiety symptoms from developing into full-blown depression and anxiety is of the utmost importance, as these severe and persistent mental disorders are associated with a large burden of disease and extensive economic costs. Due to the pragmatic nature of the RCT, results will show whether or not potential effects will hold in mental health care practice and can be considered ecologically valid. Presently, Dutch mental health care centres are highly interested in working with life-review interventions. Moreover, "The stories we live by" has the potential to be implemented in several target groups, as the intervention is for example already offered to Turkish and Moroccan older people. To conclude, when the hypothesis of the interventions superiority over care-asusual can be demonstrated, there will be available a new evidence-based life-review intervention to alleviate depressive and anxiety symptoms among people of 55 years and over. 


\section{REFERENCES}

Altman, D. G., Schulz, K. F., Moher, D., Egger, M., Davidoff, F., Elbourne, D., et al. (2001). The revised CONSORT statement for reporting randomized trials: Explanation and elaboration. Annals of Internal Medicine, 134, 663-694.

Atwood, J. D., \& Ruiz, J. (1993). Social constructionist therapy with the elderly. Journal of Family Psychotherapy, 4, 1-32.

Ayers, C. R., Sorrell, J. T., Thorp, S. R., \& Loebach Wetherell, J. (2007). Evidence- based psychological treatments for late-life anxiety. Psychology and Aging, 22, 8-17.

Baerger, D. R., \& McAdams, D. P. (1999). Life-story coherence and its relation to psychological well-being. Narrative Inquiry, 9, 69-96.

Barrett, B., \& Byford, S. (2003). Acceptable mental health care? A new decision-making tool for cost-effectiveness analysis. Mental Health Research Review, 9, 39-41.

Beekman, A. T. F., Penninx, B. W. J. H., Deeg, D. J. H., de Beurs, E., Geerings, S. W., \& van Tilburg, W. (2002). The impact of depression on the well-being, disability and use of services in older adults: A longitudinal perspective. Acta Psychiatrica Scandinavica, 105, 20-27.

Bjelland, I., Dahl, A. A., Haug, T. T., \& Neckelmann, D. (2002). The validity of the Hospital Anxiety and Depression Scale. An updated literature review. Journal of Psychosomatic Research, 52, 69-77.

Bluck, S., \& Levine, L. J. (1998). Reminiscence as autobiographical memory: A catalyst for reminiscence theory development. Ageing and Society, 18, 185-208.

Boelen, P. A. (2007). Psychometric properties of the Dutch version of the Automatic thoughts Questionnaire-Positive (ATQ-P). Cognitive Behaviour Therapy, 36, 23-33.

Bohlmeijer, E. T. (2007a). Reminiscence and depression in later life. (Doctoral Dissertation). Utrecht: Netherlands Institute of Mental Health and Addiction.

Bohlmeijer, E. T. (2007b). The stories we live by, narrative psychology as a method [in Dutch]. Amsterdam: Uitgeverij Boom.

Bohlmeijer, E. T., Westerhof, G. J., \& Emmerik-de Jong, M. (2008). The effects of integrative reminiscence on meaning in life: Results of a quasi-experimental study. Aging \& Mental Health, 12, 639-646.

Bohlmeijer, E., Roemer, M., Cuijpers, P., \& Smit, F. (2007). The effects of life-review on psychological well-being in older adults: A meta-analysis. Aging \& Mental Health, 11, 291-300.

Bohlmeijer, E., Smit, F., \& Cuijpers, P. (2003). Effects of reminiscence and life-review on late-life depression: A meta-analysis. International Journal of Geriatric Psychiatry, 18, 1088-1094.

Brewin, C. R. (2006). Understanding cognitive behaviour therapy: A retrieval competition account. Behaviour Research and Therapy, 44, 765-784.

Brooks, R. (1996). EuroQol: The current state of play. Health Policy, 37, 53-72.

Bryant, C., Jackson, H., \& Ames, D. (2008). The prevalence of anxiety in older adults: Methodological issues and a review of the literature. Journal of Affective Disorders, 109, 233-250. 
Butler, R. N. (1963). The life-review: An interpretation of reminiscence in the aged. Psychiatry, 26, 65-76.

Cappeliez, P., \& O'Rourke, N. (2002). Personality traits and existential concerns as predictors of the functions of reminiscence in older adults. Journal of Gerontology: Psychological Sciences, 57B, P116-P123.

Cappeliez, P., O'Rourke, N., \& Chaudhury, H. (2005). Functions of reminiscence and mental health in later life. Aging \& Mental Health, 9, 295-301.

Cole, M. G., Bellavance, F., \& Masour, A. (1999). Prognosis of depression in elderly community and primary care populations: A systematic review and metaanalysis. American Journal of Psychiatry, 156, 1182-1189.

Copeland, J. R., Beekman, A. T., Dewey, M. E., Hooijer, C., Jordan, A., Lawlor, B.A., et al. (1999). Depression in Europe. Geographical distribution among older people. British Journal of Psychiatry, 174, 312-321.

Costa Jr., P. T., \& McCrae, R. R. (1992). Revised NEO Personality Inventory (NEO PI-R) and NEO Five-Factor Inventory (NEO-FFI). Odessa, FL: Psychological Assessment Resources.

Cuijpers, P. (1998). A psycho-educational approach to the treatment of depression: A meta analysis of Lewinsohn's 'Coping with Depression' course. Behavior Therapy, 29, 521-533.

Cuijpers, P., \& Smit, F. (2002). Excess mortality in depression: A meta-analysis of community studies. Journal of Affective Disorders, 72, 227-236.

Cuijpers, P., de Graaf, R., \& van Dorsselaer, S. (2004). Minor depression: Risk profiles, functional disability, health care use and risk of developing major depression. Journal of Affective Disorders, 79, 71-79.

Cuijpers, P., Smit, F., \& van Straten, A. (2007). Psychological treatments of subthreshold depression: A meta-analytic review. Acta Psychiatrica Scandinavica, 115, 434441.

Cully, J. A., LaVoie, D., \& Gfeller, J. D. (2001). Reminiscence, personality, and psychological functioning in older adults. Gerontologist, 41, 89-95.

Efron, B., \& Tibshirani, R. J. (1993). An Introduction to the Bootstrap. New York: Chapman and Hall.

Euroqol group (1990). EuroQol- a new facility for the measurement of health-related quality of life. Health Policy, 16, 199-208.

Fenwick, E., Claxton, K., \& Sculpher, M. (2001). Representing uncertainty: The role of cost-effectiveness acceptability curves. Health Economics, 10, 779-787.

Fry, P. S. (1983). Structured and unstructured reminiscence training and depression in the elderly. Clinical Gerontologist, 1, 15-37.

Haight, B. K. (1992). Long-term effects of a structured life-review process. Journal of Gerontology, 47, 312-315.

Haight, B. K., Coleman, P., \& Lord, K. (1995). The linchpins of a successful life review: Structure, evaluation and individuality. In B. K. Haight \& J. D. Webster (Eds), The art and science of reminiscing: Theory, research, methods and applications (pp. 179-192). Washington DC: Taylor \& Francis.

Hakkaart-van Rooijen, L., van Straten, A., Doner, M., \& Tiemens, B. (2002). Trimbos/ 
iMTA questionnaire for costs associated with psychiatric illness (TIC-P). Rotterdam: Erasmus University.

Haringsma, R., Engels, G. I., Beekman, A. T. F., \& Spinhoven, P. (2004). The criterion validity of the Center for Epidemiological Studies Depression Scale (CES-D) in a sample of self-referred elders with depressive symptomatology. International Journal of Geriatric Psychiatry, 19, 558-563.

Hoekstra, H. A., Ormel, H., \& de Fruyt, F. (1996). NEO Personality Questionnaires: NEOPI-R and NEO-FFI [in Dutch]. Lisse, The Netherlands: Swets \& Zeitlinger.

Ingram, R. E., \& Wisnicke, K. S. (1988). Asessment of positive automatic cognition. Journal of Consulting and Clinical Psychology, 56, 898-902.

Keyes, C. L. M. (2002). The mental health continuum: From languishing to flourishing in life. Journal of Health and Social Behavior, 43, 207-222.

Keyes, C. L. M. (2005). Mental illness and/or mental health? Investigating axioms of the complete state model of health. Journal of Consulting and Clinical Psychology 73, 539-548.

Keyes, C. L. M. (2006). Mental health in adolescence: Is America's youth flourishing? American Journal of Orthopsychiatry, 76, 395-402.

Koopmanschap, M. A. (2005). PRODISQ: a modular questionnaire on productivity and disease for economic evaluation studies. Expert Review of Pharmacoeconomics \& Outcomes Research, 5, 23-28.

Kraemer, H. C., Wilson, T., Fairburn, C. G., \& Agras, W.S. (2002). Mediators and moderators of treatment effects in randomized clinical trials. Archives of General Psychiatry, 59, 877-883.

Kroph, N. P., \& Tandy, C. (1998). Narrative therapy with older clients: The use of a 'meaning-making' approach. Clinical Gerontologist, 18, 3-16.

Lamers, L. M., Stalmeier, P. F. M., McDonnell, J., Krabbe, P. F. M., \& van Busschbach, J. J. (2005). Measuring the quality of life in economic evaluations: The Dutch EQ5D tariff [in Dutch]. Nederlands Tijdschrift voor Geneeskunde, 149, 1574-1578.

Lecrubier, Y., Sheehan, D., Weiller, E., Amorim, P., Bonora, I., Sheehan, K., et al. (1997). The Mini International Neuropsychiatric Interview (M.I.N.I.), a short diagnostic interview: Reliability and validity according to the CIDI. European Psychiatry, 12, 224-231.

Licht-Strunk, E., van der Windt, D. A, van Marwijk, H. W., de Haan, M., \& Beekman, A. T. (2007). The prognosis of depression in older patients in general practice and the community. A systematic review. Family Practice, 24, 168-180.

Linssen, C., \& Habekotté, F. (2006). Narratieve psychotherapie. [Narrative psychotherapy]. In A.M. Pot, Y. Kuin \& M. Vink (Eds.), Handboek ouderenpsychologie. [Handbook psychology for the elderly] (pp. 363-372). Utrecht: De Tijdstroom.

Lipsey, M. W., \& Wilson, D.B. (1993). The efficacy of psychological, educational, and behavioral treatment. American Psychologist, 48, 1181-1209.

McAdams, D. P., Reynold, J., Lewis, M., Patten, A. H., \& Bowman, P.J. (2001). When bad things turn good and good things turn bad: Sequences of redemption and contamination in life narratives and their relation to psychosocial adaptation in midlife adults and in students. Personality and Social Psychology Bulletin, 27, 474-485. 
McDougall, F. A., Kvaal, K., Matthews, F. E., Paykel, E., Jones, P. B., Dewey, et al. (2007). Prevalence of depression in older people in England and Wales: The MRC CFA Study, Psychological Medicine, 37, 1787-1795.

Miller, M. D. (2008). Using interpersonal therapy (IPT) with older adults today and tomorrow: A review of the literature and new developments. Current Psychiatry Reports, 10, 16-22.

Murray, G., Rawlings, D., Allen, N. B, \& Trinder, J. (2003). NEO five-factor inventory scores: Psychometric properties in a community sample. Measurement and Evaluation in Counseling and Development, 36, 140-149.

Oostenbrink, J. B., Bouwmans, C. A. M., Koopmanschap, M. A. , Rutten, F. F. (2004). Manual for costing: Methods and standard costs for economic evaluations in health care [in Dutch]. Diemen: Health Insurance Board.

Osis, M., \& Stout, L. (2001). Using narrative therapy with older adults. In G. M. Kenyon, P. G. Clark, \& B. de Vries (Eds.), Narrative gerontology: Theory, research, and practice (pp. 273-290). Berlin, Germany: Springer.

Payne, M. (2000). Narrative therapy. An introduction for counsellors. London: Sage.

Pearlin, L. I., \& Schooler, C. (1978). The structure of coping. Journal of Health and Social Behaviour, 19, 2-21.

Polkinghorne, D. E. (1996). Transformative narratives: From victimic to agentic life plots. American Journal of Occupational Therapy, 50, 299-305.

Pot, A. M., Melenhorst, A., Onrust, S., \& Bohlmeijer, E. T. (2008). (Cost)effectiveness of life review for older adults: Design of a randomized controlled trial. BMC Public Health, 8, 211.

Radloff, L. S., \& Teri, L. (1986). Use of the CES-D with older adults. Clinical Gerontology, 5, 119-136.

Radloff, L.S. (1977). The CES-D scale: A self-report depression scale for research in the general population. Journal of Applied Psychological Measurement, 1, 385-401.

Schuurmans, J. (2006). Anxiety in late life, moving toward a tailored treatment. (Doctoral Dissertation). Amsterdam: Vrije Universiteit Amsterdam.

Schuurmans, J., Comijs, H. C., Beekman, A. T. F., de Beurs, E., Deeg, D. J. H., Emmelkamp, P. G. M., et al. (2005). The outcome of anxiety disorders in older people at 6-year follow-up: results from the Longitudinal Aging Study Amsterdam. Acta Psychiatrica Scandinavica, 111, 420-428.

Serrano, J. P., Latorre, J. M., Gatz, M., \& Montanes, J. (2004). Life-review therapy using autobiographical retrieval practice for older adults with depressive symptomatology. Psychology and Aging, 19, 270-277.

Sheehan, D. V., Lecrubier, Y., Sheehan, K.H., Amorim, P., Janavs, J., \& Weiller, E. (1998). The Mini-International Neuropsychiatric Interview (MINI): The development and validation of a structured diagnostic psychiatric interview for DSM-IV and ICD10. Journal of Clinical Psychiatry, 59, 22-33.

Sheehan, D., Lecrubier, Y., Sheehan, K. H., Janavs, J., Weiller, E., Keskiner, A., et al. (1997). Reliability and validity of the Mini International Neuropsychiatric Interview (M.I.N.I.) according to the SCID-P. European Psychiatry, 12, 232-241.

Smit, F., Comijs, H. C., Schoevers, R., Cuijpers, P., Deeg, D., \& Beekman, A (2007). Target 
groups for the prevention of late-life anxiety. British Journal of Psychiatry, 190, 428-434.

Smit, F., Ederveen, A., Cuijpers, P., Deeg, D., \& Beekman, A. (2006). Opportunities for cost-effective prevention of late-life depression. An epidemiological approach. Archives of General Psychiatry, 63, 290-296.

Spinhoven, P. H., Ormel, J., Sloekers, P. P. A., Kempen, G. I. J. M., Speckens, A. E. M., \& van Hemert, A.M. (1997). A validation study of the Hospital Anxiety and Depression Scale (HADS) in different groups of Dutch subjects. Psychological Medicine, 27, 363-370.

Steger, M., Frazier, P., Oishi, S., \& Kaler, M. (2006). The meaning in life questionnaire, assessing the presence of and search for meaning in life. Journal of Counselling Psychology, 53, 80-93.

van 't Veer-Tazelaar, P. J., van Marwijk, H. W.J., van Oppen, P., van Hout, H. P. J., van der Horst, H. E., Cuijpers, P., et al. (2009). Stepped-Care Prevention of Anxiety and Depression in Late Life: A Randomized Controlled Trial. Archives of General Psychiatry, 66, 297-304.

van Vliet, I. M., \& de Beurs, E. (2007). The MINI-International Neuropsychiatric Interview (M.I.N.I.). A brief structured diagnostic psychiatric interview for DSM-IV and ICD10 psychiatric disorders [in Dutch]. Tijdschrift voor Psychiatrie, 49, 393-397.

Watt, L. M., \& Cappeliez, P. (2000). Integrative and instrumental reminiscence therapies for depression in older adults: Intervention strategies and treatment effectiveness. Aging \& Mental Health, 4, 166-177.

Webster, J. D. (1993). Construction and validation of the Reminiscence Functions Scale. Journal of Gerontology: Psychological Sciences, 48, 256-262.

Webster, J. D. (1994). Predictors of reminiscence. A lifespan perspective. Canadian Journal on Aging, 13, 66-78.

Webster, J. D. (1997). The Reminiscence Functions Scale: A replication. International Journal of Aging and Human Development, 44, 137-148.

Westerhof, G. J., \& Keyes, C. L. M. (2008). Mental health is more than the absence of mental illness [in Dutch]. Maandblad Geestelijke Volksgezondheid, 63, 808-820.

Westerhof, G. J., Bohlmeijer, E. T., \& Webster, J. D. (2010). Reminiscence and mental health: A review of recent progress in theory, research, and intervention. Ageing and Society, 30, 697-721.

Williams, J. M., \& Scott, J. (1988). Autobiographical memory and depression. Psychological Medicine, 18, 689-695.

Wilson, K. C., Mottram, P. G., \& Vassilas, C. A. (2008). Psychotherapeutic treatments for older depressed people. Cochrane Database of Systematic Reviews, 1 , CD004853.

Wong, P. T. (1995). The processes of adaptive reminiscence. In B. K. Haight \& J. D.

Webster (Eds.), The art and science of reminiscing: Theory, research, methods, and applications (pp. 23-35). Washington, DC: Taylor \& Francis.

Wong, P. T., \& Watt, L. M. (1991). What types of reminiscence are associated with successful aging? Psychology and Aging, 6, 272-279.

Zigmond, A. S., \& Snaith, R. P. (1983). The hospital anxiety and depression scale. Acta Psychiatrica Scandinavica, 67, 361-370. 


\section{LIFE-REVIEW THERAPY FOR OLDER} ADULTS WITH MODERATE DEPRESSIVE SYMPTOMATOLOGY: A PRAGMATIC RANDOMIZED CONTROLLED TRIAL
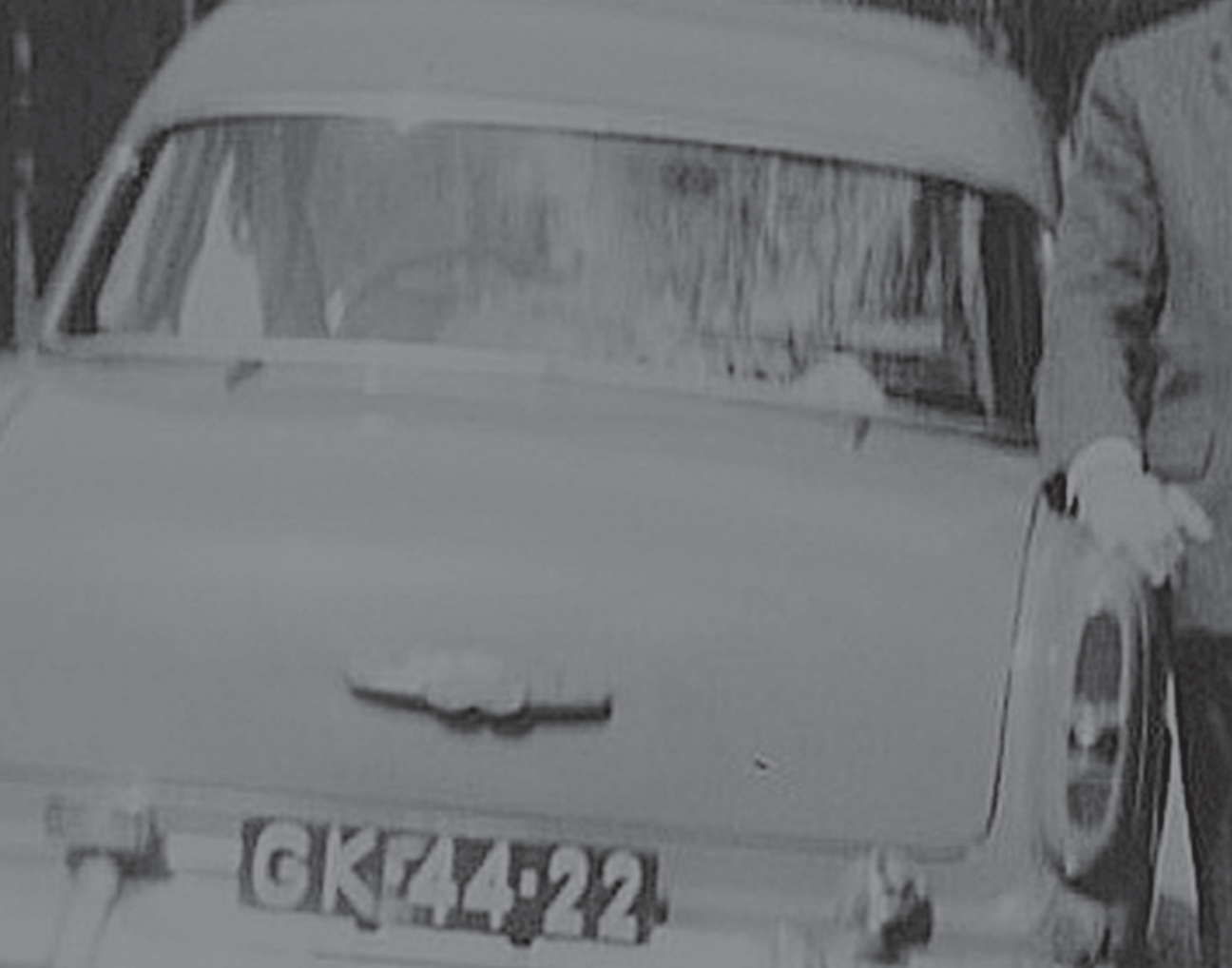

Korte, J., Bohlmeijer, E.T., Cappeliez, P., Smit, F., \& Westerhof, G.J. (2012). Life-review therapy for older adults with moderate depressive symptomatology: A pragmatic randomized controlled trial. 


\section{CHAPTER}

\section{ABSTRACT}

Although there is substantial evidence for the efficacy of life-review therapy as an early treatment of depression in later life, its effectiveness in natural settings has not been studied. The present study evaluates an intervention based on life-review and narrative therapy in a large multi-site, pragmatic randomized controlled trial (RCT). Life-review therapy was compared with care-as-usual. The primary outcome was depressive symptoms; secondary outcomes were anxiety symptoms, positive mental health, quality of life, and current major depressive episode (MDE). To identify groups for whom the intervention was particularly effective, moderator analyses were carried out (on sociodemographic variables, personality traits, reminiscence functions, clinically relevant depressive and anxiety symptoms, and past MDEs). Compared with care-as-usual ( $n=102)$, life-review therapy $(n=100)$ was effective in reducing depressive symptoms, at post-treatment $(d=.60$, $B=-5.3, p<.001)$, at 3-month follow-up $(d=.50, B=-5.0, p<.001)$ and for the intervention also at 9 -month follow-up $(t=5.7, p<.001)$. The likelihood of a clinically significant change in depressive symptoms was significantly higher [odds ratio $(O R) 3.77, p<.001$ at posttreatment; OR 3.76, $p<.001$ at the 3-month follow-up]. Small significant effects were found for symptoms of anxiety and positive mental health. Moderator analyses showed only two significant moderators, the personality trait of extraversion and the reminiscence function of boredom reduction. This study shows the effectiveness of life-review therapy as an early intervention for depression in an ecologically valid context, supporting its applicability to a broad target group. The intervention is also effective in reducing anxiety symptoms and strengthening positive mental health. 


\section{INTRODUCTION}

In older adults, clinical depression is a significant health problem, carrying a poor prognosis (Beekman., Penninx, Deeg, de Beurs, Geerings \& van Tilburg, 2002; Cole Bellavance \& Masour, 1999; Licht-Strunk, van der Windt, van Marwijk, de Haan \& Beekman, 2007). Regarding the prevalence of depression, rates between $8.8 \%$ and $23.6 \%$ have been reported (Copeland, Beekman, Dewey, Hooijer, Jordan, Lawlor et al., 1999; McDougall, Kvaal, Matthews, Paykel, Jones, Dewey et al., 2007). The most important risk factor for developing late-life clinical depression is the presence of depressive symptoms not (as yet) meeting diagnostic criteria (Cuijpers, de Graaf \& van Dorsselaer, 2004; Smit, Ederveen, Cuijpers, Deeg \& Beekman, 2006). Hence, effective early interventions directed at older adults with mild to moderate depressive symptomatology are of utmost importance. Meta-analytic evidence indicates that early interventions for older adults with depressive symptoms are indeed promising in preventing depressions (Cuijpers, Smit \& van Straten 2007).

Besides cognitive behavioural therapy (Cuijpers et al. 2007), life-review has been established as an evidence-based early treatment of depression in later life (Bohlmeijer, Roemer, Cuijpers \& Smit 2007; Bohlmeijer, Smit \& Cuijpers, 2003; Pinquart, Duberstein \& Lyness, 2007). Life-review involves a structured evaluation of one's own life, on the one hand aiming at coping with negative experiences and conflicts and on the other hand at giving a positive meaning to life (Haight, 1992; Wong, 1995; Westerhof, Bohlmeijer \& Webster, 2010). Life-review seems especially suited for older adults who experience loss of meaning in life and who hold a negative view of themselves. Critical life-events may increase the use of specific negative functions of reminiscence such as reviving bitter experiences or escaping past problems (Cappeliez, 2002; Wink \& Schiff, 2002; Wong, 1995). Associations between these functions and poorer mental health have been found recently (Cappeliez \& O'Rourke, 2006; Cappeliez, O'Rourke \& Chaudhury, 2005; Cully, LaVoie \& Gfeller, 2001; Korte, Bohlmeijer, Westerhof \& Pot, 2011; O’Rourke, Cappeliez \& Claxton, 2011).

The above underscores the importance of developing early interventions based on life-review. Recently, attempts have been made to combine life-review with other interventions aimed at people with clinically relevant mental distress (Watt \& Cappeliez, 2000; Cappeliez, 2002; Westerhof et al., 2010), for example narrative therapy (Bohlmeijer, Kramer, Smit, Onrust \& van Marwijk, 2009; Bohlmeijer, Westerhof \& Emmerik-de Jong, 2008). In narrative therapy, life-stories are considered as a reconstruction of autobiographical memories (Atwood \& Ruiz, 1993; Bluck \& Levine, 1998). The most important element in life-review combined with narrative therapy is to develop alternative, more agentic life-stories, in which clients take responsibility for their own preferred ways of living (Bohlmeijer et al., 2008; 2009).

To summarize, substantial evidence supports the efficacy of life-review as a treatment of depression in later life. However, most trials have not studied the effectiveness of life-review in its natural setting (Bohlmeijer et al., 2003; 2007; Pinquart et al., 2007). To fill that gap, we have conducted a large, multi-site, pragmatic randomized controlled 
trial $(R C T)$ in adults aged $\geq 55$ years with moderate depressive symptoms, in which we compared the effectiveness of an intervention based on life-review and narrative therapy (life-review therapy) in its natural setting with care-as-usual. To study the effects in a natural setting, the Dutch health-care system was mimicked as closely as possible in terms of patient recruitment and offering the intervention. We specifically aimed at young older adults, who are in relatively good health. Life-review might help to cope with age-related losses and declines, and to find meaning in this new phase of life (Haight, 1992; Westerhof et al., 2010; Wong, 1995). Most studies on life-review interventions have included relatively small sample sizes (Bohlmeijer et al., 2003; 2007; Pinquart et al., 2007). These small sample sizes have precluded addressing important questions about the moderating influence of client characteristics such as sociodemographic attributes, personality traits, patterns of reminiscence and level of depressive symptomatology. Here we sought to identify subgroups for which the intervention might be particularly effective. This should help to determine the suitability of the intervention for different target groups.

\section{$\overline{M E T H O D}$}

\section{Design}

The design of the current study is described in detail by Korte, Bohlmeijer and Smit (2009). We carried out a pragmatic, multi-site RCT in which participants were randomly assigned to either life-review therapy or care-as-usual.

\section{Participants and procedure}

Participants were recruited from September 2008 to September 2009, in collaboration with Dutch mental health-care services, through advertisements in newspapers and information booklets, plus a radio interview and commercial. Applicants were referred to a specifically developed website, where they could find more information about the study. Thereafter, applicants were assessed for eligibility and had to sign an informed consent form.

In total, 14 Dutch mental health-care services, in both urban and rural areas, participated in this study. They were responsible for the intake procedure, in which inclusion and exclusion criteria were examined. Therapists at these services, experienced in working with older adults, implemented the intervention. Before being allowed to offer the intervention, they were required to participate in a 2-day training program, supervised by a narrative therapist and a life-review therapist. They also participated in two half-day follow-up discussion sessions and a booster training.

Inclusion criteria were age $\geq 55$ years and the presence of moderate depressive symptoms, operationalized by a score of $\geq 10$ on the Center for Epidemiologic Studies Depression Scale (CES-D; Beekman, Deeg, van Limbeek, Braam, de Vries \& van Tilburg, 1997; Radloff, 1977). Applicants were excluded if diagnosed with current severe major depressive episode (MDE; eight or nine out of a total of nine symptoms) or with a moderate 
to high suicide risk according to the Mini International Neuropsychiatric Interview (MINI; Sheehan et al. 1998; van Vliet \& de Beurs, 2007). Furthermore, applicants were excluded if they had a score of $\leq 9$ on the CES-D (Radloff, 1977), had started taking antidepressant medication or benzodiazepines recently (within the previous 2 months), were currently receiving any psychological treatment, or if the health-care professionals assessed the presence of other serious psychopathology, in which case they were referred for psychological treatment. Participants were randomly assigned either to life-review therapy or to care-as-usual, by means of a centrally conducted, independent randomization process. The randomization was stratified by gender and presence of current MDE (no current MDE or mild to moderate current MDE), using a computer-generated sequence of numbers.

\section{Power analysis}

To demonstrate an effect size of at least .35 (Cohen's $\alpha$ ) in a one-tailed test at $\alpha=.05$ and a power of $(1-\beta)=.80$, a minimum of 80 participants in each condition was required at follow-up, estimated by power calculation in Stata 7.0 (StataCorp LD, USA). Anticipating a drop-out rate of $20 \%$ between baseline and the end of treatment, we needed to include 100 participants for each condition at baseline. This requirement was met, as we included 100 participants in the life-review therapy condition and 102 participants in the care-asusual condition.

\section{Measures}

All participants completed measures at baseline $(t 0)$, post-intervention $(t 1 ; 3$ months after baseline) and follow-up ( $t 2 ; 3$ months after the end of intervention). Only the intervention condition completed an extended follow-up ( $t 3 ; 9$ months after the intervention) whereas the control condition received the intervention after 6 months.

The primary outcome measure was depressive symptoms (CES-D; Beekman et al., 1997; Radloff, 1977; $\alpha=.83$ in this study). Secondary outcome measures were anxiety symptoms measured on the Hospital Anxiety and Depression Scale (HADS; Spinhoven, Ormel, Sloekers, Kempen, Speckens \& van Hemert, 1997; Zigmond \& Snaith, 1983; $\alpha=.77$ in this study), positive mental health (Keyes, Wissing, Potgieter, Temane, Kruger \& van Rooy, 2008; Lamers, Westerhof, Bohlmeijer, ten Klooster \& Keyes, 2011; $\alpha=.87$ in this study), quality of life assessed by the Euroqol questionnaire (EQ-5D; Euroqol Group, 1990), and current mild to moderate MDE (five to seven out of nine symptoms on the MINI; Sheehan et al., 1998; van Vliet \& de Beurs, 2007). Moderating variables were sociodemographic attributes (age, gender and educational level), personality (neuroticism, extraversion, openness to experience, agreeableness and conscientiousness; NEO-FFl; Costa \& McCrae, 1992; Hoekstra, Ormel \& de Fruyt 1996; $\alpha=.70-.78, \alpha=.50$ for openness to experience), reminiscence functions (identity, problem-solving, bitterness revival and boredom reduction; Webster, 1997; $\alpha=.79-0.85$ in this study), past MDEs (MINI; Sheehan et al., 1998; Van Vliet \& De Beurs, 2007), chronic medical conditions (Statistics Netherlands, 1989) and critical life-events (Social Readjustment Rating Scale; Holmes \& 
Rahe, 1967). A more detailed description of the measures can be found in Korte et al. (2009).

\section{Intervention and control condition}

The intervention, "The stories we live by", is conducted in groups of four to six participants and consisted of eight similarly structured sessions of $2 \mathrm{~h}$ each. The intervention has three core elements. First, the integration of difficult life-events from the past; second, the development of agentic life-stories, which helps the participants to cope with present life-events and to formulate new goals; third, the retrieval of specific positive memories, which can serve as building blocks of the new life-stories.

The first two elements were developed by integrating life-review into a narrative therapeutic framework that connects to theories about the role of life-stories in the articulation of identity and meaning (Freedman \& Combs, 1996; Gergen, 1985). A narrative therapeutic framework enhances the integration of negative events and the restoration of meaning in life in several ways. It stimulates clients to adopt an attitude of curiosity and not-knowing. In this way, ample space is created for clients to explore alternative stories and preferences (White \& Epston, 1990). Furthermore, therapists have an arsenal of questions that may be helpful in constructing alternative, more agentic stories about negative life-events and life periods (e.g., How were you able to cope with this situation? Were there any pleasant moments in this difficult time? Now, at a much later date, can you say that you have also learned from that period?). In addition, by always focusing on preferences of clients and relating them to other memories, clients are continually invited to express their values and past experiences (White, 2007). Finally, alternative stories are further elaborated by relating them to identity (e.g., What does this say about the person you are?) and to future goals and action (What can you do in the near future to live by this value or meaning?). The third core element was the attention to specific positive memories, special and unique for a certain period in the participants' lives, which are expected to activate nearly forgotten memories, especially in people with depressive symptoms (Brewin, 2006; Serrano, Latorre, Gatz \& Montanes, 2004; Williams, Barnhofer, Crane, Herman, Raes, Watkins et al., 2007).

The first five intervention sessions were focused on different life themes: origin, youth, work and care, love and conflicts, and loss and difficult times. Before each session, participants had to answer questions about those life themes. For each theme the participants had to describe one difficult life-event they were still struggling with. Then they had to answer questions that helped to develop alternative stories that would help to integrate this life-event. For each session they had to describe a specific positive memory as well. During the intervention sessions, participants had the opportunity to exchange and discuss the experiences with the other participants. In the last three sessions there was attention to some overarching themes that focused on creating an overview and on the near future. For example, participants had to recall an image that symbolized their lives and explain why (metaphor), they had to make an overview of ups and downs in their lives (course of life), and they had to think about how they wanted to arrange their lives with the knowledge they had gained during the intervention (new beginning). 
To check whether the intervention was implemented as intended, one session was audiotaped by all participating mental health-care services. Two researchers independently scored a treatment integrity measure and solved a few disagreements by consensus. The measure addressed five criteria that were crucial in correctly delivering the intervention. First, structure involved the degree to which therapists followed the structure as described in the intervention protocol. Second, life-review therapy skills encompassed skills that therapists had in asking the right therapeutic questions. Third, empathy measured whether therapists acknowledged participants' feelings and experiences. Fourth, curiosity assessed whether therapists had an attitude of curiosity and not-knowing. Fifth, group process involved the stimulation of a constructive interaction between participants, to create and elaborate alternative life-stories. All criteria were assigned one (unsatisfactory), two (satisfactory) or three points (good), with a total score ranging from 5 to 15 (5 8=unsatisfactory, 9-11=satisfactory, 12-15=good). The therapists scored satisfactory (60\%: 8 out of 14 sessions) or good (40\%: 6 out of 14 sessions).

Participants in the control condition received no intervention. However, they had unrestricted access to care-as-usual, that is they were not withheld from any treatment (e.g., they may receive psychological treatment). After conclusion of the RCT, the intervention was offered to them.

\section{Analyses}

Analyses were performed according to the intention-to-treat (ITT) approach on missing data, using Missing Value Analysis in PASW 18 (SPSS Inc., USA) to impute all missing data on the continuous measures with expectation- maximization (EM). Missing values were replaced by estimates, which were based on maximum likelihood estimates using observed data in an iterative process (Dempster, Laird \& Rubin, 1977). As a comparison of results based on the imputed ITT sample versus the observed data revealed similar outcomes, only results from the ITT analyses are reported. Statistical tests were onetailed because the hypothesis was unidirectional (assuming superiority of the intervention under the alternative hypothesis) and deemed significant at $p<.05$.

First, independent-samples $t$-tests and $x^{2}$ tests were conducted to examine differences between the conditions at baseline. Second, to examine differences between the conditions on outcome measures, regression analysis was used in the case of continuous response variables, and logistic regression was used for dichotomous variables. In both cases, the dependent variables were the post-treatment and followup outcome measures with the baseline outcome measures and the treatment dummy (intervention versus control condition) serving as the independent variables. Following Jacobson and Truax (1991), the proportion of participants was determined who showed a clinically significant change on the CES-D from baseline to post-treatment, defined as a reduction on the CES-D of at least 5 points between $t 1$ and $t 2$ while crossing the cut-off value of 16 for clinically relevant depressive symptoms (Beekman et al., 1997; cf., Smit et al., 2006; Steunenberg et al., 2006). Participants manifesting a clinically significant improvement were coded 1 (success) or 0 (failure). This dichotomous outcome was used to calculate the odds ratio $(O R)$ using logistic regression for participants who had a score 
of $\geq 16$ at t0. The number needed to treat (NNT) was calculated based on the clinically significant change proportions. To investigate whether the effects in the intervention condition were maintained at $t 2$, paired-sample $t$-tests were carried out, comparing the scores on the second follow-up with those at baseline. All analyses took into account the fact that the observations were clustered because participants were "nested" in each of the 14 mental health services. Therefore, robust standard errors were computed using the first-order Taylor-series linearization method as implemented in Stata version 8.2. Standardized mean differences (Cohen's $d$ ) at post-intervention and follow-up were calculated as the difference between the means of the treatment and control condition divided by the standard error of the control condition.

Finally, to identify whether sociodemographic variables (age, gender, educational level), personality traits, reminiscence functions, clinically relevant depressive and anxiety symptoms, past MDEs, chronic medical conditions and critical life-events moderated the effect of the intervention on the change of depressive symptoms at post-intervention, linear regression analyses were used. The cut-off scores for clinically relevant symptoms of depression $(\geq 16)$ and anxiety $(\geq 11)$ and the medians on the scores on personality traits, past MDEs, chronic medical conditions and critical life-events at baseline were used as cut-off scores for recoding them as dichotomous variables. In linear regression models, we entered the change score of $t 1-t 0$ of depressive symptoms as a dependent variable, and the intervention dummy (intervention condition $=1$ versus control condition=0), the potential moderator and their interaction as independent variables.

\section{RESULTS}

\section{Enrolment, treatment adherence and drop-out}

Figure 1 shows the flow of participants. In total, 274 older adults expressed an interest to participate in the intervention. Based on the exclusion criteria, 49 applicants were excluded before the randomization (no depressive symptoms: $n=23$, current severe MDE: $n=7$, moderate to high suicide risk: $n=3$, recent antidepressant medication: $n=5$, currently receiving psychological treatment: $n=3$, and other serious psychopathology: $n=8$ ). Eighteen additional participants decided not to participate because they lacked motivation, and five applicants were excluded for other reasons. The remaining 202 participants were randomly assigned to the intervention $(n=100)$ or the control condition $(n=102)$. After randomization, one participant decided not to start with the intervention, and seven others discontinued the intervention due to lack of motivation $(n=5)$ or health problems $(n=2)$. Of the participants, $85.1 \%$ filled out the questionnaires at all measurement times (80.4\% in the intervention group). The total percentage of missing data was $15.1 \%$, due to unanswered items (2.3\%) or incomplete assessments (12.8\%). These missing values were imputed at baseline, post-intervention and follow-up. Participants who completed the assessments did not differ significantly at baseline from those who did not complete all measures. 


\section{Baseline characteristics}

Participants had a mean age of 63 years $(S D=6.5$, range $=55-83)$ and were predominantly female (Table 1). Their education was distributed evenly across three categories $(<11$ years, 11-14 years, and $>14$ years). About one-third of the participants were retired. On average, participants had one to two chronic medical conditions $(M=1.5, S D=1.4)$ and they had experienced two to three critical life-events in the past 3 years $(M=2.3, S D=1.5)$. Table 2 shows that participants at baseline scored an average of 20.5 ( $S D=8.6)$ on the CES-D, reflecting clinically relevant depressive symptoms.

Figure 1. Flow of participants

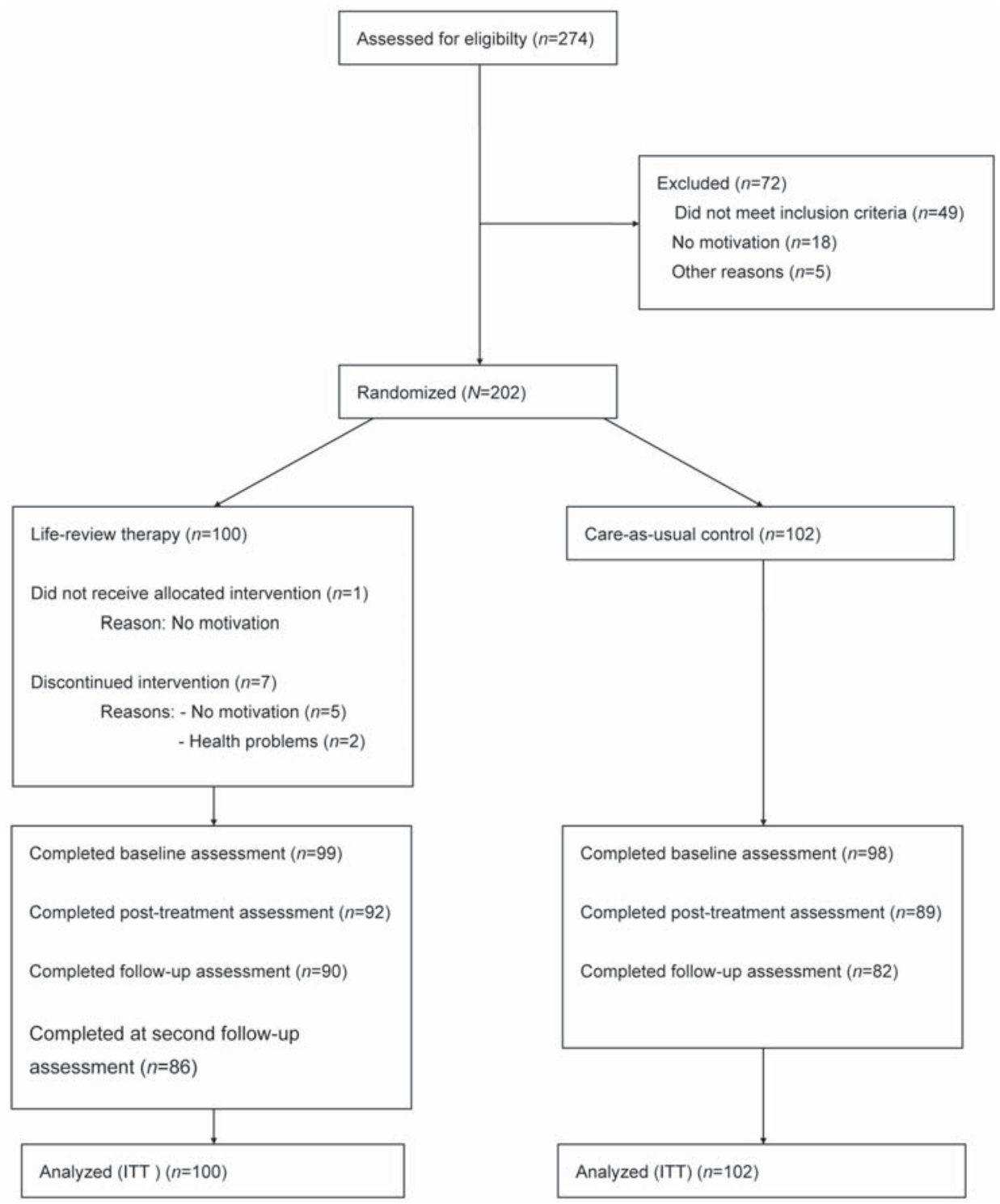


Table 1. Baseline characteristics of participants for total sample, life-review therapy and care-as-usual

\section{OUTCOME MEASURE}

Total sample $(n=202)$
Life-review

therapy

$(n=100)$
Care-

as-usual

$(n=102)$

$\mathrm{Age}^{\mathrm{a}}$

\begin{tabular}{l}
\hline M $(S D)$ \\
\hline Range
\end{tabular}

$63.3(6.5)$

$55-83$

$63.3(6.2)$

$63.3(6.8)$

Sex

\begin{tabular}{ll|l}
\hline Female \\
\hline Male
\end{tabular}

76.7

23.3

$55-83$

$55-83$

Education ${ }^{\mathrm{b}}$

\begin{tabular}{|l|l|l|l|}
\hline Less than 11 years & 36.6 & 37.0 & 36.3 \\
\hline $11-14$ years & 33.7 & 35.0 & 32.4 \\
\hline More than 14 years & 29.7 & 28.0 & 31.4 \\
\hline
\end{tabular}

Chronic medical conditionsa

\begin{tabular}{|l|l|l|l|}
\hline$M(S D)$ & $1.5(1.4)$ & $1.4(1.3)$ & $1.5(1.4)$ \\
\hline Range & $0-6$ & $0-6$ & $0-6$ \\
\hline
\end{tabular}

Critical life-events ${ }^{a}$

\begin{tabular}{|l|l|l|l|}
\hline$M(S D)$ & $2.3(1.5)$ & $2.4(1.5)$ & $2.3(1.5)$ \\
\hline Range & $0-7$ & $0-7$ & $0-7$ \\
\hline
\end{tabular}

Employment $^{\mathrm{b}}$

\begin{tabular}{|l|l|l|l|}
\hline Paid work & 15.8 & 19.0 & 12.7 \\
\hline Retired & 30.7 & 33.0 & 28.4 \\
\hline Housekeeping & 15.8 & 16.0 & 15.7 \\
\hline Volunteer work & 18.3 & 19.0 & 17.6 \\
\hline Disability pension & 15.8 & 10.0 & 21.6 \\
\hline Unemployed & 3.5 & 3.0 & 3.9 \\
\hline
\end{tabular}

Note. ${ }^{a}$ No significant differences between intervention and control condition ( $t$-test with $\left.p>.05\right)$. ${ }^{b}$ No significant differences between intervention and control condition ( $X^{2}$-test with $\left.p>.05\right)$. 


\section{Treatment effects}

Table 2 presents the means and standard errors for the outcome measures at posttreatment, first and second follow-ups, the results of the regression analysis, and the effect sizes. Compared to the control condition, participants in the intervention condition reported significantly decreased depressive symptoms at post-treatment $(B=-5.3, p<.001)$ and first follow-up $(B=-5.0, p<.001)$. Effect sizes at post-treatment $(d=.60)$ and first followup ( $d=.50)$ are medium (Cohen, 1992). The effects of the intervention condition were maintained at the second follow-up $[t 99)=5.7, p<.001]$. The proportion of participants who reached a clinically significant change at post-treatment on the CES-D in the lifereview therapy condition was $31 / 68$ (45.6\%) versus $12 / 71$ (16.9\%) in the care-as-usual condition [OR 3.77, 95\% confidence interval $(C /) 1.38-10.30, p<.001, N N T=3.5]$. At follow-up, in the intervention condition, 35/68 (51.5\%) participants versus 15/71 (21.1\%) participants in the control condition showed a successful outcome $(O R 3.76,95 \% \mathrm{Cl}$ 1.45-9.72, $p<.001, N N T=3.3)$.

Compared to the control condition, participants in the intervention condition reported a significant decrease in anxiety symptoms ( $t 1: B=-1.1, p<.01, t 2: B=-.89, p<.05)$ and a significant improvement in positive mental health $(t 1: B=4.0, p<.001, t 2: B=2.9$, $p<.001)$. Effect sizes for anxiety symptoms ( $t 1: d=.28, t 2: d=.25)$ and positive mental health ( $t 1: d=.29, t 2: d=.26)$ were small (Cohen, 1992). The effects were maintained at the second follow-up in the intervention condition [anxiety symptoms: $t(99)=5.0, p<.001$, positive mental health: $t(99)=-4.2, p<.05]$. No significant effects were found for quality of life ( $t 1: B=.02, p=.20, t 2: B=-.00, p=.41)$. Improvement on current mild to moderate MDE was not statistically significant $(p=.08, O R .57)$.

\section{Moderator analyses}

We investigated whether certain groups of participants derived more benefit from the intervention with respect to depressive symptoms. Analyses showed only two significant moderators, the personality trait of extraversion $(B=-4.1, p=.03)$ and the use of reminiscence to reduce boredom in the present $(B=4.6, p=.03)$, in the sense that people with higher levels of extraversion and lower levels of boredom reduction obtained higher benefits from the intervention. No significant interactions were found for the other putative moderators, that is age, gender, educational level, traits of neuroticism, openness to experiences, agreeableness, conscientiousness, reminiscence functions of identity, problem-solving, bitterness revival, clinically relevant depressive and anxiety symptoms at baseline, past MDEs, chronic medical conditions and critical life-events at baseline. 
Table 2. Means and standard deviations for all outcome measures (at baseline, post-treatment, follow-up and second follow-up) and results of the GLM repeated measures and Cohen's $d$ for intervention effects (taking clustering into account)

\begin{tabular}{|c|c|c|c|c|c|c|c|c|}
\hline \multirow[b]{2}{*}{ Measures } & & \multicolumn{2}{|c|}{$\begin{array}{l}\text { Life-review therapy } \\
(n=100)\end{array}$} & \multicolumn{2}{|c|}{$\begin{array}{l}\text { Care-as-usual } \\
(n=102)\end{array}$} & \multirow[b]{2}{*}{$B$} & \multirow[b]{2}{*}{$S E$} & \multirow[b]{2}{*}{$d$} \\
\hline & & $M$ & $S E$ & $M$ & $S E$ & & & \\
\hline \multicolumn{9}{|c|}{ Primary outcome } \\
\hline \multirow{4}{*}{$\begin{array}{l}\text { CES-D } \\
(0-60)\end{array}$} & Baseline & 20.5 & 1.1 & 20.6 & .74 & & & \\
\hline & $\begin{array}{l}\text { Post- } \\
\text { treatment }\end{array}$ & 15.8 & 1.2 & 21.2 & .90 & $-5.3^{\star \star \star}$ & .99 & .60 \\
\hline & Follow-up & 15.3 & 1.1 & 20.4 & 1.0 & $-5.0^{\star \star *}$ & 1.3 & .50 \\
\hline & $\begin{array}{l}\text { Second } \\
\text { follow-up }\end{array}$ & 15.4 & 1.0 & & & $t=5.7^{\star \star \star}$ & & \\
\hline \multicolumn{9}{|c|}{ Secondary outcomes } \\
\hline \multirow{4}{*}{$\begin{array}{l}\text { HADS-A } \\
(0-21)\end{array}$} & Baseline & 8.3 & .39 & 8.4 & .39 & & & \\
\hline & $\begin{array}{l}\text { Post- } \\
\text { treatment }\end{array}$ & 6.8 & .34 & 8.0 & .42 & $-1.1^{\star *}$ & .49 & .28 \\
\hline & Follow-up & 6.8 & .34 & 7.7 & .38 & $-.89^{*}$ & .36 & .25 \\
\hline & $\begin{array}{l}\text { Second } \\
\text { follow-up }\end{array}$ & 6.7 & .34 & & & $t=5.0^{\star \star \star}$ & & \\
\hline \multirow{4}{*}{$\begin{array}{l}\text { MHC-SF } \\
(0-70)\end{array}$} & Baseline & 34.2 & .97 & 34.0 & 1.2 & & & \\
\hline & $\begin{array}{l}\text { Post- } \\
\text { treatment }\end{array}$ & 38.0 & 1.5 & 33.8 & 1.5 & $4.0^{\star \star \star}$ & 1.3 & .29 \\
\hline & Follow-up & 36.9 & 1.1 & 33.7 & 1.2 & $2.9^{\star \star \star}$ & .80 & .26 \\
\hline & $\begin{array}{l}\text { Second } \\
\text { follow-up }\end{array}$ & 39.0 & 1.1 & & & $t=-4.2^{\star}$ & & \\
\hline \multirow{4}{*}{$\begin{array}{l}\text { EQ 5-D } \\
(0-1)\end{array}$} & Baseline & .83 & .02 & .81 & .01 & & & \\
\hline & $\begin{array}{l}\text { Post- } \\
\text { treatment }\end{array}$ & .81 & .02 & .78 & .02 & .02 & .02 & .17 \\
\hline & Follow-up & .81 & .02 & .80 & .01 & -.00 & .02 & .07 \\
\hline & $\begin{array}{l}\text { Second } \\
\text { follow-up }\end{array}$ & .83 & .02 & & & $t=.36$ & & \\
\hline \multirow[t]{2}{*}{ MINI-MDE } & Baseline & $19.0 \%$ & & $17.6 \%$ & & & & \\
\hline & $\begin{array}{l}\text { Post- } \\
\text { treatment }\end{array}$ & $10.0 \%$ & & $15.7 \%$ & & $\mathrm{OR}=.57$ & .22 & \\
\hline
\end{tabular}

Note. ${ }^{\star} p<.05,{ }^{* \star} p<.01{ }^{* \star \star}, p<.001$. CES-D=Center for Epidemiological Studies-Depression Scale, HADS-A=Hospital and Anxiety Scale-Anxiety scale, MHC-SF=Mental Health Continuum-Short Form, EQ-5D=EuroQol Questionnaire, MINIMDE=Mini International Neuropsychiatric Interview-mild to moderate Major Depressive Episode. 


\section{$\overline{\text { DISCUSSION }}$}

\section{Main findings}

The present study evaluated an early intervention that integrates life-review and narrative therapy under real-life conditions, using a large, pragmatic, multi-site RCT in older adults with moderate depressive symptoms. The results indicate that such a life-review therapy is effective in reducing depressive symptoms. These effects were maintained at 3-and 9-month follow-ups. We found medium effect sizes for depressive symptoms, both posttreatment $(d=.60)$ and at follow-up ( $d=.50)$. These effect sizes are comparable to the effect size of .42 that was found for early interventions on distress by Cuijpers et al. (2007). Moreover, the likelihood of a clinically significant change in depressive symptoms was significantly and substantially higher in the intervention condition than in the care-as-usual condition. These results support life-review therapy as an effective early intervention for older adults with depressive symptomatology. The effects on major depression at the 3-month follow-up were not statistically significant at $p=.08$, but the effects on clinical cases of preventive and early interventions are most prominently found after longer periods of time (Cuijpers, van Straten, Smit, Mihalopoulos \& Beekman, 2008). Our finding that the average level of depressive symptoms remained below the cut-off score for possible caseness of depression at the 9-month follow-up is promising, but it needs to be substantiated by longer follow-up measurements under controlled conditions.

In addition, significant, albeit small, effects were observed for symptoms of anxiety and positive mental health. It thus seems that life-review therapy has the potential not only to reduce symptoms of psychopathology but also to improve positive mental health, that is emotional, psychological and social well-being. There is growing recognition that enhancing positive mental health is an important objective in public mental health (Fledderus, Bohlmeijer, Smit \& Westerhof, 2011; Jané-Llopis \& Barry, 2005; Keyes, 2005; Keyes, Dhingra \& Simoes, 2010). No significant differences were found for quality of life, however. This might be explained by our method of measuring quality of life. The EQ-5D (Brooks, 1996) focuses on health-related quality of life across various health dimensions, which makes it unlikely that effects in a single domain are sufficient to cause a change on the EQ-5D. After all, factors such as mobility and self-care are probably difficult to influence with a psychological intervention.

Overall, the results showed that life-review therapy is applicable to a broad target group of adults of 55 years and over experiencing moderate depressive symptomatology. Moderator analyses on depressive symptoms identified only two significant moderators, the personality trait of extraversion and the reminiscence function of boredom reduction. Our results demonstrate that the intervention is more effective for people having higher levels of extraversion. In addition to being more energetic, more extraverted individuals may be more able and inclined to share their feelings, emotions and thoughts with others and thus may benefit more from an intervention conducted in groups. Indeed, it has been reported that extraversion predicts a higher frequency of reminiscence in general, and in particular for conversational and relational purposes (Cappeliez \& O'Rourke, 2002). More extraverted individuals may also be more inclined to look at the "silver lining" and 
thus benefit more from the components of the intervention directed at positive memories. Furthermore, older adults demonstrating higher levels of boredom reduction profit less from the intervention. High levels of boredom reduction reminiscence reflect taking solace in the past in front of an unstimulating environment or an unrewarding future (Webster, 1997). Indeed, this function of reminiscence has been linked with the difficulty in finding meaning in the present and in seeking new goals in the future (Cappeliez \& O'Rourke, 2002). Importantly, the reminiscence function of boredom reduction has been strongly linked with negative physical and psychological health outcomes, including depression and anxiety (Cappeliez \& O'Rourke, 2006; Korte et al., 2011; O'Rourke et al., 2011). It is possible that older adults who have difficulty finding meaning in the present may profit more from interventions that focus on the here and now.

There has been some criticism that participating in a life-review intervention would stimulate bitterness and rumination in people with depression (Coleman, 2005; Cully et al., 2001). This study shows that this is not the case. Effects of the intervention were independent of level of depressive symptoms and prior MDEs. It is especially noteworthy that the personality trait of neuroticism and the use of reminiscence for bitterness revival were not found to moderate the effects of life-review therapy. Bitterness revival is the repeated recall of memories about personal crisis and conflicts (Webster, 1997). It is related to neuroticism and depression (Cappeliez et al., 2005; Cappeliez \& O’Rourke, 2002; 2006; Cully et al., 2001; Korte et al., 2011; Molinari, Cully, Kendjelic \& Kunik, 2001; Webster, 1994). It seems that participants with higher levels of depressive symptoms, neuroticism and bitterness revival are also capable of developing alternative stories on their lives that are more positive, meaningful and empowering. The general lack of moderating effects suggests that the intervention is broadly applicable to a variety of participants.

This is the first study to investigate the beneficial effects of combining life-review with narrative therapy. Although the usefulness of narrative therapy with older adults has been advanced (Kroph \& Tandy, 1998), its effects have not been examined experimentally. A central focus in narrative therapy is to develop alternative stories about one's life that are more agentic (Polkinghorne, 1996), richer and more inclusive of experience (Payne, 2000; White \& Epston, 1990). A recent qualitative study on the same intervention has identified these transformations in the self-narrative (Bohlmeijer et al., unpublished observations). One interesting line of investigation would be to collect and analyze stories about therapy to ascertain whether the increase of agency in life-stories is indeed a working mechanism (Adler, Skalina \& McAdams, 2008).

\section{Limitations}

Some limitations of this study must be acknowledged. First, the control condition being a care-as-usual waiting list condition, there was no control for the possible influence of non-specific factors, such as attention and social interaction. It would have been optimal to compare the targeted intervention with an active group intervention, or at least with an attention placebo comparison group. Second, given the relatively long follow-up period, it was not possible for ethical reasons to compare the intervention with care-as-usual during 
the second follow-up. Although the effects in the intervention group were maintained at the 9-month follow-up, we cannot claim that these effects were uniquely caused by the intervention. Third, this study used self-report outcome measures, which might lead to biased findings. Future research could use more physiological outcome measures. A recent study shows, for example, that life-review is also effective in reducing high blood pressure (Houston, Allison, Sussman, Horn, Holt, Trobaugh et al., 2011). Fourth, as the participants in our study were young older adults, generalizations regarding age should be made with some caution. However, in line with meta-analytic evidence (Bohlmeijer et al., 2007), we found that, with respect to depressive symptoms, young older adults profit equally from reminiscence as old older adults.

\section{Conclusions}

This study shows that life-review therapy is effective as an early intervention for older adults with depressive symptomatology, that life-review therapy is effective under ecologically valid conditions, and that life-review therapy is effective for a large variety of older adults (with the possible exception of introverted people and those who make considerable use of reminiscence to escape the present). Although the effects of life-review therapy were maintained at the 9-month follow-up, it is recommended that the long-term effects be studied in randomized controlled conditions and that active control conditions be used to control for non-specific factors. 


\section{REFERENCES}

Adler, J. M., Skalina, L. M., \& McAdams, D. P. (2008). The narrative reconstruction of psychotherapy and psychological health. Psychotherapy Research, 18, 719-734.

Atwood, J. D., \& Ruiz, J. (1993). Social constructionist therapy with the elderly. Journal of Family Psychotherapy, 4, 1-32.

Beekman, A. T. F., Deeg, D. J., van Limbeek, J., Braam, A. W., de Vries, M. Z., \& van Tilburg, W. (1997). Criterion validity of the Center for Epidemiologic Studies Depression Scale (CES-D): Results from a community-based sample of older subjects in The Netherlands. Psychological Medicine, 27, 231-235.

Beekman, A. T. F., Penninx, B. W. J. H., Deeg, D. J. H., de Beurs, E., Geerings, S. W., \& van Tilburg, W. (2002). The impact of depression on the well-being, disability and use of services in older adults: A longitudinal perspective. Acta Psychiatrica Scandinavica, 105, 20-27.

Bluck, S., \& Levine, L. J. (1998). Reminiscence as autobiographical memory: A catalyst for reminiscence theory development. Ageing and Society, 18, 185-208.

Bohlmeijer, E. T., Westerhof, G. J., \& Emmerik-de Jong, M. (2008). The effects of integrative reminiscence on meaning in life: Results of a quasi-experimental study. Aging \& Mental Health, 12, 639-646.

Bohlmeijer, E., Kramer, J., Smit, F., Onrust, S., \& van Marwijk, H. (2009). The effects of integrative reminiscence on depressive symptomatology and mastery of older adults. Community Mental Health Journal, 45, 476-484.

Bohlmeijer, E., Roemer, M., Cuijpers, P., \& Smit, F. (2007). The effects of life-review on psychological well-being in older adults: A meta-analysis. Aging \& Mental Health, 11, 291-300.

Bohlmeijer, E., Smit, F., \& Cuijpers, P. (2003). Effects of reminiscence and life-review on late-life depression: A meta-analysis. International Journal of Geriatric Psychiatry, 18, 1088-1094.

Brewin, C. R. (2006). Understanding cognitive behaviour therapy: A retrieval competition account. Behaviour Research and Therapy, 44, 765-784.

Brooks, R. (1996). EuroQol: The current state of play. Health Policy, 37, 53-72.

Cappeliez, P. (2002). Cognitive-reminiscence therapy for depressed older adults in day hospital and long-term care. In J. D. Webster and B. K. Haight (Eds.), Critical Advances in Reminiscence Work: From Theory to Application (pp. 300-313). New York, NY: Springer.

Cappeliez, P., \& O'Rourke, N. (2002). Personality traits and existential concerns as predictors of the functions of reminiscence in older adults. Journal of Gerontology: Psychological Sciences, 57B, P116-P123.

Cappeliez, P., \& O'Rourke, N. (2006). Empirical validation of a model of reminiscence and health in later life. Journal of Gerontology: Series B: Psychological Sciences and Social Sciences, 61, 237-244.

Cappeliez, P., O'Rourke, N., \& Chaudhury, H. (2005). Functions of reminiscence and mental health in later life. Aging \& Mental Health, 9, 295-301.

Cohen, J. (1992). A power primer. Psychological Bulletin, 112, 155-159.

Cole, M. G., Bellavance, F., \& Masour, A. (1999). Prognosis of depression in elderly 
community and primary care populations: A systematic review and metaanalysis. American Journal of Psychiatry, 156, 1182-1189.

Coleman, P. G. (2005). Uses of reminiscence: Functions and benefits. Aging \& Mental Health, 9, 291-294.

Copeland, J. R., Beekman, A. T., Dewey, M. E., Hooijer, C., Jordan, A., Lawlor, B.A., et al. (1999). Depression in Europe. Geographical distribution among older people. British Journal of Psychiatry, 174, 312-321.

Costa Jr., P. T., \& McCrae, R. R. (1992). Revised NEO Personality Inventory (NEO PI-R) and NEO Five-Factor Inventory (NEO-FFI). Odessa, FL: Psychological Assessment Resources.

Cuijpers, P., de Graaf, R., \& van Dorsselaer, S. (2004). Minor depression: Risk profiles, functional disability, health care use and risk of developing major depression. Journal of Affective Disorders, 79, 71-79.

Cuijpers, P., Smit, F., \& van Straten, A. (2007). Psychological treatments of subthreshold depression: A meta-analytic review. Acta Psychiatrica Scandinavica, 115, 434-441.

Cuijpers, P., van Straten, A., Smit, F., Mihalopoulos, C., \& Beekman, A. (2008). Preventing the onset of depressive disorders: A meta analytic review of psychological interventions. American Journal of Psychiatry, 165, 1272-1280.

Cully, J. A., LaVoie, D., \& Gfeller, J. D. (2001). Reminiscence, personality, and psychological functioning in older adults. Gerontologist, 41, 89-95.

Dempster, A. P., Laird, N. M., \& Rubin, D. B. (1977). Maximum likelihood from incomplete data via the EM algorithm. Journal of the Royal Statistical Society, 39, 1-38.

Euroqol group (1990). EuroQol- a new facility for the measurement of health-related quality of life. Health Policy, 16, 199-208.

Fledderus, M., Bohlmeijer, E. T., Smit, F., \& Westerhof, G. J. (2011). Mental health promotion as a new goal in public mental health care: A randomized controlled trial of an intervention enhancing psychological flexibility. American Journal of Public Health, 100, 2372-2378.

Freedman, J., \& Combs, G. (1996). Narrative therapy: The social construction of preferred realities. New York, NY: W. W. Norton.

Gergen, K. J. (1985). The social constructionist movement in modern psychology. American Psychologist 40, 266-275.

Haight, B. K. (1992). Long-term effects of a structured life-review process. Journal of Gerontology, 47, 312-315.

Hoekstra, H. A., Ormel, H., \& de Fruyt, F. (1996). NEO Personality Questionnaires: NEOPI-R and NEO-FFI [in Dutch]. Lisse, The Netherlands: Swets \& Zeitlinger.

Holmes, T. H., \& Rahe, R. H. (1967). The Social Readjustment Rating Scale. Journal of Psychosomatic Research, 11, 213-218.

Houston, T. K., Allison, J. J., Sussman, M., Horn, W., Holt, C. L., Trobaugh, J., et al. (2011). Culturally appropriate storytelling to improve blood pressure: A randomized trial. Annals of Internal Medicine, 154, 77-84.

Jacobson, N. S., \& Truax, P. (1991). Clinical significance: A statistical approach to defining meaningful change in psychotherapy research. Journal of Consulting and Clinical Psychology, 59, 12-19. 
Jané-Llopis, E., \& Barry, M. M. (2005). What makes mental health promotion effective? Promotion and Education, 12, 47-54.

Keyes, C. L. M. (2005). Mental illness and/or mental health? Investigating axioms of the complete state model of health. Journal of Consulting and Clinical Psychology, 73, 539-548.

Keyes, C. L. M., Dhingra, S. S., \& Simoes, E. J. (2010). Change in level of positive mental health as a predictor of future risk of mental illness. American Journal of Public Health, 100, 2366-2371.

Keyes, C. L. M., Wissing, M., Potgieter, J. P., Temane, M., Kruger, A., \& van Rooy, S. (2008). Evaluation of the mental health continuum-short form (MHC-SF) in Setswana-speaking South Africans. Clinical Psychology and Psychotherapy, 15, 181-192.

Korte, J., Bohlmeijer, E. T., Westerhof, G. J., \& Pot, A. M. (2011). Reminiscence and adaptation to critical life-events in older adults with mild to moderate depressive symptoms. Aging and Mental Health, 15(5), 638-646.

Korte, J., Bohlmeijer, E.T., \& Smit, F. (2009). Prevention of depression and anxiety in later life: design of a randomized controlled trial for the clinical and economic evaluation of a life-review intervention. BMC Public Health, 9, 250.

Kroph, N. P., \& Tandy, C. (1998). Narrative therapy with older clients: The use of a 'meaning-making' approach. Clinical Gerontologist, 18, 3-16.

Lamers, S. M. A., Westerhof, G. J., Bohlmeijer, E. T., ten Klooster, P. M., \& Keyes, C. L. M. (2011). Evaluating the psychometric properties of the Mental Health Continuum-Short Form (MHC-SF). Journal of Clinical Psychology, 67, 99-110.

Licht-Strunk, E., van der Windt, D. A, van Marwijk, H. W., de Haan, M., \& Beekman, A. T. (2007). The prognosis of depression in older patients in general practice and the community. A systematic review. Family Practice, 24, 168-180.

McDougall, F. A., Kvaal, K., Matthews, F. E., Paykel, E., Jones, P. B., Dewey, et al. (2007). Prevalence of depression in older people in England and Wales: The MRC CFA Study, Psychological Medicine, 37, 1787-1795.

Molinari, V., Cully, J. A., Kendjelic, E. M., \& Kunik, M. E. (2001). Reminiscence and its relationship to attachment and personality in geropsychiatric patients. International Journal of Aging and Human Development, 52, 173-184.

O'Rourke, N., Cappeliez, P., \& Claxton, A. (2011). Functions of reminiscence and the psychological well-being of young-old and older adults over time. Aging \& Mental Health, 15, 272-281.

Payne, M. (2000). Narrative therapy. An introduction for counsellors. London: Sage.

Pinquart, M., Duberstein, P. R., \& Lyness, J. M. (2007). Effects of psychotherapy and other behavioral interventions on clinically depressed older adults: A metaanalysis. Aging \& Mental Health, 11, 645-657.

Polkinghorne, D. E. (1996). Transformative narratives: From victimic to agentic life plots. American Journal of Occupational Therapy, 50, 299-305.

Radloff, L.S. (1977). The CES-D scale: A self-report depression scale for research in the general population. Journal of Applied Psychological Measurement, 1, 385-401.

Serrano, J. P., Latorre, J. M., Gatz, M., \& Montanes, J. (2004). Life-review therapy using autobiographical retrieval practice for older adults with depressive symptomatology. Psychology and Aging, 19, 270-277. 
Sheehan, D. V., Lecrubier, Y., Sheehan, K.H., Amorim, P., Janavs, J., \& Weiller, E. (1998). The Mini-International Neuropsychiatric Interview (MINI): The development and validation of a structured diagnostic psychiatric interview for DSM-IV and ICD10. Journal of Clinical Psychiatry, 59, 22-33.

Smit, F., Ederveen, A., Cuijpers, P., Deeg, D., \& Beekman, A. (2006). Opportunities for cost-effective prevention of late-life depression. An epidemiological approach. Archives of General Psychiatry, 63, 290-296.

Spinhoven, P. H., Ormel, J., Sloekers, P. P. A., Kempen, G. I. J. M., Speckens, A. E. M., \& van Hemert, A.M. (1997). A validation study of the Hospital Anxiety and Depression Scale (HADS) in different groups of Dutch subjects. Psychological Medicine, 27, 363-370.

Statistics Netherlands (1989). Health Interview Questionnaire. Heerlen: Statistics Netherlands.

Steunenberg, B., Beekman, A. T., Deeg D. J., Bremmer, M. A., \& Kerkhof, A. J. (2007). Mastery and neuroticism predict recovery of depression in later life. American Journal of Geriatric Psychiatry, 15, 234-242.

van Vliet, I. M., \& de Beurs, E. (2007). The MINI-International Neuropsychiatric Interview (M.I.N.I.). A brief structured diagnostic psychiatric interview for DSM-IV and ICD10 psychiatric disorders [in Dutch]. Tijdschrift voor Psychiatrie, 49, 393-397.

Watt, L. M., \& Cappeliez, P. (2000). Integrative and instrumental reminiscence therapies for depression in older adults: Intervention strategies and treatment effectiveness. Aging \& Mental Health, 4, 166-177.

Webster, J. D. (1994). Predictors of reminiscence. A lifespan perspective. Canadian Journal on Aging, 13, 66-78.

Webster, J. D. (1997). The Reminiscence Functions Scale: A replication. International Journal of Aging and Human Development, 44, 137-148.

Westerhof, G. J., Bohlmeijer, E. T., \& Webster, J. D. (2010). Reminiscence and mental health: A review of recent progress in theory, research, and intervention. Ageing and Society, 30, 697-721.

White, M. (2007). Maps of narrative therapy. New York: W. W. Norton.

White, M., \& Epston, D. (1990). Narrative means to therapeutic ends. New York, NY: W. W. Norton.

Williams, J. M., Barnhofer, T., Crane, C., Herman, D., Raes, F., Watkins, E., et al. (2007). Autobiographical memory specificity and emotional disorder. Psychological Bulletin, 133, 122-148.

Wink, P., \& Schiff, B. (2002). To review or not to review? The role of personality and lifeevents in life review and adaptation to older age. In J. D. Webster \& B. K. Haight (Eds.), Critical advances in reminiscence work: From theory to application (pp. 44-60). New York: Springer.

Wong, P. T. (1995). The processes of adaptive reminiscence. In B. K. Haight \& J. D.

Webster (Eds.), The art and science of reminiscing: Theory, research, methods, and applications (pp. 23-35). Washington, DC: Taylor \& Francis.

Zigmond, A. S., \& Snaith, R. P. (1983). The hospital anxiety and depression scale. Acta Psychiatrica Scandinavica, 67, 361-370. 


\section{COSTAEFECTIVENESS OF LIFE-REVIEW} FOR OLDER ADULTS WITH MODERATE DEPRESSIVE SYMPTOMATOLOGY: A PRAGMATIC RANDOMIZED CONTROLLED TRIAL review for older adults with moderate depressive symptomatology: A pragmatic randomized controlled trial. 


\section{CHAPTER}

\section{ABSTRACT}

Life-review has been established as an evidence-based treatment of depression in later life. This study investigate the cost-effectiveness of life-review compared to careas-usual. An economic evaluation alongside a randomized controlled trial was carried out, comparing life-review $(n=100)$ to care-as-usual $(n=102)$. Individuals of 55 years and over, with moderate depressive symptomatology, were included. Treatment response was defined as a statistically reliable reduction of depressive symptoms on the Center for Epidemiologic Studies Depression scale. Total per-participant costs encompassed intervention costs, costs of receiving other treatments, participants' out-of-pocket expenses and costs stemming from production losses, and were expressed in (2009) euro (€). At 6 months follow-up, treatment response was $54.0 \%$ and $27.5 \%$ respectively in the life-review and usual care condition. The difference in effectiveness was statistically significant at $p=.001$ (2-tailed). In the respective conditions the costs were $€ 5,550$ and $€ 3,162$, with the higher costs in the intervention arm of the trial. The incremental costeffectiveness was $€ 8,675$ per improved participant. The findings suggest that offering lifereview rather than care as-usual almost doubles the likelihood of a favourable outcome. However, the better clinical outcomes are achieved at greater costs. The conclusion that life-review offers good value for money is sensitive to the willingness to pay for a favourable treatment response. It is recommended that life-review is delivered by a single therapist and in larger groups as this may improve the cost-effectiveness of this intervention. 


\section{INTRODUCTION}

Clinical depression in later life is highly prevalent (Copeland, Beekman, Dewey, Hooijer, Jordan, Lawlor et al., 1999; Djernes, 2006; McDougall, Kvaal, Matthews, Paykel, Jones, Dewey et al., 2007), is characterized by poor prognosis (Cole, Bellavance \& Masour, 1999; Beekman, Penninx, Deeg, de Beurs, Geerings \& van Tilburg, 2002; LichtStrunk, van der Windt, van Marwijk, de Haan \& Beekman, 2007) and is associated with substantial societal costs (Smit, Cuijpers, Oostenbrink, Batelaan, de Graaf \& Beekman, 2006). The most important risk factor for developing clinical depression is sub-threshold depression (Cuijpers, de Graaf \& van Dorsselaer, 2004; Smit, Ederveen, Cuijpers, Deeg \& Beekman, 2006). Therefore, early interventions directed at older adults with depressive symptomatology are of the utmost importance. Meta-analytic evidence indicates that early interventions for older adults with depressive symptoms are promising in preventing depression (Cuijpers, van Straten, Smit, Mihalopoulos \& Beekman, 2008). Economic costs associated with sub-threshold depression are just a little less than those of major depression (Cuijpers, Smit, Oostenbrink, de Graaf, ten Have \& Beekman, 2007). Hence, preventing depression in later life is also important from an economic point of view.

There is substantial meta-analytic evidence that life-review interventions are an effective treatment for depression in later life (Bohlmeijer, Smit \& Cuijpers, 2004; Pinquart, Duberstein \& Lyness, 2007; Pinquart \& Forstmeier, 2012). It involves a structured evaluation of one's own life, aimed at integrating negative experiences, resolving conflicts, and giving a positive meaning to life (Westerhof, Bohlmeijer \& Webster, 2010). Recent studies further corroborate the effectiveness of life-review as an early intervention for depression, in ecologically valid contexts (Korte, Bohlmeijer, Cappeliez, Smit \& Westerhof, 2012; Pot, Bohlmeijer, Onrust, Melenhorst, Veerbeek \& de Vries, 2010; Westerhof et al., 2010). We now investigate the cost-effectiveness of life-review compared to care-asusual. To our knowledge, this is the first economic evaluation of a preventive life-review intervention in late-life depression.

\section{MATERIALS AND METHODS}

\section{Study design}

The cost-effectiveness analysis was conducted as an a priori component alongside a pragmatic randomized controlled trial, comparing clinical outcomes and economic costs between two groups of participants aged 55 years and over with subclinical, mild and moderate depressive symptomatology. The experimental group $(n=100)$ received a life-review intervention to reduce depressive symptoms. The control group $(n=102)$ received care-as-usual while being waitlisted for life-review six months after baseline. All participants completed measures at baseline $(t 0)$ and follow-up $(t 1$; six months after baseline, three months after the end of intervention). This study was approved by the METiGG, a medical ethics committee for research in mental health-care settings in The Netherlands. In addition, this study has been registered in the Netherlands Trial Register, 
the primary Dutch register for clinical trials $(T C=1860)$. The trial has been described in detail elsewhere (Korte, Bohlmeijer \& Smit, 2009).

\section{Participants}

Participants were recruited in collaboration with Dutch mental health services through advertisements in newspapers and information booklets, plus a radio interview and commercials. Applicants were referred to a dedicated website, where they could find information about the study. Thereafter, applicants were assessed for eligibility and were required to sign an informed consent form. In total, fourteen Dutch mental health-care services, in both urban and rural areas, participated in this study. They were responsible for the intake procedure, in which inclusion and exclusion criteria were examined. To be included in the trial, participants had to present with a score of ten or higher on the Center for Epidemiologic Studies Depression (CES-D) scale (Radloff, 1977). Applicants were excluded if diagnosed with a current severe major depressive episode (MDE; eight or nine out of nine symptoms in total) or with a moderate to high suicide risk, as measured with the Mini International Neuropsychiatric Interview (MINI; Sheehan, Lecrubier, Sheehan, Amorim, Janavs, Weiller et al., 1998). Applicants were also excluded if they had a score of nine or lower on the CES-D (Radloff, 1977), had started taking antidepressant medication or benzodiazepines recently (within the previous two months), were currently receiving any psychological treatment, or if the health-care professionals found other serious psychopathology, in which case they were referred for psychological treatment. A total of 274 people initially agreed to participate, of whom 225 (82.1\%) met the inclusion criteria. Of these, 23 applicants (10.2\%) withdrew their consent prior to randomization (see Figure 1).

\section{Power analysis}

A power calculation indicated that a minimum of 80 participants were required in each condition at follow-up to demonstrate an effect size of at least .35 (Cohen's d) in a onesided test at $\alpha=.05$ and a power of $(1-\beta)=.80$. The power calculation was conducted in Stata 7.0 (StataCorp LD, USA). Anticipating a drop-out rate of $20 \%$ between baseline and the end of the study, 100 participants were sought for each condition at baseline. This requirement was met, with 100 participants in the life-review therapy condition and 102 participants in the care-as-usual condition.

\section{Randomization}

Participants were randomly assigned either to life-review therapy or to care-as-usual, by means of a centrally conducted randomization process executed by an independent statistician. The randomization was stratified by gender and presence of current major depressive episode, using a computer-generated sequence of numbers. 
Figure 1. Flow of participants.

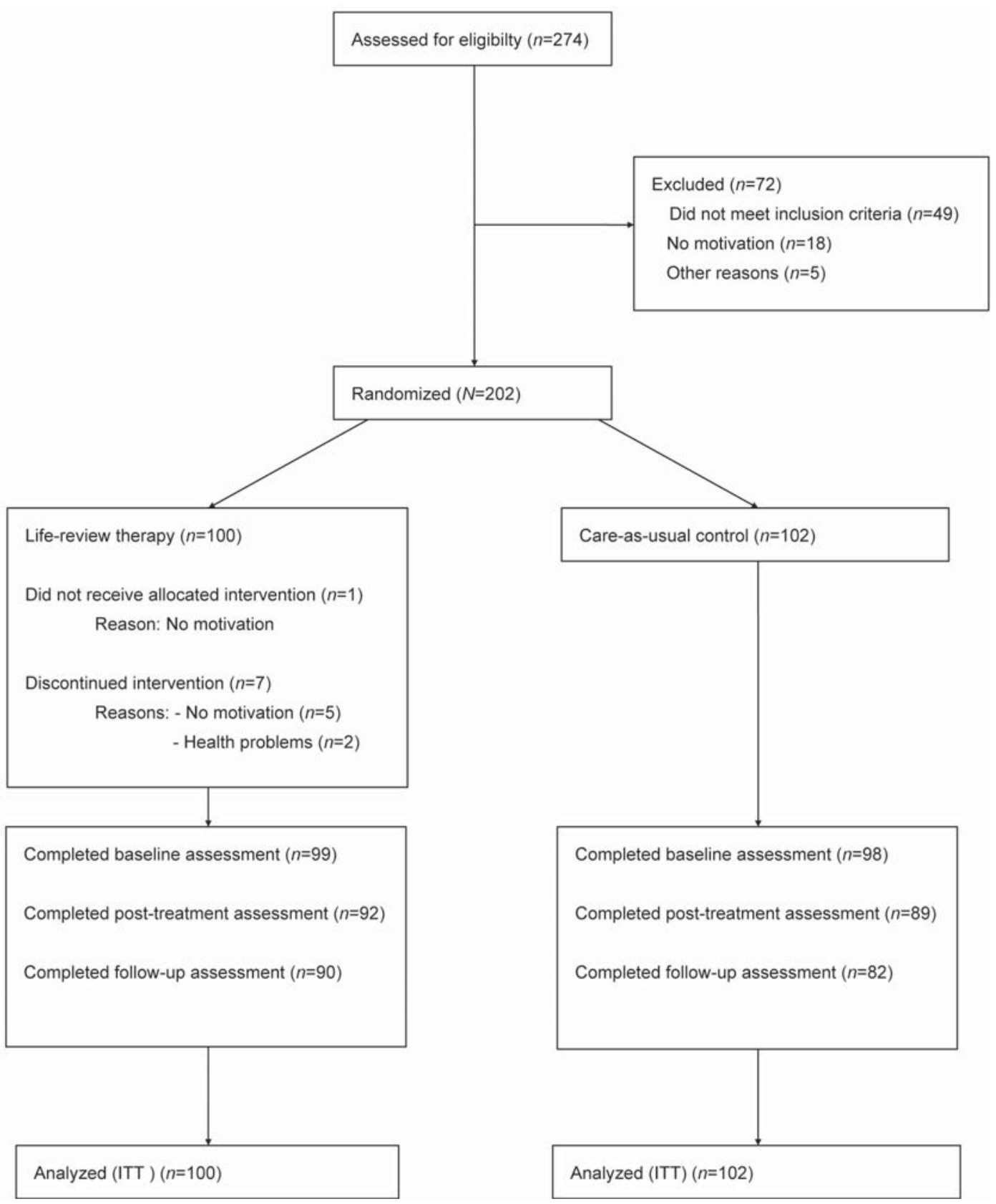




\section{Intervention and control group}

The life-review intervention, "The stories we live by", adapted from a pilot study (Bohlmeijer, Kramer, Smit, Onrust \& van Marwijk, 2009) was conducted in groups of four to six participants and consisted of eight weekly sessions of two hours. The intervention has three core elements. First, the integration of difficult life-events from the past; second, the development of meaningful and agentic life-stories that help the participants to better cope with present life-events and to set new goals; third, the retrieval of specific positive memories which can serve as building blocks for the new life-stories. The first five intervention sessions were focused on various life themes: origin, youth, work and care, love and conflicts, loss and difficult times. Before each session, participants had to answer questions about those life themes. For each theme, the participants had to describe one difficult life-event they were still struggling with. They then had to answer questions to help them develop alternative stories that would help to integrate this lifeevent. During the intervention sessions, participants had the opportunity to exchange and discuss their experiences with one another. In the final three sessions, attention was given to some overarching themes that focused on creating an overview and on the near future. The intervention was guided by one clinical psychologist and one co-therapist (prevention worker) experienced in working with older adults. Before being allowed to offer the intervention, they were required to participate in a two-day training, and to adhere to the treatment protocol.

To check whether the intervention had been carried out as intended, one randomly selected session was audiotaped by all participating mental health-care services. Two researchers independently scored a treatment integrity measure and solved a few disagreements by consensus. The measure addressed five criteria that were crucial to the proper delivery of the intervention. First, the degree to which therapists followed the structure set out in the intervention protocol. Second, life-review therapy skills encompassed the therapists' skill in terms of asking the right therapeutic questions. Third, empathy measured whether therapists acknowledged participants' feelings and experiences. Fourth, curiosity assessed whether therapists had an attitude of curiosity and not-knowing. Fifth, group process involved the stimulation of a constructive interaction between participants, to create and elaborate alternative life-stories. All criteria were assigned a score of one (unsatisfactory), two (satisfactory) or three points (good), with a total score ranging from 5 to 15 (5-8=unsatisfactory, 9-11=satisfactory, 12-15=good). The therapists were scored as satisfactory (60\%: eight out of 14 sessions) or good (40\%: six out of 14 sessions).

Participants in the control condition received no intervention. However, they had unrestricted access to care-as-usual. In the context of this economic evaluation their health care uptake was monitored and can thus be described in some detail. After the conclusion of the RCT, the life-review intervention was offered to them.

\section{Central clinical outcome}

Treatment response was defined as a change of 5 or more points in a favourable direction on the Center for Epidemiologic Studies Depression (CES-D) scale (Radloff, 1977). This 
change corresponds with Jacobson and Truax' (1991) criterion for statistically reliable change and is interpreted as a favourable treatment response.

\section{Resource use and costing}

In this study, a societal perspective was adopted to assess treatment costs, meaning that all costs were considered, regardless of who incurred them. Therefore, all relevant costs were included: health service uptake costs (direct medical costs), patients' out-of-pocket expenses (direct non-medical costs), and production losses in paid work. Costs deriving from informal care were also included in the analysis.

Data on health care uptake in the previous four weeks were collected with the Trimbos and institute of Medical Technology Assessment Questionnaire for Costs associated with Psychiatric IIIness (TIC-P), a health service receipt survey which is widely used in economic evaluations in the Netherlands (Hakkaart-van Rooijen, van Straten, Doner \& Tiemens, 2002). To calculate the costs, units of resource use were multiplied by their standard full economic costs as reported in the Dutch guideline for health economic evaluations (Oostenbrink, Bouwmans, Koopmanschap \& Rutten, 2004). These costs were originally calculated for the reference year 2003, but were indexed for the year 2009 using the consumer price index from Statistics Netherlands (see Table 1). In order to assess the consequences of the intervention as a whole, costs were set with the timehorizon of one year. Therefore, costs will not be discounted.

Direct non-medical costs were computed as the participants' travel expenses to receive professional help and loss of leisure time which was valued at $€ 9.20$ per hour (Oostenbrink et al., 2004). Informal caregivers (friends, neighbours, family) may have spent time running errands for the study participants and their time was regarded as opportunity cost valued at $€ 9.20$ per hour.

Finally, the costs stemming from production losses in paid work were calculated from the number of days that people stayed away from their work (absenteeism) plus the number of days that were spent at work, but with reduced efficiency (presenteeism). Each hour of lost productivity was valued at €52.44 and €39.94 for men and women respectively, which reflects the average gender and age-specific contribution to the per-capita gross national income in the Netherlands by people aged 55 years and over (Oostenbrink et al., 2004). 
Table 1. Direct medical and direct non-medical costs by health service type

\begin{tabular}{|c|c|c|c|c|}
\hline \multirow[b]{2}{*}{ Health service type } & \multicolumn{2}{|c|}{$\begin{array}{l}\text { Direct medical costs } \\
\text { (in } 2009 € \text { ) }\end{array}$} & \multicolumn{2}{|c|}{$\begin{array}{l}\text { Direct non-medical costs } \\
\text { (in } 2009 € \text { ) }\end{array}$} \\
\hline & Unit & $\begin{array}{l}\text { Unit cost } \\
\text { price }^{\mathrm{a}}\end{array}$ & km, hrs ${ }^{b}$ & $\begin{array}{l}\text { Unit cost } \\
\text { price }^{c}\end{array}$ \\
\hline General practitionerd & Contact & 22.15 & $1.8,1 \mathrm{~h}$ & 12.16 \\
\hline General practitioner at home & Contact & 44.31 & $0,0 \mathrm{~h}$ & 0.00 \\
\hline Company doctor & Contact & 23.30 & $17.6,0.5 \mathrm{~h}$ & 7.66 \\
\hline Social worker & Contact & 49.35 & $5,2 \mathrm{~h}$ & 21.83 \\
\hline $\begin{array}{l}\text { Private practice psychotherapist, } \\
\text { psychiatrist }\end{array}$ & Contact & 83.36 & $5,2 \mathrm{~h}$ & 21.83 \\
\hline Prevention worker & Contact & 100.34 & NA & NA \\
\hline Regional mental health service & Contact & 136.00 & $10,3 \mathrm{~h}$ & 31.82 \\
\hline Physiotherapist & Contact & 24.95 & $1.8,2 \mathrm{~h}$ & 21.27 \\
\hline Mental hospital & Contact & 96.52 & $12,4 \mathrm{~h}$ & 41.28 \\
\hline Medical specialist general hospital & Contact & 61.43 & $7,3 \mathrm{~h}$ & 31.29 \\
\hline Medical specialist teaching hospital & Contact & 109.68 & $12,3 \mathrm{~h}$ & 32.17 \\
\hline Alternative treatment ${ }^{9}$ & Contact & 52.65 & $5,1 \mathrm{~h}$ & 12.73 \\
\hline Home care & Hour & 33.67 & NA & 0.00 \\
\hline Informal care (family, friends) h & Hour & 9.20 & NA & 0.00 \\
\hline
\end{tabular}

${ }^{a}$ Integral unit cost prices (cf., Oostenbrink et al., 2004).

${ }^{b}$ Based on average distances (in special tariff taxi and public transport zones) and travel + waiting + treatment times (in hrs) for receiving treatment (cf., Oostenbrink et al., 2004).

${ }^{c}$ Costs $=(0.18$ * \#km) $+2.74+(9.20$ * \#hrs). With $0.18=$ cost per km; $2.74=1 \mathrm{~h}$ parking time; 1 zone=3km (average between taxi and public transport zones). $1 \mathrm{~h}$ time $=€ 9.20$ (Oostenbrink et al., 2004).

d Average direct medical cost price per GP surgery contact=€ 22.15. However, the majority of contacts of older people with their GP concern "medication repeat prescriptions"=€10.47 and the true type of contac in this study is unknown. Therefore we may assume that the real direct medical costs of GP contacts are probably lower.

e No parking costs assumed.

f Only Included in the calculation of the intervention costs.

g Own calculation, valued as average of homoeopath and acupuncturist (cf., Oostenbrink et al., 2004).

${ }^{\mathrm{h}}$ Valued as domestic help (cf., Oostenbrink et al., 2004).

Note. NA, not applicable. All prices are indexed for 2009 with the Consumer Price Index (CPI), source: http://statline.cbs.nl/statweb/. 


\section{Per-participant intervention costs}

The costs of offering the intervention consist of the recruitment costs of $€ 10$ per successfully recruited participant; 1 intake lasting 1 hour (+30 minutes for administration) per intake by 1 clinical psychologist at $€ 136.00 / h$; 9 Sessions (+15 min preparation) per session by 1 clinical psychologist at $€ 136.00 / \mathrm{h}$ and 1 prevention worker at $€ 100,34 / \mathrm{h}$ for eight 2 hour sessions plus one follow-up session in groups of 5 (range 4-6) participants. This amounts to $€ 1,171$ per participant.

The participants also incurred some costs. These are: 1 course book at $€ 25$; time costs (travel, course time, home work) of $50 \mathrm{~h}$ at $€ 9.20 / \mathrm{h}$; costs of travelling to the course at $€ 5$ per return trip for 1 intake and 9 sessions; and the costs of parking at $€ 2.50$ per hour for the intake plus 9 sessions ( 21.75 hours). These costs amount to $€ 589.38$ per participant.

The total per-participant costs are therefore $€ 1171.18+€ 589.38=€ 1,761$.

\section{Analysis}

\section{Statistical analyses}

The analysis was carried out on an intention-to-treat basis. Therefore, all participants were analyzed in the condition to which they were randomized and missing data were imputed.

Missing clinical endpoints (CES-D scores) were replaced using Missing Value Analysis in PASW 18 to replace missing data by their most likely value under the expectation-maximization (EM) algorithm (Dempster, Laird \& Rubin, 1977). Hence, all participants who were randomized were included in the subsequent analyses. The total percentage of missing data was $15.1 \%$, due to unanswered items $(2.4 \%)$ or incomplete assessments. Since a comparison of results based on the imputed data (intention-to-treat sample) versus the observed data (completers-only sample) revealed similar outcomes, only the results from the intention-to-treat analyses were reported.

The dependent variable was treatment response at follow-up. Participants manifesting a reliable change were coded 1 (implying favourable treatment response, "success") or else 0 ("failure"). The differences in treatment response between the conditions were evaluated using a linear probability model where the treatment dummy was regressed on the treatment response. The analysis took into account that the observations were clustered, as participants were "nested" in each of the 14 different regional mental health services. Therefore, robust standard errors were computed using the first-order Taylor-series linearization method as implemented in Stata version 8.2. Statistical tests were deemed to be significant at $p<.05$ (2-tailed).

\section{Cost-effectiveness analyses}

Missing cost data (between $1 \%$ and $5 \%$ depending on the type of costs) were imputed using regression imputation as implemented in Stata with costs as the dependent variable, and age, gender, employment status, education, baseline CES-D depressive symptom levels, and randomization status as predictor variables. In the non-imputed dataset, the 
average total per-participant cost at follow-up was $€ 5,160(S D=4660)$ in the intervention group, and $€ 2,892$ ( $S D=6832$ ) in the care-as-usual group). After imputation, the average total per-participant cost at follow-up was $€ 5,550(S D=5110)$ in the intervention group and $€ 3,162$ ( $S D=6025)$ in the care-as-usual group.

The mean total costs for each of the conditions were calculated, both at baseline and 6 month follow-up. Since mean baseline costs were quite similar across both conditions, the incremental costs could be calculated as the between-group difference at follow-up.

Both the incremental costs and incremental effects were used to calculate the incremental cost-effectiveness ratio (ICER). The ICER was calculated as (C1-C0)/(E1-E0), where $\mathrm{C}$ is the average annual per capita cost and $\mathrm{E}$ is the proportion of people who had a reliable change in depressive symptoms in the experimental and control conditions (subscripted 1 and 0 respectively). The ICER describes the incremental costs for gaining one additional treatment response.

Non-parametric bootstraps were used to simulate 2,500 ICERs that were plotted on the cost-effectiveness plane (see Figure 2). In this way, the degree of uncertainty associated with the ICER is captured. To be more precise, each simulated ICER can be plotted on one of the four quadrants of the ICER plane. In the NE-quadrant the intervention produces superior health gains at additional costs relative to routine care. In the NWquadrant less health is produced for additional costs. Clearly, this is the worst possible outcome, and the intervention is then "dominated" by the usual care condition. In the SW-quadrant less health is produced, but there are some cost-savings. And finally, in the SE-quadrant the intervention generates superior health gains (relative to the comparator condition) and does so for less costs; the intervention then "dominates" the comparator condition.

It is often seen that a new intervention falls in the NE-quadrant, because the intervention is successful in generating better health outcomes albeit at higher costs. To decide whether the intervention offers good value for money, we need to know the willingness to pay (WTP) for the health gain. However, the WTP is an unknown quantity. We therefore used a series of WTP ceilings and calculated the probability that the intervention is more acceptable than usual care from a cost-effectiveness point of view for each of the WTP ceilings. The relationship between the probability that we must conclude that the new intervention is more cost-effective and each of the WTP ceilings can be plotted in an ICER acceptability curve where increasing WTP levels are placed on the horizontal axis, while on the vertical axis the probability is placed of finding the intervention more acceptable from a cost-effectiveness point of view (see Figure 3).

\section{Sensitivity analysis}

The single most important cost-driver was the intervention: $€ 1,761$ per participant. It is also a cost-driver surrounded by some uncertainty. To ascertain the robustness of our findings, all analyses were repeated for alternative scenarios: in one scenario the costs of the intervention were increased by $20 \%$; in the other four the costs were decreased by $20 \%$ up to $80 \%$. 
The intervention costs can also be changed by altering the intervention's format, such as increasing the group size, or reducing therapist's time. In the current situation, two therapists participated in all sessions, while the group of participants was rather small. This is an intensive and costly form of therapist guidance. Therefore, all analyses were repeated in two different, less costly scenarios. In the first scenario the intervention was offered by a single clinical psychologist (instead of both a clinical psychologist and prevention worker). In the second scenario the intervention was conducted by a clinical psychologist in groups consisting of 8 instead of 5 (4-6) persons. All cost-effectiveness analyses were repeated for the two scenarios under four different assumptions. In the first assumption, reducing the costs has no influence on the effectiveness of the intervention. The last three assumptions were more conservative as we assumed that the number of treatment successes was reduced by $5 \%, 10 \%$ or $15 \%$.

\section{$\overline{\text { RESULTS }}$}

\section{Sample}

The participants had a mean age of 63.3 years $(S D=6.48$, range $55-83)$ and were predominantly female (76.7\%). Their education was distributed evenly across three categories: less than 11 years (36.6\%), 11 to 14 years (33.7\%), and more than 14 years (29.9\%). A minority of the participants still had a paid job (15.8\%). On average, participants reported one to two chronic medical conditions $(M=1.49, S D=1.36)$ and they had experienced two to three critical life-events in the last three years $(M=2.34$, $S D=1.54)$. Participants at baseline scored an average of $20.5(S D=8.6)$ on the CES-D (scale from 0 to 60 for depressive symptoms, reflecting moderate depressive symptoms. There were no significant differences in socio-demographic or clinical characteristics between the intervention and the usual care groups, indicating that randomization had resulted in comparable groups. At baseline, the mean total costs were $€ 601$ (SD=559) in the intervention group and $€ 618(S D=531)$ in the usual care group, indicating that randomization produced evenly distributed costs across the conditions.

\section{Incremental costs}

At follow-up, the average total per-participant costs were $€ 5,550$ in the intervention group and $€ 3,162$ in the care-as-usual group. The incremental costs were therefore $€ 5,550$ $€ 3,162=€ 2,388$.

\section{Incremental effectiveness}

In the intervention group 54/100=.540 (54.0\%) responded well to the treatment. In the care-as-usual group this was $27 / 102=.265$ (26.5\%). The difference in effectiveness was therefore $.540-.265=.275$ (27.5\%), likelihood ratio=2.0, NNT=3.6. This difference was evaluated using a linear probability model while taking into account the clustered data 
structure. In this model the 95\% confidence interval of the risk difference ranged from .36 to .415 and the mean risk difference of .275 was associated with a robust standard error of .065, $t=4.24$ and $p=.001$ (2-tailed), indicating that the intervention was superior.

\section{Incremental cost-effectiveness}

In this study the incremental costs were €2,388 and the incremental effects .275. Therefore, the mean incremental cost-effectiveness ratio (ICER) was estimated to be $€ 2,388 / .275=€ 8,675$ for an additional treatment response. Using the 2,500 bootstraps, the median ICER and its 95\% confidence interval could be estimated as $€ 8,873$ ( $95 \% \mathrm{Cl}$ : $€ 1,968$ to $€ 23,023)$.

On the incremental cost-effectiveness plane, each dot represents one simulated ICER. Of these, $95.2 \%$ fall in the NE-quadrant, indicating a probability of $95.2 \%$ that by applying the intervention a health gain is produced, but at additional costs. In addition, another $4.8 \%$ of the simulated ICERs fall into the SE-quadrant, indicating that more health is generated for less costs by the intervention relative to care-as-usual (see Figure 2).

Figure 2. Distribution of bootstrapped ICERs $(n=2,500)$ on the cost-effectiveness plane, primary analysis

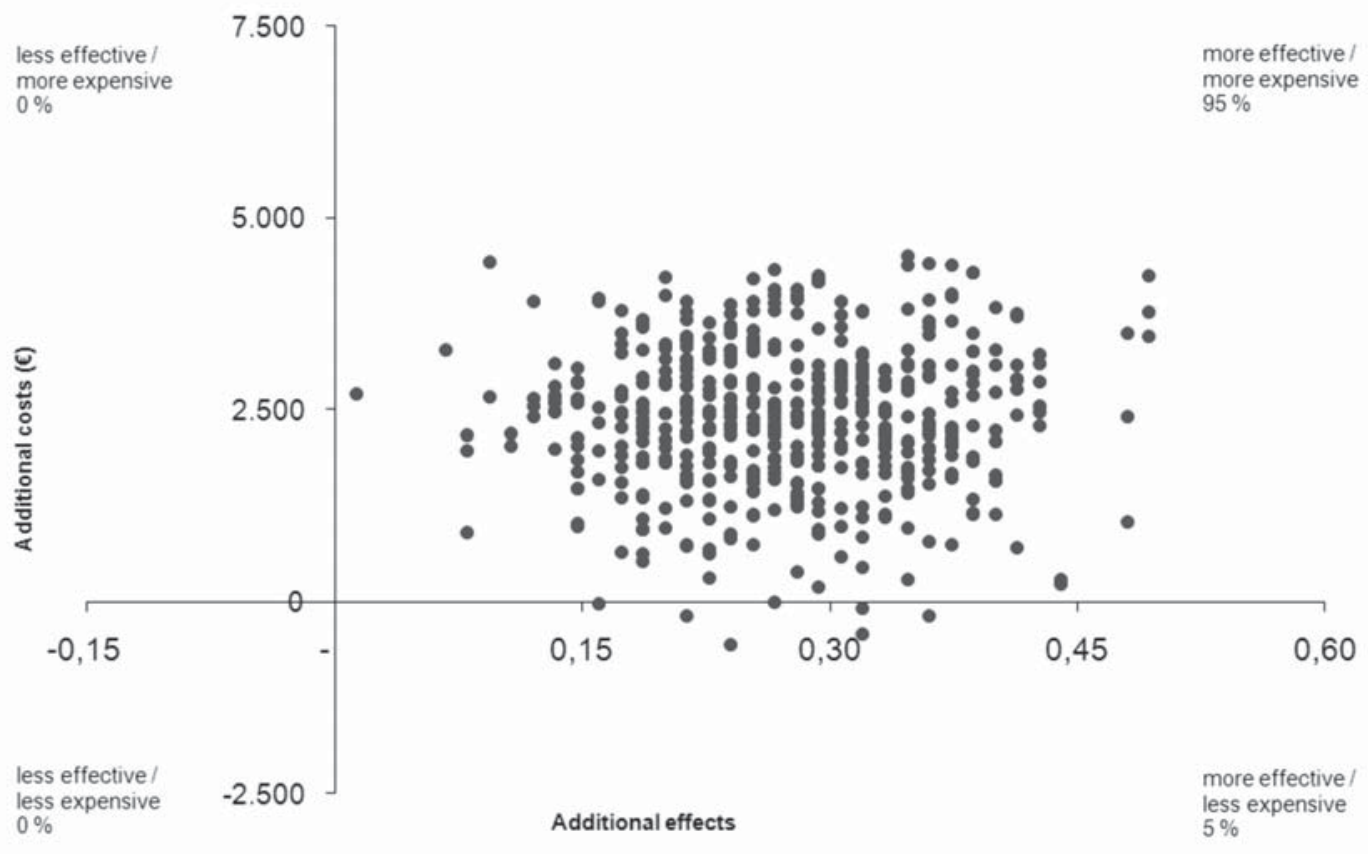




\section{Acceptability}

The incremental cost-effectiveness acceptability curve suggests that when the willingness to pay for a favourable treatment response is $€ 10,000$, $€ 20,000$, or $€ 30,000$ then the lifereview intervention would have a probability of being regarded as more cost-effective than usual care by $57.2 \%, 93.3 \%$ and $99.0 \%$, respectively (Figure 3). It can now be concluded that the intervention must be regarded as acceptable from a cost-effectiveness point of view when there is a willingness to pay of $€ 10,000$ for generating one additional treatment response.

Figure 3. Cost-effectiveness acceptability curve: Probability that the intervention is acceptable (y-axis) relative to routine primary care given varying thresholds for willingness to pay (x-axis), based on 2,500 bootstrap replications

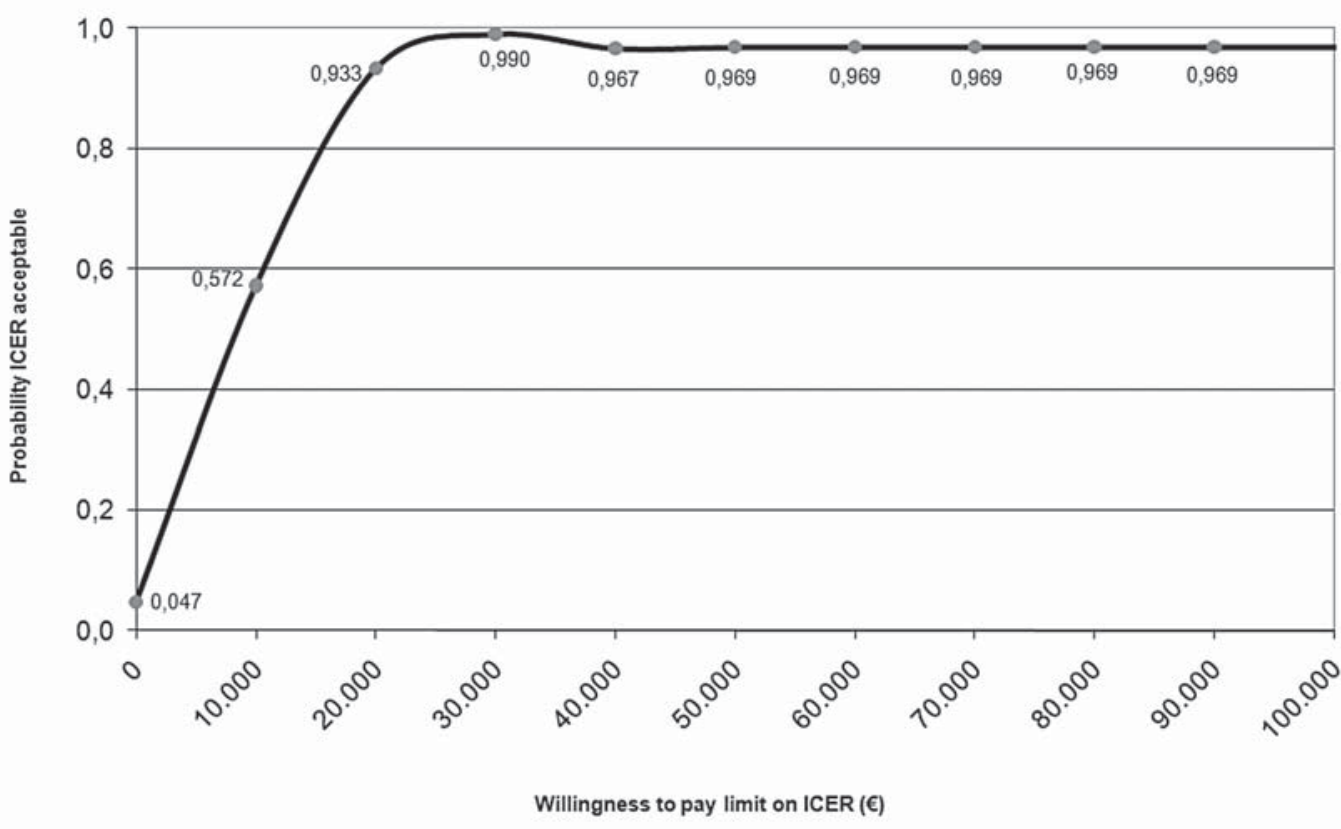

\section{Sensitivity analysis}

It appeared that increasing (by 20\%) or decreasing (by $20 \%, 40 \%, 60 \%$ or $80 \%$ ) the intervention costs did not affect the overall conclusion that the intervention produces better health at additional costs, compared with routine primary care (Table 2).

We compared the standard intervention with two less costly scenarios, the first in which the standard intervention was offered by a single therapist, and the second in which the intervention was implemented by a single therapist in (larger) groups of 8 
persons (Table 2). When the assumption was made that a less costly intervention has no influence on the effectiveness, both scenarios were more cost-effective than the standard intervention. When it was assumed that a less costly intervention reduces the number of treatment successes (by 5\%,10\% and 15\% respectively), the first scenario was still more cost-effective than the standard intervention at a $5 \%$ reduction, while the second scenario was still more cost-effective at a 10\% reduction in effectiveness.

Table 2. Sensitivity analysis: Incremental cost-effectiveness for adjusted costs of the lifereview intervention and for different scenarios

\begin{tabular}{|c|c|c|c|c|c|c|c|c|c|c|c|c|c|c|}
\hline & \multirow{2}{*}{$\begin{array}{l}\text { Standard } \\
\text { life- } \\
\text { review } \\
\text { inter- } \\
\text { vention }\end{array}$} & \multicolumn{5}{|c|}{$\begin{array}{l}\text { Adjusted costs of life-review } \\
\text { intervention }\end{array}$} & \multicolumn{4}{|l|}{ Scenario 1} & \multicolumn{4}{|l|}{ Scenario 2} \\
\hline & & $+20 \%$ & $-20 \%$ & $-40 \%$ & $-60 \%$ & $-80 \%$ & $\begin{array}{l}\text { No change } \\
\text { in success } \\
\text { rate }\end{array}$ & $-5 \%$ & $-10 \%$ & $-15 \%$ & $\begin{array}{l}\text { No change } \\
\text { in success } \\
\text { rate }\end{array}$ & $-5 \%$ & $-10 \%$ & $-15 \%$ \\
\hline Cost, $€ \mathrm{a}$ & 2,388 & 2,740 & 2,036 & 1,684 & 1,332 & 980 & 1,982 & 1,982 & 1,982 & 1,982 & 1,775 & 1,775 & 1,775 & 1,775 \\
\hline Effect & .28 & .28 & .28 & .28 & .28 & .28 & .28 & .25 & .23 & .20 & .28 & .25 & .23 & .20 \\
\hline $\begin{array}{l}\text { ICER, } € \\
\text { (median b) }\end{array}$ & 8,675 & 9,954 & 7,396 & 6,116 & 4,837 & 3,558 & 7,198 & 8,079 & 8,796 & 10,147 & 6,448 & 7,237 & 7,879 & 9,090 \\
\hline \multicolumn{15}{|c|}{ Distribution cost-effectiveness plane } \\
\hline $\begin{array}{l}1^{\text {st }} \text { quadrant } \\
\text { (north-east) }\end{array}$ & .95 & .95 & .94 & .93 & .88 & .82 & .94 & .94 & .94 & .93 & .93 & .93 & .93 & .92 \\
\hline $\begin{array}{l}2^{\text {nd }} \text { quadrant } \\
\text { (inferior: } \\
\text { north-west) }\end{array}$ & .00 & .00 & .00 & .00 & .00 & .00 & .00 & .00 & .00 & .00 & .00 & .00 & .00 & .00 \\
\hline $\begin{array}{l}3^{\text {rd }} \text { quadrant } \\
\text { (south-west) }\end{array}$ & .00 & .00 & .00 & .00 & .00 & .00 & .00 & .00 & .00 & .00 & .00 & .00 & .00 & .00 \\
\hline $\begin{array}{l}4^{\text {th }} \text { quadrant } \\
\text { (dominant: } \\
\text { south-east) }\end{array}$ & .05 & .05 & .06 & .07 & .12 & .18 & .06 & .06 & .06 & .07 & .07 & .07 & .07 & .08 \\
\hline \multicolumn{15}{|c|}{ WTP ceiling, $\%$} \\
\hline$€ 10000$ & 57 & 49 & 70 & 79 & 80 & 88 & 71 & 64 & 57 & 44 & 76 & 68 & 58 & 53 \\
\hline$€ 20000$ & 93 & 92 & 95 & 96 & 96 & 96 & 95 & 91 & 91 & 84 & 95 & 92 & 90 & 87 \\
\hline$€ 30000$ & 99 & 99 & 99 & 99 & 99 & 99 & 99 & 98 & 97 & 94 & 100 & 99 & 98 & 95 \\
\hline
\end{tabular}

Note. (ICER) incremental cost-effectiveness ratio; (WTP) willingness to pay. Scenario 1: Intervention implemented

by a clinical psychologist only (instead of both a clinical psychologist and prevention worker); Scenario 2: Intervention implemented by a clinical psychologist only (instead of both a clinical psychologist and prevention worker) and groups of 8 (instead of 4-6) persons 


\section{$\overline{\text { DISCUSSION }}$}

\section{Main findings}

This study was conducted to assess the cost-effectiveness of life-review as an early intervention of depression in later life, compared with care-as-usual. The proportion of participants that had a reliable change in depressive symptoms was significantly higher in the intervention group; $54 \%$ against $26.5 \%$ in the control group. Each improved participant cost $€ 5,550$ in the life-review condition, which was almost twice as much as the amount of $€ 3,162$ in the usual care condition. The incremental cost-effectiveness is $€ 8,675$ per improved participant. So the life-review intervention produced superior health gains at additional costs relative to care-as-usual. However, it is often seen that a new intervention is successful in generating better health outcomes at higher costs. To decide whether the intervention offers good value for money requires an understanding of the willingness to pay (WTP) for a favourable treatment response. When the WTP is $€ 10,000$, then the probability that the intervention is deemed to be more cost-effective than usual care is $57 \%$. When the WTP is raised to $€ 20,000$, then this probability has risen to $93 \%$ of being the preferred option. This suggests that at WTP ceilings of $€ 10,000$ and above the intervention must be regarded as offering good value for money. With the same thresholds, sensitivity analyses confirmed the robustness of the findings. Besides, it was shown that the intervention would have been more cost-effective when delivered by a single clinical psychologist instead of both a clinical psychologist and prevention worker. The cost-effectiveness increased even more when, in addition, the intervention was delivered in groups of 8 (instead of 4-6) persons. These findings remained robust when taking into account that reduced therapist involvement might be associated with a lower effectiveness of the intervention, i.e., when it was assumed that the number of successes was reduced by $5 \%$ and $10 \%$ respectively. Therefore, we recommend that lifereview should be delivered by a single therapist and in larger groups as this may improve the cost-effectiveness.

To our knowledge this study is the first economic evaluation of life-review. For this reason, we have to compare our results with other cost-effectiveness studies on early interventions to prevent depression in older adults - which are also rather scarce. A recent study found that a stepped-care approach might be cost-effective in preventing depression and anxiety in later life (van 't Veer-Tazelaar, Smit, van Hout, van Oppen, van der Horst, Beekman et al., 2010). So it might be worth investigating if life-review is more cost-effective when offered as a second or third step in a stepped-care framework. Another option worthwhile investigating is offering life-review online. Internet-based interventions have the potential to reach target groups who cannot be reached by more traditional treatments (Cuijpers \& Schuurmans, 2007). Besides, a first promising study shows that online interventions can be effective in reducing both anxiety and depression in later life (Spek, Nyklícek, Smits, Cuijpers, Riper \& Keyzer, 2007), and in fact can be cost-effective (Warmerdam, Smit, van Straten, Riper \& Cuijpers, 2010). 


\section{Strengths and limitations}

The research findings should be interpreted with some caution. First, due to the relatively short time-horizon of 6 months we do not know how the cost-effectiveness of life-review is affected after a longer follow-up period. Second, costs and effects were based on an imputed dataset, which might have biased the findings. However, completers did not differ from non-completers on any of the baseline variables, which attests to the robustness of our findings. Third, the measures in our study were based on self-report, and this may have introduced recall bias. For example, self-report of health care uptake might be underestimated (van den Brink, van den Hout, Stiggelbout \& van de Velde, 2004). The strengths of this study were its first attempt to study the cost-effectiveness of life-review, its randomized design and the opportunity to study its effects in a natural setting. Furthermore, because we had the availability of health care utilization data it was possible to study the cost-effectiveness of life-review from a societal perspective.

\section{Concluding remarks}

This study is the first preliminary economic evaluation of a life-review intervention. Findings suggest that offering life-review rather than care-as-usual almost doubles the likelihood of a favourable outcome. These better clinical outcomes, however, are achieved at greater costs. The conclusion that life-review offers good value for money is sensitive to the WTP ceiling that one is willing to employ. One way to improve the cost-effectiveness may be to deliver life-review interventions by a single therapist and in larger groups. More studies with longer follow-up periods are needed to further substantiate the cost-effectiveness of life-review. 


\section{REFERENCES}

Beekman, A. T. F., Penninx, B. W. J. H., Deeg, D. J. H., de Beurs, E., Geerings, S. W., \& van Tilburg, W. (2002). The impact of depression on the well-being, disability and use of services in older adults: A longitudinal perspective. Acta Psychiatrica Scandinavica, 105, 20-27.

Bohlmeijer, E., Kramer, J., Smit, F., Onrust, S., \& van Marwijk, H. (2009). The effects of integrative reminiscence on depressive symptomatology and mastery of older adults. Community Mental Health Journal, 45, 476-484.

Bohlmeijer, E., Smit, F., \& Cuijpers, P. (2003). Effects of reminiscence and life-review on late-life depression: A meta-analysis. International Journal of Geriatric Psychiatry, 18, 1088-1094.

van den Brink, M., van den Hout, W. B., Stiggelbout, A., van de Velde, C. J., \& Kievit, J. (2004). Cost measurement in economic evaluations of health care: Whom to ask? Medical Care, 42, 740-746.

Cole, M. G., Bellavance, F., Masour, A. (1999). Prognosis of depression in elderly community and primary care populations: A systematic review and metaanalysis. American Journal of Psychiatry, 156, 1182-1189.

Copeland, J. R., Beekman, A. T., Dewey, M. E., Hooijer, C., Jordan, A., Lawlor, B.A., et al. (1999). Depression in Europe. Geographical distribution among older people. British Journal of Psychiatry, 174, 312-321.

Cuijpers, P., \& Schuurmans, J. (2007). Self-help interventions for anxiety disorders: An overview. Current Psychiatry Reports, 9, 284-290.

Cuijpers, P., de Graaf, R., \& van Dorsselaer, S. (2004). Minor depression: Risk profiles, functional disability, health care use and risk of developing major depression. Journal of Affective Disorders, 79, 71-79.

Cuijpers, P., Smit, F., Oostenbrink, J., de Graaf, R., ten Have, M., \& Beekman, A. (2007). Economic costs of minor depression: A population-based study. Acta Psychiatrica Scandinavica, 115, 229-236.

Cuijpers, P., van Straten, A., Smit, F., Mihalopoulos, C., \& Beekman, A. (2008). Preventing the onset of depressive disorders: A meta analytic review of psychological interventions. American Journal of Psychiatry, 165, 1272-1280.

Dempster, A. P., Laird, N. M., \& Rubin, D. B. (1977). Maximum Likelihood from incomplete data via the EM algorithm. Journal of the Royal Statistical Society, 39, 1-38.

Djernes, J. K. (2006). Prevalence and predictors of depression in populations of elderly: A review. Acta Psychiatrica Scandinavica, 113, 312-321.

Hakkaart-van Rooijen, L., van Straten, A., Doner, M., Tiemens, B. (2002). Trimbos/iMTA questionnaire for costs associated with psychiatric illness (TIC-P) (in Dutch). Rotterdam: Erasmus University.

Jacobson, N. S., \& Truax, P. (1991). Clinical significance: a statistical approach to defining meaningful change in psychotherapy research. Journal of Consulting and Clinical Psychology, 59, 12-19.

Korte, J., Bohlmeijer, E. T., Cappeliez, P., Smit, F., \& Westerhof, G. J. (2012). Lifereview therapy for older adults with moderate depressive symptomatology: a pragmatic randomized controlled trial. Psychological Medicine, 42, 1163-1173. 
Korte, J., Bohlmeijer, E. T., \& Smit, F. (2009). Prevention of depression and anxiety in later life: design of a randomized controlled trial for the clinical and economic evaluation of a life-review intervention. BMC Public Health, 9, 250.

Licht-Strunk, E., van der Windt, D. A, van Marwijk, H. W., de Haan, M., \& Beekman, A. T. (2007). The prognosis of depression in older patients in general practice and the community. A systematic review. Family Practice, 24, 168-180.

McDougall, F. A., Kvaal, K., Matthews, F. E., Paykel, E., Jones, P. B., Dewey, et al. (2007). Prevalence of depression in older people in England and Wales: The MRC CFA Study, Psychological Medicine, 37, 1787-1795.

Oostenbrink, J. B., Bouwmans, C. A. M., Koopmanschap, M. A., \& Rutten, F. F. H. (2004). Manual for costing: Methods and standard costs for economic evaluations in health care (in Dutch). Diemen: Health Insurance Board.

Pinquart, M., \& Forstmeier, S. (2012). Effects of reminiscence interventions on psychosocial outcomes: A meta-analysis. Aging \& Mental Health, 16, 541-558.

Pinquart, M., Duberstein, P. R., \& Lyness, J. M. (2007). Effects of psychotherapy and other behavioral interventions on clinically depressed older adults: A metaanalysis. Aging \& Mental Health, 11, 645-657.

Pot, A. M., Bohlmeijer, E. T., Onrust, S., Melenhorst, A. S., Veerbeek, M., \& De Vries, W. (2010). The impact of life-review on depression in older adults: A randomized controlled trial. International Psychogeriatrics, 22, 572-581.

Radloff, L.S. (1977). The CES-D scale: A self-report depression scale for research in the general population. Journal of Applied Psychological Measurement, 1, 385-401.

Sheehan, D. V., Lecrubier, Y., Sheehan, K.H., Amorim, P., Janavs, J., \& Weiller, E. (1998). The Mini-International Neuropsychiatric Interview (MINI): The development and validation of a structured diagnostic psychiatric interview for DSM-IV and ICD10. Journal of Clinical Psychiatry, 59, 22-33.

Smit, F., Cuijpers, P., Oostenbrink, J., Batelaan, N., de Graaf, R., \& Beekman, A. (2006). Costs of nine common mental disorders: implications for curative and preventive psychiatry. The Journal of Mental Health Policy and Economics, 9, 193-200.

Smit, F., Ederveen, A., Cuijpers, P., Deeg, D., \& Beekman, A. (2006). Opportunities for cost-effective prevention of late-life depression. An epidemiological approach. Archives of General Psychiatry, 63, 290-296.

Spek, V., Nyklícek, I., Smits, N., Cuijpers, P., Riper, H., \& Keyzer, J. (2007). Internet-based c ognitive behavioural therapy for subthreshold depression in people over 50 years old: A randomized controlled clinical trial. Psychological Medicine, 37, 1797-1806.

van 't Veer-Tazelaar, P., Smit, F., van Hout, H., van Oppen, P., van der Horst, H., Beekman, A., et al. (2010). Cost-effectiveness of a stepped care intervention to prevent depression and anxiety in later life: Randomised trial. British Journal of Psychiatry, 196, 319-325.

Warmerdam, L., Smit, F., van Straten, A., Riper, H., \& Cuijpers, P. (2010). Cost-utility and cost-effectiveness of internet-based treatment for adults with depressive symptoms: Randomized trial. Journal of Medical Internet Research, 12, e53.

Westerhof, G. J., Bohlmeijer, E. T., \& Webster, J. D. (2010). Reminiscence and mental health: A review of recent progress in theory, research, and intervention. Ageing and Society, 30, 697-721. 


\section{MEDIATING PROCESSES IN AN \\ EFFECTIVE LIFE-REVIEW INTERVENTION}




\title{
CHAPTER
}

\begin{abstract}
Life-review has been established as an evidence-based treatment for depression and anxiety. This paper addresses an important gap in the existing evidence of the working mechanisms of life-review. We were able to longitudinally investigate possible mediators of a life-review intervention on depression and anxiety in the context of a large randomized controlled trial. A total of 202 older Dutch adults living in the community participated in this study. They were randomly assigned to either life-review or care-asusual. Participants were measured in terms of their depressive and anxiety symptoms, reminiscence functions, meaning in life, mastery and positive thoughts at study entry $(t 0)$, post-intervention ( $t 1 ; 3$ months after study entry), and follow-up ( $t 2 ; 3$ months after the end of the intervention). Findings suggest that processes which have been theoretically and empirically proposed as important processes of change in life-review therapy, that is, bitterness revival and boredom reduction reminiscence, mastery and positive thoughts, are indeed mediating the effects of life-review on depression and anxiety. It is now recommended to measure these processes during the intervention in order to shed light on the exact process of change and direction of causality.
\end{abstract}




\section{$\overline{\text { INTRODUCTION }}$}

There is substantial evidence from systematic reviews and meta-analyses that life-review interventions are an effective treatment for depression in later life (Bohlmeijer, Smit \& Cuijpers, 2003; Hsieh \& Wang, 2003; Payne \& Marcus, 2008; Peng, Huang, Chen \& Lu, 2009; Pinquart, Duberstein \& Lyness, 2007; Pinquart \& Forstmeier, 2012). Some studies showed that life-review is also effective in reducing symptoms of anxiety (Bohlmeijer, Roemer, Cuijpers \& Smit, 2007; Korte, Bohlmeijer, Cappeliez, Smit \& Westerhof, 2012; Pot, Bohlmeijer, Onrust, Melenhorst, Veerbeek \& de Vries, 2010). Life-review refers to a structured evaluation of one's life in a manner that involves two distinct but related adaptive processes; integrative reminiscence and instrumental reminiscence (Butler, 1963; Haight, 1992; Westerhof, Bohlmeijer \& Webster, 2010; Wong, 1995). Integrative reminiscence is the integration of both positive and negative memories within the life-story, whereas instrumental reminiscence concerns the use of past memories to cope with present problems and challenges (Cappeliez, 2002; Watt \& Cappeliez, 2000; Westerhof, Bohlmeijer \& Webster, 2010; Wong, 1995). In the present study, we will investigate possible mediators of the effectiveness of life-review on depression and anxiety within the context of a large randomized controlled trial (RCT).

There is an increased awareness and understanding about how reminiscence is related to mental health in the aging population (see Westerhof, Bohlmeijer \& Webster, 2010 for a recent review). Rather than the frequency of reminiscing per se, it is the way in which people look back upon their past that is related to mental health. A successful use of integrative reminiscence has also been described as the identity function of reminiscence (Webster, 1993). Here, memories are actively used to develop one's identity by discovering, clarifying, and crystallizing important dimensions of the sense of whom one is. Such a constructive reappraisal of the past is found to be related to lower levels of depression and anxiety (Cappeliez \& O'Rourke, 2006; Cully, LaVoie \& Gfeller, 2001). When integrative reminiscence is not successful it has been described as bitterness revival (Webster, 1993). Bitterness revival is also about our identity, but in a negative, complaining way. Instead of being integrated in the sense of who we are, negative experiences are constantly brought up. Several studies show this to be positively associated with depression and anxiety (Cappeliez \& O'Rourke, 2006; Cappeliez, O'Rourke \& Chaudhury, 2005; Cully et al., 2001; Korte, Bohlmeijer, Westerhof \& Pot, 2011). Instrumental uses of reminiscence can also be functional or dysfunctional in terms of mental health. Problem-solving reminiscence (Webster, 1993) refers to how memories of past coping strategies can be reused in the present, which was found to be linked to lower levels of depression and anxiety (Cully et al., 2001; Cappeliez \& O'Rourke, 2006). In boredom reduction, the main goal is to escape from the present by romanticizing the past (Webster, 1993). Although this may have a temporary function in an understimulating situation, studies have consistently shown that increased levels of boredom reduction are associated with higher levels of depression and anxiety (Cappeliez \& O'Rourke, 2006; Cappeliez et al., 2005; Cully et al., 2001; Korte et al., 2011). Whereas these relations of integrative and instrumental reminiscence with mental health were found in cross-sectional studies, a recent study found similar 
evidence in a longitudinal study (O'Rourke, Cappeliez \& Claxton, 2011). Cappeliez and Robitaille (2010) found evidence that assimilative and accommodative coping mediate these longitudinal effects of reminiscence styles on mental health.

The next step toward understanding the adaptive value of reminiscence is to explore in more detail how reminiscence is related to depression and anxiety. Successful integrative and instrumental reminiscence may contribute to the accumulation of mental resources that are related to depression and anxiety. We will focus here on three such resources that are known to be related to mental health: meaning in life (Pinquart, 2002), mastery (Steunenberg, Beekman, Deeg, Bremmer \& Kerkhof, 2007), and positive thoughts (Ingram, Kendall, Siegle, Guarino \& McLaughlin, 1995). Successful integrative reminiscence may contribute to a sense of meaning in life as it contributes to finding coherence and purpose in one's own life experiences. Indeed, some studies found a crosssectional or longitudinal relationship between reminiscence and meaning in life (Cappeliez \& O'Rourke, 2006; Krause, 2004). Instrumental reminiscence may contribute to an enhanced sense of mastery, as it makes productive use of successful coping strategies from the past. Again, cross-sectional and longitudinal studies have found a relationship between successful reminiscence and aspects of mastery, such as coping (Cappeliez \& Robitaille, 2010) or goal seeking (Cappeliez \& O’Rourke, 2006). Finally, both integrative and instrumental reminiscence may contribute to the development of positive thoughts as they both include reminiscing about positive past experiences. Cross-sectional relations were found between reminiscence and life satisfaction, happiness, and self-esteem (Cappeliez \& O'Rourke, 2006; Cappeliez et al., 2005; Webster, 1998; Webster \& McCall, 1999). Furthermore, there is strong evidence from studies on autobiographical memory that the retrieval of specific positive memories is related to lower levels of depression (Brewin, 2006; Williams, Barnhofer, Crane, Herman, Raes, Watkins et al., 2007).

The above studies, which were carried out in the general population make it clear that both integrative and instrumental reminiscence can play an important role in an individual's ability to adapt to depression and anxiety, which may be achieved via the accumulation of meaning, mastery, and positive thoughts. This generates usefu information regarding effective therapeutic processes in life-review interventions (Westerhof, Bohlmeijer \& Webster, 2010). Accordingly, integrative reminiscence can be divided into two therapeutic processes. The first therapeutic process is to use the past in order to strengthen one's identity (i.e., identity reminiscence). This is accomplished by focusing on the clients' successes and strengths during various stages of their life and in different ways of functioning. The second therapeutic process is to reduce the revival of bitter experiences (i.e., bitterness revival reminiscence). Reduction of bitterness revival involves providing new meaning and value to negative memories. One way to achieve this is for an individual to systematically evaluate the course of his or her life. In this way, important themes may come forward, leading to new insights and fewer bitter memories. These two processes, strengthening identity reminiscence and reducing bitterness revival reminiscence, may lead to an increase in meaning in life (Wong, 1995).

Instrumental reminiscence can also be divided into two therapeutic processes. The first therapeutic process is to remember past problem-solving strategies (i.e., problem-solving reminiscence). This is achieved by recalling memories involving a 
successful adaptation on the part of the client; for example, an adaptation to critical life-events or chronic medical conditions. Such memories may be helpful in applying successful coping strategies for present problems. The second therapeutic process involves reducing memories that are conjured up in order to escape current problems (i.e., boredom reduction reminiscence). One way to discourage boredom reduction is to formulate new goals that are related to important life values and objectives. As depressed individuals have the tendency to pursue goals that are hard to fulfill (Pekrun, Elliot \& Maehr, 2006; Sideridis, 2005; 2007), it is important to formulate realistic goals. These two processes, strengthening problem-solving reminiscence and discouraging boredom reduction reminiscence, may lead to improved feelings of mastery. Wong (1995) and Parker (1995; 1999) noticed that a proper recall of problem-solving strategies can help an individual to experience and maintain a sense of mastery.

A more general therapeutic process, which involves both integrative and instrumental reminiscence, is the development of more positive thoughts about the self and the future (Cappeliez, 2002). This is accomplished through the retrieval of specific positive memories. As people with depression tend to have a stronger association with negative and more general memories (Brewin, 2006; Williams et al., 2007), paying more attention to specific positive memories in depressive older adults will help to activate memories that were almost forgotten (Serrano, Latorre, Gatz \& Montanes, 2004).

The development of meaning, mastery, and positive thoughts through integrative and instrumental reminiscence thus provides an interesting avenue for lifereview interventions focusing on depression and anxiety. A recent meta-analysis of 128 studies on reminiscence and life-review interventions showed that such interventions are not only successful in alleviating depression, but also in fostering meaning in life, mastery, and positive well-being (Pinquart \& Forstmeier, 2012). However, few empirical longitudinal studies have examined whether these proposed processes actually mediate the effects of life-review interventions. As far as we know, no studies were conducted on the changes in integrative and instrumental reminiscence that may explain the alleviation of depressive symptoms through life-review interventions. Westerhof, Bohlmeijer, van Beljouw, and Pot (2010) demonstrated that improvement in meaning in life mediates the effects of a lifereview intervention on depressive symptoms. An early empirical study on the effectiveness of life-review for older adults' depression suggested that improvement in mastery is a key process underlying the effect of decreasing depressive symptoms (Watt, 1996). Findings of Serrano et al. (2004) have shown that practice in autobiographical memory for specific positive memories may explain the effectiveness of life-review on depression.

This paper addresses an important gap in the existing evidence of the working mechanisms of life- review. Mediating effects of the proposed life-review processes will be studied in the context of a large RCT (Korte et al., 2012; for pilot studies see Bohlmeijer, Kramer, Smit, Onrust \& van Marwijk, 2009; Bohlmeijer, Westerhof \& Emmerik-de Jong, 2008). This trial evaluated an intervention that combines life-review with narrative therapy. The most important element in the intervention is to develop alternative, more agentic lifestories, in which clients take responsibility for their own preferred ways of living (Bohlmeijer et al., 2008, 2009; Korte et al., 2012). It was shown that, compared with care-as-usual, participants in the life-review condition reported significantly decreased symptoms of 
depression and anxiety, both at post-treatment and 3-month follow-up. Moderate effect sizes for depressive symptoms (.60 at post-treatment and .50 at follow-up) and small effect sizes for anxiety symptoms (.28 at post-treatment and .25 at follow-up) were found. In the present study, we hypothesize that a reduction in bitterness revival and boredom reduction reminiscence, as well as an increase in identity and problem-solving reminiscence, meaning in life, mastery, and positive thoughts during the intervention mediate the effects of life-review on depression and anxiety.

\section{$\overline{M E T H O D}$}

\section{Participants}

The participants $(N=202)$ had a mean $(M)$ age of 63.3 years (standard deviation $[S D] 6.48$, range 55-83) and were predominantly female (76.7\%). Their education was distributed evenly across three categories [less than 11 years (36.6\%), 11 to 14 years (33.7\%), and more than 14 years (29.9\%)]. A minority of the participants was still in paid employment (15.8\%). On average, participants reported one to two chronic medical conditions $(M=1.49, S D=1.36)$ and had experienced two to three critical life-events in the last 3 years $(M=2.34, S D=1.54)$. In total, $28.7 \%$ of the participants were on a stable antidepressant or antianxiety regimen. Participants at study entry scored an average of 20.5 (SD =8.6, range 1-41) on the Dutch Version of the Center for Epidemiological Studies Depression Scale (CES-D, scale of 0 to 60 for depressive symptoms), and an average of 8.4 ( $S D=3.5$, range 1-18) on the HADS-A (scale of 0 to 21 for anxiety symptoms). Independent samples $t$-tests and $x^{2}$ tests showed no significant differences at study entry between the intervention and control condition for any of these variables (see Table 1). 
Table 1. Characteristics of participants

\begin{tabular}{|c|c|c|c|}
\hline & $\begin{array}{l}\text { LIFE-REVIEW } \\
(n=100)\end{array}$ & $\begin{array}{l}\text { CARE- } \\
\text { AS-USUAL } \\
(n=102)\end{array}$ & $p$-value \\
\hline \multicolumn{4}{|l|}{$\mathrm{Age}^{\mathrm{a}}$} \\
\hline$M(S D)$ & $63.3(6.2)$ & $63.3(6.8)$ & .152 \\
\hline Range & $55-83$ & $55-83$ & \\
\hline \multicolumn{3}{|l|}{ Sex } & .277 \\
\hline Female & 80.0 & 73.5 & \\
\hline Male & 20.0 & 26.5 & \\
\hline \multicolumn{3}{|l|}{ Education ${ }^{\mathrm{b}}$} & .306 \\
\hline Less than 11 years & 37.0 & 36.3 & \\
\hline $11-14$ years & 35.0 & 32.4 & \\
\hline More than 14 years & 28.0 & 31.4 & \\
\hline \multicolumn{4}{|l|}{ Employment ${ }^{\mathrm{b}}$} \\
\hline Paid work & 19.0 & 12.7 & .303 \\
\hline Retired & 33.0 & 28.4 & \\
\hline Housekeeping & 16.0 & 15.7 & \\
\hline Volunteer work & 19.0 & 17.6 & \\
\hline Disability pension & 10.0 & 21.6 & \\
\hline Unemployed & 3.0 & 3.9 & \\
\hline \multicolumn{4}{|l|}{ Chronic medical conditions ${ }^{a}$} \\
\hline$M(S D)$ & $1.4(1.3)$ & $1.5(1.4)$ & .705 \\
\hline Range & $0-6$ & $0-6$ & \\
\hline \multicolumn{4}{|l|}{ Critical life-events ${ }^{\mathrm{a}}$} \\
\hline$M(S D)$ & $2.4(1.5)$ & $2.3(1.5)$ & \\
\hline Range & $0-7$ & $0-7$ & \\
\hline Antidepressant or anti-anxiety medication ${ }^{b}$ & 28.0 & 29.4 & .947 \\
\hline \multicolumn{4}{|l|}{ Depressive symptoms $(0-60)^{\mathrm{a}}$} \\
\hline$M(S D)$ & $20.5(8.6)$ & $20.6(8.6)$ & .917 \\
\hline Range & $1-40$ & $1-41$ & \\
\hline \multicolumn{4}{|l|}{ Anxiety symptoms $(0-21)^{a}$} \\
\hline$M(S D)$ & $8.3(3.3)$ & $8.4(3.7)$ & .854 \\
\hline Range & $2-16$ & $1-18$ & \\
\hline
\end{tabular}

Note. ${ }^{a}$ No significant differences between intervention and control condition ( $t$-test with $\left.p>.05\right)$. ${ }^{b}$ No significant differences between intervention and control condition ( $x^{2}$-test with $\left.p>.05\right)$. 


\section{Procedure}

The data of this study was derived from a multisite, pragmatic RCT on the effectiveness of a life-review intervention (Korte et al., 2012). The trial was pragmatic, as we studied the effects in its natural setting. Hence, the Dutch health care system was mimicked as closely as possible in terms of patient recruitment and offering the intervention. Participants were recruited in collaboration with 14 Dutch mental health care services. The therapists and psychologists at these mental health care services, all of whom were experienced in working with older adults, were responsible for the intake procedure and the intervention. Inclusion criteria were being 55 years of age or older and presenting moderate depressive symptoms (a score of 10 on the CES-D; Beekman, Deeg, van Limbeek, Braam, de Vries \& van Tilburg, 1997). Applicants were excluded if they had been diagnosed with a current severe major depressive episode (MDE; 8 or 9 out of 9 symptoms in total) or with a moderate to high suicide risk according to the Dutch version of the Mini International Neuropsychiatric Interview (MINI; van Vliet \& de Beurs, 2007). In addition, applicants were excluded if they had started taking antidepressant medication or benzodiazepines recently (within the previous 2 months) or were currently receiving some form of psychological treatment, for example, another group therapy or individual treatment by a clinical psychologist. Finally, people were excluded if the presence of another serious psychopathology was identified; in which case they were referred for psychological treatment. Examples of this were borderline personality disorder and social phobia.

The design and method of the RCT is described in detail by Korte, Bohlmeijer, and Smit (2009). In brief, participants were randomly assigned to either life-review $(n=100)$ or care-as-usual ( $n=102)$. The randomization was stratified by gender and the presence of a current major depressive episode. Participants completed measures at study entry (t0), post-intervention ( $t$; directly after the intervention, 3 months after study entry), and follow-up ( $t 2 ; 3$ months after the end of the intervention). The initial measurement was conducted within 2 weeks before the start of treatment. Power analysis indicated that 100 participants in each condition were required to detect an effect size of at least .35 (Cohen's $d$ ) in a one-tailed test at $\alpha=.05$ and a power of $(1$-beta $)=.80$. The RCT has been approved by a Dutch medical-ethics committee for research in mental health care settings (METiGG). It is registered in the Netherlands Trial Register; the primary Dutch register for clinical trials (TC=1860).

\section{Intervention and control group}

The intervention, "The stories we live by" (Bohlmeijer \& Westerhof, 2010), was conducted in groups of four to six participants and consisted of eight 2-hour sessions. It was specifically developed for younger older adults, building on findings that reminiscence plays an important role in developmental regulation throughout the life span (Pasupathi, Weeks \& Rice, 2006; Webster, 1998; Webster \& Gould, 2007). The intervention is based on the two adaptive processes of life-review: integrative and instrumental reminiscence (Westerhof, Bohlmeijer \& Webster, 2010). It focuses on the integration of difficult lifeevents from the past and on the development of meaningful and agentic life-stories which 
helps the participants to cope with present-day life-events and to formulate new goals. The intervention has three core elements. First, the integration of difficult life-events from the past; second, the development of agentic life-stories which helps the participants to cope with present life-events and to formulate new goals; third, the retrieval of specific positive memories, which can serve as building blocks of the new life-stories.

The first two elements were developed by integrating life-review into a narrative therapeutic framework that connects to theories about the role of life-stories in the articulation of identity and meaning (Freedman \& Combs, 1996; Gergen, 1985). A narrative therapeutic framework enhances the integration of negative events and the restoration of meaning in life in several ways. It stimulates clients to adopt an attitude of curiosity and not knowing. In this way, ample space is created for clients to explore alternative stories and preferences (White \& Epston, 1990). Furthermore, therapists have an arsenal of questions that may be helpful in constructing alternative, more agentic stories about negative life-events and life periods (e.g., "How were you able to cope with this situation?", "Where there any pleasant moments in this difficult time?", and "Now, at a much later date, can you say that you have also learned from that period?"). In addition, by always focusing on the clients' preferences and relating them to other memories, clients are continually invited to express their values and past experiences (White, 2007). Last, alternative stories are further elaborated, by relating them to identity ("What does this say about the person you are?") and by relating them to future goals and action ("What can you do in the near future to live by this value or meaning?"). The third core element was the attention to specific positive memories, special and unique for a certain period in the participants' lives, which are expected to activate nearly forgotten memories, especially in people with depressive symptoms (Brewin, 2006; Serrano et al., 2004; Williams et al., 2007).

The first five sessions were focused on different life themes across the life span, which were based on the protocol of Birren and Deutchman (1991): Origin, youth, work and care, love and conflicts, and loss and difficult times. Before each session, participants had to answer questions about those life themes. They had to describe one difficult lifeevent they are still struggling with. Then they had to answer questions which helped to integrate this life-event. For each session they had to describe a specific positive memory as well. During the sessions, participants had the opportunity to exchange and discuss experiences with the other participants. In the last three sessions, attention was given to some overarching themes that focused on creating an overview and on formulating new life goals: metaphor, course of life, and a new beginning. Participants in the control condition group also received the intervention, after the conclusion of the RCT. During the study, no form of treatment was withheld from them and they had unrestricted access to care-as-usual.

\section{Measures}

Outcome variables were depressive symptoms and anxiety symptoms. Possible mediators were reminiscence functions, meaning in life, positive thoughts, and mastery. Depressive symptoms were measured using the Dutch version of the 20-item CES-D (Beekman et al., 1997). Examples of items were "I was bothered by things that don't 
usually bother me", "I felt everything I did was an effort" and "I felt that people disliked me". In this study, the scale showed good internal consistency ( $\alpha=.83$ ).

Anxiety symptoms were assessed using the anxiety scale of the Dutch version of the Hospital Anxiety and Depression Scale, a 7-item measure (HADS-A; Spinhoven, Ormel, Sloekers, Kempen, Speckens \& van Hemert, 1997). Examples of items were "I feel tense or wound up lately", "Worrying thoughts go through my mind" and "I get sudden feelings of panic lately". The scale showed satisfactory internal consistency in this study $(\alpha=.77)$.

Reminiscence functions were measured using the Dutch version of the Reminiscence Functions Scale (Webster, 1993). For the purpose of this study we used four subscales that were consistently related to mental health (Cappeliez \& O'Rourke, 2006; Cappeliez et al., 2005; Cully et al., 2001; Korte et al., 2011; O’Rourke et al., 2011): identity (six items), problem-solving (six items), bitterness revival (five items), and boredom reduction (six items). Examples of items were: "When I reminisce, it is... because it helps me contrast the ways I have changed with the ways I have stayed the same", "to see how my past fits in with my journey through life", "to try to understand myself better" (identity), "to help me plan for the future", "to help solve some current difficulty", "to remind me that I have the skills to cope with present problems" (problem-solving), "to keep painful memories alive", "to rehash lost opportunities", "to keep memories of old hurts fresh in my mind" (bitterness revival), "for lack of any better mental stimulation", "for something to do" and "to pass the time during idle or restless hours" (boredom reduction). The four subscales showed good internal consistency in the present sample (identity: $\alpha=.85$, problem-solving: $\alpha=.79$, bitterness revival: $\alpha=.83$, boredom reduction: $\alpha=.86$ ).

Meaning in life was measured with the Dutch version of the Meaning in Life Questionnaire (MLQ; Steger, Frazier, Oishi \& Kaler, 2006). The scale comprises two subscales, the presence of meaning (five items) and the search for meaning in life (five items). Examples of presence of meaning items were "I understand my life's meaning", "My life has a clear sense of purpose" and "I have a good sense of what makes my life meaningful". Search for meaning items were for example "I am looking for something that makes my life feel meaningful", "I am always searching for something that makes my life feel significant" and "I am seeking a purpose or mission for my life". The subscales showed a good internal consistency in the present study ( $\alpha=.80$ for presence of meaning and $\alpha=.84$ for search for meaning).

Positive thoughts were measured using the Dutch version of the 30-item Automatic Thoughts Questionnaire Positive (ATQ-P; Boelen, 2007). Examples of items were "I am comfortable with life", "I have many good qualities" and "There are many people who care about me". In the present study, the scale showed a high internal consistency $(\alpha=.92)$.

Mastery was assessed with the abbreviated Dutch version of the Mastery Scale (Pearlin \& Schooler, 1978). This scale consists of five items that are intended to assess beliefs about perceived control over one's life in general or beliefs regarding one's ability to control an event. Some examples of statements made were "I have little control about things that happen to me", "There is not much that I can do to change important things in my life" and "Some of my problems I can't seem to solve at all". In the present study, the scale showed a good internal consistency $(\alpha=.80)$. 


\section{Analyses}

Analyses were performed according to the intention-to-treat approach on missing data, using Missing Value Analysis in PASW 18 to impute all missing data on the continuous measures with the expectation-maximization method. Missing values were replaced by estimates, which were based on maximum likelihood estimates using observed data in an iterative process (Dempster, Laird \& Rubin, 1977). Hence, all participants who were randomized were included in the statistical analyses. The results based on the imputed intention-to-treat sample were similar to those obtained with observed data only, so we only report the former.

First, regression analyses were used to examine differences between the life-review condition and the care-as-usual condition on the possible mediators. The dependent variables were the post-treatment outcome measurements compared to the initial measurements with the treatment dummy (life-review vs. care-as-usual) serving as the independent variables. In addition, the effect sizes (Cohen's $d$; small, $d=.20$; medium, $d=.50$; large, $d=.80$; see Cohen, 1992) at post-intervention were calculated, using the pooled SD method. Second, the hypothesis that the effects of the intervention would be mediated by reminiscence, meaning in life, positive thoughts, and mastery was tested by carrying out two-step hierarchical regression analyses. Depressive and anxiety symptoms at $t 2$ were outcome variables. In the first step, we entered the group variable as a dummy (control=0 vs. intervention=1) and the initial scores of both the outcome variable and the mediator variable. In the second step, we added the change in mediator variable (t0-t1). Subsequently, bootstrapping procedures ( $n=5000$ bootstrap resamples) were performed, to determine the significance of the indirect effect of the meditational pattern. Bootstrapping is the recommended test of mediation to overcome limitations of statistical methods that make assumptions about the shape of the sampling distribution, such as symmetry or normality, and is the recommended test of mediation (Preacher \& Hayes, 2004; MacKinnon, Fairchild \& Fritz, 2007). As prescribed, an indirect effect was considered significant in the event that zero was not contained in the $95 \%$ confidence interval. In addition, multivariate bootstrapping was performed to examine significant mediators in the same model. In this way, it is possible to determine the effect of each mediator while controlling for the other mediators.

\section{$\overline{\text { RESULTS }}$}

Table 2 gives an overview of the treatment effects of life-review as compared with careas-usual on possible mediators. There was a significant decline in bitterness revival and boredom reduction reminiscence and a significant improvement in mastery and positive thoughts, with small effect sizes post-treatment. No effects were found for identity and problem-solving reminiscence, presence of meaning, and search for meaning; so these variables were excluded from the mediation analyses.

Hierarchical regression analyses showed that bitterness revival, boredom reduction, mastery, and positive thoughts partially mediated the effects on depression (see Table 3). Although the explained variance was reduced, the group effect (care-as-usual vs. life-review) was still significant. Bootstrapping analyses demonstrated that the indirect effects of the proposed mediators were all significant. Furthermore, hierarchical regression 
analyses showed that bitterness revival and boredom reduction reminiscence, mastery, and positive thoughts fully mediated the effects on anxiety (see Table 3). Bootstrapping analyses demonstrated that these effects were all significant. So those participants who experienced a decline in bitterness revival and boredom reduction, and an improvement in mastery and positive thoughts, showed a stronger decrease in depressive symptoms and anxiety symptoms. Multivariate bootstrapping indicated that, after controlling for all significant mediators, only an improvement in positive thoughts remained a significant mediator, both for depressive and anxiety symptoms. Bootstrapping values varied between -2.09 and -.12 (see Table 4).

Table 2. Intervention effects for possible mediators

\begin{tabular}{|c|c|c|c|c|c|c|c|}
\hline \multirow[b]{2}{*}{ Measures } & & \multicolumn{2}{|c|}{$\begin{array}{l}\text { LIFE-REVIEW } \\
(n=100)\end{array}$} & \multicolumn{2}{|c|}{$\begin{array}{l}\text { CARE- } \\
\text { AS-USUAL } \\
(n=102)\end{array}$} & \multirow[b]{2}{*}{ Beta } & \multirow[b]{2}{*}{$d$} \\
\hline & & M & $S D$ & M & $S D$ & & \\
\hline \multirow{2}{*}{$\begin{array}{l}\text { Identity reminiscence (scale } \\
\text { between 6-42) }\end{array}$} & Study entry & 23.8 & 5.4 & 23.5 & 5.5 & & \\
\hline & Post-treatment & 24.7 & 5.7 & 24.0 & 5.4 & .04 & .13 \\
\hline \multirow{2}{*}{$\begin{array}{l}\text { Problem-solving reminiscence } \\
\text { (scale between 6-42) }\end{array}$} & Study entry & 23.0 & 5.0 & 22.9 & 5.2 & & \\
\hline & Post-treatment & 23.9 & 5.6 & 23.2 & 5.1 & .05 & .13 \\
\hline \multirow{2}{*}{$\begin{array}{l}\text { Bitterness revival reminiscen- } \\
\text { ce (scale between } 5-35 \text { ) }\end{array}$} & Study entry & 14.3 & 5.1 & 14.5 & 5.7 & & \\
\hline & Post-treatment & 12.9 & 5.1 & 15.1 & 5.5 & $.19^{\star \star \star}$ & .41 \\
\hline \multirow{2}{*}{$\begin{array}{l}\text { Boredom reduction reminis- } \\
\text { cence (scale between 6-42) }\end{array}$} & Study entry & 13.6 & 5.4 & 13.2 & 6.5 & & \\
\hline & Post-treatment & 12.3 & 5.4 & 13.8 & 5.9 & $-.16^{\star *}$ & .27 \\
\hline \multirow{2}{*}{$\begin{array}{l}\text { Presence of meaning in life } \\
\text { (scale between 5-25) }\end{array}$} & Study entry & 15.0 & 3.5 & 15.2 & 3.4 & & \\
\hline & Post-treatment & 15.6 & 4.3 & 15.2 & 3.9 & .07 & .10 \\
\hline \multirow{2}{*}{$\begin{array}{l}\text { Search for meaning in life } \\
\text { (scale between 5-25) }\end{array}$} & Study entry & 18.0 & 3.6 & 18.0 & 3.3 & & \\
\hline & Post-treatment & 17.8 & 3.8 & 17.2 & 4.4 & .08 & .15 \\
\hline \multirow[t]{2}{*}{ Mastery (scale between 5-25) } & Study entry & 14.9 & 3.3 & 14.7 & 3.5 & & \\
\hline & Post-treatment & 15.9 & 3.7 & 14.6 & 3.4 & $.17^{\star \star}$ & .37 \\
\hline \multirow{2}{*}{$\begin{array}{l}\text { Positive thoughts (scale } \\
\text { between } 30-150 \text { ) }\end{array}$} & Study entry & 91.8 & 14.1 & 90.5 & 16.0 & & \\
\hline & Post-treatment & 96.9 & 15.9 & 90.6 & 17.2 & $-.16^{\star \star *}$ & .38 \\
\hline
\end{tabular}


Table 3. Mediation analysis on symptoms of depression and anxiety $(\mathrm{N}=202)$

\begin{tabular}{|c|c|c|c|c|}
\hline & \multicolumn{2}{|c|}{$\begin{array}{l}\text { Depressive symptoms } \\
\text { t2 (OV) }\end{array}$} & \multicolumn{2}{|c|}{$\begin{array}{l}\text { Anxiety symptoms } \\
\text { t2 (OV) }\end{array}$} \\
\hline & Step 1 Beta & Step 2 Beta & Step 1 Beta & Step 2 Beta \\
\hline $\begin{array}{l}\text { Life-review } \\
\text { (reference: care-as-usual) }\end{array}$ & $-.26^{\star * \star}$ & $-.20^{\star \star \star}$ & $-.12^{*}$ & -.06 \\
\hline Study entry OV & $.51^{\star \star \star}$ & $.48^{\star \star \star}$ & $.61^{\star \star \star}$ & $.60^{\star \star \star}$ \\
\hline $\begin{array}{l}\text { Study entry bitterness revival } \\
\text { reminiscence }\end{array}$ & .11 & $.20^{*}$ & $.14^{\star *}$ & $.23^{\star \star *}$ \\
\hline $\begin{array}{l}\text { Improvement in bitterness revival } \\
\text { reminiscence }(t 1-t 0)\end{array}$ & & $.22^{\star \star}$ & & $.22^{\star * *}$ \\
\hline Explained variance (adjusted $R^{2}$ ) & .35 & .38 & .41 & .45 \\
\hline Bootstrap Cl & & $-2.03,-.40^{*}$ & & $-.76,-.15^{\star}$ \\
\hline $\begin{array}{l}\text { Life-review } \\
\text { (reference: care-as-usual) }\end{array}$ & $-.26^{* * *}$ & $-.22^{\star \star \star}$ & $-.12^{\star}$ & -.09 \\
\hline Study entry OV & $.52^{\star \star \star}$ & $.51^{\star * *}$ & $.62^{\star \star \star}$ & $.60^{\star \star *}$ \\
\hline $\begin{array}{l}\text { Study entry boredom reduction } \\
\text { reminiscence }\end{array}$ & .01 & .10 & .04 & .11 \\
\hline $\begin{array}{l}\text { Improvement in boredom } \\
\text { reduction reminiscence }(t 1-t 0)\end{array}$ & & $.22^{\star *}$ & & $.22^{\star \star *}$ \\
\hline Explained variance (adjusted $R^{2}$ ) & .33 & .36 & .39 & .41 \\
\hline Bootstrap Cl & & $-1.53,-.18^{*}$ & & $-.51,-.06^{*}$ \\
\hline Life-review (reference: care-as-usual) & $-.25^{\star \star \star}$ & $-.17^{\star \star}$ & $-.12^{\star}$ & -.05 \\
\hline Study entry OV & $.37^{* * *}$ & $.33^{\star * *}$ & $.57^{\star \star *}$ & $.54^{\star \star *}$ \\
\hline Study entry positive thoughts & $-.33^{\star \star *}$ & $-.42^{\star \star \star}$ & $-.18^{\star}$ & $-.25^{\star \star \star}$ \\
\hline Improvement in positive thoughts $(t 1-t 0)$ & & $-.33^{\star \star \star}$ & & $-.29^{\star \star \star}$ \\
\hline Explained variance (adjusted $R^{2}$ ) & .42 & .52 & .42 & .49 \\
\hline Bootstrap Cl & & $-2.72,-.65^{\star}$ & & $-.87,-.21^{\star}$ \\
\hline Life-review (reference: care-as-usual) & $-.26^{\star \star \star}$ & $-.22^{* * *}$ & $-.12^{*}$ & -.07 \\
\hline Study entry OV & $.44^{\star \star *}$ & $.41^{\star \star *}$ & $.59^{\star \star \star}$ & $.58^{\star \star *}$ \\
\hline Study entry mastery & $-.23^{\star \star *}$ & $-.32^{\star \star \star}$ & -.11 & $-.21^{\star *}$ \\
\hline Improvement in mastery $(t 1-t 0)$ & & $-.22^{\star \star \star}$ & & $-.24^{\star \star \star}$ \\
\hline Explained variance (adjusted $R^{2}$ ) & .38 & .41 & .40 & .45 \\
\hline Bootstrap Cl & & $-1.75,-.26^{\star}$ & & $-.75,-.11^{*}$ \\
\hline
\end{tabular}

Note. ${ }^{*} p<.05,{ }^{* *} p<.01,{ }^{* \star *} p<.001$, OV: outcome variable. Depressive symptoms were measured using the Center for Epidemiological Studies Depression Scale (CES-D) and anxiety symptoms were measured using the anxiety scale of the Hospital Anxiety and Depression Scale (HADS-A). 
Table 4. Multivariate mediation on symptoms of depression and anxiety

\begin{tabular}{|l|l|l|}
\hline & $\begin{array}{l}\text { Depressive } \\
\text { symptoms (t2) }\end{array}$ & $\begin{array}{l}\text { Anxiety } \\
\text { symptoms (t2) }\end{array}$ \\
\hline $\begin{array}{l}\text { Improvement in bitterness revival } \\
\text { reminiscence }(t 1-\mathrm{t} 0)\end{array}$ & $-1.56, .01$ & $-.45, .15$ \\
\hline $\begin{array}{l}\text { Improvement in boredom reduction } \\
\text { reminiscence }(t 1-\mathrm{t} 0)\end{array}$ & $-1.04, .30$ & $-.52, .04$ \\
\hline Improvement in positive thoughts $(t 1-\mathrm{t} 0)$ & $-2.09,-.25$ & $-.74,-.12$ \\
\hline Improvement in mastery $(t 1-\mathrm{t} 0)$ & $-.55, .71$ & $-.45, .09$ \\
\hline
\end{tabular}

\section{DISCUSSION}

Although life-review is effective in reducing depression and anxiety, the processes by which life-review achieves its effectiveness have hardly been studied within the context of large RCTs. Studies in the general population suggest several possible mediators (e.g., Webster, Bohlmeijer \& Westerhof, 2010; Westerhof, Bohlmeijer \& Webster, 2010), but longitudinal studies on mediators of life-review are scarce. We were able to longitudinally investigate possible mediators of a life-review intervention on the symptoms of depression and anxiety in the context of a large RCT. Our hypothesis was partly confirmed: a reduction in bitterness revival and boredom reduction reminiscence, and an increase in mastery and positive thoughts were associated with a significant decrease in depressive symptoms and anxiety symptoms at 3-month follow-up. These findings support the evidence for mediation processes that have been proposed as working elements within specific lifereview therapies. It clearly illustrates that both integrative and instrumental reminiscence can play an important role in reducing depression and anxiety, which may be achieved via the accumulation of positive thoughts and mastery.

It was shown that after checking for all significant mediators, only an improvement in positive thoughts remained significantly associated with depressive and anxiety symptoms. This suggests that the focus on positive thoughts is a key mechanism in explaining the effectiveness of life-review, a finding that can be brought back to the two main adaptive processes of life-review: integrative and instrumental reminiscence. Together, these processes may lead to the development of more positive thoughts about the self and the future, which may play a major role in recovery from depression (Cappeliez, 2002; Watt \& Cappeliez, 2000; Wong, 1995). This finding corroborates a cognitive model of life-review and depression (Cappeliez, 2002). An increase in positive thoughts may be the result of repairing underlying maladaptive schematic information-processing styles and dysfunctional causal attribution styles. Although our findings indicate that mainly positive thoughts explain the changes in depression and anxiety, this does not necessarily imply that changes in reminiscence are not of importance. However, it rather means that their effectiveness on depression and anxiety might be achieved through an increase in 
positive thoughts. To actually test the assumption that an improvement in integrative and instrumental reminiscence indeed leads to reduced depression and anxiety, via positive thoughts, studies with experimental designs and multiple measurements are needed.

We did not find any mediating effects for identity and problem-solving reminiscence. One reason for this might be that the participants in our study had moderate depressive symptoms at study entry, while most studies that found associations between positive reminiscence and mental health were carried out among the general older population. One might wonder why engaging in identity and problem-solving reminiscence does not lead to decreased distress in depressed older adults. As we have seen, studies on autobiographical memory have shown that depressed individuals have difficulties in recalling specific positive memories (Williams et al., 2007). The self-reported use of positive reminiscence does not necessarily include the retrieval of such specific positive memories. So it may be that the Reminiscence Functions Scale (Webster, 1993) is not specific enough to detect a change in more positive ways of remembering. Serrano et al. (1994) found a mediating effect when using the Autobiographical Memory Test, a more direct measure of specific positive memories (Williams \& Broadbent, 1986). Strikingly, we did not find any mediating effects for meaning in life. This is in contrast with Westerhof, Bohlmeijer, van Beljouw, et al. (2010) who found that an improvement in meaning in life mediated the effects of a life-review intervention on depressive symptoms in later life. One explanation for this might be that we used a measurement instrument with a good test-retest stability that can be regarded as trait-like (Meaning in Life Scale; Steger et al., 2006), while Westerhof, Bohlmeijer, van Beljouw, et al. (2010) used a more state-like instrument (the SELE-instrument; Dittmann-Kohli \& Westerhof, 1997). In a pilot study, we did find a significant effect on meaning in life, measured with this more state-like instrument (Bohlmeijer et al., 2008). So it might be that life-review is more suited for people who experience a decreased meaning in life as a result of unexpected circumstances, for example, critical life-events, and would not be suitable for older adults who experience less meaning in life in general. Therefore, to correctly measure changes in meaning in life in life-review interventions, instruments which are more sensitive to change should be used.

In recent discussions it was put forward that a good strategy to develop effective life-review therapy for older adults with mental health problems is to link lifereview with other therapeutic frameworks (Westerhof, Bohlmeijer \& Webster, 2010), for example to cognitive therapy (Watt \& Cappeliez, 2000) or creative therapy (Pot et al., 2010). A recent meta-analysis of Pinquart and Forstmeier (2012) showed that such hybrid life-review therapies have stronger effects on depression and positive well-being than interventions which focus solely on life-review. In the present study the focus is on the mediating processes of an intervention combining life-review with narrative therapy. This intervention has been found to be effective (Bohlmeijer et al., 2008; 2009; Korte et al., 2012). Findings of the present study suggest that life-review within a narrative framework is effective in integrating difficult memories and increasing the instrumental use of memories, by decreasing bitterness revival and boredom reduction reminiscence, and by strengthening mastery and positive thoughts. These findings have an important implication for the implementation and dissemination of life-review within a narrative 
framework. Counsellors and therapists who facilitate the intervention should be well familiar with the mediating processes that influence the effects of the intervention. And it is recommended that they are specifically trained in narrative interventions that promote these processes. Though cognitive therapy and narrative therapy differ in their underlying theories and in the interventions that are used by the therapist, the finding that specific positive thoughts is a key mechanism in explaining the effectiveness suggests that they bring about similar processes within the context of life-review therapy. The main difference between both therapies is that they seem to have different mechanisms of change. Life-review with narrative therapy focuses on the construction of positive thoughts by deconstructing problem-saturated stories and by constructing meaningful stories with more agentic plots, while life-review with cognitive therapy explores and challenges dysfunctional, most often negative thoughts. It is important to note that life-review within a narrative therapeutic framework is essentially different from narrative therapy. The basic element in life-review therapy is a structured evaluation of the past. Narrative therapeutic interventions are carried out to help build new stories about the self and the world; stories that express hope, mastery, and meaning. The starting point for narrative therapy is the here and now. The client is only asked to reminisce if this is helpful in the process of deconstruction or restorying (Osis \& Stout, 2002; White, 2007).

Some limitations in this study should be noted. First, we compared life-review with care-as-usual, instead of using an active control group, which makes it difficult to determine whether the mediating effects are specifically associated with the intervention. A second limitation is that no assessments were made during the course of the intervention. Therefore, it was not possible to analyze the precise sequence of change in reminiscence and mental resources on changes in depression and anxiety. Third, the majority of the older adults in our study were female and relatively young, which implies a limitation for the generalization of the findings. Therefore, in future studies it would be interesting to broaden the study sample by including more men and adults from more senior segments of the population. This would allow for testing possible differences between men and women and young-old and old-old adults. However, a recent meta-analysis showed that levels of change in depressive symptoms and positive wellbeing did not vary according to either gender or age (Pinquart \& Forstmeier, 2012). A fourth, and perhaps more general, limitation in mediation analysis is that mediation does not imply a causal relationship. So perhaps other mechanisms were actually causing change.

To conclude, the present study suggests processes that have been theoretically and empirically proposed as important processes of change in life-review therapy, that is, bitterness revival and boredom reduction reminiscence, mastery, and positive thoughts, are indeed mediating the effects of life-review on depression and anxiety. It is now recommended to measure these processes during the intervention in order to shed light on the exact process of change and direction of causality. 


\section{REFERENCES}

Beekman, A. T. F., Deeg, D. J., van Limbeek, J., Braam, A. W., de Vries, M. Z., \& van Tilburg, W. (1997). Criterion validity of the Center for Epidemiologic Studies Depression scale (CES-D): results from a community-based sample of older subjects in the Netherlands. Psychological Medicine, 27, 231-235.

Birren, J. E., \& Deutchman, D. E. (1991). Guided autobiography groups for older adults. Baltimore, MD: John Hopkins University Press.

Boelen, P. A. (2007). Psychometric properties of the Dutch version of the Automatic thoughts Questionnaire-Positive (ATQ-P). Cognitive Behaviour Therapy, 36, 23-33.

Bohlmeijer, E. T., Kramer, J., Smit, F., Onrust, S., \& Van Marwijk, H. (2009). The effects of integrative reminiscence on depressive symptomatology and mastery of older adults. Community Mental Health Journal, 45, 476-484.

Bohlmeijer, E. T., Roemer, M., Cuijpers, P., \& Smit, F. (2007). The effects of life-review on psychological well-being in older adults: A meta-analysis. Aging \& Mental Health, 11, 291-300.

Bohlmeijer, E. T., Smit, F., \& Cuijpers, P. (2003). Effects of reminiscence and life-review on late-life depression: A meta-analysis. International Journal of Geriatric Psychiatry, 18, 1088-1094.

Bohlmeijer, E. T., \& Westerhof, G. J. (2010). The stories we live by [in Dutch]. Amsterdam: Boom Uitgeverij.

Bohlmeijer, E. T., Westerhof, G. J., \& Emmerik-de Jong, M. (2008). The effects of integrative reminiscence on meaning in life: Results of a quasi-experimental study. Aging \& Mental Health, 12, 639-646.

Brewin, C. R. (2006). Understanding cognitive behaviour therapy: A retrieval competition account. Behaviour Research and Therapy, 44, 765-784.

Butler, R. N. (1963). The life-review: An interpretation of reminiscence in the aged. Psychiatry, 26, 65-76.

Cappeliez, P. (2002). Cognitive-reminiscence therapy for depressed older adults in day hospital and long-term care. In J. D. Webster and B. K. Haight (Eds.), Critical Advances in Reminiscence Work: From Theory to Application (pp. 300-313). New York, NY: Springer.

Cappeliez, P., \& O'Rourke, N. (2006). Empirical validation of a model of reminiscence and health in later life. Journal of Gerontology: Series B: Psychological Sciences and Social Sciences, 61, 237-244.

Cappeliez, P., O'Rourke, N., \& Chaudhury, H. (2005). Functions of reminiscence and mental health in later life. Aging \& Mental Health, 9, 295-301.

Cappeliez, P., \& Robitaille, A. (2010). Coping mediates the relationships between reminiscence and psychological well-being among older adults. Aging \& Mental Health, 14, 807-818.

Cohen, J. (1992). A power primer. Psychological Bulletin, 112, 155-159.

Cully, J. A., LaVoie, D., \& Gfeller, J. D. (2001). Reminiscence, personality, and psychological functioning in older adults. Gerontologist, 41, 89-95. 
Dempster, A. P., Laird, N. M., \& Rubin, D. B. (1977). Maximum Likelihood from incomplete data via the EM algorithm. Journal of the Royal Statistical Society, 39, 1-38.

Dittmann-Kohli, F., \& Westerhof, G. J. (1997). The SELE-sentence completion questionnaire: A new instrument for the assessment of personal meaning in research on aging. Anuario de Psicologia, 73, 7-18.

Freedman, J., \& Combs, G. (1996). Narrative therapy: The social construction of preferred realities. New York, NY: W. W. Norton.

Gergen, K. J. (1985). The social constructionist movement in modern psychology. American Psychologist, 40, 266-275.

Haight, B. K. (1992). Long-term effects of a structured life-review process. Journal of Gerontology, 47, 312-315.

Hsieh, H. F., \& Wang, J. J. (2003). Effect of reminiscence therapy on depression in older adults: A systematic review. International Journal of Nursing Studies, 40, 335-345.

Ingram, R. E., Kendall, P. C., Siegle, G., Guarino, J., \& McLaughlin, S. C. (1995). Psychometric properties of the Positive Automatic Thoughts Questionnaire. Psychological Assessment, 7, 495-507.

Korte, J., Bohlmeijer, E.T., Cappeliez, P., Smit, F., \& Westerhof, G.J. (2012). Life-review therapy for older adults with moderate depressive symptomatology: a pragmatic randomized controlled trial. Psychological Medicine, 42, 1163-1173.

Korte, J., Bohlmeijer, E. T., \& Smit, F. (2009). Prevention of depression and anxiety in later life: Design of a randomized controlled trial for the clinical and economic evaluation of a life-review intervention. BMC Public Health, 9, 250.

Korte, J., Bohlmeijer, E. T., Westerhof, G. J., \& Pot, A. M. (2011). Reminiscence and adaptation to critical life-events in older adults with mild to moderate depressive symptoms. Aging \& Mental Health, 15, 638-646.

Krause, N. (2004). Stressors arising in highly valued roles, meaning in life, and the physical health status of older adults. Journal of Gerontology Series B, Psychological Sciences and Social Sciences, 59, S287-S297.

MacKinnon, D. P., Fairchild, A. J., \& Fritz, M. S. (2007). Mediation analysis. Annual Review of Psychology, 58, 593-614.

O'Rourke, N., Cappeliez, P., \& Claxton, A. (2011). Functions of reminiscence and the psychological well-being of young-old and older adults over time. Aging \& Mental Health, 15, 272-281.

Osis, M., \& Stout, L. (2001). Using narrative therapy with older adults. In G. M. Kenyon, P. G. Clark, \& B. de Vries (Eds.), Narrative gerontology: Theory, research, and practice (pp. 273-290). Berlin, Germany: Springer.

Parker, R. G. (1995). Reminiscence: A community theory framework. The Gerontologist, 35, 515-525.

Parker, R. G. (1999). Reminiscence as continuity: Comparison of young and older adults. Journal of Clinical Geropsychology, 5, 147-157.

Pasupathi, M., Weeks, T., \& Rice, C. (2006). Reflecting on life: Remembering as a major process in adult development. Journal of Language and Social Psychology, 25, 244-263. 
Payne, K. T., \& Marcus, D. K. (2008). The efficacy of group psychotherapy for older adult clients: A meta-analysis. Group Dynamics: Theory, Research, and Practice, 12, 268-278.

Pearlin, L. I., \& Schooler, C. (1978). The structure of coping. Journal of Health and Social Behaviour, 19, 2-21.

Pekrun, R., Elliot, A. J., \& Maier, M. A. (2006). Achievement goals and discrete achievement emotions. Journal of Educational Psychology, 98, 583-597.

Peng, X. D., Huang, C. Q., Chen, L. J., \& Lu, Z. C. (2009). Cognitive behavioural therapy and reminiscence techniques for the treatment of depression in the elderly: A systematic review. The Journal of International Medical Research, 37, 975-982.

Pinquart, M. (2002). Creating and maintaining purpose in life in old age: A meta-analysis. Ageing International, 27, $90-114$.

Pinquart, M., Duberstein, P. R., \& Lyness, J. M. (2007). Effects of psychotherapy and other behavioral interventions on clinically depressed older adults: A metaanalysis. Aging \& Mental Health, 11, 645-657.

Pinquart, M., \& Forstmeier, S. (2012). Effects of reminiscence interventions on psychosocial outcomes: A meta-analysis. Aging \& Mental Health, 16(5), 541-558.

Pot, A. M., Bohlmeijer, E. T., Onrust, S., Melenhorst, A. S., Veerbeek, M., \& de Vries, W. (2010). The impact of life-review on depression in older adults: A randomized controlled trial. International Psychogeriatrics, 22, 572-581.

Preacher, K. J., \& Hayes, A. F. (2004). SPSS and SAS procedures for estimating indirect effects in simple mediation models. Behavior Research Methods, Instruments \& Computers, 36, 717-731.

Serrano, J. P., Latorre, J. M., Gatz, M., \& Montanes, J. (2004). Life-review therapy using autobiographical retrieval practice for older adults with depressive symptomatology. Psychology and Aging, 19, 270-277.

Sideridis, G. D. (2005). Goal orientation, academic achievement, and depression: Evidence in favour of a revised goal theory framework. Journal of Educational Psychology, 97, 366-375.

Sideridis, G. D. (2007). Why are students with LD depressed? A goal orientation model of depression vulnerability. Journal of Learning Disabilities, 40, 526-539.

Spinhoven, P. H., Ormel, J., Sloekers, P. P. A., Kempen, G. I. J. M., Speckens, A. E. M., \& van Hemert, A. M. (1997). A validation study of the Hospital Anxiety and Depression Scale (HADS) in different groups of Dutch subjects. Psychological Medicine, 27, 363-370.

Steger, M., Frazier, P., Oishi, S., \& Kaler, M. (2006). The meaning in life questionnaire, assessing the presence of and search for meaning in life. Journal of Counselling Psychology, 53, 80-93.

Steunenberg, B., Beekman, A. T., Deeg, D. J., Bremmer, M. A., \& Kerkhof, A. J. (2007). Mastery and neuroticism predict recovery of depression in later life. The American Journal of Geriatric Psychiatry, 15, 234-242.

van Vliet, I. M., \& de Beurs, E. (2007). The MINI-International Neuropsychiatric Interview (M.I.N.I.). A brief structured diagnostic psychiatric interview for DSM-IV and ICD10 psychiatric disorders [in Dutch]. Tijdschrift voor Psychiatrie, 49, 393-397. 
Watt, L. M. (1996). Integrative and instrumental reminiscence therapies for the treatment of depression in older adults. (Doctoral Dissertation). Ottawa: School of Psychology, University of Ottawa.

Watt, L. M., \& Cappeliez, P. (2000). Integrative and instrumental reminiscence therapies for depression in older adults: Intervention strategies and treatment effectiveness. Aging \& Mental Health, 4, 166-177.

Webster, J. D. (1993). Construction and validation of the Reminiscence Functions Scale. Journals of Gerontology: Psychological Sciences, 48, 256-262.

Webster, J. D. (1998). Attachment styles, reminiscence function, and happiness in young and elderly adults. Journal of Aging Studies, 12, 315-330.

Webster, J. D., Bohlmeijer, E. T., \& Westerhof, G. J. (2010). Mapping the future of reminiscence: A conceptual guide for research and practice. Research on Aging, 32, 527-564.

Webster, J. D., \& Gould, O. (2007). Reminiscence and vivid personal memories across adulthood. International Journal of Aging \& Human Development, 64, 149-170.

Webster, J. D., \& McCall, M. E. (1999). Reminiscence functions across adulthood: A replication and extension. Journal of Adult Development, 6, 73-85.

Westerhof, G. J., Bohlmeijer, E. T., van Beljouw, I. M. J., \& Pot, A. M. (2010). Improvement in personal meaning mediates the effects of a life-review intervention on depressive symptoms in a randomized controlled trial. The Gerontologist, 50, 541-549.

Westerhof, G. J., Bohlmeijer, E. T., \& Webster, J. D. (2010). Reminiscence and mental health: A review of recent progress in theory, research, and intervention. Ageing \& Society, 30, 697-721.

White, M. (2007). Maps of narrative therapy. New York: W. W. Norton.

White, M., \& Epston, D. (1990). Narrative means to therapeutic ends. New York, NY: W. W. Norton.

Williams, J. M. G., \& Broadbent, K. (1986). Autobiographical memory in attempted suicide patients. Journal of Abnormal Psychology, 95, 144- 149.

Williams, J. M., Barnhofer, T., Crane, C., Herman, D., Raes, F., Watkins, E., et al. (2007). Autobiographical memory specificity and emotional disorder. Psychological Bulletin, 133, 122-148.

Wong, P. T. (1995). The processes of adaptive reminiscence. In B. K. Haight \& J. D. Webster (Eds.), The art and science of reminiscing: Theory, research, methods, and applications (pp. 23-35). Pennsylvania, PA: Taylor and Francis. 


\section{LIFE-REVIEW IN GROUPS? AN EXPLORATIVE ANALYSIS OF SOCIAL PROCESSES THAT FACILITATE OR HINDER THE EFFECTIVENESS OF LIFE-REVIEW}

Korte, J., Drossaert, C.H.C., Westerhof, G.J., \& Bohlmeijer, E.T. (submitted). Life-review in groups? An explorative analysis of social processes that facilitate or hinder the effectiveness of life-review. 


\section{CHAPTER}

\section{ABSTRACT}

Life-review can be implemented within a group as well as on an individual level. There has been some discussion about which format is most effective. This study investigates the social aspects of a life-review group intervention from the perspective of the client within the context of a large, randomized controlled trial. This was an exploratory study using a qualitative methodology. We conducted semi-structured interviews to explore how participants felt about the benefits and barriers of receiving life-review in a group. Transcripts of the interviews were analyzed using inductive analysis. The social processes of life-review in a group included experiencing a sense of belonging, feeling accepted, finding good company, disclosing oneself, learning to express oneself, finding recognition, realizing that others have problems too, being more successful at coping than others, learning from others, and being able to help others. Negative processes were less often mentioned and included having difficulties with sharing in a group, finding no recognition, and anxiety caused by the prospect of finding no recognition. These social processes can be divided into three categories: first, having a good atmosphere in the group; second, disclosure to peers; and third, relating to others. Our results suggest that offering lifereview in a group setting may have added value. Clients experienced a variety of social processes that enhance the effects of the therapy. Future research, however, is needed to further examine the importance of these social processes and their effects on depression. 


\section{$\overline{\text { INTRODUCTION }}$}

Life-review can be regarded as an evidence-based treatment of depression in later life (Bohlmeijer, Smit \& Cuipers, 2003; Korte, Bohlmeijer, Cappeliez, Smit \& Westerhof, 2012; Pinquart, Duberstein \& Lyness, 2007; Pinquart \& Forstmeier, 2012). It refers to a structured evaluation of one's life in a manner that involves two distinct but related adaptive processes; integrative reminiscence and instrumental reminiscence (Butler, 1963; Haight, 1992; Westerhof, Bohlmeijer \& Webster, 2010; Wong, 1995). Integrative reminiscence is the integration of both positive and negative memories within the life-story of an individual, whereas instrumental reminiscence concerns the use of past memories to cope with present problems and challenges (Cappeliez, 2002; Watt \& Cappeliez, 2000; Westerhof et al., 2010; Wong, 1995). Life-review interventions seem especially suited for older adults who experience loss of meaning in life and who hold a negative view of themselves. Critical life-events may increase the use of specific negative functions of reminiscence such as reviving bitter experiences or escaping from past problems (Cappeliez, 2002; Wink \& Schiff, 2002; Wong, 1995). Associations between these functions and poorer mental health have been found (Cappeliez \& O'Rourke, 2006; Cappeliez, O'Rourke \& Chaudhury 2005; Cully, LaVoie \& Gfeller, 2001; Korte, Bohlmeijer, Westerhof \& Pot, 2011; O'Rourke, Cappeliez \& Claxton, 2011). Moreover, it has been recently demonstrated that diminishing these negative reminiscence functions in a life-review intervention leads to a reduction in the symptoms of depression and anxiety (Korte, Westerhof \& Bohlmeijer, 2012).

An important next step in intervention research is to study the mechanisms of life-review interventions. The present study investigates the added value of implementing life-review in a group format from the perspective of the client. Life-review can be implemented both as a group intervention and as an individual intervention. There has been some discussion about which format is most effective. Haight, Coleman and Lord (1995) stressed that conducting the intervention at an individual level is the linchpin of life-review as it provides a sense of safety for discussing and sharing sensitive issues. Additionally, individual sessions can be easily adapted to the personal needs of the participant (Pinquart \& Forstmeier, 2012). However, the usefulness of group formats has also been underscored, in that they offer possibilities for exchanging life experiences and learning from other group members (Birren \& Deutschman, 1991; Bohlmeijer, Westerhof \& Emmerik-de Jong, 2008; Korte et al., 2012; Watt \& Cappeliez, 2000). It has been hypothesized that individual interventions may be more significant in reducing depression and enhancing self-esteem, and that group interventions may be more effective in enhancing life satisfaction, psychological well-being and social integration (Haight \& Dias, 1992). However, meta-analytic evidence indicates that individual and group formats are equally effective in reducing depressive symptoms (Bohlmeijer et al., 2003; Pinquart \& Forstmeijer, 2012). The question regarding which format is more effective might also depend on the setting in which life-review is implemented. It has been shown that individual life-review is effective for frail, older adults mainly living in nursing homes and who are in the last years of their lives (e.g., Haight, Michel \& Hendrix, 1998; Haight, Michel \& Hendrix, 2000; Serrano, Latorre, Gatz \& Montanes, 2004). The positive effects of life- 
review in groups have been demonstrated in younger older adults (e.g., Bohlmeijer et al., 2008; Cappeliez, 2002; Pot, Bohlmeijer, Onrust, Melenhorst, Veerbeek \& De Vries, 2009; Korte et al., 2012). These findings might suggest that old older adults benefit more from more traditional life-review, which was originally described by Butler (1974) as an individual process of coming to terms with unresolved conflicts from the past and with approaching vulnerability and death. Young older adults might benefit more from life-review in a group setting which involves evaluating one's entire lifespan and setting realistic future goals in the presence of like-minded people (Westerhof et al., 2010).

In summary, it remains unclear whether life-review is more effective individually or in a group setting. Insights into how social processes might facilitate or hinder the effectiveness of life-review are still missing. Moreover, the group processes of lifereview have never been studied from the perspective of the client. Understanding clients is important from a clinical perspective. Clients can help us to understand what works in day-to-day, descriptive layman's terms. This yields valuable information about how interventions should be developed in order to address specific problems as they are perceived by clients (Gallegos, 2005; Hanson \& Young, 2012). This manuscript addresses the above information gaps by investigating what clients regard as the positive and negative aspects of receiving life-review in a group setting. The present study was conducted in the context of a large, randomized controlled trial (Korte et al., 2012). In this trial it was shown that, compared with care-as-usual, participants in the life-review condition reported significantly decreased symptoms of depression with moderate effect sizes, both at post-treatment and 3-month follow-up. The aim of the present study is two-fold. First, we will explore which social processes take place in the life-review group intervention, according to the participants. Second, to gain more insight into the effectiveness of the group format, we will investigate which processes might facilitate or hinder its effectiveness on depression.

\section{$\overline{M E T H O D S}$}

\section{Design}

This was an exploratory study using a qualitative methodology. We conducted semistructured interviews with 20 participants to explore how they value the social aspects of a life-review group intervention. Transcripts of the interviews were analyzed using inductive analysis.

\section{Context}

The present study was part of a large, multi-site, pragmatic randomized controlled trial that evaluated the effectiveness of "The stories we live by"; a life-review group intervention for older adults with mild to moderate depressive symptoms (Korte et al., 2012). In total, 202 participants were randomly assigned to the life-review group intervention ( $n=100)$ or to care-as-usual $(n=102)$. The design of the RCT has been described in detail elsewhere (Korte, Bohlmeijer \& Smit, 2009). 
The life-review intervention was developed by Bohlmeijer \& Westerhof (2010) and consisted of eight weekly sessions of two hours. The intervention had three core elements. First, the integration of difficult life-events from the past; second, the development of meaningful and agentic life-stories that help the participants to better cope with present life-events and to set new goals; third, the retrieval of specific positive memories which can serve as building blocks for the new life-stories. The intervention was implemented in small groups of four people. This small group format guarantees that every participant has enough time during each session to discuss his or her autobiographical writings and reflections. In addition, the therapists who offered the interventions were responsible for facilitating the group process. In the introductory session, they made the appropriate arrangements with the participants regarding confidentiality. During the intervention meetings, participants had the opportunity to exchange and discuss their experiences with one another. The therapists ensured that each individual participant had an equal amount of time to share his or her life-story.

\section{Sample}

In the current study, 20 participants were selected for the semi-structured interviews, which took place three weeks after the final session of the intervention. To gain more insights into the social processes of life-review which might facilitate or hinder its effectiveness, participants were selected based upon the effectiveness of the intervention on depressive symptoms. Hence, the current study sample includes two groups of participants. The first group consisted of 10 participants who demonstrated a substantial reduction in depressive symptoms after the intervention (a difference of $\geq 5$ on the Center for Epidemiological Studies Depression Scale (CES-D); Beekman, Deeg, van Limbeek, Braam, de Vries \& van Tilburg, 1997), while the second group consisted of 10 participants whose depressive symptoms did not improve (a difference of $\leq 1$ or an increase on the CES-D). These two groups of participants were randomly selected and did not differ with regard to age and sex. Participants had a mean age of 62 years and $80 \%$ of them were female, which is representative for the total sample of participants in the RCT.

\section{Data collection}

Participants were interviewed individually, following a semi-structured interview schedule to allow flexibility, individual contextualization and probing of issues that arose (Smith, 1995).

The interviews were part of a process evaluation, in which the general impact of the intervention was evaluated. Participants were questioned about their positive and negative experiences with the intervention and particular attention was also paid to the specific components of the intervention. The main focus of this study was how the participants experienced life-review in a group setting both positively and negatively. Therefore, the most important question encapsulating the essence of this study was how participants felt about sharing their personal experiences in a group. In addition, all interviews were scanned for other relevant quotes that referred to other social aspects of life-review. 
All interviews were conducted in the participants' homes. The interviews lasted between 45 and 120 minutes. Before the interview, all participants gave their written informed consent. The interviews were audiotaped with the participants' permission and transcribed verbatim. Transcripts were anonymized and only one researcher (JK) had access to the participants' names.

\section{Data analysis}

All data were analyzed by two coders (JK and CHCD). The coders were blinded with regard to the effects of the intervention on the participants' depression. During the first stage of the process, both coders read the transcripts in their entirety, several times, to familiarize themselves with the data and identify emerging social themes. Relevant quotes were selected and divided into themes and subthemes by each of the two coders independently, using inductive analysis (Patton, 1990). The two coders met to discuss their findings and resolve any differences, and subsequently developed a thematic framework that is presented in Table 1. During the next step of the process, each interview was independently reread and recoded using this thematic framework. A coding sheet was filled out for each participant to identify whether a particular social theme was present or not (Table 2). The results were then discussed to reach absolute consensus.

All quotes presented in this article were translated from Dutch into English by a native English-speaker. To ensure anonymity, we removed all identifying information from the quotes.

\section{RESULTS}

In general, clients mentioned many more benefits (positive processes) than barriers (negative processes) when asked about their experiences of taking part in the life-review intervention in a group setting. All themes that derived from the analysis have been summarized in Table 1 and discussed below.

\section{Positive social processes}

Ten positive social processes of life-review were identified. They can be divided into three categories.

\section{Good group atmosphere}

The first category was described as "good group atmosphere" and included a sense of belonging, feeling accepted and finding good company. Respondents mentioned a good atmosphere as being a precondition for sharing, but many also described the atmosphere in the group as a beneficial, healing process in its own right.

Sense of belonging. Almost all of the participants experienced a sense of belonging to the group: "You don't really know each other, so the fact that you can actually come 
together in a group and say: "like we have just done now..." - that is what creates a bond.". Besides, participants valued the good and open atmosphere within the group: "It was very open. No holds were barred. People could say whatever they wanted, very emotional issues were also dealt with". This good atmosphere enabled participants to feel safe enough to share intimate experiences: "Opening up came very naturally to us, actually. We felt safe enough to share our experiences" and "Don't forget: It was a safe and trusted group. The following was also said: we expect all of you to be sure that whatever you say in the group will stay in the group. That meant that each person found it easier to take the plunge and share something in the group. And so then you just came to expect it of each other.".

Feeling accepted. A related aspect to experiencing a sense of belonging was that most participants felt accepted, understood and heard by the other participants and therapists. Many participants perceived this acceptance by others as beneficial and rewarding, as is illustrated by the following quotes: "I was taken very seriously when I was there: that did me a lot of good" and "I was never able to say stuff like "how do you experience this?" or "how did you feel about that?". It was definitely nice to be in a new situation for a change, and to be able to talk about your past. In an environment where I was not seen as someone who only ever cried their eyes out or complained.".

Finding good company. Finally, some participants mentioned that they simply appreciated the personal contact with other peers: "I found it intimate and cosy.". In some cases, participants even became friends with each other.

\section{Disclosure to peers}

The second category referred to disclosure to peers, which involved disclosing oneself and learning to express oneself.

Disclosing oneself. Many interviewees indicated that they felt good, proud or relieved about sharing experiences and expressing emotions with others. For example: "I experienced it as being very invigorating and sometimes also a great relief that you could share such things with each other". Sometimes, participants admitted that they had never spoken before about those emotional experiences: "I thought that I would never be as open as that, and that I would never dare to talk about such things after everything I have been through. And yet, a kind of energy is released, with all of us together, so that it just ends up coming out". Some participants said that they were able to disclose their experiences only because they were in the company of people whom they felt were in the same boat: "Any feelings of embarrassment tend to leave you when you are in the middle of such an exercise. You can be totally open about yourself because everyone is in this together".

Learning to express oneself. Aside from the fact that participants felt good about sharing experiences, a few participants mentioned explicitly that they had learned to express themselves better by sharing their experiences with others: "I believe that I have become more self-assured, I also find it much easier to speak out". Other participants explicitly 
gained better personal insights into the way they act and present themselves through direct comments from others in the group: "During the sessions it was revealed that I simply assume that other people will automatically understand me, without me having to say anything to them. That is not the case. So I learned that in fact I must say something if I want to be sure that somebody else has truly understood me.".

\section{Relating to others}

The third category referred to the process of "relating to others" and included finding recognition, realizing that others have problems too, being more successful at coping than others, learning from others, and being able to help others.

Finding recognition. Many participants found recognition in the life-stories and experiences of other participants: "Something that also happened with amazing regularity was that we found recognition in each other's stories. It is fantastic to find such recognition". Mainly, participants recognized themselves in other participants because they were of the same age and generation: "We all belong to the same generation, so you hear a lot of things like "Oh yes, look at these photos, the outfits, that image of the 1950s, and those parents and how they behaved'" and "The generations where the focus was heavily on upbringing - that keeps coming up time and time again".

Realizing that others have problems too. Many participants compared their own experiences with those of the other participants. They realized that they were not the only ones who had been through a lot during their lives and they felt good about that insight: "It is a fantastic feeling to know that so many other people are also struggling with all sorts of problems" and "In my case, it suddenly dawned on me that other people have also had their own personal struggles to contend with. There are very few people who go through life without encountering a single problem." By comparing their own experiences with others, participants noticed that almost everybody has their own problems. This helped participants to put their problems and experiences into perspective: "You put everything into perspective. In the sense that other people also go through a lot. It is just part of life. You encounter loss, almost everyone has experienced that. When you get older, you will always have people whom you will lose.".

Being more successful at coping than others. Another way in which participants compared their own experiences with those of the other participants was that some noticed that they were better able to cope with certain life experiences and problems than their peers in the group: "I thought that I was actually the strongest one out of the other three participants when it came to conjuring up positive memories". Other participants felt proud about the very fact that they had survived despite all the misery they had experienced: "Despite all the horrible things that I have experienced, when I look at myself and compare myself to the other participants, then I actually come out very well."

Learning from others. Besides finding recognition, many participants found it beneficial to learn from the other participants' life-stories, how others have coped with particular life 
experiences, situations or problems. Examples are: "Through their personal experiences they have given me some extra bonus points. This is why it is good to talk to other people once in a while" and "When we discussed it with each other, then the other participants sometimes gave very wise answers." .

Being able to help others. Participants not only reported that they learned something from others, some of them also discovered that they can offer something meaningful to somebody else: "The fact that you are capable of helping others in some small way too. Offering them a listening ear and being open to their needs". Some participants demonstrated to other participants how they coped with certain situations. In this way, they experienced that they could be a good example to others: "I helped those other ladies too. After all, I interpreted it in my own way. When you get older, you become more laid back in the way you think about things and this, in my view, was the advantage that I had compared to the other participants.".

\section{Negative social processes}

Negative social processes could be divided into three themes, which included difficulties with sharing in a group, finding no recognition, and anxiety caused by the prospect of finding no recognition.

Difficulties with sharing in a group. A few participants did not acknowledge the good atmosphere in the group. They felt uncomfortable about sharing their own personal experiences in a group setting: "I found it difficult to reveal things about myself in front of others. I just don't feel comfortable talking about myself". Other participants realized that they are not much of a group person: "I'm not really a group person, actually. In fact, I'm a bit reserved and quite shy" and "I'm not a great talker. I'm quite good at talking to people on a one-to-one basis, but when I am in the company of a lot of people I tend to become very nervous.".

Finding no recognition. Some participants explicitly experienced that they were not recognized by the other participants or by the therapists: "I believe in God and get a lot of support from this, others simply said: oh, I don't believe in God at all.". One participant even felt misunderstood: "Sometimes I was cut off mid-sentence; they just misunderstood me. I found that awful.".

Anxiety about the prospect of not finding recognition. Sometimes participants had an implicit anxiety about not being recognized by the other participants: "When you had to tell your own personal life-story, then all the old fears came to the surface again: Will I be understood? and Can I actually say this? Am I sharing too much?". Some participants were afraid that their story was not interesting enough to share: "I feel that my own lifestory was not interesting enough, but of course that was not such a big issue". Other participants worried about not being a good storyteller: "I was worried that I would not be able to tell my story in a spirited enough way.". 
Table 1. Positive and negative social processes of life-review

\begin{tabular}{|c|c|}
\hline Themes & Typical quote \\
\hline \multicolumn{2}{|l|}{ Positive processes } \\
\hline \multicolumn{2}{|l|}{ Good group atmosphere } \\
\hline Sense of belonging & $\begin{array}{l}\text { It was very open. No holds were barred: you could say whatever } \\
\text { you wished, all the emotional issues were dealt with too. }\end{array}$ \\
\hline Feeling accepted & I was taken seriously and that felt great. \\
\hline Finding good company & I found it intimate and cosy. \\
\hline \multicolumn{2}{|l|}{ Disclosure to peers } \\
\hline Disclosing oneself & $\begin{array}{l}\text { I thought that I would never be as open as that, and that I would } \\
\text { never dare to talk about such things after everything I have been } \\
\text { through. And yet, a kind of energy is released, with all of us toge- } \\
\text { ther, so that it just ends up coming out. }\end{array}$ \\
\hline Learning to express oneself & $\begin{array}{l}\text { I believe that I have become more self-assured, I also find it much } \\
\text { easier to speak out. }\end{array}$ \\
\hline \multicolumn{2}{|l|}{ Relating to others } \\
\hline Finding recognition & $\begin{array}{l}\text { Something that also happened with amazing regularity was that } \\
\text { we found recognition in each other's stories. It is fantastic to find } \\
\text { such recognition. }\end{array}$ \\
\hline $\begin{array}{l}\text { Realizing that others have } \\
\text { problems too }\end{array}$ & $\begin{array}{l}\text { It is a fantastic feeling to know that so many other people are also } \\
\text { struggling with all sorts of problems. }\end{array}$ \\
\hline $\begin{array}{l}\text { Being more successful at } \\
\text { coping than others }\end{array}$ & $\begin{array}{l}\text { Despite all the horrible things that I have experienced, when I } \\
\text { look at myself and compare myself to the other participants, } \\
\text { then I actually come out very well. }\end{array}$ \\
\hline Learning from others & $\begin{array}{l}\text { Through their personal experiences they have given me some } \\
\text { extra bonus points. This is why it is good to talk to other people } \\
\text { once in a while. }\end{array}$ \\
\hline Being able to help others & $\begin{array}{l}\text { The fact that you are capable of helping others in some small way } \\
\text { too. Offering them a listening ear and being open to their needs. }\end{array}$ \\
\hline \multicolumn{2}{|l|}{ Negative processes } \\
\hline $\begin{array}{l}\text { Difficulties with sharing in a } \\
\text { group }\end{array}$ & $\begin{array}{l}\text { I found it difficult to reveal things about myself in front of others. } \\
\text { I just don't feel comfortable talking about myself. }\end{array}$ \\
\hline Finding no recognition & $\begin{array}{l}\text { I believe in God and this gives me a lot of inner strength, but } \\
\text { others in the group just said: well, I don't believe in God at all. }\end{array}$ \\
\hline Anxiety of no recognition & $\begin{array}{l}\text { When you had to tell your own personal story, then all the old fears } \\
\text { came to the surface again: Will I be understood and Can I actually } \\
\text { say this? Am I sharing too much? }\end{array}$ \\
\hline
\end{tabular}




\section{Differences between participants}

Table 2 shows the number of participants that mentioned a particular social process at least once in their interview. Although the data should be interpreted with caution due to the small sample size, Table 2 shows the differences between participants that had a decrease in depressive symptoms after the interventions, and participants that did not. As can be seen, for most processes there were only small differences to no differences at all in participants' experiences. There were no differences at all for the positive social theme of being more successful at coping than others and for the negative social themes of finding no recognition and anxiety about the prospect of finding no recognition. There were small differences (10\% or $20 \%$ ) for the positive social processes of gaining a sense of belonging, feeling accepted, finding good company, disclosing oneself, learning to express oneself, finding recognition, learning from others and being able to help others (all of these were reported somewhat less frequently by the participants with no improvement in depressive symptoms, except for the themes of being able to help others and learning to express oneself). Moderate differences (30\% or more) were found for the positive social theme of realizing that others have problems too (this was more frequently reported by participants who showed an improvement in depressive symptoms) and for the negative social theme of difficulties with sharing in a group (this was more frequently reported by participants with no improvement in their depressive symptoms). 
Table 2. Differences between participants with and without improved depressive symptoms

\begin{tabular}{|c|c|c|c|c|c|c|}
\hline \multirow[b]{2}{*}{ Themes } & \multicolumn{2}{|c|}{ Total sample $(N=20)$} & \multicolumn{2}{|c|}{ Improvement $^{\mathrm{a}}(\mathrm{n}=10)$} & \multicolumn{2}{|c|}{ No improvement ${ }^{\mathrm{b}}(n=10)$} \\
\hline & $n$ & $\%$ & $n$ & $\%$ & $n$ & $\%$ \\
\hline \multicolumn{7}{|l|}{ Positive processes } \\
\hline \multicolumn{7}{|l|}{ Good group atmosphere } \\
\hline Sense of belonging & 13 & 65 & 7 & 70 & 6 & 60 \\
\hline Feeling accepted & 9 & 45 & 5 & 50 & 4 & 40 \\
\hline Finding good company & 3 & 15 & 2 & 20 & 1 & 10 \\
\hline \multicolumn{7}{|l|}{ Disclosure to peers } \\
\hline Disclosing oneself & 8 & 40 & 5 & 50 & 3 & 30 \\
\hline $\begin{array}{l}\text { Learning to express } \\
\text { oneself }\end{array}$ & 3 & 15 & 1 & 10 & 2 & 20 \\
\hline \multicolumn{7}{|l|}{ Relating to others } \\
\hline Finding recognition & 8 & 40 & 5 & 50 & 3 & 30 \\
\hline $\begin{array}{l}\text { Realizing that others have } \\
\text { problems too }\end{array}$ & 7 & 35 & 5 & 50 & 2 & 20 \\
\hline $\begin{array}{l}\text { Being more successful at } \\
\text { coping than others }\end{array}$ & 4 & 20 & 2 & 20 & 2 & 20 \\
\hline Learning from others & 8 & 40 & 5 & 50 & 3 & 30 \\
\hline Being able to help others & 4 & 20 & 1 & 10 & 3 & 30 \\
\hline \multicolumn{7}{|l|}{ Negative processes } \\
\hline $\begin{array}{l}\text { Difficulties with sharing in } \\
\text { a group }\end{array}$ & 4 & 20 & 0 & 0 & 4 & 40 \\
\hline Finding no recognition & 3 & 15 & 2 & 10 & 1 & 10 \\
\hline Anxiety of no recognition & 4 & 20 & 2 & 20 & 2 & 20 \\
\hline
\end{tabular}

Note. ${ }^{a}$ difference of $\geq 5$ on the Center for Epidemiological Studies Depression Scale (CES-D), ${ }^{b}$ difference of $\leq 1$ or an increase on the CES-D 


\section{$\overline{\text { DISCUSSION }}$}

In this study we aimed to explore the social processes of life-review that might facilitate or hinder its effectiveness from the perspective of the client. The results of this study show that conducting life-review in a group is highly appreciated by the participants and that the group format might facilitate the effects of life-review. In general, clients reported many more benefits (positive processes) than barriers (negative processes) in relation to receiving life-review in a group.

Ten social processes were identified that may improve the effect of life-review. These processes could be further divided into three categories. The first category refers to having a good atmosphere in the group. The most important themes within this category were experiencing a sense of belonging and feeling accepted and feeling safe enough to share life-stories with others. These aspects seem to be prerequisites for an effective lifereview group intervention. When sharing experiences, a warm and accepting atmosphere must be present for health benefits to appear (Lepore \& Helgeson, 1999; Lepore, Silver, Wortman \& Wayment, 1996). This warm and accepting group atmosphere is related to the concept of wisdom environment (Randall \& Kenyon, 2002), which is defined as an environment where stories are told and listened to in an open, non-judgmental manner, in order to help co-author life-stories. Having a good atmosphere in the group is not only a prerequisite, but might also be a direct beneficial consequence of participating in a group intervention. It may be a very rewarding (and healing) experience to have full attention from people who are able to understand your situation in a way that does not happen in daily life. As participants form attachments they experience emotional support from each other, which involves expressions of caring, encouragement and reassurance (Helgeson \& Gottlieb, 2000). Unfortunately, some participants felt uncomfortable when sharing their experiences in a group. This aspect seems to be related to the effectiveness of life-review, as it was reported more frequently by participants who showed no improvement in their depression. Our findings underscore the importance of having a good atmosphere in a group. Therefore, we stress the importance of creating a warm, open and accepting atmosphere. This might be achieved by using strategies to facilitate the group process as used in the present study. These strategies involve implementing life-review interventions in small groups, making arrangements with the participants regarding confidentiality, and taking care that each individual participant has an equal amount of time to share his or her life-story. Additionally, these results have implications for the inclusion of participants in a life-review group intervention. It should be a requirement that participants are willing to review their lives in a group and that they are willing to share their experiences with others. If people are not willing to do this or are unable to do this, they should be referred to individual life-review therapy. Another theme that was linked to having a good atmosphere in a group was that some participants found that they enjoyed the company of each other.

The second category involves disclosing to peers. Many of the respondents described it as a relief that they were able to disclose their personal life-story to others. It has been shown that disclosing and expressing feelings about traumatic events has 
health benefits (Pennebaker \& Beall, 1986; Pennebaker, Colder \& Sharp, 1990). Being able to disclose and express oneself can be seen as important steps in the process of integrating painful memories; which is an important adaptive mechanism of life-review (Wong, 1995). By recounting painful memories, participants will be able to become aware of the impact of painful events on their lives, work through the emotions, and begin the process of acceptance and integration with the present. In this way, both the positive and negative experiences of the past can be incorporated into participants' self-concepts (Cappeliez, 2002; Wong, 1995).

The third category of group processes refers to relating to others. An important process in this category is finding recognition from the group, which involves the validation of each other's experiences. This requires another participant to have had similar experiences and, hence, understand them (Helgeson \& Gottlieb, 2000). Conversely, some participants found no recognition or experienced anxiety about the prospect of not finding recognition. One reason why validation might not occur is that not all group members respond in the same way to a certain level of distress (Coates \& Winston, 1983), or that the group is too heterogeneous, and participants therefore have too few experiences in common (Helgeson \& Gottlieb, 2000). Other social aspects reported by participants involve social comparison. In times of uncertainty or stress, people compare themselves with others to evaluate their feelings and abilities (Festinger, 1954). Realizing that others have problems too may normalize the experience (Helgeson \& Gottlieb, 2000). Indeed, in our study many participants reported that they found it helpful to learn that others face similar problems. Participants also compared themselves with others who were less successfully coping with their problems than they were. This so-called "downward social comparison" is supposed to enhance self-esteem, as participants are enabled to feel fortunate about their own circumstances in comparison with others who are worse off (Wills, 1981). Another social process was that participants learned from other participants. It is most likely that participants are able to provide sound advice and useful ideas about ways of coping because they have first-hand experience with the stressor (Helgeson \& Gottlieb, 2000). In addition to participants being able to learn from others, they were also able to help others. This refers to the "helper-therapy principle" (Riessman, 1965). Helping others leads to feelings of self-efficacy and competence, which might increase positive feelings about the self. These aspects might be optimally utilized when group leaders adopt an attitude of curiosity and not-knowing. In this way, co-authorship is created which enables participants to restructure their life-stories according to their own preferences (White \& Epston, 1990). The above processes all help participants to develop the skills required to cope with their problems, which according to Carkhuff (1973) is a main ingredient in the effectiveness of group therapy. These processes may strengthen instrumental reminiscence, an adaptive mechanism of life-review. To effectively deal with life experiences, people need a sense of mastery and competence. By comparing their own experiences with other participants, people become aware of adverse and successful coping strategies, which might help them to effectively cope with present difficulties (Cappeliez, 2002; Wong, 1995).

One might wonder whether the group processes as reported in this study are unique to life-review interventions. The social aspects of life-review can be regarded 
as more generic, non-specific factors of any therapeutic intervention. Such non-specific factors have repeatedly been shown to produce improvements in client outcomes (Corey \& Corey, 2002; Horvath \& Bedi, 2002). In order to gain a better understanding of the mechanisms of life-review, we compared the processes that were mentioned by participants who benefitted from the therapy with those mentioned by participants who did not benefit from the life-review (i.e., improved on scores on depression). Although the results must be interpreted with some caution due to the small sample size, patients without an improvement mention on average somewhat fewer positive social processes and more negative social processes. More specifically, it seems that participants who benefited from the intervention make more social comparisons, meaning that they are better able to normalize their experiences. These results suggest that social comparisons facilitate the effectiveness of life-review on depression.

Some strengths and limitations should be acknowledged in this study. Our study is the first that investigated the additional value of offering life-review in a group setting and from the perspective of the client. One limitation is that the study sample was rather small. As we achieved data saturation, we can assume that all relevant social processes have been identified. However, to gain more insight into to the extent to which each of these social processes is experienced, more quantitative studies are needed. Moreover, experimental studies are needed to investigate whether a group life-review intervention is indeed more effective than an individual life-review intervention, and to investigate whether social processes causally hinder or facilitate the effectiveness of life-review group interventions. These issues will be addressed by our future study in which we will use a large, randomized controlled trial to evaluate the effectiveness of two different life-review formats; a self-help intervention versus an intervention with online peer support.

To conclude, this study highlights the additional value of offering life-review in groups. Results showed that several positive social aspects are valued as important by participants. Feeling accepted and feeling safe enough to share life-stories with others, as well as experiencing a sense of belonging, seem to be prerequisites for an effective life-review intervention. Processes that were mentioned most frequently were: being able to disclose oneself, finding recognition, learning from others and realizing that others have problems too. Experimental studies are needed to investigate which social processes moderate or mediate the effectiveness of life-review. 


\section{REFERENCES}

Beekman, A.T.F., Deeg, D.J., van Limbeek, J., Braam, A.W., de Vries, M.Z., \& van Tilburg, W. (1997). Criterion validity of the Center for Epidemiologic Studies Depression scale (CES-D): Results from a community-based sample of older subjects in the Netherlands. Psychological Medicine, 27, 231-235.

Birren, J. E., \& Deutchman, D. E. (1991). Guided autobiography groups for older adults. Baltimore, MD: John Hopkins University Press.

Bohlmeijer, E., Smit, F., \& Cuipers, P. (2003). Effects of reminiscence and life review on late-life depression: A meta-analysis. International Journal of Geriatric Psychiatry, 18, 1088-1094.

Bohlmeijer, E. T., \& Westerhof, G. J. (2010). The stories we live by [in Dutch]. Amsterdam: Boom Uitgeverij.

Bohlmeijer, E. T., Westerhof, G. J., \& Emmerik-de Jong, M. (2008). The effects of integrative reminiscence on meaning in life: Results of a quasi-experimental study. Aging \& Mental Health, 12, 639-646.

Butler, R. N. (1963). The life-review: An interpretation of reminiscence in the aged. Psychiatry, 26, 65-76.

Butler, R. N. 1974. Successful aging and the role of the life review. Journal of the American Geriatrics Society, 22, 12, 529-535.

Cappeliez, P. (2002). Cognitive-reminiscence therapy for depressed older adults in day hospital and long-term care. In J. D. Webster and B. K. Haight (Eds.), Critical Advances in Reminiscence Work: From Theory to Application (pp. 300-313). New York, NY: Springer.

Cappeliez, P., O'Rourke, N., \& Chaudhury, H. (2005). Functions of reminiscence and mental health in later life. Aging \& Mental Health, 9, 295-301.

Coates, D., \& Winston, T. (1983), Counteracting the deviance of depression: Peer support groups for victims. Journal of Social Issues, 39, 169-194.

Cully, J. A., LaVoie, D., \& Gfeller, J. D. (2001). Reminiscence, personality, and psychological functioning in older adults. Gerontologist, 41, 89-95.

Festinger, L. (1954). A theory of social comparison processes. Human Relations, 7, $117-$ 140.

Gallegos, N. (2005). Study client perspectives on what contributes to symptom relief in psychotherapy: A qualitative outcome. Journal of Humanistic Psychology, 45, 355-382.

Haight, B. K., Coleman, P., \& Lord, K. (1995). The linchpins of a successful life review: Structure, evaluation and individuality. In B. K. Haight \& J. D. Webster (Eds), The art and science of reminiscing: Theory, research, methods and applications (pp. 179-192). Washington DC: Taylor \& Francis.

Haight, B. K. (1992). Long-term effects of a structured life-review process. Journal of Gerontology, 47, 312-315.

Haight, B.K., Michel, Y., \& Hendrix, S. (2000). The extended effects of the life review in nursing home residents. International Journal of Aging and Human Development, 50, 151-168. 
Haight, B.K, \& Dias, J. K. (1992). Examining key variables in selected reminiscing modalities. International Psychogeriatrics, 4, 279-290.

Haight, B.K., Michel, Y., \& Hendrix, S. (1998). Life review: Preventing despair in newly relocated nursing home residents short- and long-term effects. International Journal of Aging and Human Development, 47, 119-142.

Hanson, B., \& Young, M.A. (2012). Why depressive symptoms cause distress: The clients' perspective. Journal of Clinical Psychology, 68, 860-874.

Helgeson, V. S., \& Gottlieb, B. H. (2000). Support groups. In S. Cohen, L. G. Underwood, \& B. H. Gottlieb (Eds.), Social support measurement and intervention: A handbook for health and social scientists. Oxford: Oxford University Press.

Korte, J., Bohlmeijer, E.T., Cappeliez, P., Smit, F., \& Westerhof, G.J. (2012). Life-review therapy for older adults with moderate depressive symptomatology: A pragmatic randomized controlled trial. Psychological Medicine, 42, 1163-1173.

Korte, J., Bohlmeijer, E.T., \& Smit, F. (2009). Prevention of depression and anxiety in later life: design of a randomized controlled trial for the clinical and economic evaluation of a life-review intervention. BMC Public Health, 9, 250.

Korte, J., Westerhof, G. J., \& Bohlmeijer, E. T. (2012, online first). Mediating processes in an effective life-review intervention. Psychology and Aging, doi: 10.1037/ a0029273.

Korte, J., Bohlmeijer, E. T., Westerhof, G. J., \& Pot, A. M. (2011). Reminiscence and adaptation to critical life-events in older adults with mild to moderate depressive symptoms. Aging and Mental Health, 15, 638-646.

Lepore, S. J., \& Helgeson, V. S. (1999). Psychoeducational support group enhances quality of life after prostate cancer. Cancer research, therapy and control, 8, 81-92.

Lepore, S. J., Silver, R. C., Wortman, C. B., \& Wayment, H. A. (1996). Social constraints, intrusive thoughts, and depressive symptoms among bereaved mothers. Journal of Personality and Social Psychology, 70, 271-282.

O'Rourke, N., Cappeliez, P., \& Claxton, A. (2011). Functions of reminiscence and the psychological well-being of young-old and older adults over time. Aging \& Mental Health, 15, 272-281.

Patton, M. Q. (1990). Qualitative evaluation and research methods (2nd ed.). Newbury Park, CA: Sage.

Pennebaker, J.W., Beall, S.K. (1986). Confronting a traumatic event: Toward an understanding of inhibition and disease. Journal of Abnormal Psychology, 95, 274-281.

Pennebaker, J.W., Colder, M., \& Sharp, L.K. (1990). Accelerating the coping process. Journal of Personality and Social Psychology, 58, 528-537.

Pinquart, M., Duberstein, P. R., \& Lyness, J. M. (2007). Effects of psychotherapy and other behavioral interventions on clinically depressed older adults: A metaanalysis. Aging \& Mental Health, 11, 645-657.

Pinquart, M., \& Forstmeier, S. (2012). Effects of reminiscence interventions on psychosocial outcomes: A meta-analysis. Aging \& Mental Health, 16, 541-558.

Pot, A. M., Bohlmeijer, E. T., Onrust, S., Melenhorst, A. S., Veerbeek, M., \& de Vries, W. 
(2010). The impact of life-review on depression in older adults: A randomized controlled trial. International Psychogeriatrics, 22, 572-581.

Randall, W., \& Kenyon, G. (2002). Reminiscence as reading our lives: Toward a wisdom environment. In J. Webster \& B. Haight (Eds.), Critical advances in reminiscence: Theoretical, empirical, and clinical perspectives (pp. 233-53). New York: Springer.

Reissman, F. (1965). The helper therapy principle. Social Work, 10, 29-38.

Serrano, J. P., Latorre, J. M., Gatz, M., \& Montanes, J. (2004). Life-review therapy using autobiographical retrieval practice for older adults with depressive symptomatology. Psychology and Aging, 19, 270-277.

Smith, J.A. (1995). Semi-structured interviewing and qualitative analysis. In J.A. Smith, R. Harre, \& L.V. Langenhove (Eds), Rethinking Methods in Psychology. London: Sage.

Watt, L.M., \& Cappeliez, P. (2000). Integrative and instrumental reminiscence therapies for depression in older adults: Intervention strategies and treatment effectiveness. Aging and Mental Health, 4, 166-177.

Westerhof, G. J., Bohlmeijer, E. T., \& Webster, J. D. (2010). Reminiscence and mental health: A review of recent progress in theory, research, and intervention. Ageing \& Society, 30, 697-721.

White, M., \& Epston, D. (1990). Narrative means to therapeutic ends. New York, NY: W. W. Norton.

Wills, T.A. (1981). Downward comparison principles in social psychology. Psychological Bulletin, 90, 245-271.

Wong, P. T. (1995). The processes of adaptive reminiscence. In B. K. Haight \& J. D. Webster (Eds.), The art and science of reminiscing: Theory, research, methods, and applications (pp. 23-35). Pennsylvania, PA: Taylor and Francis.

Wink, P., \& Schiff, B. (2002). To review or not to review? The role of personality and lifeevents in life review and adaptation to older age. In J. D. Webster \& B. K. Haight (Eds.), Critical advances in reminiscence work: From theory to application (pp. 44-60). New York, NY: Springer. 


\section{GENERAL DISCUSSION}




\section{CHAPTER}

\section{GENERAL DISCUSSION}

In this chapter, the three main aims of this thesis will be discussed. First, new insights in the relationship between reminiscence and mental health will be addressed. Second, the effectiveness of life-review for older adults with mild to moderate depressive symptoms will be discussed. Third, this chapter will elaborate on possible mechanisms of (group) life-review. Following this, the strengths and limitations of this thesis will be discussed, as well as implications for future studies and clinical practice. 


\section{Reminiscence and its adaptive functions}

The first aim of this thesis was to investigate the adaptive role of reminiscence in older adults with mild to moderate depressive symptoms. It has often been claimed that reminiscence may facilitate or hinder adaptation or healthy ageing in later life. Although the relationship between reminiscence and mental health has been studied extensively, three important knowledge gaps remain. These are addressed by this thesis. First, to the best of our knowledge, the way in which people reminisce has never been studied in direct correlation to changes in later life. Second, studies on reminiscence and mental health have been carried out mostly among the older population at large and not in clinically depressed sample groups. Third, it is still unclear how reminiscence is related to distress. In this thesis (see chapters 2 and 3 ), we were able to study the contextual factors of reminiscence, as well as the mental resources that mediate the relationship between reminiscence and mental health, in a sample of older adults with mild to moderate symptoms of depression.

Figure 1 in the general introduction (p. 7) described our hypotheses regarding the relationship between reminiscence and mental health, based on earlier findings (as described in the general introduction of this thesis), while Figure 3 (p. 16) describes the findings of this thesis. This section compares our findings with earlier findings on reminiscence and mental health and will discuss similarities and differences. Our first hypothesis was that contextual factors, i.e., the presence of chronic diseases and experiences of critical life events, influence how older adults look back upon their lives. Our results showed that older adults who experienced more critical life events reminisce more often for the purposes of reinforcing their identity and problem-solving; the so-called positive functions of reminiscence. Moreover, it was demonstrated that the relationship between critical life events and anxiety is mediated by problem-solving reminiscence (see chapter 2). Problem-solving reminiscence involves reflecting on past strategies, coping techniques and skill sets which enabled the person in question to cope successfully in the past. If people become aware and believe in the efficacy of such strengths, then current problems are less likely to generate anxiety. If older adults access memories of former successful coping strategies they feel reassured and this results in a reduction of anxiety. The experience of critical life events was not related to negative functions of reminiscence, i.e., bitterness revival and boredom reduction reminiscence. This finding might be explained by the nature of the life events. The life events that were found to be related to the positive functions were most often work-related, e.g., change of job and loss of employment. So, these are life events that lead to the revival of mental resources rather than the activation of regrets and boredom reduction. Remarkably, we did not find any relation between chronic medical conditions and reminiscence functions. This may be explained by the way in which the presence of chronic medical conditions was measured. Participants' medical conditions were considered chronic when they had been present for at least six months (or longer) at baseline. It might be that, in fact, the chronic medical conditions had been present for much longer. In such a case, the older adults might have already adapted to their disease.

Our second hypothesis was that, as in the general older population, in a sample of older adults with mild to moderate depressive symptoms positive reminiscence functions 
would be negatively related to distress, while negative reminiscence functions would be positively related to distress. Our results indeed showed a positive correlation of negative reminiscence with distress (i.e., depressive symptoms and anxiety symptoms) (chapters 2 and 3), which is in line with the findings for the general older population (Cappeliez \& O'Rourke, 2006; Cappeliez, O'Rourke \& Chaudhury, 2005; Cully, LaVoie \& Gfeller, 2001). However, no results were found for the relation between positive reminiscence functions and distress (chapters 2 and 3). This implies that the research on reminiscence functions in the general population can be partly generalized to older adults with symptoms of depression and anxiety, at least for the relation between negative reminiscence and distress.

Our third hypothesis was that reminiscence may foster mental health through the accumulation of feelings of mastery and meaning in life, which was partly confirmed by our findings. It was shown that positive reminiscence was positively related to mental resources, whereas negative reminiscence was negatively related to mental resources (chapter 3). Moreover, it was demonstrated that the negative functions of reminiscence were related to lower distress (depressive and anxiety symptoms) through the mental resources of mastery and meaning in life. These results mean that more frequent reminiscence for bitterness revival and boredom reduction is accompanied by lower levels of the mental resources of meaning in life and a sense of mastery. In turn, the negative relation between these mental resources and distress indicate that lower levels of mental resources are associated with increased distress. These findings underline the fact that mental resources, more specifically mastery and meaning in life, are important in explaining the link between negative reminiscence and distress. Other studies indeed acknowledged the adaptive function of meaning in life (Krause, 2004; 2007) and mastery (Zarit, Femia, Gatz \& Johansson, 1999) in depressive symptoms among older adults. These findings are largely in line with Cappeliez and Robitaille (2010). As in our study, they found a negative relation between negative reminiscence and coping (i.e., assimilative coping and accommodative coping). However, in contrast to our findings, they identified a significant mediation of the link between positive reminiscence and well-being by coping. Their model can only be partially expanded to people with mild to moderate distress and to the mental resources investigated in our study. Just as in most studies on reminiscence, the sample of Cappeliez and Robitaille's (2010) study was composed of a general sample of older adults, whereas our study specifically targeted older adults with mild to moderate depressive symptomatology. So again, we were unable to demonstrate a relationship between positive reminiscence and distress. Why does engaging in positive reminiscence functions not lead to decreased distress in older adults who are depressed? Studies on autobiographical memory have shown that depressed individuals have difficulties in recalling specific positive memories (Williams, Barnhofer, Crane, Herman, Raes, Watkins, et al., 2007). When engaging in positive reminiscence, they might in fact stick to overgeneral memories. This might not be helpful for the purposes of consolidating identity or finding a solution to a current problem. The self-reported use of positive reminiscence on the Reminiscence Functions Scale (Webster, 1993) might therefore not be related to depression. Serrano, Latorre, Gatz and Montanes (2004) showed that providing practice in producing specific positive memories is indeed effective in reducing distress among depressed older adults. 
To conclude, our findings contribute to the present body of knowledge on the relationship between reminiscence and mental health, both empirically and clinically. Our study affords a better understanding of how reminiscence is related to distress, especially in depressed older adults, by taking contextual factors into account. In this respect, we have shown how important mental resources, i.e., mastery and meaning, are. From a clinical perspective, our findings suggest that it is useful to focus on strengthening these mental resources in therapeutic, reminiscence-based strategies for older adults with depressive symptoms.

Figure 3. Critical life events, reminiscence, mental resources and distress in older adults with mild to moderate depressive symptoms

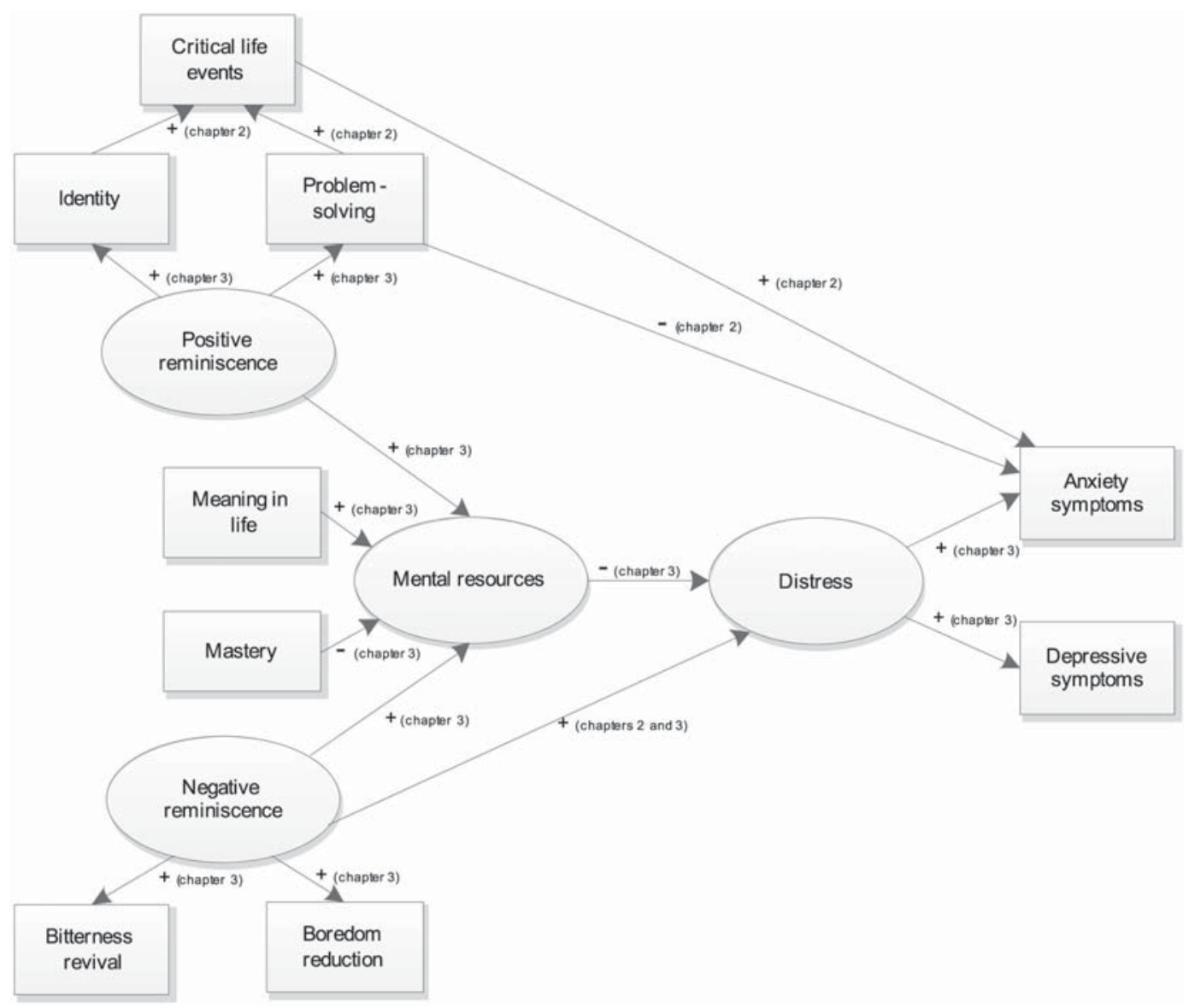




\section{Life-review for mild to moderate depressive symptoms in later life}

The second aim of this thesis was to evaluate the effectiveness of an early intervention that integrates life-review and narrative therapy ("The stories we live by") for older adults with mild to moderate depressive symptomatology. Although life-review can be regarded as an evidence-based treatment of major depression and is possibly also an effective early intervention for depression, its effectiveness has not been studied in large, pragmatic, randomized controlled trials (RCTs). This thesis evaluated the effectiveness of life-review under real-life conditions, using a large, pragmatic, multi-site RCT. In addition, the costeffectiveness of life-review was assessed relative to care-as-usual (see chapters 4 to 6).

Results indicated that life-review combined with narrative therapy is effective in reducing depressive symptoms. These effects were maintained at 3-month and 9-month follow-ups. Medium effect sizes for depressive symptoms were found, both posttreatment $(d=.60)$ and at follow-up ( $d=.50)$. These effect sizes are equal to the effect sizes that were reported in a recent meta-analysis by Pinquart and Forstmeier (2012) on the effectiveness of life-review on depression; .57 at post-treatment and .50 at follow-up. In an earlier meta-analysis it was shown that life-review was equally effective as cognitive and behavioural therapy in depression (Pinquart, Duberstein \& Lyness, 2007). These therapies were more effective in reducing depression than other psychological interventions, such as psychodynamic therapy or interpersonal therapy. The effect sizes in our study are also comparable to the effect size of .42 that was observed for early interventions on depression by Cuijpers, Smit and van Straten (2007). The proportion of participants that manifested with a reliable change in depressive symptoms (defined as a reduction on the CES-D of at least 5 points; Beekman, Deeg, van Limbeek, Braam, de Vries \& van Tilburg, 1997) was significantly higher in the intervention group; $54 \%$ against $26.5 \%$ in the control group. Moreover, the likelihood of a clinically significant change in depressive symptoms (defined as a reduction on the CES-D of at least 5 points, while crossing the cut-off value of 16 for clinically relevant depressive symptoms; Beekman et al., 1997; cf., Smit, Ederveen, Cuijpers, Deeg \& Beekman, 2006; Steunenberg, Beekman, Deeg \& Kerkhof, 2006) was significantly and substantially higher in the intervention condition than in the care-as-usual condition. These results delineate life-review as an effective early intervention for older adults with depressive symptoms. The effects on diagnosed major depression at the 3-month follow-up were not statistically significant ( $p=.08$ ). However, as effects on clinical cases of preventive and early interventions are most prominently found after longer periods of time (Cuijpers, van Straten, Smit, Mihalopoulos \& Beekman, 2008), it might be that the life-review intervention is effective after a longer follow-up period.

Each participant manifesting with a reliable improvement in depressive symptoms, cost $€ 5,550$ in the life-review condition, which was almost twice as much as the amount of $€ 3,162$ in the usual care condition. The incremental cost-effectiveness was $€ 8,675$ per improved participant. Hence, the life-review intervention produced superior health gains at additional costs relative to care-as-usual. However, it is often seen that a new intervention is successful in generating better health outcomes for higher costs. To decide whether the intervention offers good value for money requires an understanding of the willingness to pay (WTP) for a favourable treatment response. When the WTP is set at $€ 10,000$ for gaining an additional treatment response, then the probability that the 
intervention costs are acceptable is $57 \%$. When the WTP is raised to $€ 20,000$, then this probability has risen to $93 \%$ of being the acceptable treatment option. This suggests that at WTP ceilings of $€ 10,000$ and above the intervention must be regarded as offering good value for money. With the same thresholds, sensitivity analyses confirmed the robustness of the findings. Besides, it was shown that the intervention would have been more cost-effective when delivered by a single clinical psychologist instead of both a clinical psychologist and a prevention worker. The cost-effectiveness increased even more when, on top of this, the intervention was delivered in groups of 8 individuals (instead of 4-6 individuals). These findings remained robust when taking into account that reduced therapist involvement and larger groups might be associated with a lower effectiveness of the intervention, i.e., when it was assumed that the number of treatment successes was reduced by $5 \%$ and $10 \%$, respectively. Therefore, we recommend that life-review should be delivered by a single therapist and in larger groups as this may improve the cost-effectiveness.

To our knowledge, this thesis presents the first economic evaluation of a lifereview intervention. For this reason, we have to compare our results with other costeffectiveness studies on early interventions to prevent depression in older adults - which are also rather scarce. A recent study found that a stepped-care approach might be costeffective in preventing depression and anxiety in later life (van 't Veer-Tazelaar, Smit, van Hout, van Oppen, van der Horst, Beekman, et al., 2010). So it might be worth investigating whether life-review contributes to the cost-effectiveness of a stepped-care approach when offered as a second or third step within such a stepped-care framework. Another option worth investigating is offering life-review online. Internet-based interventions have the potential to reach target groups that cannot be reached by the more traditional treatments (Cuijpers \& Schuurmans, 2007). Besides, a first promising study shows that online interventions can be effective in reducing both anxiety and depression in later life (Spek, Nyklícek, Smits, Cuijpers, Riper \& Keyzer, 2007), and in fact can be costeffective (Warmerdam, Smit, van Straten, Riper \& Cuijpers, 2010). "The stories we live by" intervention is currently being developed as an online programme. We will start a large RCT to examine whether this programme is effective for people of 40 years of age and over with mild to moderate depressive symptoms.

In addition, this thesis demonstrated significant, albeit small, effects for anxiety symptoms and positive mental health (effect sizes between .25 and .29). A few studies also found effects for anxiety (Bohlmeijer, Roemer, Cuijpers \& Smit, 2007; Pot, Bohlmeijer, Onrust, Melenhorst, Veerbeek \& De Vries, 2010) and our results for positive mental health are in line with the effects on positive well-being as found by Pinquart and Forstmeier (2012). It seems that life-review has the potential not only to reduce symptoms of psychopathology but also to improve positive mental health; that is, emotional, psychological and social well-being. There is growing recognition that enhancing positive mental health is increasingly becoming an important objective in public mental health (Fledderus, Bohlmeijer, Smit, Westerhof, 2011; Jané-Llopis \& Barry, 2005; Keyes, 2005; Keyes, Dhingra \& Simoes, 2010; Lamers, Westerhof, Bohlmeijer, ten Klooster \& Keyes, 2012). No significant differences were found for quality of life, however. This might be explained by our method of measuring quality of life. The EQ-5D (Brooks, 1996) focuses on health-related quality of life across various health dimensions, which makes it unlikely that effects in a single domain are sufficient to cause a substantial change on the EQ-5D. 
After all, factors such as mobility and self-care are probably difficult to influence with a psychological intervention.

An important strength of this RCT is that life-review was evaluated in its natural setting, which strengthens its external validity. Hence, the Dutch healthcare system was mimicked as closely as possible in terms of patient recruitment and the way in which interventions are offered. The mental health services participating in the studies are comparable to other mental health care services in the Netherlands, which further strengthens the generalizability of the findings. An additional strength is the large number of participants that were included in the study on the effectiveness of life-review. It is the first study that evaluated the effectiveness of life-review in such a large sample. A further strength of this RCT is that it is the first attempt to evaluate the cost-effectiveness of life-review. Because we had obtained health care utilization data and data on changes in productivity at work, it was possible to study the cost-effectiveness of life-review from a societal perspective. Another strength is that a diagnostic interview was used (the Mini International Neuropsychiatric Interview (MINI); van Vliet \& de Beurs, 2007) to assess major depressive disorders according to the DSM-IV criteria, thus assessing the treatment effects at the level of psychiatric disorder, and not only at symptom level.

\section{The mechanisms of life-review}

The third aim of this thesis was to study possible mechanisms of life-review. Several studies on reminiscence and mental health (see the general introduction and chapters 2 and 3 of this thesis) have shown that reminiscence functions are only moderately related to mental health. However, it now appears that influencing these functions in reminiscence interventions is not only effective in promoting mental health, but might even be the major clinical pathway causing this effectiveness (see the section on the mechanisms of life-review). Studies within the general population suggest several possible moderators and mediators (e.g., Webster, Bohlmeijer \& Westerhof, 2010; Westerhof, Bohlmeijer \& Webster, 2010), but longitudinal studies on the mechanisms of life-review are scarce. Conceptually, an analysis of moderators would help to identify the subgroups for whom life-review is particularly effective, whereas an analysis of mediators may shed light on which elements of the intervention have the most therapeutic value (Kraemer, Wilson, Fairburn \& Agras, 2002). This thesis investigated possible moderators and mediators of a life-review intervention on the symptoms of depression and anxiety within the context of a large randomized controlled trial (chapters 5, 7 and 8). Figure 2 of the general introduction (p. 10) described our hypotheses regarding the mechanisms of life-review, while Figure 4 of the general discussion (p.18) shows our actual findings.

The moderating factors of life-review were studied in an explorative way (see chapter 5). We investigated a number of prognostic factors that might strengthen or weaken the effectiveness of life-review, i.e., sociodemographic variables, personality, reminiscence functions, past major depressive episodes, chronic medical conditions and critical life events. Figure 4 shows that we identified two significant moderators: the personality trait of extraversion and the reminiscence function of boredom reduction. The general lack of moderating effects suggests that the intervention is broadly applicable to a variety of participants. The intervention appears to be less suitable for people who are introvert and who tend to reminisce for boredom reduction. Additionally, our qualitative 
study suggested that feeling accepted and feeling safe enough to share your life-stories with others, as well as experiencing a sense of belonging, seem to be prerequisites for an effective life-review intervention (see chapter 8).

Regarding the mediating factors of life-review, we hypothesized that the effects of life-review on distress would be promoted and inhibited by positive and negative reminiscence, respectively and further modified by mental resources that have been theoretically proposed as mechanisms of life-review such as mastery, meaning in life and positive thoughts. Our results showed that a reduction in bitterness revival and boredom reduction reminiscence, and an increase in mastery and positive thoughts were associated with a significant decrease in depressive symptoms and anxiety symptoms at three-month follow-up (see chapter 7 ). These findings clearly illustrate that both integrative and instrumental reminiscence can play an important role in reducing depression and anxiety, which may be achieved via the accumulation of positive thoughts and mastery. In addition, from the perspective of the clients, several group processes appeared to be of importance for the effectiveness of life-review. Processes that were mentioned most frequently were being able to disclose oneself, finding recognition, learning from others and realizing that others have problems too (see chapter 8). To conclude, life-review appears to achieve its effectiveness in the following ways: by discouraging bitterness revival and boredom reduction reminiscence, by strengthening mastery and positive thoughts, and by stimulating group processes as learning to disclose oneself, finding recognition, learning from others and realizing that others have problems too.

In this thesis, some seemingly conflicting findings came forward when the studies of the

Figure 4. Mechanisms of life-review

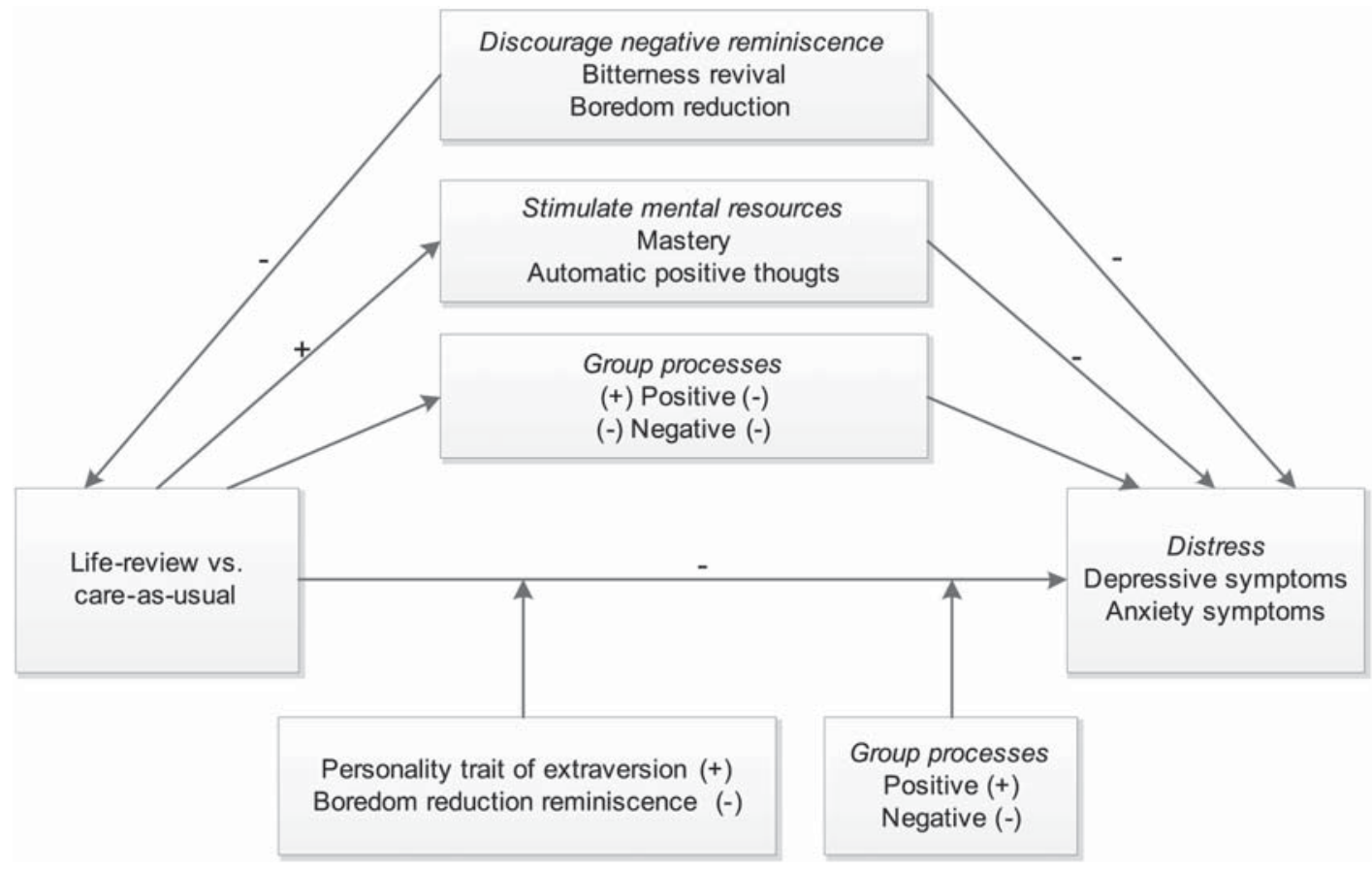


mechanisms of life-review (chapter 7) were compared with the studies that investigate the relation between reminiscence and mental health (chapters 2 and 3). These conflicting findings raise questions on how reminiscence functions should be studied and measured, and whether the elements in "The stories we live by" intervention are optimally designed to achieve the desired effect. Some studies in this thesis investigated the functions of reminiscence separately (chapters 2 and 7 ), while another study handled reminiscence as consisting of two latent factors, i.e., positive and negative reminiscence (chapter 3). It has been shown that both approaches have their added value, which suggests that there is not really a best way to study reminiscence, but that the chosen methodology must depend on the proposed hypotheses. Regarding the working elements of life-review, we obtained robust findings for the importance of negative reminiscence, mastery and positive thoughts, while the importance of meaning in life and positive reminiscence was not proven beyond doubt.

In chapter 2 it was found that problem-solving reminiscence mediated the relationship between critical life events and anxiety symptoms (chapter 2). Chapter 7 , however, shows no mediation effects for problem-solving reminiscence on the effectiveness of life-review with respect to anxiety symptoms. An explanation for this conflicting finding might be that we used two different samples. In the study of chapter 2 , participants with a major depressive episode were excluded, while 18.3\% of the participants in chapter 7 were diagnosed with a mild to moderate depressive episode. So the latter group of participants had more severe levels of depression at study entry. Given that these older adults have less symptom variation, it might be more difficult to find a relation between reminiscence and distress. A similar discrepancy emerged for the mental resource of experiencing meaning in life. While a cross-sectional study showed that meaning in life mediated the relationship between negative reminiscence and distress (chapter 3), the longitudinal study on the effectiveness of life-review on distress found no mediation effects for meaning in life (chapter 7 ). It seems rather difficult to fully capture the concept of meaning in life, which might be an explanation for the fact that we were unable to demonstrate robust findings for meaning in life. Specifically, in our study we used a measurement instrument with a good test-retest stability that suggested that meaning in life should perhaps best be regarded as a stable trait (Meaning in life scale; Steger, Frazier, Oishi \& Kaler, 2006). However, other studies used a more state-like instrument (the SELEinstrument; Dittmann-Kohli \& Westerhof, 1997), for example in the study of Westerhof, Bohlmeijer, van Beljouw and Pot (2010), who found that an improvement in meaning in life did mediate the effects of a life-review intervention on depressive symptoms in later life. So it might be that life-review is more suited for people who experience a decreased meaning in life as a result of external circumstances, e.g., critical life events, and would be less suitable for older adults who experience less meaning in life in general.

It seems intuitively inconsistent that we found mediating effects for positive thoughts, but not for the positive functions of reminiscence. One might wonder why engaging in positive reminiscence does not lead to decreased distress in depressed older adults, while developing more positive thoughts does seem to reduce distress. As was mentioned before, studies on autobiographical memory showed that depressed individuals have difficulties in recalling specific positive memories (Williams et al., 2007). So one might wonder if the Reminiscence Functions Scale (RFS; Webster, 1993) 
is specific enough to detect changes in an intervention study. It does not necessarily include the retrieval of specific positive memories. Serrano et al. (1994) found a mediating effect when using the Autobiographical Memory Test; a more direct measure of specific positive memories (Williams \& Broadbent, 1986). Besides, on closer examination of the RFS, it can be seen that the self-reported uses of reminiscence are not directly aimed at detecting, facilitating or hindering processes of remembering. Therefore, in future studies we advise including a more specific measure of reminiscence, which is also more sensitive to detecting changes in intervention studies.

To conclude, we now have a better understanding of the mechanisms of lifereview. We have supporting evidence that life-review is applicable to a broad target group and we have consistently demonstrated that negative reminiscence and mastery are important mediating factors of life-review and reminiscence. Besides, we have demonstrated the added value of offering life-review as a group intervention, from the perspective of the client.

\section{Limitations and suggestions for future research}

We acknowledge several limitations in this study, which give suggestions for future research. First, we have included only four reminiscence functions in our studies. It may be worthwhile to investigate how other functions, specifically the social reminiscence functions, are related to distress. Especially since our qualitative study shows the relevance of the more social aspects of life-review. A related limitation is that we have included only three mental resources as potential mediators (mastery, meaning in life and positive thoughts) in the relation between reminiscence and distress and on the effectiveness of life-review. In future studies, it might be interesting to additionally investigate the social functions of reminiscence and other potentially mediating mental resources, such as selfefficacy and self-esteem. Our results support the premise that it is useful to focus not only on how reminiscence is related to mental health, but also on the contextual factors of reminiscence. Therefore, we advise including both types of factors to examine the role of reminiscence in adaptation or evaluating life-review based interventions. Webster et al. (2010) developed a sophisticated model of reminiscence that identifies and discusses the antecedents, modes, contexts, mediators, moderators, functions and consequences of reminiscence. We believe that such models can guide future research and practice. We would therefore encourage researchers to examine these models for specific hypotheses and concepts. A second limitation is that our study samples comprised participants who had volunteered to participate in a clinical trial on the effectiveness of a life-review intervention. It may be that they have higher expectations about the effectiveness of reminiscing and have even more experience with reminiscence as a helpful coping strategy compared to people who did not choose to participate. So they may have interpreted the Reminiscence Functions Scale (Webster, 1993) differently, which might have affected the findings. Possibly, this has led to a reduction in the variance, which makes it more difficult to find significant associations between reminiscence and mental health. A third limitation was that our control condition in the RCT was a care-as-usual waiting list condition. So there was no control for the possible influence of non-specific factors, such as attention 
and social interaction. It would have been optimal to compare the targeted intervention with an active group intervention, or at least with an attention placebo comparison group. For ethical reasons it was not possible to compare the intervention with care-asusual during the second follow-up. Although the effects in the intervention group were maintained at the 9-month follow-up, we cannot claim that these effects were uniquely caused by the intervention. In addition, due to the relatively short time-horizon of 6 months we do not know how the cost-effectiveness of life-review is affected after a longer followup period. So longer follow-up periods are needed to further substantiate the (cost-) effectiveness of life-review. A fourth limitation is that the majority of the older adults in our study were female and relatively young, which implies a limitation for the generalization of the findings. Therefore, in future studies it would be interesting to broaden the study sample by including more men and adults from more senior segments of the population. However, in this thesis, regarding the effectiveness of life-review, it was shown that the levels of change in depression and anxiety did not vary according to either gender or age. These findings are in line with a recent meta-analysis by Pinquart \& Forstmeier (2012). A fifth limitation is that this study used self-report outcome measures, which might lead to biased findings. Future research could use more physiological outcome measures and outcomes evaluated by independent assessors. A recent study shows, for example, that life-review is also effective in reducing high blood pressure (Houston, Allison, Sussman, Horn, Holt, Trobaugh et al., 2011). With respect to the economic analyses, self-report may have introduced recall bias. For example, self-report of health care uptake might be underestimated (van den Brink, van den Hout, Stiggelbout, van de Velde \& Kievit 2004). A sixth limitation is that costs and effects were based on an imputed dataset, which might have biased the findings. However, completers did not differ from non-completers on any of the baseline variables, which attests to the robustness of our findings. A seventh limitation was that no assessments were made during the course of the intervention. Therefore, it was not possible to analyze the precise sequence of change in reminiscence and mental resources on changes in depression and anxiety. A related, and perhaps more general, limitation in mediation analysis is that mediation does not imply a causal relationship. So perhaps other mechanisms were actually causing change. It is recommended to measure possible mediators during the intervention in order to shed light on the exact process of change and direction of causality.

\section{Implications for clinical practice}

This thesis yields several implications for clinical practice. Our results demonstrate that the intervention is more effective for people who have higher levels of extraversion and lower levels of boredom reduction. Extravert individuals may be more able and inclined to share their feelings, emotions and thoughts with others and thus may benefit more from an intervention conducted in groups. This fits in with the findings of our qualitative study, in which we showed the added value of offering life-review in groups. Our results suggest that participants who report difficulties when they share their experiences in a group did not profit from the intervention, as they had no reduction in depressive symptoms. Indeed, it has been reported that extraversion predicts a higher frequency 
of reminiscence in general, and in particular for conversational and relational purposes (Cappeliez \& O'Rourke, 2002). In addition, Cappeliez and O'Rourke (2006) demonstrated that the social functions of reminiscence have an indirect influence on mental health. They suggest that the social functions of reminiscence provide content and occasions to experience a positive mood in the company of others. We therefore think that group processes should not be underestimated. It is advised that therapists judge whether a specific client will profit more from life-review individually or from life-review in a group. More extravert individuals may also be more inclined to look at the "silver lining" and thus benefit more from the components of the intervention directed at positive memories. Individuals who reminisce more often for boredom reduction may romanticize the past and possibly try to escape from present problems. Therefore, it might be problematic for these older adults that "The stories we live by" aims to find meaning in the present and seeks new goals in the future. Based on the above findings we advise that individuals who are not comfortable with sharing experiences in a group and who are not willing to find meaning in the present and future should be excluded from life-review interventions. There has been some criticism that participating in a life-review intervention would stimulate bitterness and rumination in people with depression (Coleman, 2005; Cully et al., 2001). Our findings show that this is not the case. Effects of the intervention were independent of the level of depressive symptoms and prior MDEs. It is especially noteworthy that the personality trait of neuroticism and the use of reminiscence for bitterness revival were not found to moderate the effects of life-review therapy. It seems that participants with higher levels of depressive symptoms, neuroticism and bitterness revival are also capable of developing alternative stories on their lives that are more positive, meaningful and empowering.

It was been shown in this thesis that after checking for all significant mediators, only an improvement in positive thoughts remained significantly associated with depressive and anxiety symptoms. This suggests that the focus on positive thoughts is a key mechanism in explaining the effectiveness of life-review, a finding that can be brought back to the two main adaptive processes of life-review: integrative and instrumental reminiscence. Together, these processes may lead to the development of more positive thoughts about the self and the future, which may play a major role in recovery from depression (Cappeliez, 2002; Watt \& Cappeliez, 2000; Wong, 1995). An increase in positive thoughts may be the result of repairing underlying, maladaptive, schematic, information-processing styles and dysfunctional causal attribution styles. Although our findings indicate that mainly positive thoughts explain the changes in depression and anxiety, this does not necessarily imply that changes in reminiscence are not of importance. However, it may imply that their effectiveness on depression and anxiety might be achieved through an increase in positive thoughts. To actually test the assumption that an improvement in integrative and instrumental reminiscence indeed leads to reduced depression and anxiety, via positive thoughts, studies with experimental designs and multiple measurement points are needed.

In recent discussions it was put forward that a good strategy to develop effective life-review interventions for older adults with mental health problems is to link life-review with other therapeutic frameworks (Westerhof, Bohlmeijer \& Webster, 2010), for example 
to cognitive therapy (Watt \& Cappeliez, 2000) or creative therapy (Pot et al., 2009). A recent meta-analysis by Pinquart and Forstmeier (2012) showed that such hybrid life-review therapies have stronger effects on depression and positive well-being than interventions which focus solely on life-review. This thesis is one of the first to show the beneficial effects of combining life-review with narrative therapy (chapter 5). Although the usefulness of narrative therapy with older adults has been advanced (Kroph \& Tandy, 1998), its effects have not been examined experimentally. A central focus in narrative therapy is to develop alternative stories about one's life that are more agentic (Polkinghorne, 1996), richer and more inclusive of experience (Payne, 2000; White \& Epston, 1990). One interesting line of investigation would be to collect and analyze stories about therapy to ascertain whether the increase of agency in life-stories is indeed a working mechanism (Adler, Skalina \& McAdams, 2008).

Another therapy that has been successfully integrated with life-review, in order to reduce depressive symptoms and clinical depression, is cognitive therapy (Watt \& Cappeliez, 2000). Though life-review combined with cognitive therapy and life-review combined with narrative therapy differ in their underlying theories and in the interventions that are used by the therapist, the finding that specific positive thoughts is a key mechanism in explaining the effectiveness suggests that they bring about similar processes within the context of life-review. The main difference between both therapies is that they seem to have different mechanisms of change. Life-review with narrative therapy focuses on the construction of positive thoughts by deconstructing problem-saturated stories and by constructing meaningful stories with more agentic plots, while life-review with cognitive therapy explores and challenges dysfunctional, most often negative thoughts. It is important to note that life-review within a narrative therapeutic framework is essentially different from narrative therapy. The basic element in life-review is a structured evaluation of the past. Narrative therapeutic interventions are carried out to help build new stories about the self and the world; stories that express hope, mastery and meaning. The starting point for narrative therapy is the here and now. The client is only asked to reminisce if this is helpful in the process of deconstruction or restorying (Osis \& Stout, 2002; White, 2007). Findings of this thesis suggest that life-review within a narrative framework is effective in integrating difficult memories and increasing the instrumental use of memories, by decreasing bitterness revival and boredom reduction reminiscence, and by strengthening mastery and positive thoughts (chapter 7). These findings have an important implication for the implementation and dissemination of life-review within a narrative framework. Counsellors and therapists who facilitate the intervention should be very familiar with the mediating processes that influence the effects of the intervention. And it is recommended that they are specifically trained in the narrative interventions that promote these processes.

Another aspect that is relevant for the implementation of "The stories we live by" intervention is that the participants seemed satisfied with the intervention. They evaluated the intervention with an average score of 7.7 (on a scale from 1 to 10). Most participants evaluated the intervention as good and useful. Results of a treatment integrity measure demonstrated that therapists scored satisfactory to good in correctly delivering the intervention. Because the intervention seems to be effective, feasible, and 
acceptable, nationwide implementation is an important next step. From this perspective, it is important to note that at present about $50 \%$ of the mental health care services in the Netherlands already offer the intervention on a regular basis. Besides, the intervention has been officially registered as effective by the Dutch portal for health promotion and prevention, which is part of the Centre for Healthy Living.

\section{Conclusion}

This thesis has demonstrated how reminiscence can have an adaptive value for mental health in later life. In a sample of older adults with mild to moderate depressive symptomatology, it has been shown that people reminisce more often for positive reminiscence when confronted with critical life events, that problem-solving reminiscence mediates the relation between critical life events and anxiety, and that mental resources (i.e., meaning in life and mastery) mediate the relation of negative reminiscence with distress. In addition, it has been demonstrated that life-review combined with narrative therapy is effective as an early intervention for older adults with mild to moderate depressive symptomatology, that life-review is effective under ecologically valid conditions, that better outcomes are achieved at higher costs, and that life-review is effective for a broad cross-section of older adults. Finally, this study has shown that life-review achieves its effectiveness by theoretically proposed and empirically validated processes of change, i.e., bitterness revival and boredom reduction reminiscence, mastery and positive thoughts. We recommend more studies with longer follow-up periods in order to further substantiate the (cost-)effectiveness of life-review. 


\section{REFERENCES}

Adler, J. M., Skalina, L. M., \& McAdams, D. P. (2008). The narrative reconstruction of psychotherapy and psychological health. Psychotherapy Research, 18, 719-734.

Beekman, A. T. F., Deeg, D. J., Van Limbeek, J., Braam, A. W., de Vries, M. Z., \& van Tilburg, W. (1997). Criterion validity of the Center for Epidemiologic Studies Depression Scale (CES-D): Results from a community-based sample of older subjects in The Netherlands. Psychological Medicine, 27, 231-235.

Bohlmeijer, E., Roemer, M., Cuijpers, P., \& Smit, F. (2007). The effects of life-review on psychological well-being in older adults: A meta-analysis. Aging \& Mental Health, 11, 291-300.

van den Brink, M., van den Hout, W. B., Stiggelbout, A., van de Velde, C. J., \& Kievit, J. (2004). Cost measurement in economic evaluations of health care: Whom to ask? Medical Care, 42, 740-746.

Brooks, R. (1996). EuroQol: The current state of play. Health Policy, 37, 53-72.

Cappeliez, P. (2002). Cognitive-reminiscence therapy for depressed older adults in day hospital and long-term care. In J. D. Webster and B. K. Haight (Eds.), Critical Advances in Reminiscence Work: From Theory to Application (pp. 300-313). New York, NY: Springer.

Cappeliez, P., \& O'Rourke, N. (2002). Personality traits and existential concerns as predictors of the functions of reminiscence in older adults. Journal of Gerontology: Psychological Sciences, 57B, P116-P123.

Cappeliez, P., \& O'Rourke, N. (2006). Empirical validation of a model of reminiscence and health in later life. Journal of Gerontology: Series B: Psychological Sciences and Social Sciences, 61, 237-244.

Cappeliez, P., O'Rourke, N., \& Chaudhury, H. (2005). Functions of reminiscence and mental health in later life. Aging \& Mental Health, 9, 295-301.

Cappeliez, P., \& Robitaille, A. (2010). Coping mediates the relationships between reminiscence and psychological well-being among older adults. Aging \& Mental Health, 14, 807-818.

Coleman, P. G. (2005). Uses of reminiscence: Functions and benefits. Aging \& Mental Health, 9, 291-294.

Cuijpers, P., \& Schuurmans, J. (2007). Self-help interventions for anxiety disorders: An overview. Current Psychiatry Reports, 9, 284-290.

Cuijpers, P., Smit, F., \& van Straten, A. (2007). Psychological treatments of subthreshold depression: A meta-analytic review. Acta Psychiatrica Scandinavica, 115, 434-441.

Cuijpers, P., van Straten, A., Smit, F., Mihalopoulos, C., \& Beekman, A. (2008). Preventing the onset of depressive disorders: A meta analytic review of psychological interventions. American Journal of Psychiatry, 165, 1272-1280.

Cully, J. A., LaVoie, D., \& Gfeller, J. D. (2001). Reminiscence, personality, and psychological functioning in older adults. Gerontologist, 41, 89-95.

Dittmann-Kohli, F., \& Westerhof, G. J. (1997). The SELE-sentence completion 
questionnaire: A new instrument for the assessment of personal meaning in research on aging. Anuario de Psicologia, 73, 7-18.

Fledderus, M., Bohlmeijer, E. T., Smit, F., \& Westerhof, G. J. (2011). Mental health promotion as a new goal in public mental health care: A randomized controlled trial of an intervention enhancing psychological flexibility. American Journal of Public Health, 100, 2372-2378.

Houston, T. K., Allison, J. J., Sussman, M., Horn, W., Holt, C. L., Trobaugh, J., et al. (2011). Culturally appropriate storytelling to improve blood pressure: A randomized trial. Annals of Internal Medicine, 154, 77-84.

Jané-Llopis, E., \& Barry, M. M. (2005). What makes mental health promotion effective? Promotion and Education, 12, 47-54.

Keyes, C. L. M. (2005). Mental illness and/or mental health? Investigating axioms of the complete state model of health. Journal of Consulting and Clinical Psychology, 73, 539-548.

Keyes, C. L. M., Dhingra, S. S., \& Simoes, E. J. (2010). Change in level of positive mental health as a predictor of future risk of mental illness. American Journal of Public Health, 100, 2366-2371.

Kraemer, H. C., Wilson, T., Fairburn, C. G., \& Agras, W.S. (2002). Mediators and moderators of treatment effects in randomized clinical trials. Archives of General Psychiatry, 59, 877-883.

Krause, N. (2004). Stressors arising in highly valued roles and the physical health status of older adults. The Journals of Gerontology, 59B, S287-S291.

Krause, N. (2007). Evaluating the stress-buffering function of meaning in life among older people. Journal of Aging and Health, 19, 792-812.

Kroph, N. P., \& Tandy, C. (1998). Narrative therapy with older clients: The use of a 'meaning-making' approach. Clinical Gerontologist, 18, 3-16.

Lamers, S. M. A., Westerhof, G. J., Bohlmeijer, E. T., ten Klooster, P. M., \& Keyes, C. L. M. (2011). Evaluating the psychometric properties of the Mental Health Continuum-Short Form (MHC-SF). Journal of Clinical Psychology, 67, 99-110.

Osis, M., \& Stout, L. (2001). Using narrative therapy with older adults. In G. M. Kenyon, P. G. Clark, \& B. de Vries (Eds.), Narrative gerontology: Theory, research, and practice (pp. 273-290). Berlin, Germany: Springer.

Payne, K. T., \& Marcus, D. K. (2008). The efficacy of group psychotherapy for older adult clients: A meta-analysis. Group Dynamics: Theory, Research, and Practice, 12, 268-278.

Pinquart, M., Duberstein, P. R., \& Lyness, J. M. (2007). Effects of psychotherapy and other behavioral interventions on clinically depressed older adults: A metaanalysis. Aging \& Mental Health, 11, 645-657.

Pinquart, M., \& Forstmeier, S. (2012). Effects of reminiscence interventions on psychosocial outcomes: A meta-analysis. Aging \& Mental Health, 16, 541-558.

Polkinghorne, D. E. (1996). Transformative narratives: From victimic to agentic life plots. American Journal of Occupational Therapy, 50, 299-305.

Pot, A. M., Bohlmeijer, E. T., Onrust, S., Melenhorst, A. S., Veerbeek, M., \& De Vries, W. (2010). The impact of life-review on depression in older adults: A randomized controlled trial. International Psychogeriatrics, 22, 572-581. 
Serrano, J. P., Latorre, J. M., Gatz, M., \& Montanes, J. (2004). Life-review therapy using autobiographical retrieval practice for older adults with depressive symptomatology. Psychology and Aging, 19, 270-277.

Smit, F., Ederveen, A., Cuijpers, P., Deeg, D., \& Beekman, A. (2006). Opportunities for cost-effective prevention of late-life depression. An epidemiological approach. Archives of General Psychiatry, 63, 290-296.

Spek, V., Nyklícek, I., Smits, N., Cuijpers, P., Riper, H., \& Keyzer, J. (2007). Internet-based cognitive behavioural therapy for subthreshold depression in people over 50 years old: A randomized controlled clinical trial. Psychological Medicine, 37, 1797-1806.

Steger, M., Frazier, P., Oishi, S., \& Kaler, M. (2006). The meaning in life questionnaire, assessing the presence of and search for meaning in life. Journal of Counselling Psychology, 53, 80-93.

Steunenberg, B., Beekman, A. T. F., Deeg, D. J. H., \& Kerkhof, A. J. F. M. (2006). Personality and the onset of depression in late life. Journal of Affective Disorders, 92, 243-251.

van 't Veer-Tazelaar, P., Smit, F., van Hout, H., van Oppen, P., van der Horst, H., Beekman, A., et al. (2010). Cost-effectiveness of a stepped care intervention to prevent depression and anxiety in later life: Randomised trial. British Journal of Psychiatry, 196, 319-325.

van Vliet, I. M., \& de Beurs, E. (2007). The MINI-International Neuropsychiatric Interview (M.I.N.I.). A brief structured diagnostic psychiatric interview for DSM-IV and ICD10 psychiatric disorders [in Dutch]. Tijdschrift voor Psychiatrie, 49, 393-397.

Warmerdam, L., Smit, F., van Straten, A., Riper, H., \& Cuijpers, P. (2010). Cost-utility and cost-effectiveness of internet-based treatment for adults with depressive symptoms: Randomized trial. Journal of Medical Internet Research, 12, e53.

Watt, L. M., \& Cappeliez, P. (2000). Integrative and instrumental reminiscence therapies for depression in older adults: Intervention strategies and treatment effectiveness. Aging \& Mental Health, 4, 166-177.

Webster, J. D. (1993). Construction and validation of the Reminiscence Functions Scale. Journal of Gerontology: Psychological Sciences, 48, 256-262.

Webster, J. D., Bohlmeijer, E. T., \& Westerhof, G. J. (2010). Mapping the future of reminiscence: A conceptual guide for research and practice. Research on Aging, 32, 527-564.

Westerhof, G. J., Bohlmeijer, E. T., van Beljouw, I. M. J., \& Pot, A. M. (2010). Improvement in personal meaning mediates the effects of a life review intervention on depressive symptoms in a randomized controlled trial. Gerontologist, 50, 541549.

Westerhof, G. J., Bohlmeijer, E. T., \& Webster, J. D. (2010). Reminiscence and mental health: A review of recent progress in theory, research, and intervention. Ageing and Society, 30, 697-721.

White, M. (2007). Maps of narrative therapy. New York: W. W. Norton.

White, M., \& Epston, D. (1990). Narrative means to therapeutic ends. New York, NY: W. W. Norton. 
Williams, J. M., Barnhofer, T., Crane, C., Herman, D., Raes, F., Watkins, E., et al. (2007). Autobiographical memory specificity and emotional disorder. Psychological Bulletin, 133, 122-148.

Williams, J. M. G., \& Broadbent, K. (1986). Autobiographical memory in attempted suicide patients. Journal of Abnormal Psychology, 95, 144-149.

Wong, P. T. (1995). The processes of adaptive reminiscence. In B. K. Haight \& J. D. Webster (Eds.), The art and science of reminiscing: Theory, research, methods, and applications (pp. 23-35). Washington, DC: Taylor \& Francis.

Zarit, S. H., Femia, E. E., Gatz, M., \& Johansson, B. (1999) Prevalence, incidence and correlates of depression in the oldest old: The OCTO study. Aging \& Mental Health, 3, 119-128. 


\section{$\sin \theta$}

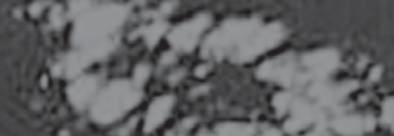

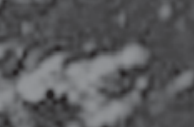

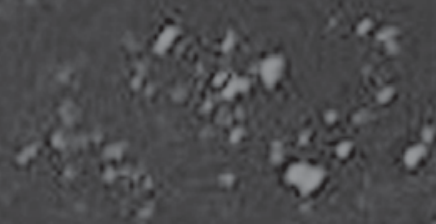

C.t.

(t) thent

THE STORIES WE LIVE BY - The adaptive role of reminiscence

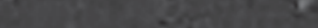

tei 4

18

and

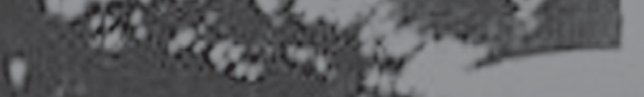

\section{SAMENYATIIYG}
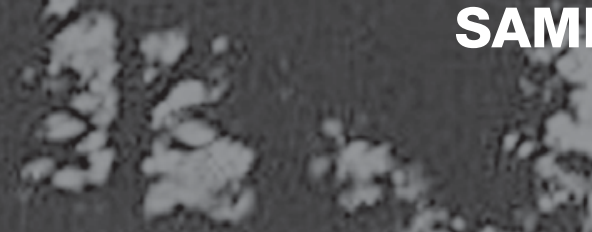

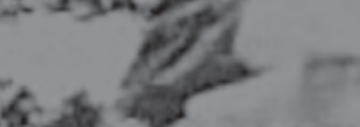

cotses

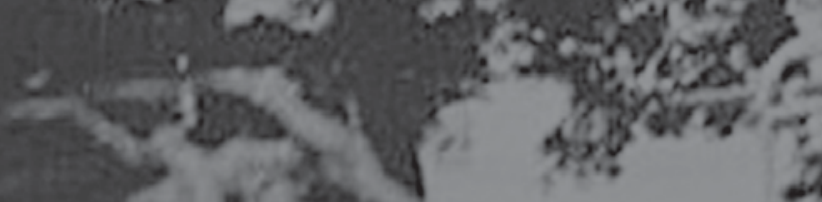

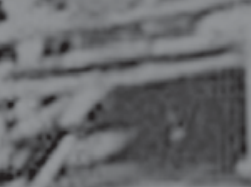

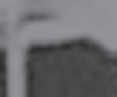

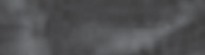
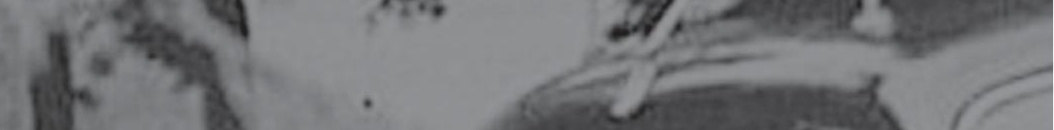

$6 x^{2}+x^{2}$

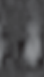

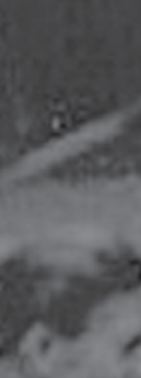

150

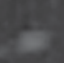

a.

ut

10

rede 5

is i

an सै के जी

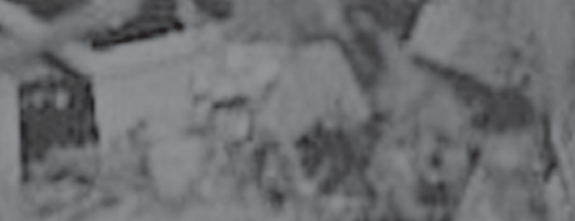

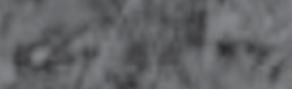




\section{SUMMARY IN DUTCH}

Hoofdstuk 1 beschrijft de drie belangrijkste doelen van dit proefschrift. Het eerste doel is onderzoek naar de adaptieve rol van reminiscentie voor ouderen met lichte tot matige depressieklachten. Reminiscentie kan worden gedefinieerd als het vrijwillig ophalen van algemene of specifieke herinneringen, individueel of met anderen. Er worden verschillende functies van reminiscentie onderscheiden, die een positieve of een negatieve invloed kunnen hebben op de geestelijke gezondheid. Het ophalen van herinneringen om de identiteit te versterken en om problemen op te lossen (positieve reminiscentiefuncties) hangt positief samen met geestelijke gezondheid, terwijl het gebruik van het verleden om bittere herinneringen te herleven en verveling tegen te gaan (negatieve reminiscentiefuncties) negatief samenhangt met geestelijke gezondheid en positief samenhangt met psychische klachten. Hoewel de literatuur een goed overzicht geeft van hoe de verschillende reminiscentiefuncties samenhangen met geestelijke gezondheid zijn er drie belangrijke beperkingen. Ten eerste zijn de reminiscentiefuncties en hun invloed op geestelijke gezondheid nauwelijks onderzocht in bepaalde contexten. Hoewel wordt beweerd dat mensen vaker reminisceren als ze worden geconfronteerd met belangrijke veranderingen in hun leven, zijn er weinig studies die deze bewering ondersteunen. Ten tweede zijn bijna alle studies naar reminiscentie en geestelijke gezondheid uitgevoerd in de algemene oudere populatie, bij mensen zonder psychische klachten. Aangezien bijna alle reminiscentie-gebaseerde interventies zijn gericht op het verminderen van psychische klachten, is het belangrijk om te weten of de gevonden relaties tussen reminiscentie en geestelijke gezondheid ook opgaan voor ouderen met klinisch relevante klachten. Ten derde is het nog onduidelijk hoe reminiscentie precies gerelateerd is aan psychische klachten. Theoretisch wordt gesuggereerd dat reminiscentie geestelijke gezondheid bevordert doordat gevoelens van mastery en zingeving toenemen. Om rekening te houden met bovenstaande beperkingen zijn in dit proefschrift contextuele factoren van reminiscentie bestudeerd bij ouderen met psychische klachten en is onderzocht of gevoelens van mastery en zingeving de relatie tussen reminiscentie en geestelijke gezondheid inderdaad mediëren (hoofdstuk 2 en 3).

Het tweede doel van dit proefschrift is het evalueren van de effectiviteit van "Op verhaal komen", een interventie specifiek voor ouderen met lichte tot matige depressieklachten, die life-review integreert met narratieve therapie. In hoofdstuk 1 wordt het belang onderschreven van preventieve interventies gericht op ouderen met depressieve klachten, ter voorkoming van het ontwikkelen van een depressieve stoornis. Ouderen worden met het huidige preventieve aanbod van interventies lastig bereikt. Lifereview lijkt een acceptabele en aantrekkelijke interventiemethode voor deze doelgroep, omdat deze aansluit bij een natuurlijke activiteit van veel ouderen: het terugkijken op het eigen leven en het evalueren daarvan. Life-review is een gestructureerde vorm van reminiscentie waarbij zowel positieve als negatieve herinneringen worden geïntegreerd in het levensverhaal (integratieve reminiscentie) en waarbij het verleden wordt gebruikt 
om huidige problemen het hoofd te kunnen bieden (instrumentele reminiscentie). Verschillende meta-analyses laten zien dat life-review kan worden beschouwd als een "evidence-based" methode voor het behandelen van depressie. In dit proefschrift is in een grote, gerandomiseerde trial onderzocht of life-review ook (kosten)effectief kan worden toegepast als preventieve interventiemethode bij ouderen met lichte tot matige depressieve klachten (hoofdstuk 4-6). In hoofdstuk 1 is beschreven dat steeds vaker pogingen worden gedaan om life-review te combineren met andere interventies, gericht op mensen met lichte tot matige psychische klachten. "Op verhaal komen" combineert life-review met narratieve therapie. Deze interventie bevat drie kernelementen. Ten eerste, de integratie van moeilijke levensgebeurtenissen in het levensverhaal. Ten tweede, het ontwikkelen van alternatieve, meer positieve levensverhalen en het formuleren van nieuwe doelen waardoor deelnemers (beter) leren omgaan met huidige (moeilijke) levensgebeurtenissen. Ten derde, het ophalen van specifieke positieve herinneringen, die als bouwstenen kunnen dienen voor alternatieve levensverhalen.

Het derde doel van dit proefschrift was het bestuderen van mogelijke mechanismen van life-review. Er is tot nu toe weinig bekend over hoe de effecten van life-review precies tot stand komen. Om te bepalen of specifieke subgroepen meer baat hebben bij life-review zijn moderatoranalyses uitgevoerd (hoofdstuk 5). In hoofdstuk 1 zijn theoretisch en empirisch voorgestelde - maar nauwelijks onderzochte - therapeutische processen van life-review beschreven: integratieve en instrumentele reminiscentie, zingeving en mastery. Er zijn mediatieanalyses uitgevoerd om vast te stellen of deze processen de effecten op life-review inderdaad mediëren (hoofdstuk 7). Life-review interventies kunnen zowel individueel als in groepen worden aangeboden. Er is discussie gaande over welke vorm het meest effectief is. In dit proefschrift is onderzocht wat de voordelen zijn van het aanbieden van life-review in een groep, bekeken vanuit het perspectief van de cliënt (hoofdstuk 8).

In hoofdstuk 2 is de rol onderzocht van reminiscentie als een manier om met belangrijke levensgebeurtenissen en chronische ziekten op latere leeftijd te kunnen omgaan. In totaal namen 171 ouderen, met een gemiddelde leeftijd van 64 jaar, met lichte tot matige depressieklachten deel aan deze studie. Deelnemers vulden vragenlijsten in voor de volgende uitkomstmaten: belangrijke levensgebeurtenissen, chronische ziekten, reminiscentiefuncties, depressieklachten, angstklachten en levenstevredenheid. Resultaten toonden aan dat reminiscentie om het herleven van bitterheid en het tegengaan van verveling positief samenhing met depressie- en angstklachten en negatief met levenstevredenheid. Reminiscentie om problemen op te lossen hing vervolgens negatief samen met angstklachten. Wanneer alle reminiscentiefuncties werden meegenomen bleek dat het oplossen van problemen uniek samenhing met angst en het herleven van bitterheid met depressiesymptomen en levenstevredenheid. Interessant bleek de bevinding dat reminiscentie om problemen op te lossen de relatie medieerde tussen het ervaren van belangrijke levensgebeurtenissen en de mate van angstklachten. Hoofdstuk 2 bouwt voort op de theorie dat reminiscentie een belangrijke rol speelt in de confrontatie met levensgebeurtenissen en daardoor in het handhaven van geestelijke gezondheid. Daarnaast suggereert dit hoofdstuk dat het zinvol is wanneer therapeuten zich bij mensen 
met depressieklachten zouden richten op het verminderen van het herleven van bitterheid en bij mensen met angstklachten op het versterken van reminiscentie om problemen op te lossen.

In hoofdstuk 3 is, voor een beter begrip van de adaptieve waarde van reminiscentie, een mediatiemodel getest bij ouderen met lichte tot matige depressieklachten. Door gebruik te maken van structural equation modeling is onderzocht of mentale bronnen (mastery en zingeving) de relatie medieerden tussen reminiscentie (positief: ontwikkelen van de identiteit en oplossen van problemen; negatief: herleven van bitterheid en vermindering van verveling) en psychische klachten (angst- en depressieklachten). In totaal namen 202 ouderen deel aan deze studie. Resultaten lieten zien dat de relatie tussen negatieve reminiscentie en psychische klachten volledig werd gemedieerd door mentale bronnen. Met andere woorden, negatieve reminiscentie is gerelateerd aan verminderde psychische klachten door een verminderde zingeving en gevoelens van mastery. Deze studie draagt bij aan de bestaande kennis over de relatie tussen reminiscentie en geestelijke gezondheid, zowel empirisch als klinisch. Zij helpt beter te begrijpen hoe reminiscentie gerelateerd is aan psychische klachten, met name bij depressieve ouderen, en toont het belang van mentale bronnen - mastery en zingeving - in deze. Vanuit een klinisch perspectief suggereren de bevindingen het nut van het versterken van mentale bronnen bij therapeutische, reminiscentie-gebaseerde strategieën voor ouderen met depressieklachten.

In hoofdstuk 4 is het belang benadrukt van preventieve interventies die zowel effectief, acceptabel als economisch verantwoord zijn. Depressie- en angstklachten bij ouderen kunnen zich namelijk ontwikkelen tot ernstige gezondheidsproblemen met nadelige effecten op de kwaliteit van leven en een mogelijk slechte prognose. Dit hoofdstuk beschrijft het design van een studie die "Op verhaal komen" evalueert, een recentelijk ontwikkelde preventieve life-review groepsinterventie, voor mensen van 55 jaar en ouder met depressieklachten. Zowel de klinische als economische effectiviteit zijn geëvalueerd in een pragmatische, gerandomiseerde, gecontroleerde trial. De deelnemers in de interventieconditie ontvingen de preventieve interventie, terwijl de deelnemers in de controleconditie toegang hadden tot care-as-usual. Klinische uitkomstmaten waren: depressie- en angstklachten, huidige depressieve episode, kwaliteit van leven en positieve geestelijke gezondheid. Deze werden gemeten bij baseline, onmiddellijk na de interventie en tijdens twee follow-up metingen (respectievelijk 6 en 12 maanden na de baseline). Een aanvullend doel was subgroepen te identificeren waarvoor de interventie met name geschikt is en therapeutische paden te bepalen die de effectiviteit van de interventie verklaren. Dit is gedaan door te analyseren of de effecten worden gemodereerd door demografische gegevens, persoonlijkheid, eerdere depressieve episodes, belangrijke levensgebeurtenissen en chronische ziekten en of zij worden gemodereerd door reminiscentiefuncties, mastery, positieve gedachten en zingeving. Tenslotte is de kosteneffectiviteit van de interventie bepaald in vergelijking tot care-asusual. Zowel de life-review interventie zelf als de evaluatie van deze interventie dragen bij aan de bestaande kennis van life-review. Ten eerste is de interventie uniek door de combinatie van life-review met narratieve therapie en door haar focus op specifieke, 
positieve herinneringen. Ten tweede worden er vragen beantwoord met betrekking tot de (kosten)effectiviteit en werkzaamheid van life-review.

Hoofdstuk 5 beschrijft de resultaten van een grote, multi-site, pragmatische, gerandomiseerde, gecontroleerde trial die de effectiviteit van life-review en narratieve therapie als een vroege behandeling van depressie op latere leeftijd evalueert (het design van deze studie is besproken in hoofdstuk 4). Hoewel er substantiële "evidence" is voor de effectiviteit van life-review, zijn haar effecten nauwelijks onderzocht in een natuurlijke setting. In vergelijking tot care-as-usual $(n=102)$ was life-review therapie $(n=100)$ effectief in het verminderen van depressieklachten, zowel onmiddellijk na de interventie als na een follow-up periode van drie maanden. In de interventiegroep bleef dit effect tevens behouden na een follow-up periode van negen maanden. De kans op een klinisch significante verandering op depressieklachten was bovendien significant hoger, zowel onmiddellijk na de interventie als bij de follow-up periode van drie maanden. Daarnaast zijn er kleine, maar significante effecten gevonden voor angstklachten en positieve geestelijke gezondheid. Moderatoranalyses lieten slechts twee significante moderatoren zien: de persoonlijkheidstrek "extraversie" en de reminiscentiefunctie "reductie van verveling". Deze studie toont de effectiviteit aan van life-review therapie als een vroege interventie voor depressie in een ecologisch valide context en ondersteunt de toepasbaarheid voor een brede doelgroep.

In hoofdstuk 6 is de kosteneffectiviteit van life-review vergeleken met care-as-usual, als onderdeel van de gerandomiseerde, gecontroleerde trial als beschreven in hoofdstuk 4 en 5. Een gunstige uitkomst (een verbetering) werd gedefinieerd als een statistisch betrouwbare vermindering van depressiesymptomen op de Center for Epidemiologic Studies Depression scale. De totale kosten per deelnemer werden uitgedrukt in euro's (voor het jaar 2009) en bestonden uit interventiekosten, kosten voor het ontvangen van andere behandelingen, "out-of-pocket" kosten en kosten voortkomend uit productieverliezen. Bij de follow-up periode van 6 maanden bleek in 54\% van de gevallen een gunstige uitkomst in de life-review conditie en in $27.5 \%$ van de gevallen in de careas-usual conditie. Dit verschil was statistisch significant. De kosten waren hoger in de interventieconditie (€5550 vs. €3162). De incrementele kosteneffectiviteit was $€ 8675$ per verbeterde deelnemer. De bevindingen lieten zien dat het aanbieden van life-review de kans op een gunstige uitkomst bijna verdubbelt. Deze betere klinische uitkomsten werden echter bereikt tegen hogere kosten. Verdere analyses lieten zien dat de vraag, of lifereview een positieve kosteneffectiviteit biedt, wordt beïnvloed door de bereidheid om voor een gunstige uitkomst te betalen. Daarnaast kwam op basis van gevoeligheidsanalyses de aanbeveling naar voren om de life-review interventie door één therapeut te laten aanbieden en in grotere groepen (in plaats van door twee therapeuten in groepen van vier, zoals nu het geval was).

Hoofdstuk 7 beschrijft het onderzoek naar mogelijke mediatoren van life-review in de context van de grootschalige RCT, als beschreven in de hoofdstukken 4 tot en met 6. Hoewel de effectiviteit van life-review inmiddels is komen vast te staan, is het nog 
onduidelijk wat nu precies de werkzame processen zijn van life-review. De uitkomstmaten (gemeten tijdens baseline, onmiddellijk na de interventie en drie maanden na afloop van de interventie) waren depressieklachten en angstklachten. Mogelijk mediatoren (gemeten tijdens baseline en onmiddellijk na de interventie) waren reminiscentiefuncties, persoonlijke zingeving, mastery en positieve gedachten. De bevindingen lieten zien dat het herleven van bittere herinneringen en het tegengaan van verveling (reminiscentiefuncties), mastery en positieve gedachten de effecten van life-review op depressieklachten en angstklachten medieerden. Processen die theoretisch en empirisch zijn voorgesteld als werkzame processen in life-review medieerden inderdaad het effect van life-review op depressieklachten en angstklachten. Een belangrijke implicatie voor de implementatie van life-review is dat therapeuten voldoende kennis hebben van de processen die van invloed zijn op de effectiviteit. Om deze processen te kunnen bevorderen is een specifieke training wenselijk. Om meer inzicht te krijgen in de exacte processen van verandering en de richting van causaliteit is aanbevolen deze processen ook gedurende de interventie te meten.

Hoofdstuk 8 beschrijft een studie naar de sociale aspecten van life-review, vanuit het perspectief van de cliënt. Life-review interventies kunnen individueel of in een groep worden aangeboden. Er is discussie gaande over welke vorm het meest effectief is. In een exploratieve, kwalitatieve studie is de meerwaarde van life-review in een groep onderzocht. Er zijn semigestructureerde interviews afgenomen zodat deelnemers de voor- en/of nadelen van de groepsinterventie konden aangeven. Bij de analyse van transcripten is gebruik gemaakt van een inductieve analyse. Op basis van deze analyse kwamen de volgende sociale processen van life-review naar voren: het gevoel hebben erbij te horen, het gevoel hebben te worden geaccepteerd, het gezellig hebben, het delen van persoonlijke en intieme ervaringen, leren om jezelf uit te drukken, het vinden van herkenning, realiseren dat anderen ook problemen hebben, realiseren dat je beter dan anderen kunt omgaan met je problemen, leren van anderen en in staat zijn anderen te helpen. Negatieve processen, die overigens minder vaak werden genoemd, waren: moeite hebben met het delen in een groep, geen herkenning vinden en bang zijn om niet te worden erkend. Deze sociale processen konden worden onderverdeeld in drie categorieën. In de eerste plaats, het hebben van een goede sfeer binnen de groep; ten tweede, het delen van ervaringen met gelijkgestemden; en als laatste, jezelf vergelijken met anderen. De resultaten suggereren dat het aanbieden van life-review in een groep meerwaarde heeft. Deelnemers gaven aan baat te hebben bij een verscheidenheid aan sociale processen, die vermoedelijk de effectiviteit van life-review versterken. Verder onderzoek is echter nodig om het belang van deze sociale processen en het effect op depressie nader te onderzoeken.

In hoofdstuk 9 zijn allereerst de belangrijkste resultaten van dit proefschrift bediscussieerd. Vervolgens zijn de sterke en zwakke aspecten van dit proefschrift besproken en zijn aanbevelingen gedaan voor toekomstige studies en de klinische praktijk. De onderzoeksresultaten dragen zowel empirisch als klinisch bij aan de bestaande kennis over de relatie tussen reminiscentie en geestelijke gezondheid. Dit onderzoek leidt in de 
eerste plaats, door het meenemen van contextuele factoren en mentale bronnen, tot een beter begrip over hoe reminiscentie precies gerelateerd is aan psychische klachten, specifiek bij gedeprimeerde ouderen. Ten tweede is in dit proefschrift de effectiviteit geëvalueerd van "Op verhaal komen", een interventie specifiek voor ouderen met lichte tot matige depressieklachten, die life-review integreert met narratieve therapie. Resultaten wezen uit dat deze methode om vroegtijdig depressieve klachten te verminderen kan worden beschouwd als "evidence-based". Kosteneffectiviteitsanalyses lieten zien dat de interventie-effecten op depressieve klachten gepaard gaan met hogere kosten dan careas-usual. Het komt vaker voor dat een nieuwe interventie goede gezondheidseffecten bereikt tegen hogere kosten. Gevoeligheidsanalyses ondersteunden de aanbeveling om de interventie door één therapeut en in grotere groepen aan te bieden. Daarnaast lieten de resultaten zien dat de interventie effectief is in het verminderen van angstklachten en in het versterken van positieve geestelijke gezondheid. Een beperking van de gerandomiseerde trial was dat de controlegroep een care-as-usual groep was, waardoor er niet kon worden gecontroleerd voor de invloed van non-specifieke factoren zoals aandacht en sociale interactie. Een verdere tekortkoming was dat er beperkt, tot een periode van 9 maanden na de interventie, inzicht is in de lange termijn (kosten)effecten van life-review. Dit leidde tot de aanbeveling om de interventie in de toekomst te vergelijken met een actievere controlegroep en langere follow-up periodes in te bouwen. Ten derde beschreef dit proefschrift mechanismen van life-review. Resultaten wezen uit dat de lifereview interventie kan worden toegepast bij een breed toegankelijke doelgroep. Ook lieten ze zien dat de effecten van life-review worden bereikt door het ontmoedigen van negatieve reminiscentie en het versterken van gevoelens van mastery en positieve gedachten. Bovendien leken verschillende groepsprocessen de effecten van life-review te versterken, bezien vanuit het perspectief van de cliënt. Op basis van deze bevindingen is het in toekomstige studies wellicht interessant ook sociale functies van reminiscentie als potentiële mediatoren mee te nemen. Een algemene beperking van dit proefschrift was, dat de meerderheid van de ouderen in de beschreven studies vrouw was en relatief jong, hetgeen een nuancering impliceert voor de generalisatie van de bevindingen. In het proefschrift zijn echter geen modererende effecten gevonden voor geslacht en leeftijd.

In hoofdstuk 9 zijn verschillende implicaties besproken voor de klinische praktijk. Zo lieten de resultaten zien dat de interventie geschikter lijkt voor mensen met lagere niveaus van reminiscentie om verveling tegen te gaan en hogere niveaus van extraversie. Extraverte mensen zijn mogelijk beter in staat hun gevoelens en gedachten (met anderen) te delen en profiteren daardoor wellicht meer van een groepsinterventie. Dit wordt ondersteund door de kwalitatieve studie waarin werd gevonden dat mensen die moeite hadden om hun ervaringen te delen in een groep geen baat hadden bij de interventie. De kritiek dat life-review bitterheid zou stimuleren werd tegengesproken in dit proefschrift. Het lijkt erop dat deelnemers met hogere niveaus van depressieklachten, neuroticisme en die vaker reminisceren om het herleven van bitterheid ook in staat zijn alternatieve, positievere, meer betekenisvolle levensverhalen te ontwikkelen. Dit proefschrift liet zien dat, indien er werd gecontroleerd voor alle significante mediatoren, alleen een verbetering in positieve gedachten significant gerelateerd bleef aan depressie- en angstklachten, een bevinding die kan worden teruggevoerd op de twee adaptieve processen van life-review: 
integratieve en instrumentele reminiscentie. Deze processen samen leiden mogelijk tot de ontwikkeling van positievere verhalen over het zelf en de toekomst, hetgeen een belangrijke rol zou kunnen spelen in het verminderen van depressie. Dit impliceert dat de effectiviteit van reminiscentiefuncties wordt bereikt door een toename in positieve gedachten. Om de bewering te testen dat een verbetering in integratieve en instrumentele reminiscentie inderdaad, door een toename in positieve gedachten, leidt tot verminderde depressieen angstklachten zijn studies met experimentele designs en meerdere meetmomenten nodig. In recente discussies wordt beweerd dat het een zinvolle strategie is life-review interventies te combineren met andere therapeutische modellen, zoals bijvoorbeeld cognitieve gedragstherapie. Dergelijke hybride life-review interventies hebben sterkere effecten op depressie en positief welbevinden dan interventies die alleen gericht zijn op life-review. Dit proefschrift is een van de eerste onderzoeken die de effectiviteit laat zien van een interventie voor ouderen met depressieve klachten, die life-review combineert met narratieve therapie. 


\section{DANKWOORD}




\section{ACKNOWLEDGEMENTS}

Een promotieonderzoek voer je niet alleen uit. De afgelopen jaren heb ik met erg veel plezier samengewerkt met een groot aantal inspirerende collega's. Ik kijk dan ook terug op een zeer prettige tijd, waarin ik veel heb geleerd en me heb kunnen ontwikkelen als onderzoeker en als mens. Graag wil ik iedereen bedanken die eraan heeft bijgedragen dat ik deze periode succesvol heb kunnen afronden. Een aantal mensen wil ik graag in het bijzonder bedanken.

Ernst, vanaf het allereerste begin heb je mij onder je hoede genomen. In eerste instantie als dagelijks begeleider en later ook als promotor. Met je aanstekelijke enthousiasme heb je me steeds weten te motiveren en heb je ervoor gezorgd dat ik telkens het beste uit mezelf wist te halen. Gerben, jij kwam in een later stadium als tweede begeleider. Met jouw komst was de ideale begeleiding een feit. Je kritische blik en enorme kennis hebben me veel gebracht. Waar ik jullie beiden erg dankbaar voor ben is de vrijheid die je me hebt gegeven. Zo werd het mogelijk dat ik het doen van wetenschappelijk onderzoek kon combineren met de klinische praktijk. Ik vind het geweldig dat ik jullie collega kan blijven, om volledig het vertrouwen te krijgen en ik kijk dan ook erg uit naar onze toekomstige samenwerking. Filip, bijzonder fijn dat jij mijn co-promotor kon zijn. Jij heb mijn proefschrift geperfectioneerd. Ik heb je adviezen en prettige begeleiding altijd als uitermate zinvol en prettig ervaren.

Marcel, dankzij jou werd ik enthousiast om te gaan promoveren. Je hebt me begeleid bij zowel mijn bachelor- als masteronderzoek, een periode waar ik met veel positieve gevoelens op terugkijk. Erg leuk ook dat ons onderzoek nog twee mooie publicaties heeft opgeleverd. Toen ik mijn ambitie uitsprak om te willen promoveren heb jij me aanbevolen bij Ernst. Daar ben ik je zeer dankbaar voor.

De onderzoeksresultaten waren nooit bereikt zonder de fantastische inzet van de deelnemende GGZ-instellingen. Dankzij jullie enthousiasme wisten we bovendien telkens dat we met iets moois bezig waren. Ook de interventiedeelnemers ben ik veel dank verschuldigd, vooral voor het invullen van alle vragenlijsten en voor het participeren in interviews. Zonder jullie was dit proefschrift er niet geweest.

Prof. dr. Nan Stevens en Prof. dr. Anne Margriet Pot, wat een eer om jullie in mijn promotiecommissie te mogen hebben. Ook wil ik graag Prof. dr. Kees Aarts en collega's Karlein Schreurs en Peter ten Klooster bedanken voor deelname aan mijn promotiecommissie.

Ik wil graag alle collega's van de vakgroep PGT (en voorheen PCGR) bedanken voor de ontzettend prettige werksfeer. Het uitvoeren van een promotieonderzoek is uiteraard een 
serieuze aangelegenheid. Maar naast het harde werken was er ook ruimte voor een stuk gezelligheid. Ik heb het als een echte luxe ervaren, al die jaren omringd te zijn geweest met zulke leuke en gezellige "collega-vrienden". Saskia, Sanne, Martine, Laurien, Roos V, Marloes, Ingrid, Rilana, Maria, Hester, Roos A, Pia, Stephy, Petra, Lex, Nicol, Jobke, Anne Marie en Marieke: wat ontzettend fijn dat jullie er altijd voor me waren! Het rondje lopen in de pauze, het halen van lekkere koffie, tal van gezellige etentjes en andere leuke uitjes. Dankzij jullie was het iedere dag een feest om naar het werk te gaan. Ik hoop van harte dat we elkaar in de toekomst blijven zien, maar daar maak ik me niet echt zorgen over.

Kamer 403 is de afgelopen jaren mijn thuisbasis geweest op de UT. Samen met Saskia en Sanne deelde ik hier lief en leed en hebben we elkaar door ons promotieonderzoek heen geholpen. Erg bijzonder dat we dit jaar allemaal promoveren en dat we het hele traject met elkaar van zo dichtbij hebben meegemaakt. Saskia, dankzij jou voelde ik me vanaf dag één thuis op de UT. Je bent een goede vriendin geworden en je bent echt mijn muziekmaatje. Hopelijk bezoeken we samen nog veel mooie concerten! Ontzettend bedankt dat je mijn paranimf wilt zijn. Sanne, ook jij bent een goede vriendin van me geworden. Ik ben erg dankbaar dat jij onze kamer kwam versterken. Jouw rust en kalmte hebben me door menig stressvol moment geloodst. Ons hoogtepunt was toch wel de gezamenlijke reis naar Boston en New York, dat was echt een onvergetelijk ervaring. Ik hoop jullie beide dames nog vaak om mij heen te hebben in de toekomst!

Het leven bestaat natuurlijk - en gelukkig - niet alleen uit werk. Marieke, Sarah, Mariël, Mariët, Kim, Annemieke, Tim, Ruud, Bert, Sytse en Gerrald: jullie zijn de beste vrienden die iemand zich kan wensen. Jullie betekenen veel voor me. Het is heerlijk om te weten dat ik altijd bij jullie terecht kan. De legendarische weekendjes weg, de gezellige feestjes, lunches, etentjes en high tea's: het zijn heel belangrijke afwisselingen van de dagelijkse werkzaamheden. Ik vond het super dat jullie altijd zo geïnteresseerd waren in mijn promotieonderzoek. Jullie luisterend oor heeft zeker een bijdrage geleverd aan alle inspanningen.

Familie is ook erg belangrijk voor me. Onze band is voor mijn gevoel uitzonderlijk. Dankzij jullie kan ik altijd mezelf zijn en heb ik mij altijd zeer gesteund gevoeld gedurende mijn promotieonderzoek. Marianne \& Kees, Frans \& Cindy, Esther en Nicole \& Danaé, fijn dat jullie er allemaal voor me zijn en dat we elkaar nog zo regelmatig zien bij alle verjaardagen. Ik vind dit erg bijzonder en hoop dat dit nog lang zo blijft. Petrie \& Hendrik Jan, Willeke \& Boudewijn, wat ben ik blij om jullie als schoonfamilie te hebben. Altijd geïnteresseerd en attent, dat vind ik zeer waardevol. Twee sterke vrouwen die altijd in mij hebben geloofd en overtuigd waren van mijn kunnen zijn mijn oma's. Helaas kan één van jullie niet bij mijn verdediging zijn, maar ik voel nog steeds veel steun van jullie beiden.

Noëll en René, vanaf mijn jonge jaren hebben jullie een belangrijke rol in mijn leven gespeeld en dat zal altijd zo blijven. Het is geweldig om te weten dat jullie er altijd voor me zullen zijn, een zeer geruststellende gedachte. Anne Floor, wat ben jij een fantastische zus, een betere bestaat er niet. In sommige opzichten lijken we vreselijk veel op elkaar en dat leidt geregeld tot een hoop hilariteit - en in sommige opzichten vullen we elkaar 
juist goed aan. Ik ben er enorm trots op dat je je creatieve talent hebt willen gebruiken bij het ontwerp van mijn proefschrift. Wat is het ontzettend mooi geworden. En ik wil je ook heel erg bedanken dat je mijn paranimf wilt zijn, dat betekent veel voor me. Thijs, jou wil ik bedanken voor je interesse en gezelligheid. Je bent echt een bijzonder toffe zwager. Pap en mam, wat bof ik met jullie als ouders. Jullie oneindige steun is voor mij zeer van belang en werkt als een constante motivator voor alles wat ik doe. De schitterende reizen die we samen hebben gemaakt vormden een mooie onderbreking van het promotieonderzoek.

Johan, wat is het heerlijk om jou in mijn leven te hebben. Ik ken eerlijk gezegd geen positiever ingesteld persoon dan jij en dat werkt ontzettend goed voor mij. Op de momenten waarop het eventjes wat minder soepel gaat - en dat gebeurt onherroepelijk tijdens een promotietraject - laat je mij altijd overal de positieve kant van inzien en weet je mij telkens te overtuigen van mijn eigen kunnen. Ik voel me ontzettend thuis bij jou en daar ben ik je geweldig dankbaar voor.

Enschede, oktober 2012 
THE STORIES WE LIVE BY - The adaptive role of reminiscence in later life 
THE STORIES WE LIVE BY - The adaptive role of reminiscence in later life 


\section{THE STORIES WE LIVE BY}

The adaptive role of reminiscence in later life 
